\title{
Comparing and Linking Organic Carbon and Iron in Soil and Headwater Stream in a Pasture and a Forest Catchment in a Central Appalachian Region, West Virginia
}

\author{
Lili Lei \\ lilei@mix.wvu.edu
}

Follow this and additional works at: https://researchrepository.wvu.edu/etd

Part of the Agricultural Science Commons, and the Agronomy and Crop Sciences Commons

\author{
Recommended Citation \\ Lei, Lili, "Comparing and Linking Organic Carbon and Iron in Soil and Headwater Stream in a Pasture and a \\ Forest Catchment in a Central Appalachian Region, West Virginia" (2020). Graduate Theses, Dissertations, \\ and Problem Reports. 7769. \\ https://researchrepository.wvu.edu/etd/7769
}

This Dissertation is protected by copyright and/or related rights. It has been brought to you by the The Research Repository @ WVU with permission from the rights-holder(s). You are free to use this Dissertation in any way that is permitted by the copyright and related rights legislation that applies to your use. For other uses you must obtain permission from the rights-holder(s) directly, unless additional rights are indicated by a Creative Commons license in the record and/ or on the work itself. This Dissertation has been accepted for inclusion in WVU Graduate Theses, Dissertations, and Problem Reports collection by an authorized administrator of The Research Repository @ WVU. For more information, please contact researchrepository@mail.wvu.edu. 
Comparing and Linking Organic Carbon and Iron in Soil and Headwater Stream in a Pasture and a Forest Catchment in a Central Appalachian Region, West Virginia

Lili Lei

Follow this and additional works at: https://researchrepository.wvu.edu/etd

Part of the Agricultural Science Commons, and the Agronomy and Crop Sciences Commons 


\title{
Comparing and Linking Organic Carbon and Iron in Soil and Headwater Stream in
}

\section{a Pasture and a Forest Catchment in a Central Appalachian Region, West Virginia}

\author{
Lili Lei \\ A doctoral dissertation submitted to the \\ Davis College of Agriculture, Natural Resources, and Design \\ at West Virginia University \\ In Partial Fulfillment of the Requirements for the degree of \\ Doctor of Philosophy \\ in \\ Plant and Soil Sciences \\ Louis M. McDonald, Ph.D., Chair \\ James A. Thompson, Ph.D. \\ Dorothy Vesper, Ph.D. \\ William Peterjohn, Ph.D.
}

Division of Plant and Soil Sciences

Morgantown, West Virginia

2020

Keywords: Organic Carbon, Iron, Headwater stream, Pasture, Forest, Catchment

Copyright 2020 Lili Lei 


\section{Abstract \\ Comparing and Linking Organic Carbon and Iron in Soil and Headwater Stream in a Pasture and a Forest Catchment in a Central Appalachian Region, West Virginia}

\section{Lili Lei}

Continued global warming and surface water brownification are two main environmental issues which have attracted attention and are related to soil organic carbon (SOC) cycling. Iron oxides differ in reducibility and thus have essential roles in regulating SOC preservation and remineralization in soil and transport of dissolved organic carbon (DOC) from soil to surface water. In the central Appalachian region, anthropogenic disturbances are increasing, which leads to major issues of soil degradation and depletion of SOC concentrations. Cropland and pasture soils are subject to intense disturbances compared to the forest soil, which may lead to differences in SOC fractions and Fe oxides, their interactions, and the export of DOC to surface water. Variable geology and climate have confounding effects on SOC fractions and dynamics. Thus, the use of pseudo-replicated studies may be informative. Thus, a single fine-scale watershed was chosen in this study, which was derived from the same parent materials and had similar climate conditions. These perspectives will provide a theoretical basis for a better understanding of SOC cycling in watersheds of differing scales. They will also aid the development of agricultural best management practices to increase soil ecological functions in mitigating global warming and surface water brownification.

SOC fractions have various stabilization mechanisms and turnover times, which change with depth and are highly influenced by land use. In this study, we used total organic carbon (TOC), particulate organic carbon (POC), mineral-associated organic carbon (MOC), and carbon management index (CMI) as indicators to compare cropland with manure application (CM) and continuous pasture (CP) to a hardwood forest (HF) at soil depths of 0-10 and $10-25 \mathrm{~cm}$. Land use, depth, and the interactions between them all had significant influences on TOC, POC, MOC, MOC/TOC ratio, and CMI except for the main effect of land use on TOC. CM showed significantly larger POC (12.4 $\left.\mathrm{g} \mathrm{kg}^{-1}\right)$ and smaller MOC $\left(8.36 \mathrm{~g} \mathrm{~kg}^{-1}\right)$ at $10-25 \mathrm{~cm}$ compared to HF and CP soils. $\mathrm{CM}$ soil at $10-25 \mathrm{~cm}$ had improved soil quality and SOC lability as indicated by a significantly larger CMI value (419.2) while CP soil had decreased soil quality and SOC lability at both $0-10 \mathrm{~cm}$ (83.7) and 10-25cm (73.6) compared to HF soil. This study implied high sensitivity of the SOC in cropland and pasture surface soils to degrade under disturbance, which implies that better management strategies are still needed to improve soil carbon quality for these agricultural systems.

The essential roles of $\mathrm{Fe}$ oxides in stabilizing long-term soil SOC, especially aromatic dissolved organic carbon $\left(\mathrm{DOC}_{\mathrm{aro}}\right.$ ), are well-established in forest soils and sediments. We chose to focus on these processes in agricultural soils in which the input and translocation of native DOC to deeper soils is impacted by management practices. We quantified SOC, Fe oxide bound SOC (Fe-bound OC), and the $\mathrm{DOC}_{\text {aro }}$ sorption in a forest, a cropland, and a pasture soil at 0-10 and 10$25 \mathrm{~cm}$. Significantly larger amounts of Fe oxides in the cropland soil was observed compared to the forest and pasture soils at both depths $(\mathrm{p}<0.05)$. Land management practices and depth both significantly influenced proportion of the Fe-bound OC ( $\mathrm{p}<0.05)$. Larger maximum sorption of DOC in the cropland $\left(315.0 \mathrm{mg} \mathrm{kg}^{-1}\right)$ and pasture $\left(395.0 \mathrm{mg} \mathrm{kg}^{-1}\right)$ soils than the forest soil (96.6 $\mathrm{mg} \mathrm{kg}^{-1}$ ) at 10-25 $\mathrm{cm}$ was found. DOC $_{\text {aro }}$ sorption decreased in the three soils at $0-10 \mathrm{~cm}$ (slope of -0.002 to $\left.-0.014 \mathrm{~L} 2 \mathrm{mg}^{-2} \mathrm{~m}^{-1}\right)$ as well as the forest soil at $10-25 \mathrm{~cm}\left(-0.016 \mathrm{~L}^{2} \mathrm{mg}^{-2} \mathrm{~m}^{-1}\right)$ with increasing equilibrium DOC concentration. Conversely, the cropland and pasture soils at 10-25 
cm increased ( 0.012 to $\left.0.014 \mathrm{~L}^{2} \mathrm{mg}^{-2} \mathrm{~m}^{-1}\right)$. These results indicate that the forest, cropland, and pasture managed soils may have more complex sorption behaviors in stabilizing $\mathrm{DOC}_{\text {aro }}$ and non$\mathrm{DOC}_{\text {aro }}$ than previously known.

DOC and iron $(\mathrm{Fe})$ have been observed to be important contributors to surface water brownification. Additionally, the DOC quality influences water color by forming Fe-DOC complexes that provide additive effects and is influenced by dominant land use type within watersheds. However, the influence of quantity and quality of DOC on Fe and water color is poorly understood in headwater streams. The aim of this study was to investigate the effects of DOC and $\mathrm{Fe}$ on water color in forest (FC) and pasture (GFC) fine-scale watersheds to remove the confounding effects of climate and soil parent materials. Significant differences of DOC, Fe, and water absorbance at $420 \mathrm{~nm}\left(\mathrm{a}_{420}\right)$ between FC and GFC were found $(\mathrm{p}<0.05)$. A dominant contribution to water color was from DOC $(95.5$ - 63.7\%) with a decreasing trend when Fe increased from 0.011 to $0.258 \mathrm{mg} \mathrm{L}^{-1}$. There were no significant interactions between $\mathrm{FC}$ and GFC and $\mathrm{Fe}$ on either $\mathrm{a}_{420} / \mathrm{DOC}(\mathrm{p}=0.06)$ or specific ultraviolet absorbance at $254 \mathrm{~nm}\left(\mathrm{SUVA}_{254}\right)(\mathrm{p}=$ 0.30). Increasing $\mathrm{a}_{420} / \mathrm{DOC}$ and $\mathrm{SUVA}_{254}$ were significantly associated with increasing $\mathrm{Fe}$ concentration ( $\mathrm{p}<0.01$ ). Significant interactions were found between FC and GFC and Fe on spectral slope ratio $(S$ ratio) $(\mathrm{p}<0.01)$. The response rate of $S$ ratio with increasing Fe per unit was 0.235 for GFC while it was -11.043 for FC. These differences indicate that land use may change the quality of DOC, influence Fe-DOC interactions, and thus affect water color.

DOC and Fe concentrations cause surface water brownification. Land-use effects on the quantity and quality of DOC are well-established in large-scale watersheds. However, there is more to understand about how soil Fe oxides are involved in DOC and Fe processes in soil and stream, especially in fine-scale catchments. We investigated DOC, SUVA 254 , exchangeable Fe $\left(\mathrm{Fe}_{\mathrm{ex}}\right)$, and amorphous Fe concentrations $\left(\mathrm{Fe}_{\mathrm{amor}}\right)$ in soils as well as DOC, SUVA 254 , and dissolved $\mathrm{Fe}$ in stream water within a fine-scale forest and pasture catchment. Forest soil had a significantly larger average DOC concentration $\left(71.7 \pm 33.8 \mathrm{mg} \mathrm{kg}^{-1}\right)$ and lower average SUVA $254(2.8 \pm 1.0 \mathrm{~L}$ $\mathrm{m}^{-1} \mathrm{mg}^{-1}$ ) than the pasture soil at 0-10 $\mathrm{cm}$ (DOC: $71.7 \pm 33.8 \mathrm{mg} \mathrm{kg}^{-1}$; SUVA $_{254}: 4.2 \pm 1.4 \mathrm{~L} \mathrm{~m}^{-1}$ $\left.\mathrm{mg}^{-1}\right)$. The pasture soil at $0-10 \mathrm{~cm}$ had significantly larger average $\mathrm{Fe}_{\mathrm{ex}}(132.8 \pm 57.6 \mathrm{mg} \mathrm{kg}-1)$ and Feamor $\left(813.9 \pm 461.2 \mathrm{mg} \mathrm{kg}^{-1}\right)$ concentrations than the forest soil $\left(\mathrm{Fe}_{\mathrm{ex}}: 120.3 \pm 55.4 \mathrm{mg} \mathrm{kg}^{-1}\right.$;

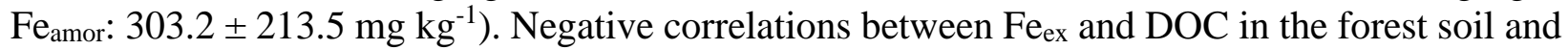
positive correlations between $\mathrm{Fe}_{\mathrm{ex}}, \mathrm{Fe}_{\mathrm{amor}}$ and $\mathrm{SUVA}_{254}$ in both forest and pasture soils were found $(\mathrm{p}<0.05)$. The pasture headwater stream had significantly larger DOC, SUVA 254 , and Fe than the forest headwater stream $(\mathrm{p}<0.05)$. This study indicated Fe oxides may have different interactions with DOC, which leads to differences in the quantity and quality of DOC and dissolved Fe in watersheds of differing scales.

Collectively, the results indicated land use and season were important factors altering the SOC and Fe dynamics in agricultural and forest catchments. Additionally, this study indicated Fe oxides may interact with DOC differently in watersheds differing in scale, which leads to differences in the quantity and quality of DOC and dissolved Fe in these watersheds. Therefore, studies combining the effects of Fe-reducing processes are helpful in explaining the changes of DOC and $\mathrm{Fe}$ and thus surface water brownification at local scale. To better understand Fe-oxyhydroxides and DOC interactive processes at fine-scale local environments, the next step should be to establish the effects of hydrologic processes and DOC sources. This may help explain DOC stabilization and destabilization as well as surface water brownification. 


\section{Acknowledgements}

It is a long journey to pursue a Ph.D. and I am thankful to all individuals and organizations who supported throughout the entire span of my doctoral study at WVU.

First, I would like to give special thanks to my advisor Dr. Louis McDonald. I definitely could not have done this without his belief in me. His expertise, encouragement, and guidance have helped me immensely. I want to thank all my other committee members (Dr. Thompson, Dr. Vesper, and Dr. Peterjohn) for their guidence and support. This dissertation combined all the knowledge I have learned from all of them, and I cannot imagine completing the study without their help.

Second, I would like to express my gratitude toward Division of Plant and Soil Sciences, Davis College of Agriculture, Natural Resource and Design at West Virginia University for providing this opportunity. I would like to thank Dr. Eugenia M. Pena-Yewtukhiw, Dr. Sven Verlinden, Dr. Zachary Freedman, and Dr. Yong-Lak Park. Their career advices made the final stage less stressful. In addition, I would like to thank Dr. Kang Mo Ku, Joan Wright, Lanjun Deng, and Robert Rockis for their assistance in lab analysis. I would like to thank Dr. Katrina Stewart, Dr. Nikki Byrne-Hoffman, Dr. Amy Kuhn, Dr. Vagner Benedito, and Dr. John Oughton for all their support of improving my teaching ability. I also want to thank both my past and present colleagues for their friendship and support along the way (Yu-Chun Chiu, Fumin Wang, Rebecca McGrail, Bethani Chambers, Yadav Sapkota, Kelly Morgano, Kara Dallaire, Justin Brackenrich, Katie Stutler, Chris Skinner, James Leonard, Christopher Burney, and Jarrett Fowler).

Last, I want to thank my parents, Xinsehng Lei and Xueli Wang, for their unconditional love, support, and scarifies so that I may pursue my education here at West Virginia University. I thank my husband (Zhanxiao Ma) and my daughter (Jessie Ma) for all their unconditional love, support, and joy they bring to my life. I would like to thank other family members and friends for their help and encouragement. 


\section{Contents}

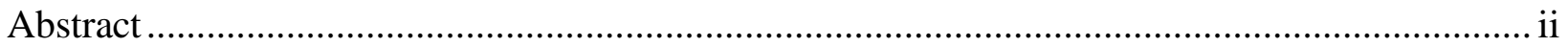

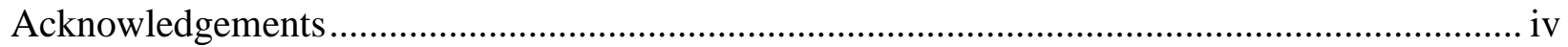

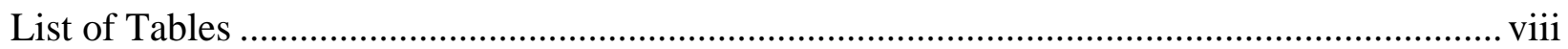

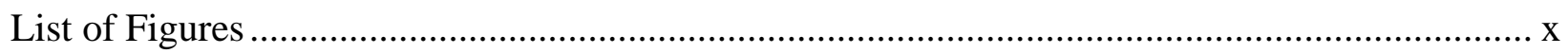

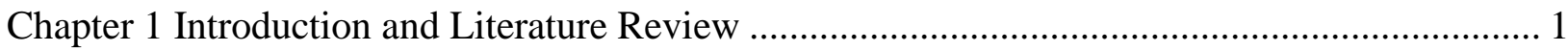

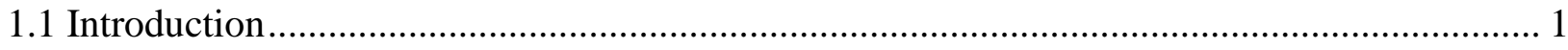

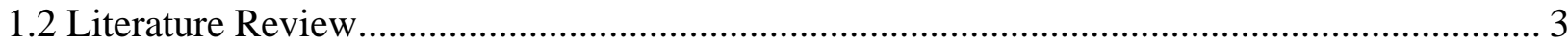

1.2.1 Effects of land management practices on SOC fractions......................................... 4

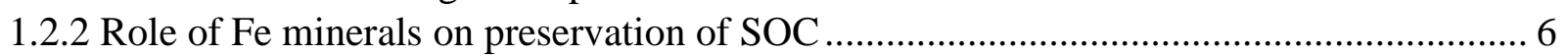

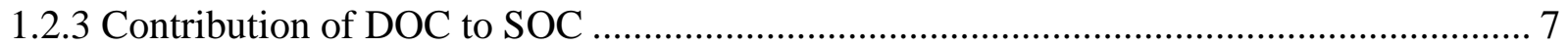

1.2.4 Quantity and quality of DOC under different land management practices ..................... 8

1.2.5 Interactions between Fe, DOC, and SOC preservation............................................... 10

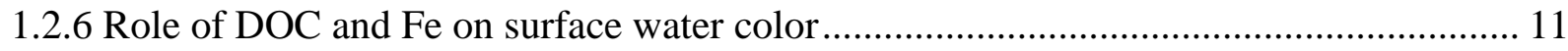

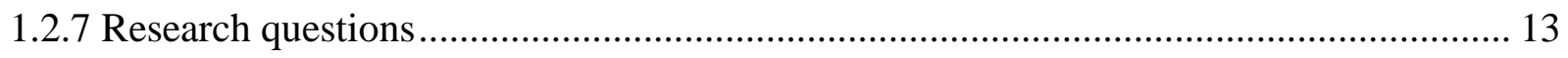

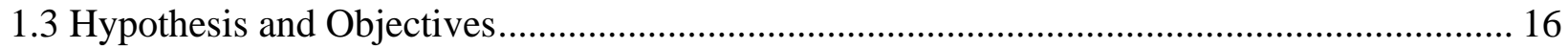

Chapter 2 Soil Organic Carbon Fractions and Carbon Management Index in the Surface Soil: Comparing a Forest, a Cropland, and a Pasture Soil in a Central Appalachian Region, West

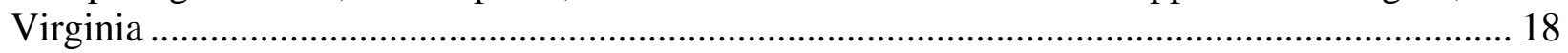

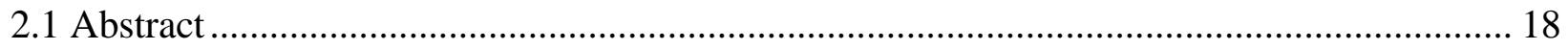

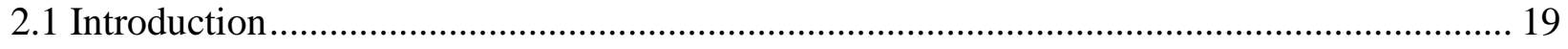

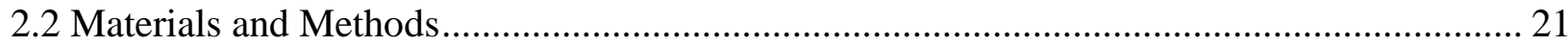

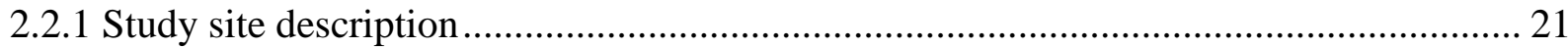

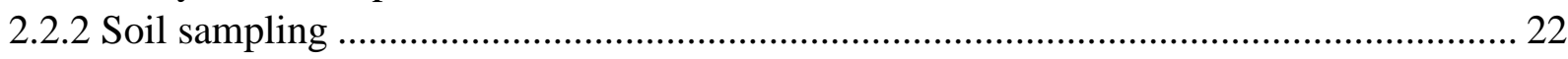

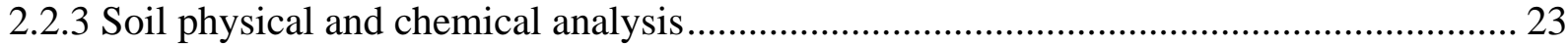

2.2.4 Carbon management index ................................................................................. 24

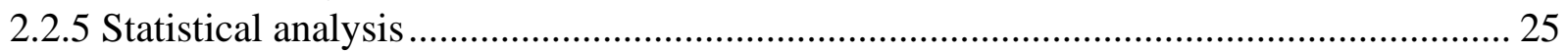

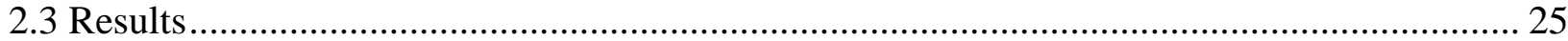

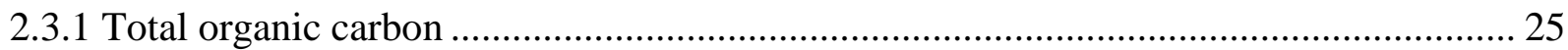

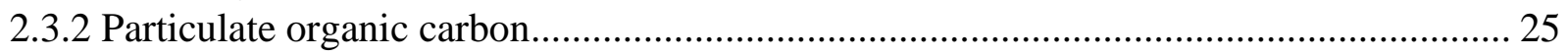

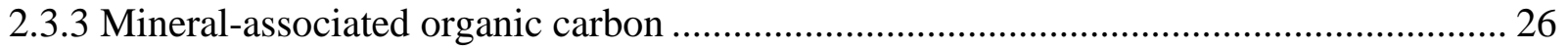

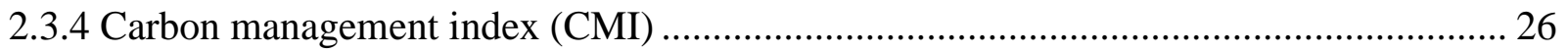

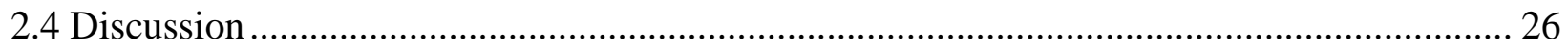

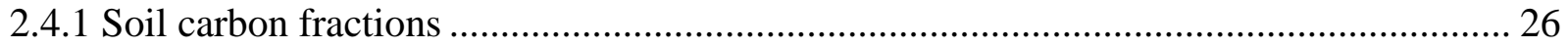

2.4.2 Implication for long-term land use and management practices under climate change.... 28

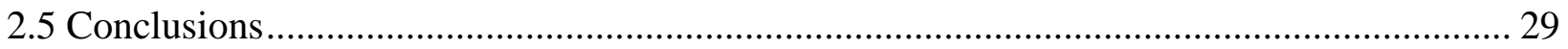


Chapter 3 Fe-bound Organic Carbon and Sorption of Aromatic Dissolved Organic Carbon in Surface Soil: Comparing a Forest, a Cropland, and a Pasture Soil in a Central Appalachian Region,

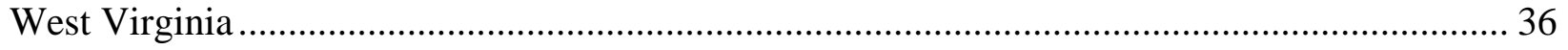

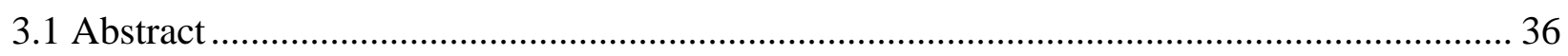

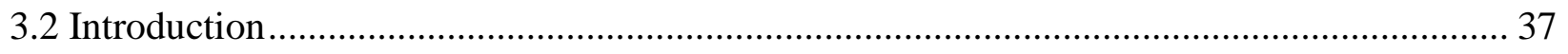

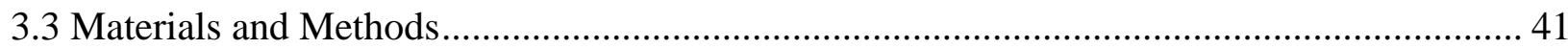

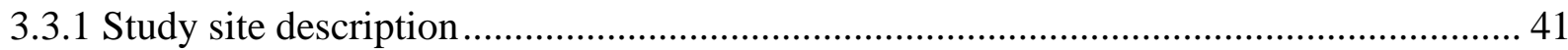

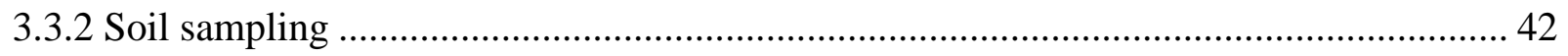

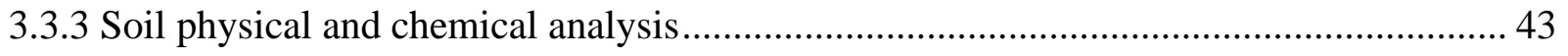

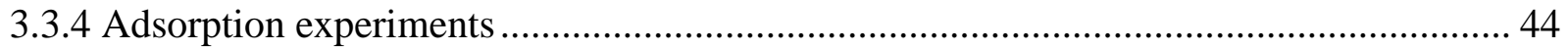

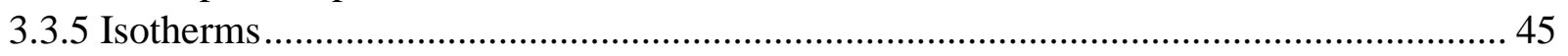

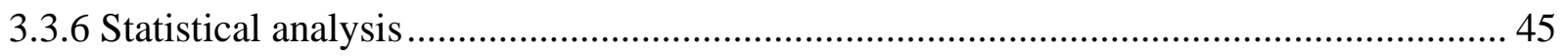

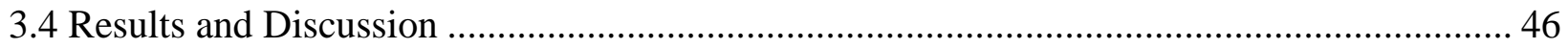

3.4.1 Effects of soil texture on TOC, Fe-bound OC in proportion, and reactive Fe................ 46

3.4.2 TOC and Fe-bound OC in forest, cropland, and pasture managed soils........................ 47

3.4.3 Reactive Fe and OC: Fe molar ratio among three land use management practices......... 48

3.4.4 Association between OC and amorphous and exchangeable Fe................................ 49

3.4.5 Sorption of DOC to three land use management practices soils.................................. 50

3.4.6 Changes of aromaticity of DOC during sorption ................................................. 51

3.4.7 Implications for land use and stabilization of DOC for long-term SOC accumulation... 53

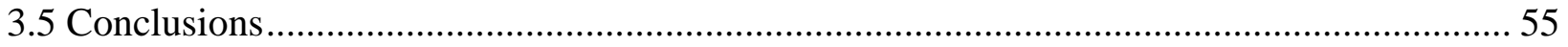

Chapter 4 Assessment of Dissolved Organic Carbon and Iron Effects on Water Color Between a Forest and Pasture Dominated Fine-scale Catchment in a Central Appalachia Region, West

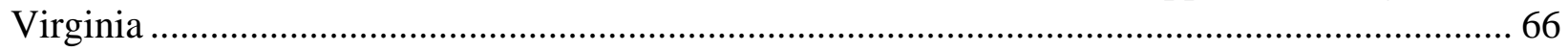

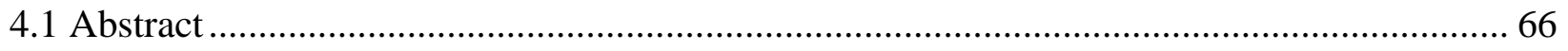

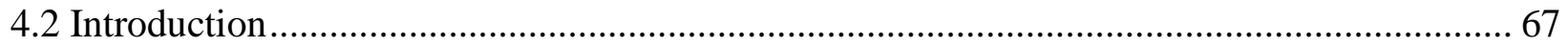

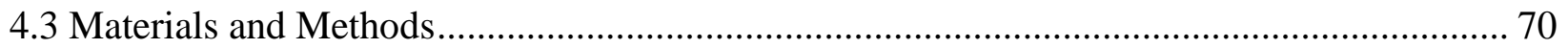

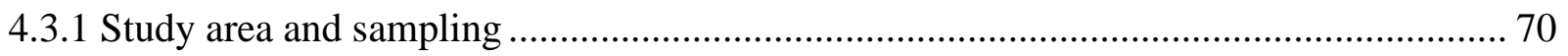

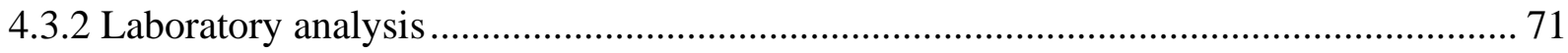

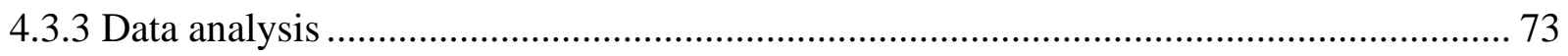

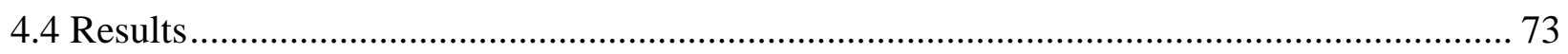

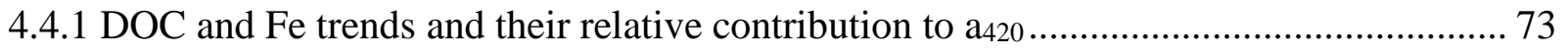

4.4.2 Estimating variations of interaction between DOC and $\mathrm{Fe}$.................................... 74

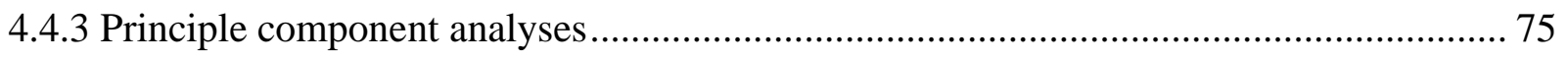

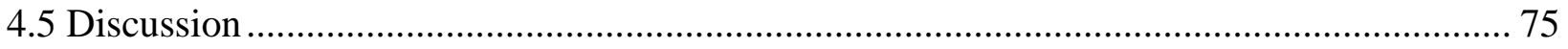

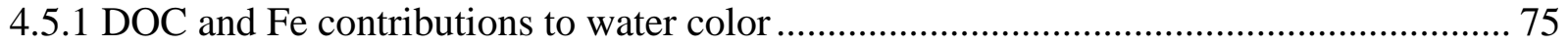

4.5.2 DOC quality influence DOC-Fe interaction in water ............................................. 77

4.5.3 Implication for land use management to mitigate water color increase ....................... 80

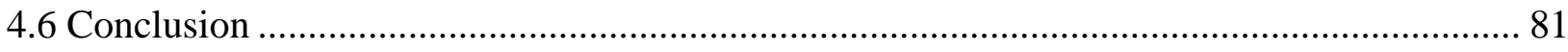


Chapter 5 Comparing Dissolved Organic Carbon and Fe in the Soil and Headwater Streams in a Forest and a Pasture Catchment in a Central Appalachian Region, West Virginia..................... 92

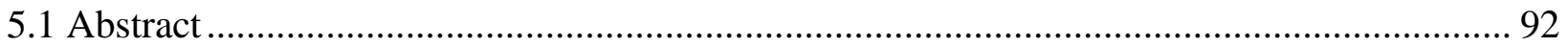

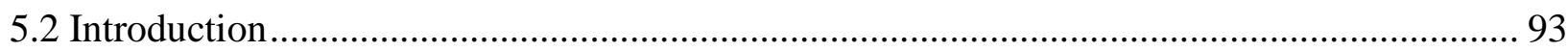

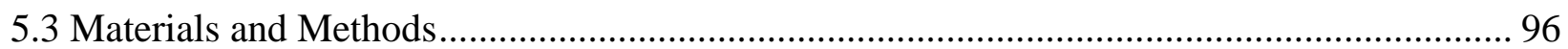

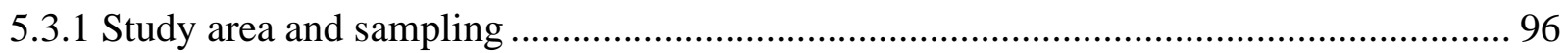

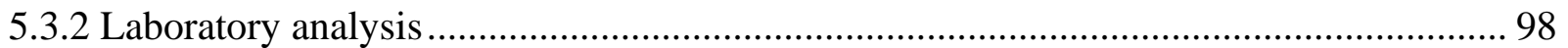

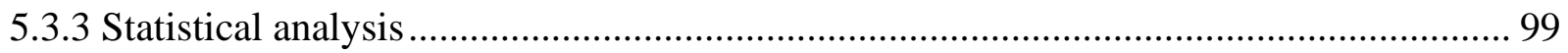

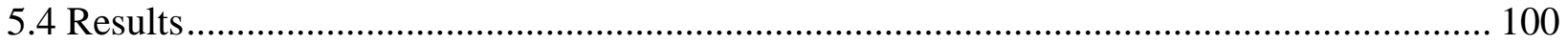

5.4.1 Average and seasonal changes of DOC, $\mathrm{SUVA}_{254}$ and Fe concentrations in the soils at the forest and pasture catchments ........................................................................................ 100

5.4.2 Seasonal changes of DOC and Fe concentrations in the forest and pasture headwater

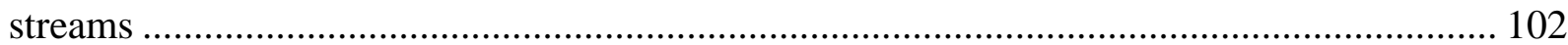

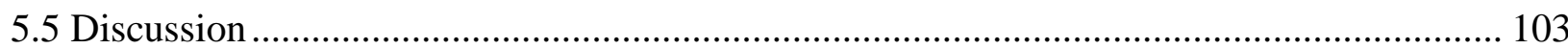

5.5.1 Effects of land-use management practices on the average DOC and SUVA 254 in the soil

5.5.2 Seasonal changes of DOC and SUVA 254 in the forest and pasture soils...................... 104

5.5.3 Comparison of average of DOC and SUVA between two catchments ....................... 105

5.5.4 Linking DOC and Fe between soil and stream ....................................................... 107

5.5.6 Iron role in regulating the quantity and quality of DOC in soils .............................. 109

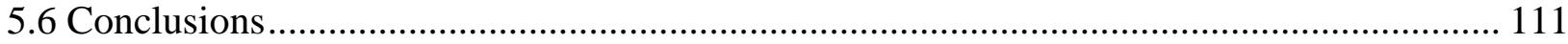

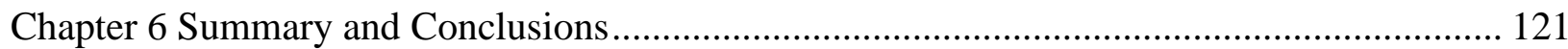

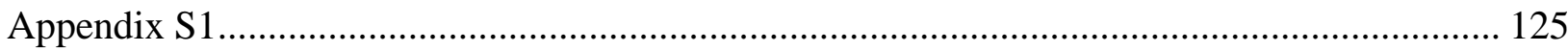

Appendix S2 Predictors for variations of DOC and Fe concentrations in forest and pasture

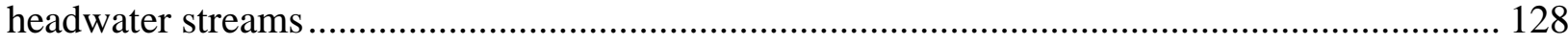

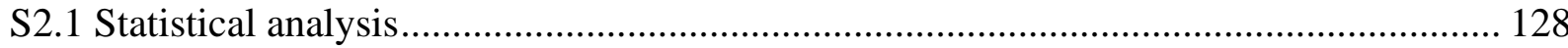

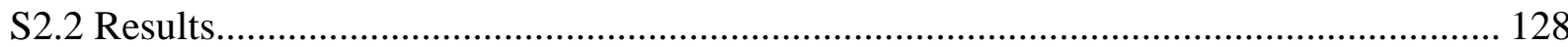

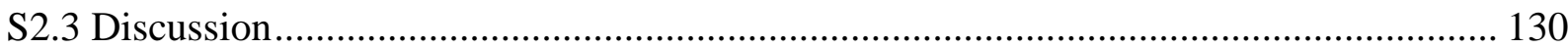

S2.3.1 Significant explaining factors of DOC variation in headwater stream ..................... 130

$\mathrm{S} 2.3 .2$ Iron role in regulating the quantity and quality of DOC in soils ............................. 131

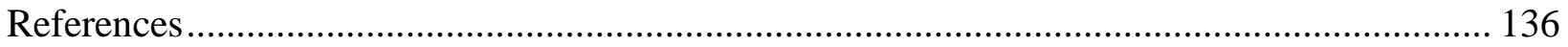




\section{List of Tables}

Table 2. 1 Soil physical and chemical properties at 0-10 $\mathrm{cm}$ and 10-25 $\mathrm{cm}$ depths under hardwood forest $(\mathrm{HF})$, cropland with manure (CM), and continuous pasture (CP) soils.

Table 2. 2 Impact of land management practice and depth on carbon pool index (CPI), lability index (LI), and carbon management index (CMI).... 31

Table 3. 1 The properties of DOC stock solution, extracted from hardwood forest (HF), cropland with manure application (CM), and continuous pasture $(\mathrm{CP})$ soils at $0-5 \mathrm{~cm}$ depth, used in sorption experiment.

Table 3. 2 Correlation matrix of Spearman correlation coefficients (r) of the investigated

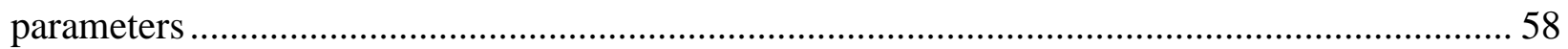

Table 3. 3 Linear regressions between $\triangle$ SUVA $_{254}$ of DOC solution and equilibrium DOC concentration for three land type soils at 0-10 cm and 10-25 cm depths.

Table 3. 4 Estimated linear regression using a standard square least approach between total organic carbon (TOC), Fe-bound $\mathrm{OC}$, and reactive $\mathrm{Fe}$ and the combined silt and clay content in in hardwood forest $(\mathrm{HF})$, cropland with manure application (CM), and continuous pasture (CP) soils

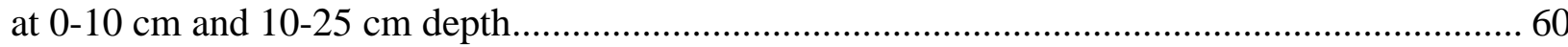
Table 3. 5 Sorption characteristics of three land type soils at $0-10 \mathrm{~cm}$ and $10-25 \mathrm{~cm}$ depths..... 61

Table 4. 1 Means of a420, dissolved organic carbon (DOC), and iron (Fe) at FC and GFC headwater streams $(\mathrm{n}=3)$. .88

Table 4. 2 The estimated single and multiple linear regression for a420 explained by dissolved organic carbon (DOC) and iron (Fe).

Table 4. 3 Mixed model analyses of variance of the effects of stream type (FC and GFC; fixed effects), Fe (random effects) and interaction between Fe and stream type on carbon specific absorbance (a420/DOC), spectral slope ratio (S ratio), and specific ultra-violet absorption at 254 nm (SUVA 254$)$ with location nested within stream types as fixed effect.

Table 4. 4 Pearson's correlation coefficients among DOC quantity and quality, $\mathrm{Fe}$ and a 420 parameters at FC and GFC headwaters

Table 5. 1 Correlation matrix of Spearman correlation coefficients ( $r$ ) of the investigated parameters in hardwood forest (HF) and continuous pasture (CP) soils 118 Table 5. 2 The average and standard deviation of DOC, Fe, and SUVA254 of six months (October, November, January, February, June, and July) in the two locations (C and F) at the forest headwater stream and four locations (GH, GG, GF, and GC) at the pasture headwater stream. 119 Table 5. 3 Non-parametric Wilcoxon signed-rank test of DOC, Fe, and SUVA254 among the six locations ( $\mathrm{F}$ and $\mathrm{C}$ at the forest headwater stream; GH, GG, GF, and $\mathrm{GC}$ at the pasture headwater stream (first column) and non-parametric comparisons for each pair using Wilcoxon methods (fourth to ninth columns) 120 
Table S1- 1 The two-ways repeated measures of variance analysis (repeated depth and month) 125

Table S1- 2 The average and standard deviation of TOC, DOC, SUVA $254, \mathrm{Fe}_{\mathrm{ex}}$, and $\mathrm{Fe}_{\text {amor }}$ of six months (October, November, January, February, June, and July) in hardwood forest (HF) and continuous pasture $(\mathrm{CP})$ soils at $0-10$ and $10-25$ depths. 126

Table S2- 1 Significant final predictor variables for dissolved organic carbon (DOC) and dissolved iron $(\mathrm{Fe})$ in both forest and pasture headwater streams at different locations $(\mathrm{F}, \mathrm{C}, \mathrm{GH}, \mathrm{GG}, \mathrm{GF}$, and GC) which represented different influences from different land management practices. ... 134 Table S2- 2 Significant final predictor variables for dissolved organic carbon (DOC) and dissolved iron $(\mathrm{Fe})$ in both forest and pasture headwater streams at different locations $(\mathrm{F}, \mathrm{C}, \mathrm{GH}, \mathrm{GG}, \mathrm{GF}$, and GC) using forward stepwise regression analysis 135 


\section{List of Figures}

Figure 2. 1 The location of study site. The rectangles represented $10 \times 10 \mathrm{~m}$ sampling plots (not to scale)

Figure 2. 2 Total organic carbon (TOC) at 0-10 $\mathrm{cm}$ and 10-25 cm depths under hardwood forest (HF, gray filled bar), cropland with manure (CM, black filled bar), and continuous pasture (CP, white filled bar) soils. 33

Figure 2. 3 Particulate organic carbon (POC) at $0-10 \mathrm{~cm}$ and $10-25 \mathrm{~cm}$ depths under hardwood forest (HF, gray filled bar), cropland with manure (CM, black filled bar), and continuous pasture (CP, white filled bar) soils. 34

Figure 2. 4 Mineral associated organic carbon (MOC) (A) and MOC/TOC (total organic carbon) (B) at 0-10 cm and 10-25 cm depths under hardwood forest (HF, gray filled bar), cropland with manure (CM, black filled bar), and continuous pasture ( $\mathrm{CP}$, white filled bar) soils. 35

Figure 3. 1 Total organic carbon (TOC) (A), Fe-bound OC (B), reactive Fe (C), and organic carbon Fe molar ratio (D) in forest (HF), cropland (CM), and pasture (CP) soils at $0-10 \mathrm{~cm}$ and $10-25 \mathrm{~cm}$ depth 62

Figure 3. 2 Regression relationship between the amount of released DOC (A) and SUVA 254 of DOC released (B) from soils after $0.5 \mathrm{M} \mathrm{HCl}$ at $0-10 \mathrm{~cm}$ (diamonds) and $10-25 \mathrm{~cm}$ (squares), 0.25 $\mathrm{M} \mathrm{HCl}$ and $0.25 \mathrm{M} \mathrm{NH}_{2} \mathrm{OH} \cdot \mathrm{HCl}$ extraction at $0-10 \mathrm{~cm}$ (circles) and $10-25 \mathrm{~cm}$ (triangles) in forest (black fill), cropland (gray fill), and pasture (no fill). 63

Figure 3. 3 Dissolved organic carbon (DOC) sorption to the forest (HF-a), cropland (CM-a), and pasture (CP-a) soils and the change of $\mathrm{SUVA}_{254}\left(\triangle \mathrm{SUVA}_{254}\right)$ of the DOC solution after sorption to the forest (HF-b), cropland (CM-b), and pasture (CP-b) soils at 0-10 cm and 10-25 cm depth.

Figure 3. 4 Fe-bound OC in hardwood forest (HF), cropland with manure application (CM), and continuous pasture (CP) soils at $0-10 \mathrm{~cm}$ and $10-25 \mathrm{~cm}$ depth.

Figure 4. 1 Sampling sites and water sampling locations 82

Figure 4. 2 The relative contributions of $\mathrm{Fe}$ and DOC to $\mathrm{a}_{420}$ at forest dominant and pasture

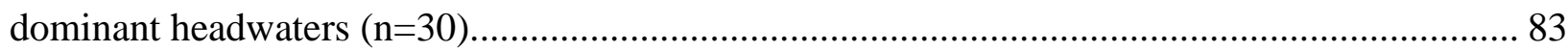

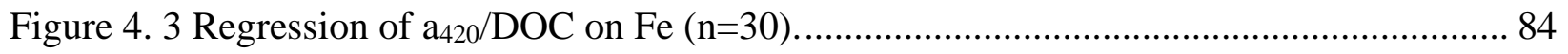

Figure 4. 4 Regression of specific ultra-violet absorption at $254 \mathrm{~nm}\left(\mathrm{SUVA}_{254}\right)$ on Fe at GFC and

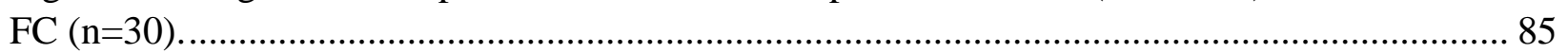

Figure 4. 5 Regression of spectral slope ratio (S ratio) on Fe at GFC and FC (n=30)............... 86 Figure 4. 6 Loading plots for component 1 and 2 at FC (left) and GFC (right) headwaters ......... 87

Figure 5. 1. The location of study site. The rectangles represented $10 \mathrm{~m} \times 10 \mathrm{~m}$ soil sampling plots (not to scale) while the black filled circles represented stream water sampling locations. ........ 113 Figure 5. 2 Precipitation during the sampling period .......................................................... 114 Figure 5. 3 Dissolved organic carbon (DOC) (a) concentration and the specific ultraviolet absorbance at $254 \mathrm{~nm}$ of DOC (SUVA 254 ) (b) of six months (October, November, January, 
February, June, and July) in hardwood forest (HF) and continuous pasture (CP) soils at 0-10 and 10-25 depths. The asterisk represented the average of the six months....

Figure 5. 4 Exchangeable $\mathrm{Fe}$ extracting using $0.5 \mathrm{M} \mathrm{HCl}$ extraction $\left(\mathrm{Fe}_{\mathrm{ex}}\right)$ and microbially reducible Fe extracting using $0.25 \mathrm{M} \mathrm{HCl}$ and $0.25 \mathrm{M} \mathrm{NH}_{2} \mathrm{OH} \cdot \mathrm{HCl}\left(\mathrm{Fe}_{\mathrm{amor}}\right)$ of six months (October, November, January, February, June, and July) in hardwood forest (HF) and continuous pasture (CP) soils at 0-10 and 10-25 depths. The asterisk represented the average of the six months... 116 Figure 5. 5 Dissolved organic carbon (DOC) (a) and dissolved iron (Fe) (b) in the forest headwater stream at $\mathrm{F}$ and $\mathrm{C}$ location and in the pasture headwater stream at GH, GG, GF, and GC location in October, November, January, February, June, and July. 117 Figure 5. 6 Specific ultraviolet absorbance at $254 \mathrm{~nm}$ of DOC $\left(\right.$ SUVA $\left._{254}\right)$ in the forest headwater stream at $\mathrm{F}$ and $\mathrm{C}$ location and in the pasture headwater stream at GH, GG, GF, and GC location in October, November, January, February, June, and July. 117

Figure S1- 1 Total organic carbon of six months (October, November, January, February, June, and July) in hardwood forest (HF) and continuous pasture (CP) soils at 0-10 and 10-25 depths.

Figure S2- 1 The significant explanatory variables selected using stepwise regression models for dissolved organic carbon (DOC) (dashed lines) and dissolved iron (solid lines) in forest (non-bold lines) and pasture (bold lines) headwater streams. 133 


\section{Chapter 1 Introduction and Literature Review}

\subsection{Introduction}

Soil organic carbon (SOC) influences soil productivity, terrestrial vegetation production, and aquatic water quality by facilitating the transport of nutrients and pollutants (Lehmann and Kleber, 2015; Schmidt et al., 2011). Soil contains $2400 \mathrm{Pg} \mathrm{C}$ in a $2 \mathrm{~m}$ depth and is the largest terrestrial organic carbon (OC) pool, which is 3.2 times larger compared to the atmospheric $\mathrm{CO}_{2}$ pool (Sparks, 2003). A small change in SOC concentration leads to a substantial change in the atmospheric $\mathrm{CO}_{2}$ concentration and in dissolved organic carbon (DOC) concentration in surface water (Baldock, 2007). Global warming and surface water brownification are two current environmental issues, which have attracted attention and are related to SOC cycling (Han et al., 2017; Kritzberg and Ekström, 2012).

The preservation and remineralization of SOC are significantly influenced by iron (Fe), DOC and their interactions (Ouellet et al., 2012). DOC is the reactive SOC pool by acting as the fresh carbon supply for microbial energy, electron shuttle for Fe and OC cycling, or forming Fe-DOC complexes through sorption to soil minerals to preserve DOC (Anesio et al., 2005; Lovley et al., 1998; Singh et al., 2016). Land use is an important factor contributing to the variations in the quantity and quality of SOC fractions (Chantigny, 2003; Martens et al., 2004; Poeplau and Don, 2013; Sainepo et al., 2018; Takata et al., 2011; Wilson and Xenopoulos, 2009). The stability of SOC is driven by fresh C supply from topsoil to the subsoil (Hobley et al., 2017). The most stable components contributing to SOC stabilization are likely from aromatic compounds, which are preferentially retained by reactive Fe minerals in the soil and thus increase SOC retention time (Kalbitz and Kaiser, 2008; Kramer et al., 2012; Riedel et al., 2013). Thus, Fe-bound OC plays an 
important role in sequestering SOC in the long run to mitigate SOC-related environmental issues (Kalbitz et al., 2005).

Current studies focus mostly on Fe-bound OC in sediment and forest soil (Mu et al., 2016; Zhao et al., 2016). It has been estimated that $(19-45) \times 10^{15} \mathrm{~g}$ of OC in sediments is preserved by reactive Fe on a global scale (Lalonde et al., 2012). Pasture and cropland soils are expected to have a larger potential to preserve SOC compared to forest soils (Wiesmeier et al., 2014). However, limited research about Fe-bound OC has been done in agricultural ecosystems. In the central Appalachian region, temperate hardwood forest, pasture, and cropland are the top three dominant land-use types. Due to increasing anthropogenic disturbances, soil degradation and depletion of SOC are major issues. Thus, assessing the soil carbon quality is paramount to develop best management practices for restoration and sustainable agriculture in this region. Most of the previous studies focus on SOC sequestration of soils disturbed by surface mining (Chaudhuri et al., 2011; Chaudhuri et al., 2012) and dissolved organic C fluxes in peatland soils (Yavitt, 1994). However, there are few studies on the effects of cropland and pasture on SOC fraction pools and thus SOC dynamics, especially by incorporating effects of aromatic DOC and Fe oxides.

DOC is the mobile and active SOC pool, which can be easily leached to stream water and deteriorate surface water quality. Increased surface water brownification in the Northern Hemisphere has been observed due to increased DOC and Fe concentrations (Maloney et al., 2005; Pace and Cole, 2002; Roulet and Moore, 2006; Weyhenmeyer et al., 2014). Stream water DOC concentration is strongly correlated with the quality and quantity of SOC pools since the catchment soil is the main source, especially in upstream water (Aitkenhead et al., 1999; Battin et al., 2008; Dillon and Molot, 1997; Graeber et al., 2012; Tank et al., 2010). It has been shown that changes in land uses lead to changes in the amount and composition of DOC in streams (Graeber et al., 
2012; Petrone et al., 2011; Wilson and Xenopoulos, 2009; Yang et al., 2012), which may influence the presence of $\mathrm{Fe}$, the complexes of DOC with $\mathrm{Fe}$, and thus water color.

Recent studies have quantified the contribution of DOC and Fe to water color according to the concentration of DOC and Fe in large-scale watersheds based on dominant land covers within whole watersheds (Ekström et al., 2016; Köhler et al., 2013a; Kritzberg et al., 2014; Kutser et al., 2015; Sarkkola et al., 2013; Weyhenmeyer et al., 2014; Williamson et al., 2015). However, little information is available in terms of combining both the quality and quantity of DOC and Fe to explain water color in fine-scale agricultural and forestry headwater streams.

Thus, inspired by these gaps, SOC fractions and Fe minerals were determined among a forest, a cropland, and a pasture soil in the central Appalachian region and associated seasonal changes. Laboratory-controlled adsorption experiments were also performed to investigate aromatic DOC adsorption behavior and estimated soil maximum adsorption capacity. Additionally, the correlation between DOC and Fe mineral contents in the soil to headwater DOC and dissolved Fe concentrations was determined. It could provide valuable information in developing best management practices to increase SOC sequestration to mitigate SOC degradation and depletions as well as reducing soluble DOC and Fe leaching to mitigate surface water brownification. It may also be helpful to reduce uncertainty in $\mathrm{C}$ models for a better prediction of $\mathrm{C}$ dynamics in soil, atmosphere, and surface water, especially in fine-scale watersheds.

\subsection{Literature Review}

Land management practices are one of the main factors leading to the variations in SOC fractions and in the quantity and quality of DOC in headwater ecosystems (Chantigny, 2003; Fellman et al., 2008; Neff et al., 2006; Poeplau et al., 2011; Sainepo et al., 2018; Takata et al., 2011). Fe oxides play an important role in the processes of SOC dynamics in ecosystems (Coward 
et al., 2018; Coward et al., 2017; Mu et al., 2016; Shields et al., 2016; Zhao et al., 2016). Therefore, the influence of land management practices on SOC fractions and Fe minerals in different ecosystems are reviewed, especially interactions between DOC and Fe oxides. In addition, the role of DOC and Fe in contributing to surface water brownification are reviewed.

\subsubsection{Effects of land management practices on SOC fractions}

Sequestering more SOC has been considered as a strategy to improve soil quality and mitigate global climate change (Schmidt et al., 2011). Land use and management practices influence SOC stocks and dynamics by altering the quantity and quality of plant inputs, microbial inputs, and the decomposition rate of the inputs (Martens et al., 2004).

Forested land tends to have a larger SOC stock and a larger level of SOC saturation than cropland and pasture (Murty et al., 2002; Wiesmeier et al., 2014). Thus, cropland and pasture soils are predicted to have a higher potential to sequester SOC compared to forest soils (Wiesmeier et al., 2014). Therefore, management practices are widely adopted aiming to increase SOC at pasture and cropland agricultural systems (Gomiero et al., 2011).

SOC is reactive to land-use change, especially labile SOC in subsurface soils (Hobley et al., 2017; Poeplau and Don, 2013; Sheng et al., 2015). Particulate organic carbon (POC), mineral associated organic carbon (MOC), and labile organic carbon (LOC) fractions differ in stabilization mechanisms and thus vary in turnover times (Buyanovsky et al., 1994; Six et al., 2000). LOC and POC have faster turnover times and are sensitive to changes compared to MOC (Budge et al., 2011; Du et al., 2015; Duval et al., 2013). Thus, SOC fractions are considered more sensitive indicators than SOC and are increasingly used to assess land management effects (Gong et al., 2009; Jamala, 2013; Purakayastha et al., 2008). 
SOC fractions are significantly influenced by land management practices. POC is reported to be the most sensitive SOC fraction to the alternation of management practices (Duval et al., 2013; Duval et al., 2016). Fertilization and no-tillage are two ways of increasing agricultural SOC concentration and altering the SOC fractions (Gong et al., 2009; Lopez-Bellido et al., 2017). Notillage or conservation practices increase SOC stock associated with microaggregates and thus contribute to long-term stable OC sequestration in microaggregates (Ghosh et al., 2016; LopezBellido et al., 2017). Organic manure is commonly applied for enhancing crop productivity and improving soil quality (Lopez-Bellido et al., 2017; Lou et al., 2011; Manna et al., 2005; Verma and Sharma, 2007). The accumulation of macroaggregate protected SOC or POC is enhanced with manure application, which increases the protection of soil labile SOC (Aoyama et al., 1999; Bhattacharyya et al., 2010).

The carbon management index (CMI) was proposed by Blair et al. (1995) to relate SOC pools and OC lability. CMI is reported to be highly correlated with soil physical, chemical and biological properties (Vieira et al., 2007). It reflects the effects of human activities and external factors on SOC fractions (Sainepo et al., 2018; Xu et al., 2006). Thus, it is proposed as a more sensitive indicator and has been used to assess the effects of management practices on SOC sequestration and soil health (Ghosh et al., 2016; Lou et al., 2011; Sainepo et al., 2018). Since a higher CMI correlates with larger soil C pool and increased C lability; a larger CMI indicates carbon rehabilitation while a smaller CMI implies $\mathrm{C}$ degradation compared with a reference soil (Blair et al., 1995). A soil with better soil quality is expected to have a larger CMI index and crop productivity (Vieira et al., 2007). 


\subsubsection{Role of Fe minerals on preservation of SOC}

Iron has profound influences on biogeochemical processes by modulating the preservation and remineralization of OC. Iron oxides have smaller particle sizes and a larger surface area than other metal oxides, so they have larger sorption capacity for OC compared to other metal oxides (Burdige and Lerman, 2006; Kaiser and Guggenberger, 2007). The important roles of Fe minerals in preserving OC in soil and sediment have been identified by many researchers (Coward et al., 2017; Kaiser and Guggenberger, 2007; Lalonde et al., 2012; Zhao et al., 2016). It has been estimated that $(19-45) \times 10^{15} \mathrm{~g}$ OC in sediments and $266-809 \times 10^{15} \mathrm{~g}$ OC in forest soils are preserved by Fe oxides on the global scale (Lalonde et al., 2012; Zhao et al., 2016).

Three mechanisms of SOC accumulation have been proposed (Lützow et al., 2006). The first one is that the recalcitrant $\mathrm{OC}$ is selected preserved, for example, plant litter and microbial products (Kallenbach et al., 2016; Kramer and Gleixner, 2008; Lorenz et al., 2007). However, the decomposition of the recalcitrant SOC is enhanced due to more available degradable low molecular weight DOC (Fontaine et al., 2007; Hamer and Marschner, 2005). Thus, another mechanism is that SOC can be stabilized if it is not accessible spatially to decomposers (Baldock et al., 1992; Chabbi et al., 2009). For example, occlusion of SOC by aggregation (Lützow et al., 2006). Lastly, DOC can be sorbed by interacting with Fe, Al, Mn-oxides on soil mineral surfaces through sorption and thus preserved (Coward et al., 2017; Kalbitz and Kaiser, 2008; Kothawala et al., 2008; Wagai and Mayer, 2007). Fe-bound OC is resistant to degradation and mineralization by microbes (Kalbitz et al., 2005). For example, a significant relationship is found between poorly crystalline Fe minerals and slow turnover times of SOC (Porras et al., 2017).

The amount of Fe-bound OC in soil and sediment is various in different ecosystems and has a wide range. In forest soils, the Fe-bound OC contributes up to 57\% of the total SOC (Wagai and 
Mayer, 2007; Zhao et al., 2016). In permafrost soils, Fe-bound OC accounts for $19.5 \pm 12.3 \%$ of total SOC (Mu et al., 2016). In sediments, Lalonde et al. (2012) reported 21.5 $\pm 8.6 \%$ OC is bound by reactive Fe phases and this amount probably increases with more OC coprecipitating with reactive Fe during the post-depositional stage (Shields et al., 2016).

Agricultural management practices alter the concentrations of Fe oxides in soil solution, which influences the preservation of DOC by Fe oxides (Huang et al., 2016a). Poorly crystalline iron oxides in agricultural soils are significantly increased due to manure application (Huang et al., 2016b; Wen et al., 2019; Zhang et al., 2013). Since soil Fe occurs in various forms differing in reducibility, it is important to have a better understanding of Fe oxides with different reducibility in stabilizing SOC, for example, exchangeable Fe and microbially reducible Fe (Lovley and Phillips, 1987; Van Bodegom et al., 2003). However, multiple forms of Fe oxides with different reducibility in stabilizing SOC is still understudied, especially in both intensive and less-intensive agricultural soils.

\subsubsection{Contribution of DOC to SOC}

DOC accounts for the most labile OC pool in soil and contributes significantly to the preservation of SOC. Up to $55 \mathrm{Mg} \mathrm{ha}^{-1} \mathrm{SOC}$ is derived from DOC, which represents $19-50 \%$ OC of total SOC in mineral soils (Kalbitz and Kaiser, 2008). DOC constitutes $22 \%$ of annual OC inputs below $40 \mathrm{~cm}$ in a coniferous forest while $2 \%$ in a prairie soil (Sanderman and Amundson, 2008). The residence time of DOC transported from topsoil increases to $90-150$ years when sorbed onto subsoil (Sanderman and Amundson, 2008).

Differences in DOC amount and composition influence its interaction with the soil matrix and thus the preservation of labile DOC. A larger SOM turnover time has been found in soil matrix with larger fresh carbon supplies because this fresh carbon provides an energy source for soil 
microorganisms, which stimulates mineralization of buried OC (Chabbi et al., 2009; Fontaine et al., 2007). Thus, a larger SOC preservation potential is expected for soil systems that have a fast depletion of SOC, such as cropland soils with disturbances (Smith, 2004; Wiesmeier et al., 2014).

The most stable components contributing to SOC preservation are likely from aromatic compounds that are preferentially retained by soil short-range ordered minerals (Kramer et al., 2012). Aromatic compounds were rapidly and primarily adsorbed to goethite surface or bacteriogenic Fe oxides, which is followed by lignin-like and then aliphatic compounds (Coward et al., 2018; Sowers et al., 2019). Riedel et al. (2013) reported similar results that rapid adsorption and removal of aromatic compounds from solution while carboxyl-rich aliphatic acids are largely retained in solution without stabilization. The retention time of aromatic compounds increases from 30 years to larger than 90 years once they sorb to soil minerals (Kalbitz and Kaiser, 2008; Kramer et al., 2012; Riedel et al., 2013).

\subsubsection{Quantity and quality of DOC under different land management practices}

Land management practices change both the quantity and quality of DOC in soil and differ among landscape types (Chantigny, 2003; Kalbitz, 2001; Lee et al., 2018). DOC chemistry differs among landscape types due to different plant litter input, hydrologic connectivity, and microbial processing (Lee et al., 2018).

Agriculture land management practices lead to decreasing DOC concentration and reduced SOC stocks (Berhongaray et al., 2013; Boyer and Groffman, 1996; Petrone et al., 2009). Long term agriculture inputs increase aromatic structure and dissolved fulvic acid content, which leads to lower $\mathrm{C} / \mathrm{N}$ ratio, high absorption in the UV-vis spectra, and low molecule weight (LMW) DOC (Delprat et al., 1997; Kalbitz et al., 1999). For example, manure and crop residue application decreases LMW DOC in arable soils compared to forest soils (Takata et al., 2011). The structural 
complexity of DOC increases with an increasing ratio of continuous croplands to wetlands (Wilson and Xenopoulos, 2009).

Chromophoric DOC (CDOC) absorbs UV-vis light and some fractions of CDOC have fluorescent properties (Coble et al., 2014). Strong relationships have been observed among humic-like fluorescence intensity, fluorescence index, DOC concentration, and DOC molecular size (Wu et al., 2007). Land use influences the quantity and quality of DOC and thus spectroscopic properties of DOC (Kalbitz et al., 1999; Yang et al., 2012). Conventionally tilled soils had less absorbance at $254 \mathrm{~nm}$ and a larger humidification index (Zhang et al., 2011). DOC concentration correlates positively with humic-like fluorescence but negatively with protein-like fluorescence in the surface water of agricultural catchments (Petrone et al., 2011).

The quantity and quality of DOC leaching from soil affect the quantity and quality of DOC in aquatic ecosystems (Fellman et al., 2008; Neff et al., 2006). Land management practices are one of the main reasons for the variations of DOC input and output to ecosystems (Chantigny, 2003). Urban land cover significantly contributed to surface water pollution while increasing ratio of wetlands within a landscape significantly contribute to decreasing DOC concentrations in surface water (Wang et al., 2014; Williams et al., 2005). Both intensive and less-intensive agricultural land use had significant effects on terrestrial-aquatic carbon processes (Glendell and Brazier, 2014; Lee et al., 2018). Intensively cultivated soils lead to the redistribution of catchment-scale SOC to sediment through water erosion, which accelerates the export of DOC to stream and alters DOC quality (Glendell and Brazier, 2014; Graeber et al., 2015; Wang et al., 2010). Similarly, DOC processes and fluorescent properties are significantly influenced by non-intensive agricultural management practices through different plant litter input and degree of microbial processing within a mixed landscape (Lee et al., 2018). 
Temperature and rainfall are the other potential drivers of seasonal DOC trends due to changes in hydrologic connectivity and microbial processing across a landscape (Lee et al., 2018). DOC concentration is larger during summer and smaller in winter (Koehler et al., 2009). The composition of DOC is variable across seasons. For example, the more hydrophilic fractions are present during winter and spring while the more hydrophobic fractions are present during summer and autumn in forest soils (Kaiser et al., 2002). Day-to-day and seasonal patterns of precipitation are important factors when explaining DOC fluxes (Howarth et al., 1991).

\subsubsection{Interactions between $\mathrm{Fe}, \mathrm{DOC}$, and SOC preservation}

The interactions between Fe and OC shape the chemistry of Fe. The preservation and retention of OC are affected by Fe minerals. Dissolved Fe interacts with organic ligands, which alter Fe solubility and thus Fe bioavailability (Raiswell and Canfield, 2012). Organometallic complexes tend to produce a more actively cycling SOC pool because of its more soluble property (Porras et al., 2017).

The oxic and anoxic interface is the redox transition environment where Fe and OC chemical interactions occur (Aller et al., 1996). When Fe oxides are reduced in anoxic microsites, there is no preservative effect of Fe on OC. Ferric Fe and DOC are likely interacting with each other and forming complexes in the oxic microsites where availability of DOC decreases (Lalonde, 2014). Dissolved reduced $\mathrm{Fe}$ in the anoxic layer can precipitate as Fe oxides in the oxic layer by coagulation, which removes a large fraction of DOC (Burdige, 1993; Riedel et al., 2013). This Fe-OM complexes may be buried and then survive in the anoxic environments where OM degradation rates are low.

Plant-derived aromatic and lignin-like high molecular weight compounds are preferentially retained by reactive amorphous $\mathrm{Fe}$ oxides by forming irreversible inner-sphere bonds, which 
resist the desorption of adsorbed DOC and thus contributes to long-term SOC preservation (Coward et al., 2018; Kramer et al., 2012; Oren and Chefetz, 2012; Zimmerman et al., 2004). It has been shown that more than $90 \%$ dissolved Fe and about $27 \%$ of DOC (mainly plant-derived aromatic compounds) were rapidly removed within 24 hours in anoxic fen pore water through coagulation (Riedel et al., 2013). When soil solutions rich in oxidized lignin and carboxyl compounds is translocated through the soil profile, these compounds are preferentially sorbed onto short-range ordered Fe minerals and thus increase the retention time of these compounds (Kramer et al., 2012).

\subsubsection{Role of DOC and Fe on surface water color}

Surface water brownification is frequently reported in many large-scale watersheds of the northern hemisphere (Haaland et al., 2010; Weyhenmeyer et al., 2016). It is a current environmental concern with wide-reaching ecological and societal impact, e.g. on functions of aquatic ecosystems (Williamson et al., 2015) and potentially increasing pretreatment cost of drinking water due to the formation of toxic byproducts (Richardson et al., 2007).

It is known that DOC contributes to water darkening due to the presence of colored DOC (Pace and Cole, 2002; Roulet and Moore, 2006). Given the interaction of Fe with DOC, Fe has received more attention recently and it has been reported that Fe can provide additive effects to water color by forming complexes with DOC (Maloney et al., 2005; Weyhenmeyer et al., 2014). The complexes between $\mathrm{Fe}$ and DOC can extend the residence time of both Fe and DOC in water (Maloney et al., 2005) and thus increase water brownification (Sarkkola et al., 2013).

Many studies have reported that land use is an important driver of surface water brownification (Kritzberg et al., 2019; Worrall et al., 2004). SOC pools are the stream water DOC sources and thus land use/land cover is an important factor influencing the transport of DOC and Fe in the soil 
to adjacent water bodies, especially in upstream water (Aitkenhead et al., 1999; Dillon and Molot, 1997; McDowell, 1984). It has been shown that changes in land use lead to changes in the amount and composition of DOC in streams (Graeber et al., 2012; Petrone et al., 2011; Wilson and Xenopoulos, 2009; Yang et al., 2012). The changes in amount and composition of DOC may influence the presence of Fe, Fe-DOC complexes, and thus water color. To counteract surface water brownification, Kritzberg et al. (2019) reported the most feasible way may be through managing the land use in the hydrologically connected parts of the landscape.

In addition to land cover, other biotic and abiotic factors govern the DOC input and output processes, such as temperature, discharge, vegetation, hydrology, and soil mineralogy (Armstrong et al., 2012; Camino-Serrano et al., 2014; Erlandsson et al., 2008; Lambert et al., 2013; Maurice et al., 2002; Sanderman and Amundson, 2008). Most studies have quantified the contributions of DOC and Fe to water color according to concentration of DOC and Fe in large-scale watersheds based on dominant land cover of the catchment sampling locations (Ekström et al., 2016; Köhler et al., 2013a; Kritzberg et al., 2014; Kutser et al., 2015; Sarkkola et al., 2013; Weyhenmeyer et al., 2014; Williamson et al., 2015). However, multiple locations within a watershed bring more factors beyond the land cover, especially for high order streams, which are weakly addressed and thus a limitation of these studies. Additionally, the quantity and quality of DOC and Fe change with passage through watersheds (Fellman et al., 2009; Neubauer et al., 2013). Thus, there is still uncertainty regarding the role of land cover on water color in these large-scale watershed studies. Recent studies have been directed to fine-scale headwater streams with similar influencing factors (De Paula et al., 2016; Kellner et al., 2018). In addition, the quality of OM alters the interactions between DOC and Fe, which may impact water color (Xiao et al., 2013). However, studies 
combining quality of OM to explain water color are rarely conducted, especially in fine-scale headwater watersheds with different land uses.

\subsubsection{Research questions}

In natural environments, Fe oxides have a larger affinity for OC than other metal oxides (Kaiser and Guggenberger, 2007). The Fe-bound OC inhibits the degradation and mineralization by microbes (Kalbitz et al., 2005) and has a longer residence time. Thus, a better understanding of the role of Fe oxides in regulating SOC dynamics is helpful for developing best management practices to mitigate $\mathrm{C}$ related environmental issues.

It has been reported that pasture and cropland soils have a larger potential to preserve OC compared to forest soils (Wiesmeier et al., 2014). Current research focuses on quantifying the Febound OC in natural ecosystems, such as forest soils and sediment. In forest soils, up to $57 \%$ of total OC is bound to Fe oxides (Wagai and Mayer, 2007). The amount of Fe-bound OC was significantly different among meadow, steppe and desert steppe in a permafrost region (Mu et al., 2016).

Long-term agricultural practices reshape the quantity and quality of SOC factions present in soil, such as physical distribution, aromatic structure, structural complexity, and molecule weight (Cotrufo et al., 2019; Kalbitz et al., 1999; Takata et al., 2011; Wilson and Xenopoulos, 2009). This impacts the interactions between SOC and Fe oxides due to the alteration of quantity and quality of SOC fractions accessible to soil Fe minerals, which is largely different from sediment and forest ecosystems. Cropland and pasture soils are predicted to have a larger ability to sequester $\mathrm{C}$ than forest soils (Wiesmeier et al., 2014). However, there are few studies investigating the potential differences of these soils in sequestering SOC. 
In the central Appalachian region, anthropogenic disturbances are increasing, which leads to the degradation of SOC and deterioration of surface water quality (Bryce et al., 1999). In this region, forest, pasture, and cropland soils account for 62,18 , and $8 \%$ of land use, respectively. Thus, assessing the soil carbon quality is paramount to develop best management practices for restoration and sustainable agriculture. Most of the previous studies focus on SOC sequestration in soils disturbed by surface mining (Chaudhuri et al., 2011; Chaudhuri et al., 2012) and dissolved organic C fluxes in peatland soils (Yavitt, 1994). However, there are few studies on the effects of cropland and pasture soils on SOC fraction pools and the capacity of cropland and pasture soils to sequester OC, especially considering different soil depth increments in this region. This information would be helpful for developing management strategies to improve soil quality in the Appalachian region and similar mountain ecosystems.

Iron minerals complex with aromatic DOC compounds; the DOC and iron complexes are more stable due to much longer retention time once they sorb to soil minerals (Kalbitz and Kaiser, 2008; Kramer et al., 2012; Riedel et al., 2013). Short-range ordered minerals complexing with aromatic DOC compounds via chemical retention are a potential mechanism of transport and accumulation of Fe-bound OC in deeper volcanic and forest soils (Kramer et al., 2012; Porras et al., 2017). However, there is still a research gap regarding the adsorption behavior of aromatic DOC in agricultural soils at different depths with different management practices.

The interactions between DOC and reactive Fe are surface-controlled sorption and desorption processes. Batch experiments have been used to establish sorption isotherms, whereby the soil is incubated with a range of initial DOC concentrations and allowed to come to an steady state (Coward et al., 2018; Guggenberger and Kaiser, 2003; Kaiser and Guggenberger, 2000; Kaiser et al., 1996; Kothawala et al., 2008). This is a reliable approach for estimating DOC adsorption 
capacity. The sorption isotherm can be used to predict potential sorption capacity of DOC in soil. This would also provide valuable information for developing more precise $\mathrm{C}$ models and assessing SOC dynamics.

Current studies on the contribution of DOC and Fe to water color in large-scale watersheds are conducted based on the dominant land cover of the catchments (Ekström et al., 2016; Köhler et al., 2013a; Kritzberg et al., 2014; Kutser et al., 2015; Sarkkola et al., 2013; Weyhenmeyer et al., 2014; Williamson et al., 2015), which brings more factors beyond the land cover, for example, parent materials and geological processes. To address the uncertainties and limitations of these studies, fine-scale catchments with similar parent materials, geological processes, and topography, and climate were chosen. Additionally, the quantity and quality of DOC and Fe change with passage through watersheds (Fellman et al., 2009; Neubauer et al., 2013), which may alter the interactions between DOC and Fe and thus impact water color (Xiao et al., 2013). However, studies combining quality of OM to explain water color are rarely conducted, especially in finescale headwater watersheds with different land use.

Given these research gaps, three specific questions in this study were focused on.

1. How did SOC fractions differ in a hardwood forest, cropland, and pasture soils at 0-10 $\mathrm{cm}$ and $10-25 \mathrm{~cm}$ ?

2. How did $\mathrm{Fe}$ oxides and adsorption of aromatic DOC to soils managed under a hardwood forest, cropland, and pasture 0-10 $\mathrm{cm}$ and $10-25 \mathrm{~cm}$ differ?

3. How did DOC and Fe oxides in soil influence DOC and Fe concentrations in the associated fine-scale headwater streams? 
All this information is valuable for a better understanding of the interaction of DOC and Fe in nature forest, cropland, and pasture soil. They can also provide a helpful guide to develop appropriate practices to solve environmental problems; For example, decreasing SOC storage in soil, and increasing DOC concentration in surface water.

\subsection{Hypothesis and Objectives}

The evidence from previous research suggests that aromatic DOC and reactive Fe are two important components contributing to SOC sequestration and that cropland and grassland soils have a larger potential to sequester $\mathrm{C}$ than forest soils.

In Chapter 2, we hypothesized that forest, cropland, and pasture soils would show differences in SOC fractions and carbon management index. The objectives of this study were to quantify TOC, POC, MOC, and carbon management index in cropland, pasture, and forest soils at $0-10$ $\mathrm{cm}$ and $10-25 \mathrm{~cm}$.

In Chapter 3, we hypothesized that if cropland and pasture soils had larger potential to stabilize more organic carbon, then cropland and pasture soils would show larger amounts of Fe-bound OC, more sorption of aromatic DOC, and larger sorption capacity than the forest soil. The objectives of this study were 1) operationally quantify three forms of Fe oxides (exchangeable, amorphous Fe, and crystallized Fe oxides), three forms of SOC (total SOC (TOC), Fe-bound OC, and DOC released during amorphous Fe extraction), and Fe and TOC molar ratio (OC: Fe), and 2) quantify the sorption of DOC and changes of aromaticity of DOC after sorption using batch experiments from pasture, cropland, and hardwood forest managed soils.

In Chapter 4, we hypothesized that the pasture headwater streams had larger DOC and Fe concentrations and thus water color compared to the forest headwater streams. In addition, the 
quality of DOC influenced water color by influencing interactions with Fe. The aims were to quantify and compare DOC and Fe concentrations and their relative contributions to water color between pasture and forest dominated headwater streams, and to determine which were the DOC fractions that interacted with Fe indicated by DOC quality indexes and thus contributed to watercolor in these two headwater streams.

In Chapter 5, we hypothesized that, due to long-term effects of agricultural management practices in the pasture catchment, the pasture catchment would show higher concentrations and a larger seasonal variation of DOC, Fe content, and aromaticity of DOC than the forest catchment. The aims of this study were to 1) compare the temporal variations in DOC amount and composition in both soil and stream waters, and 2) examine the temporal variations of exchangeable $\mathrm{Fe}$ and amorphous Fe minerals in the soil as well as the temporal and spatial variations in dissolved Fe concentration in an agricultural pasture catchment and forest catchment in West Virginia. 
Chapter 2 Soil Organic Carbon Fractions and Carbon Management Index in the Surface Soil: Comparing a Forest, a Cropland, and a Pasture Soil in a Central Appalachian Region, West Virginia

\subsection{Abstract}

Soil organic C (SOC) fractions have various stabilization mechanisms and turnover times, which change with depth and are highly influenced by land use. In this study, we used total organic carbon (TOC), particulate organic carbon (POC), mineral-associated organic carbon (MOC), and carbon management index (CMI) as indicators to compare cropland with manure application (CM) and continuous pasture (CP) to a hardwood forest (HF) at soil depths of $0-10$ and $10-25 \mathrm{~cm}$. Land use, depth, and the interactions between them all had significant influences on TOC, POC, MOC, MOC/TOC ratio, and CMI except for the main effect of land use on TOC. CM showed significantly larger POC $\left(12.4 \mathrm{~g} \mathrm{~kg}^{-1}\right)$ and smaller MOC $\left(8.36 \mathrm{~g} \mathrm{~kg}^{-1}\right)$ at $10-25 \mathrm{~cm}$ compared to HF and CP soils. CM soil at $10-25 \mathrm{~cm}$ had improved soil quality and SOC lability as indicated by a significantly larger CMI value (419.2) while CP soil had decreased soil quality and SOC lability at both $0-10 \mathrm{~cm}$ (83.7) and $10-25 \mathrm{~cm}$ (73.6) compared to HF soil. This study implied high sensitivity of the SOC in cropland and pasture surface soils to degrade under disturbance, which implies that better management strategies are still needed to improve soil carbon quality for these agricultural systems.

Key words: Land management practices · Particulate organic carbon · Mineral associated organic carbon 


\subsection{Introduction}

Soil organic carbon (SOC) influences soil productivity, terrestrial vegetation production, and aquatic water quality by facilitating the transport of nutrients and pollutants (Lehmann and Kleber, 2015; Schmidt et al., 2011). Land use is active drivers of SOC allocation among soil aggregates, which changes SOC fraction distribution and thus alters long-term SOC stabilization mechanisms (Aoyama et al., 1999; Arai and Tokuchi, 2010; Chabbi et al., 2009; Cotrufo et al., 2019; Du et al., 2015; Leifeld et al., 2009). Anthropogenic disturbances can decrease SOC storage and change SOC associated properties (Jones and Falloon, 2009), which leads to decreased soil productivity and increased greenhouse gas emissions (Butman et al., 2015; Grosse et al., 2011; Pongratz et al., 2009; Schlesinger, 1986; Van Miegroet and Olsson, 2011).

In the central Appalachian region, anthropogenic disturbances are increasing, which leads to major issues of soil degradation, depletion of SOC stocks, and deterioration of aquatic ecosystems (Bryce et al., 1999). The forest, pasture, and cropland soils account for 62, 18, and $8 \%$ of land use in this region, respectively. Thus, assessing the soil carbon status is paramount to develop best management practices for restoration and sustainable agriculture for this region. Most previous studies focused on SOC sequestration in drastically disturbed soils (Chaudhuri et al., 2011; Chaudhuri et al., 2012) or dissolved organic C fluxes in peatland soils (Yavitt, 1994). There are few studies on the effects of cropland and pasture on SOC fraction pools, especially when considering different soil depth increments. This information would be useful in developing management strategies to improve soil quality in the central Appalachian region and similar mountainous ecosystems.

Changes in SOC are commonly used to assess the effects of management practices (Diekow et al., 2005). Particulate organic C (POC) and mineral-associated organic C (MOC) are more 
sensitive fractions that reflect effects of the external environment and human activities on SOC pool dynamics (Cotrufo et al., 2019; Xu et al., 2006). SOC fractions have various stabilization mechanisms and turnover times, which change with depth and are highly influenced by land use (Cotrufo et al., 2019; Jobbágy and Jackson, 2000; Sainepo et al., 2018). The C management index (CMI) is highly correlated with soil physical, chemical, and biological properties (Vieira et al., 2007). CMI relates to SOC pool and the change of SOC lability (Ghosh et al., 2016; Lou et al., 2011; Sainepo et al., 2018; Vieira et al., 2007). Thus, these are useful indicators to assess effects of land use on SOC fractions and the capacity of management systems to promote soil quality (Buyanovsky et al., 1994; Duval et al., 2016; Gong et al., 2009; Lou et al., 2011; Sainepo et al., 2018). A better understanding of SOC fraction dynamics is essential to evaluate best management practices to maximize the sustainability and productivity of agricultural lands (Smith, 2008).

Current studies assess the effects of land use on SOC fractions at the scale of larger watersheds with contrasting differences in climate and variable geology (Duval et al., 2016; Kalambukattu et al., 2013; Luo et al., 2017; Nahrawi et al., 2012; Sainepo et al., 2018). Climate and soil properties are important factors influencing SOC fraction dynamics (Gosling et al., 2013; Jobbágy and Jackson, 2000; Luo et al., 2017). These contrasting differences with a watershed bring uncertainty in interpreting the effects of land use on SOC fraction pools due to other local variability (Bird et al., 2001; Jones and Falloon, 2009). Thus, a better understanding of influences of land use on SOC fraction pools at a finer regional scale may be helpful to address this uncertainty (Bird et al., 2001). In addition, these SOC fractions are common SOC pools of current SOC models (Abramoff et al., 2018). Quantifying SOC pools and concentrations at a finer regional scale is essential for constructing robust global C models by considering depth distribution, especially for 
predicting SOC storage in cropland and pasture soils (Jones and Falloon, 2009; Schmidt et al., 2011).

To avoid the confounding effects of variable geology and climate effects on SOC fractions, the use of pseudo-replicated studies may be informative. In our study, we chose a single finescale watershed, which was derived from the same parent materials and had similar climate conditions (Kellner et al., 2018). We selected a cropland, a pasture, and a forest soil within this small catchment which have been maintained in this state for more than 20-years. The objective of this study was to quantify TOC, POC, and MOC in a cropland, pasture, and forest soil at 0-10 $\mathrm{cm}$ and $10-25 \mathrm{~cm}$ as well as CMI in the cropland and pasture soils by comparing to the forest soil.

\subsection{Materials and Methods}

\subsubsection{Study site description}

This study was carried out in Morgantown, West Virginia (39 $40^{\prime}$ N, $79^{\circ} 56^{\prime}$ W) (Fig. 2.1). Three representative land-use types were forest, pasture, and cropland. The slope gradient of the forest and pasture is from 3\% to 35\% while the slope of cropland is $0-3 \%$. The elevation ranges from $287 \mathrm{~m}$ to $381 \mathrm{~m}$ above sea level. The mean annual precipitation is $109.6 \mathrm{~cm}$. The mean annual temperature is $11.25^{\circ} \mathrm{C}$ (Wright, 1982).

The forest was mixed deciduous hardwood (HF) with trees that were approximately 120 years old (Fithian, 1979). The dominant hardwood types included white oak (Quercus alba), northern red oak (Quercus rubra), yellow poplar (Liriodendron tulipifera), white ash (Fraxinus americana), and hickory (Carya tomentosa) (Witt 1981). The pasture was continuously pasture (CP) with 0.5-0.75 dry dairy cows or/and heifers per hectare for 20 years. The pasture was mowed once in October every year. The vegetation present included grasses, legumes, and forbs. The dominant species included red clover (Trifolium pretense), white clover (Trifolium repens), 
ironweed (Vernonia baldwinii), smartweed (Polygonum pensylvanica), horsenettle (Solanum carolinense), Kentucky bluegrass (Poa pratensis), and timothy (Phleum pretense). The cropland was a continuous corn (Zea mays) field with manure application (CM). Composted dairy manure had been incorporated at a rate of 2700 to $3600 \mathrm{~kg} \mathrm{ha}^{-1}$ dry matter each year for at least 20 years. An additional $100 \mathrm{~kg} \mathrm{ha}^{-1}$ urea was applied when corn was 0.2-0.5 m tall. Winter wheat (Triticum aestivum) was planted as a cover crop after the corn was harvested.

\subsubsection{Soil sampling}

Through a combination of computer mapping and field surveys, four $10 \mathrm{~m} \times 10 \mathrm{~m}$ plots were selected within the forest, cropland, and pasture (Figure 2.1). The elevation of the four plots at forest field was from $303.5-338.7 \mathrm{~m}$. The slope was $25-35 \%$. The soil was mapped as CulleokaWestmoreland silt loams (Fine-loamy, mixed, active, mesic Ultic Haplusdalfs) (Soil Survey Staff, 2017). The four plots from the pasture were located within delineations of the same soil map unit as the forest plots and had similar elevation (324.4 -341.8 m) and slope (25-35\%). The parent material of forest and pasture soils was loamy residuum weathered from limestone, sandstone, and shale (Soil Survey Staff, 2017). In the cropland, the elevation of the four plots was from 289.0 - 292.4 m. The soil was mapped as Holly silt loam) (Fine-loamy, mixed, active, nonacid, mesic Typic Fluvaquents) and Lobdell silt loam (Fine-loamy, mixed, active, mesic Fluvaquentic Eutrudepts). These four plots were on the flood plain adjacent to the slope where the forest and pasture plots were located. The parent material was recent loamy alluvium derived from limestone, sandstone, and shale.

Soil samples were collected in May 2018. Four $10 \times 10 \mathrm{~m}$ plots with similar microenvironmental conditions like vegetation distribution, were randomly selected in the field for each land type. The forest plots had a very thin, minimally decomposed litter layer $(<1 \mathrm{~cm})$. When 
sampling, the litter layer was removed. The pasture plots were not disturbed by feeding and watering dry dairy cows and heifers and at least 5 meters away from the edge of the field. One plot was on the shoulder slope. Two plots were on the backslope. The other one was on the footslope. The cropland plots were at least $10 \mathrm{~m}$ away from a riparian grass buffer. Six soil sample cores were collected from each plot in an $\mathrm{S}$ pattern to a depth of $25 \mathrm{~cm}$ using a soil sampling probe $(3 \mathrm{~cm}$ in diameter). The six soil cores from each plot were divided into two layers $(0-10 \mathrm{~cm}$ and $10-25 \mathrm{~cm}$ ) and composited in pairs to represent three replications at each depth at each plot. Four replications from four plots were composited so that there were three replications at each depth for each land use.

\subsubsection{Soil physical and chemical analysis}

Soil samples were air-dried at room temperature, ground, and sieved through a 2-mm sieve. Soil $\mathrm{pH}$ and electrical conductivity (EC) were determined using a 1:1 (m:V) dry soil to distilled water ratio using a Mettler Toledo SevenCompact $\mathrm{pH}$ and EC meter (Mettler Toledo, Columbus, OH, USA). Soil particle size distribution was determined using methods described by Kettler et al. (2001). Mehlich 3 extractable $\mathrm{P}, \mathrm{K}, \mathrm{Ca}$, and Mg were determined by inductively coupled plasma-optical emission spectroscopy (ICP-OES) (Optima DV-2100, Perkin Elmer, Waltham, MA, USA) (Wolf and Beegle, 2011).

All soil samples for $\mathrm{C}$ fraction determinations were acidified with $1 \mathrm{M} \mathrm{HCl}$ with a 1:2 (m:V) solid:solution ratio to degas any inorganic carbon in soil and heated at $70^{\circ} \mathrm{C}$ for 24 hours. The total organic carbon (TOC) was determined from the oven dried samples. Mineral associated organic carbon (MOC) and particulate organic carbon (POC) were determined by dispersing dried soil samples in $0.5 \%$ sodium hexametaphosphate at a 1:5 (m:V) solid:solution ratio (Cambardella and Elliott, 1992; Sherrod et al., 2002). The suspension was shaken for $16 \mathrm{~h}$ at 200 cycles per 
minute and then was washed through $53-\mu \mathrm{m}$ sieves. The filtered slurry was collected, oven dried at $70^{\circ} \mathrm{C}$ for $24 \mathrm{~h}$, and ground. The organic carbon in the filtrate $(<53 \mu \mathrm{m})$ was referred to as MOC. The POC content was calculated by subtracting MOC from TOC (Cambardella and Elliott, 1992), which was used as the labile OC for CMI estimation (Sainepo et al., 2018; Vieira et al., 2007). All C concentrations were determined by dry combustion (Elementar Vario MAX Cube, Hanau, Germany).

\subsubsection{Carbon management index}

It has been suggested that the carbon management index (CMI) is a more sensitive indicator of SOC response to management practices than other C measurements (Blair et al., 1995; Ghosh et al., 2016). It was calculated following Blair et al. (1995) using Eq 1.

$$
\mathrm{CMI}=\mathrm{CPI} \times \mathrm{LI} \times 100
$$

Where CPI is the carbon pool index and LI is the lability index and were calculated using Eqs 2 and 3 , respectively.

$$
\begin{aligned}
& \mathrm{CPI}=\frac{\text { Total organic } \mathrm{C} \text { in the treatment soil } \mathrm{g} \mathrm{kg}^{-1}}{\text { Total organic } \mathrm{C} \text { in the reference soil } \mathrm{g} \mathrm{kg}^{-1}} \\
& \mathrm{LI}=\frac{\mathrm{L} \text { of the treatment soil }}{\mathrm{L} \text { of the reference soil }}
\end{aligned}
$$

Where L refers to organic carbon lability and calculated using the Eq 4.

$$
\mathrm{L}=\frac{\text { Labile organic } \mathrm{C} \mathrm{g} \mathrm{kg}}{\text { non }- \text { labile organic } \mathrm{C} \mathrm{g} \mathrm{kg}}
$$

In our study, the forest soil was used as the reference soil. The cropland or pasture soils were used as the treatment soil. A CMI of 100 is often used for the reference soil (Blair et al., 1995; Ghosh et al., 2016; Li et al., 2015; Sainepo et al., 2018; Vieira et al., 2007). Therefore, the CMI of the forest soil at both depths was 100 in our study. The CMI of treatment soils at each depth 
was compared to the CMI of the forest soil at the same depth. A CMI value larger than 100 indicated improved soil quality while a CMI value smaller than 100 indicated soil degradation and decreased soil quality (Blair et al., 1995; Sainepo et al., 2018; Vieira et al., 2007).

\subsubsection{Statistical analysis}

Repeated measures analysis of variance (rmANOVA) and Tukey tests were performed to test the effects of land use type, depth, and their interaction on TOC, POC, MOC, MOC/TOC, LI, $\mathrm{CPI}$, and CMI at $\alpha<0.05$. All analysis was conducted using the $\mathrm{R}$ software package (R Development Core Team, 2017).

\subsection{Results}

\subsubsection{Total organic carbon}

Land use had no significant influence on TOC $(p=0.289)$. A significant influence of depth and an interaction between TOC and depth were observed ( $\mathrm{p}<0.01)$. Soil TOC was significantly larger in the soil at $0-10 \mathrm{~cm}$ than $10-25 \mathrm{~cm}(p<0.01)$. The TOC was $41.4 \mathrm{~g} \mathrm{~kg}^{-1}$ in HF and 40.4 $\mathrm{g} \mathrm{kg}^{-1}$ in $\mathrm{CP}$, which was significantly larger than TOC in CM (32.3 $\left.\mathrm{g} \mathrm{kg}^{-1}\right)$ at 0-10 cm (Fig. 2). However, TOC in HF (12.8 $\left.\mathrm{g} \mathrm{kg}^{-1}\right)$ and CP $\left(10.3 \mathrm{~g} \mathrm{~kg}^{-1}\right)$ was significantly lower than CM (20.8 $\mathrm{g}$ $\mathrm{kg}^{-1}$ ) at 10-25 cm (Fig. 2.2).

\subsubsection{Particulate organic carbon}

Land use, depth, and the interaction between them all had significant influences on POC $(p<$ 0.01). The highest POC (23.8 $\left.\mathrm{g} \mathrm{kg}^{-1}\right)$ was found in $\mathrm{HF}$ at $0-10 \mathrm{~cm}$, although this was not significantly different than the POC of CM $\left(20.5 \mathrm{~g} \mathrm{~kg}^{-1}\right)$ and CP $\left(21.7 \mathrm{~g} \mathrm{~kg}^{-1}\right)$ at $0-10 \mathrm{~cm}$ (Fig. 2.3). The $\mathrm{CM}$ at $10-25 \mathrm{~cm}$ had larger POC $\left(12.4 \mathrm{~g} \mathrm{~kg}^{-1}\right)$ than $\mathrm{HF}\left(4.7 \mathrm{~g} \mathrm{~kg}^{-1}\right)$ and $\mathrm{CP}\left(3.5 \mathrm{~g} \mathrm{~kg}^{-1}\right)$ at 10-25 cm which were observed as the two lowest POC contents (Fig. 2.3). 


\subsubsection{Mineral-associated organic carbon}

Significant main effects of type, depth, and the interaction between them were found for MOC and MOC/TOC ratio $(p<0.01)$. The MOC was significantly larger in the soil at $0-10 \mathrm{~cm}$ than $10-$ $25 \mathrm{~cm}$ (Fig. 2.4A). The two highest MOC were found at HF $\left(17.6 \mathrm{~g} \mathrm{~kg}^{-1}\right)$ and $\mathrm{CP}\left(18.7 \mathrm{~g} \mathrm{~kg}^{-1}\right)$ at 0-10 cm, which was significantly larger than $\mathrm{CM}$ at $0-10 \mathrm{~cm}$ (Fig. 2.4A). There were no significant differences found among the three land use at $10-25 \mathrm{~cm}$. Contrary to MOC, the two highest MOC/TOC ratio values were found at $\mathrm{HF}(64 \%)$ and $\mathrm{CP}(66 \%)$ at $10-25 \mathrm{~cm}$, which was significantly larger than CM (40\%) at 10-25 cm as well as all the three land uses at $0-10 \mathrm{~cm}$ (Fig. 2.4B).

\subsubsection{Carbon management index (CMI)}

Significant main effects of land use, depth, and their interactions on LI, CPI, and CMI were found $(p<0.01)$. The highest LI (2.57), CPI (1.62) and CMI (419.2) were found in CM at 10-25 $\mathrm{cm}$ and were significantly larger than $\mathrm{CM}$ at $0-10 \mathrm{~cm}$ and $\mathrm{CP}$ at both $0-10 \mathrm{~cm}$ and $10-25 \mathrm{~cm}$ (Table 2.2). The CP had the lowest CMI (73.6) at 10-25 $\mathrm{cm}$ due to the lowest LI (Table 2.2). There were no significant differences between CPI and CMI for $\mathrm{CM}$ at $0-10 \mathrm{~cm}$ and $\mathrm{CP}$ at both $0-10 \mathrm{~cm}$ and 10-25 cm (Table 2.2).

\subsection{Discussion}

\subsubsection{Soil carbon fractions}

We found significantly lower TOC and MOC in cropland soil compared to forest and pasture soil in the topsoil layer $(0-10 \mathrm{~cm})$ (Fig. 2.2 and Fig. 2.4A). Although long-term manure application significantly increases TOC, the benefit of manure application might be offset by the tillage effect in the cropland soil in this study. This would increase the flux of carbon dioxide and thus SOC loss (Reicosky et al., 1997; Tong et al., 2014). Similar results were reported by Singh et al. (2015) 
where straw amendment in a cereal monoculture system didn't significantly increase topsoil carbon sequestration. The lower content of MOC in cropland is also likely due to tillage, which contributes to the decrease of the soil microaggregate proportion in soil (Lopez-Bellido et al., 2017). Contrary to TOC and MOC trends, there was no significant difference in POC among three land uses at 0-10 cm (Fig. 2.3). Sui et al. (2013) reported increased POC in soil at 0-30 cm after chemical $\mathrm{N}$ fertilizer and manure application. The POC concentration in the cropland soil at $0-10$ $\mathrm{cm}$ in our study may have been enhanced by manure application.

The TOC, POC, and MOC all significantly decreased with increasing depth $(p<0.01)$, which is consistent with the finding of Somasundaram et al. (2017). At 10-25 cm, the TOC and POC were significantly larger in cropland than pasture and forest soils (Fig. 2.2 and Fig. 2.3) while there were no significant differences in MOC among three land uses. This indicated that manure application could increase POC but have limited influence on MOC in cropland soil at 10-25 cm (Fig. 2.3 and Fig. 2.4A). No-tillage practices may promote POC to transform to MOC for long term stabilization in this cropland soil (Six et al., 2000). Other studies have found that MOC was larger than POC in the forest and cropland soil (Jamala, 2013; Somasundaram et al., 2017). However, our study observed the dominant organic carbon fractions depended on depth and land use. The largest MOC/TOC ratio (>60\%) was found in forest and pasture soil at 10-25 $\mathrm{cm}$ (Fig. 2.4B). The MOC/TOC of cropland at $10-25 \mathrm{~cm}$ and all three soils at $0-10 \mathrm{~cm}$ were all less than 50\% (Fig. 2.4B). The lower MOC/TOC ratio at cropland, forest, and pasture in topsoil could be attributed to long-term SOC input from manure application in cropland, litter contribution in the forest, and root system in the pasture (Aoyama et al., 1999; Rumpel and Kögel-Knabner, 2011). 


\subsubsection{Implication for long-term land use and management practices under climate change}

Most studies at large scale found degraded soil quality of agricultural soils (Ghosh et al., 2016; Kalambukattu et al., 2013; Sainepo et al., 2018; Vieira et al., 2007; Xu et al., 2006). Conversely, our study observed the cropland soil at $0-25 \mathrm{~cm}$ had improved soil quality after long-term manure application (as indicated by larger CMI values; Table 2.2). However, the dominant POC pool leads to the sensitivity of the cropland soil to the changes of land use (Buyanovsky et al., 1994; Duval et al., 2016; Gong et al., 2009; Lou et al., 2011; Sainepo et al., 2018). A truly effective practice for long-term $\mathrm{C}$ stabilization may be no-tillage with organic amendments in agricultural soils due to the promoted transformation of labile OC to protected $\mathrm{OC}$ in macroaggregates and microaggregates (Aoyama et al., 1999; Du et al., 2018; Lopez-Bellido et al., 2017; Six et al., 2000). For example, no-tillage and alley cropping are recommended practices for long-term stable SOC stabilization in the current tilled agricultural system (Wolz et al., 2018).

Our study didn’t find significant differences in TOC, POC, and MOC concentrations between pasture and forest soils at the two depths. However, both the topsoil and subsoil had decreased soil quality as indicated by CMI compared to the adjacent forest soil (Table 2.2). This is consistent with previous studies (Kalambukattu et al., 2013; Sainepo et al., 2018; Xu et al., 2006). This implies improved management practices for the pasture soil could improve SOC lability and nutrient cycling. Management practices increasing SOC input and driving the translocation of labile SOC to subsurface soil may be helpful to increase long-term SOC stabilization.

Land uses are key factors influencing SOC dynamics and its fractions (Lou et al., 2011; Smith, 2008). Exploring best management practices is still a priority to solve current environmental issues due to anthropogenic disturbance, like reducing SOC loss and restoring OC in the soil to mitigate global warming (Smith, 2008). SOC fractions are essential components of current global 
carbon models (Abramoff et al., 2018). This fine-scale study found different trends of SOC fractions compared to large-scale studies, which indicate more fine-scale studies are essential for a better assessment of land management effects for a more accurate prediction of SOC dynamics. This is imperative for including regional and local scale SOC data for constructing accurate global C models (Bird et al., 2001; Jones and Falloon, 2009), especially for soils under anthropogenic disturbances.

\subsection{Conclusions}

We found that the cropland soil at 10-25 cm under manure application and tillage had a larger POC content compared to the pasture and forest soil while no differences in MOC content were observed. According to CMI, improved SOC lability only occurred in cropland soil while decreased SOC lability were observed in pasture soils at both $0-10$ and 10-25 cm. However, the dominant contribution to SOC was from POC at cropland and pasture which implied potential rapid SOC loss under disturbance due to a fast turnover time of POC, especially the topsoil. Our study indicates that management practices increasing SOC input and driving the translocation of labile SOC to subsurface soil may be helpful to increase SOC stabilization in these agricultural soils. 
Table 2. 1 Soil physical and chemical properties at $0-10 \mathrm{~cm}$ and $10-25 \mathrm{~cm}$ depths under hardwood forest $(\mathrm{HF})$, cropland with manure $(\mathrm{CM})$, and continuous pasture $(\mathrm{CP})$ soils.

\begin{tabular}{lcccccc}
\hline & \multicolumn{2}{c}{ Forest $(\mathrm{HF})$} & \multicolumn{2}{c}{ Cropland (CM) } & \multicolumn{2}{c}{ Pasture (CP) } \\
& $0-10 \mathrm{~cm}$ & $10-25 \mathrm{~cm}$ & $0-10 \mathrm{~cm}$ & $10-25 \mathrm{~cm}$ & $0-10 \mathrm{~cm}$ & $10-25 \mathrm{~cm}$ \\
\hline $\mathrm{pH}$ & 5.3 & 4.8 & 7.0 & 6.3 & 5.5 & 5.6 \\
Electric Conductivity $\left(\mu \mathrm{s} \mathrm{cm}^{-1}\right)$ & 134.4 & 59.9 & 260.5 & 152.6 & 194.2 & 103.3 \\
Total N $\left(\mathrm{g} \mathrm{kg}^{-1}\right)$ & 3.4 & 1.1 & 2.7 & 1.5 & 4.1 & 1.0 \\
Total C $\left(\mathrm{g} \mathrm{kg}^{-1}\right)$ & 41.4 & 12.8 & 32.3 & 20.8 & 40.4 & 10.3 \\
Exchange Ca $\left(\mathrm{mg} \mathrm{kg}^{-1}\right)$ & 912.3 & 154.2 & 2856.0 & 1450.5 & 1246.0 & 587.5 \\
Exchange Mg $\left(\mathrm{mg} \mathrm{kg}^{-1}\right)$ & 121.7 & 40.1 & 250.9 & 159.0 & 141.6 & 84.2 \\
Exchange K $\left(\mathrm{mg} \mathrm{kg}^{-1}\right)$ & 114.6 & 55.8 & 201.5 & 53.7 & 241.9 & 121.5 \\
Exchange P $\left(\mathrm{mg} \mathrm{kg}^{-1}\right)$ & 22.4 & 8.3 & 42.5 & 8.1 & 49.3 & 9.8 \\
Bulk density $\left(\mathrm{Mg} \mathrm{m}^{-3}\right)$ & 1.1 & 1.3 & 1.4 & 1.5 & 1.5 & 1.7 \\
Sand $(\%)$ & $36.0 \%$ & $26.9 \%$ & $33.3 \%$ & $35.1 \%$ & $44.7 \%$ & $35.6 \%$ \\
Silt $(\%)$ & $53.6 \%$ & $57.6 \%$ & $51.4 \%$ & $49.1 \%$ & $45.7 \%$ & $52.3 \%$ \\
Clay $(\%)$ & $10.4 \%$ & $15.5 \%$ & $15.3 \%$ & $15.8 \%$ & $9.6 \%$ & $12.1 \%$ \\
\hline
\end{tabular}


Table 2. 2 Impact of land management practice and depth on carbon pool index (CPI), lability index (LI), and carbon management index (CMI)

\begin{tabular}{cccccc}
\hline Land management practice & Depth & L & LI & CPI & CMI \\
\hline \multirow{2}{*}{ Cropland with manure (CM) } & $0-10$ & 1.73 & $1.28 \mathrm{~b}$ & $0.78 \mathrm{~b}$ & $100.2 \mathrm{~b}$ \\
& $10-25$ & 1.48 & $2.57 \mathrm{a}$ & $1.62 \mathrm{a}$ & $419.2 \mathrm{a}$ \\
Continuous pasture (CP) & $0-10$ & 1.16 & $0.86 \mathrm{c}$ & $0.98 \mathrm{~b}$ & $83.7 \mathrm{~b}$ \\
& $10-25$ & 0.52 & $0.90 \mathrm{c}$ & $0.81 \mathrm{~b}$ & $73.6 \mathrm{~b}$ \\
Hardwood forest (HF) & $0-10$ & 1.35 & 1.00 & 1.00 & 100 \\
& $10-25$ & 0.57 & 1.00 & 1.00 & 100 \\
\hline
\end{tabular}

Different letters within a column were significantly different at $p<0.05(\mathrm{n}=3)$. L: lability of organic carbon. 


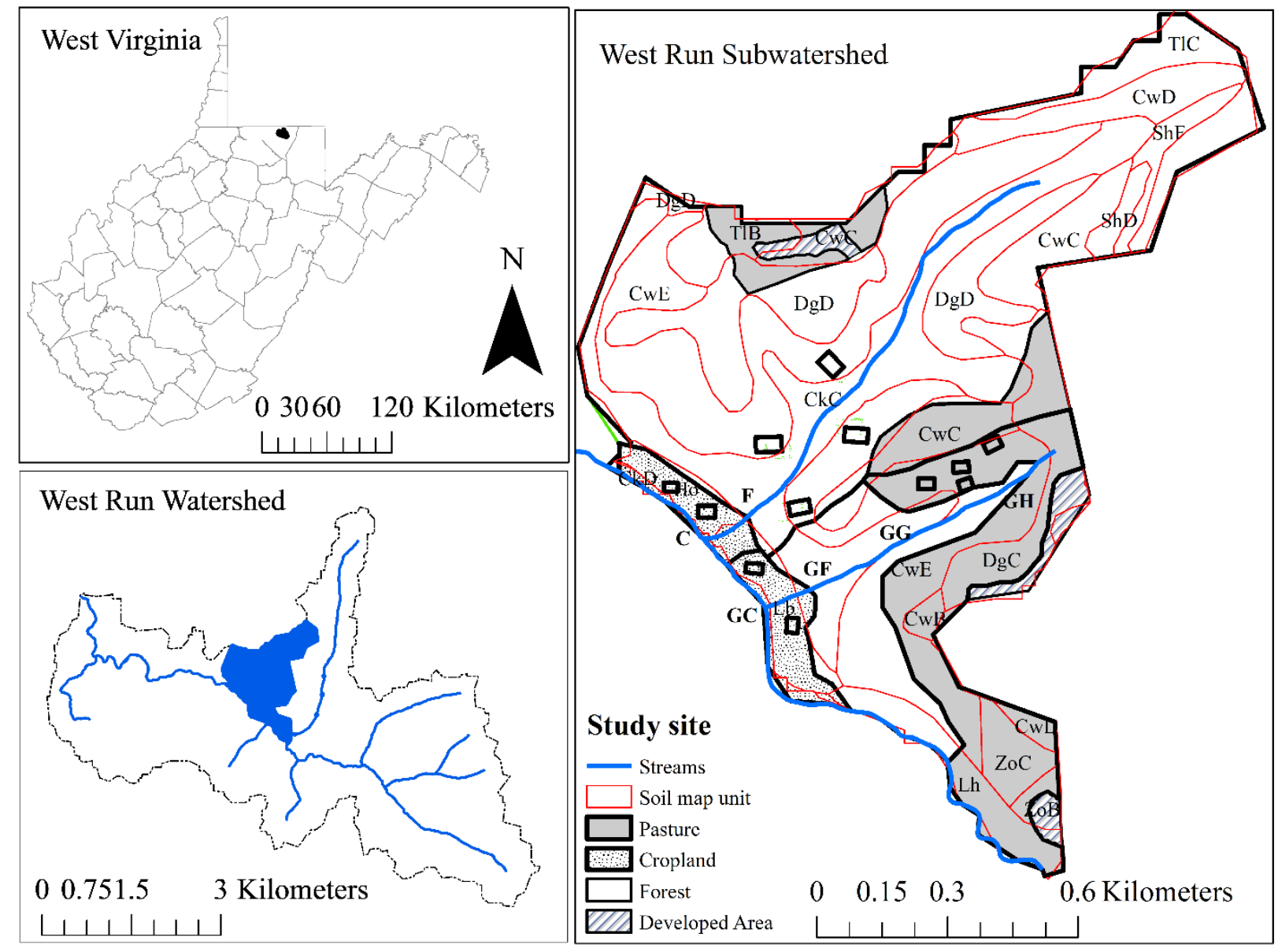

Figure 2. 1 The location of study site. The rectangles represented $10 \times 10 \mathrm{~m}$ sampling plots (not to scale). 


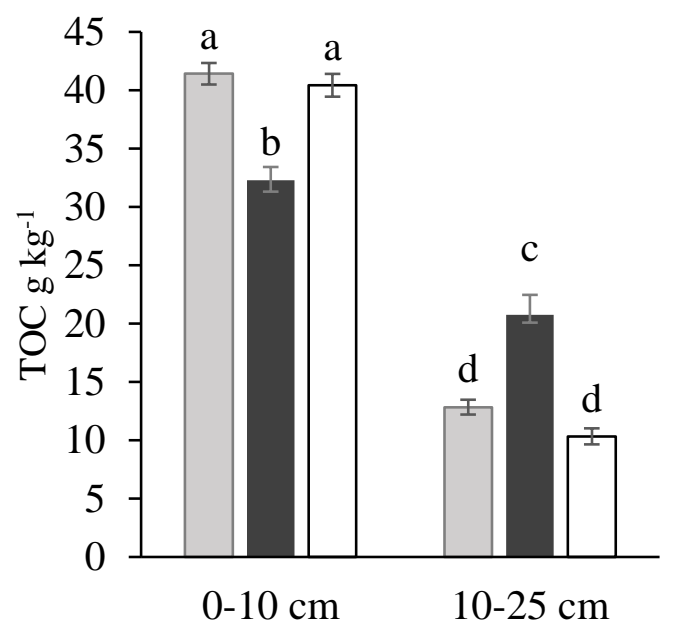

Soil depth

Figure 2. 2 Total organic carbon (TOC) at 0-10 $\mathrm{cm}$ and 10-25 cm depths under hardwood forest (HF, gray filled bar), cropland with manure (CM, black filled bar), and continuous pasture ( $\mathrm{CP}$, white filled bar) soils.

Different letters indicated significant differences at $p<0.05$. The error bar represented the standard deviation $(n=3)$. 


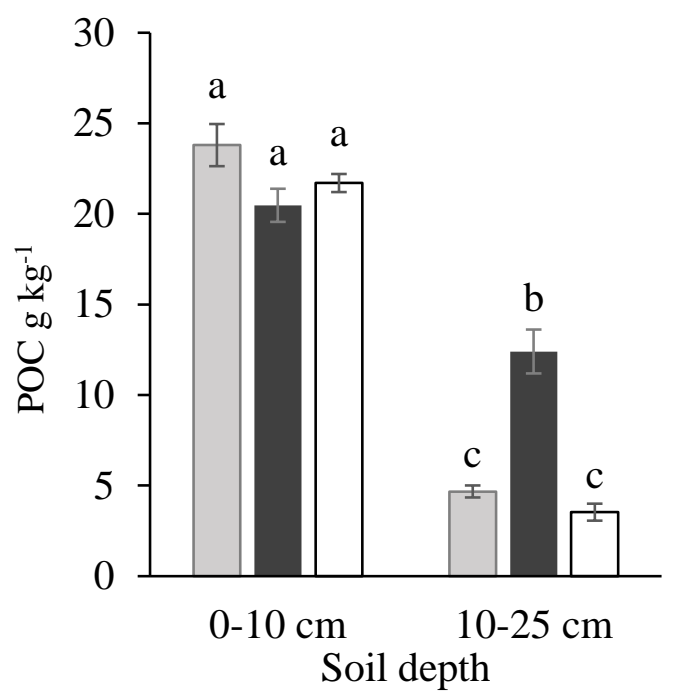

Figure 2. 3 Particulate organic carbon (POC) at $0-10 \mathrm{~cm}$ and $10-25 \mathrm{~cm}$ depths under hardwood forest (HF, gray filled bar), cropland with manure (CM, black filled bar), and continuous pasture ( $\mathrm{CP}$, white filled bar) soils.

Different letters indicated significant differences at $p<0.05$. The error bar represented the standard deviation $(n=3)$. 

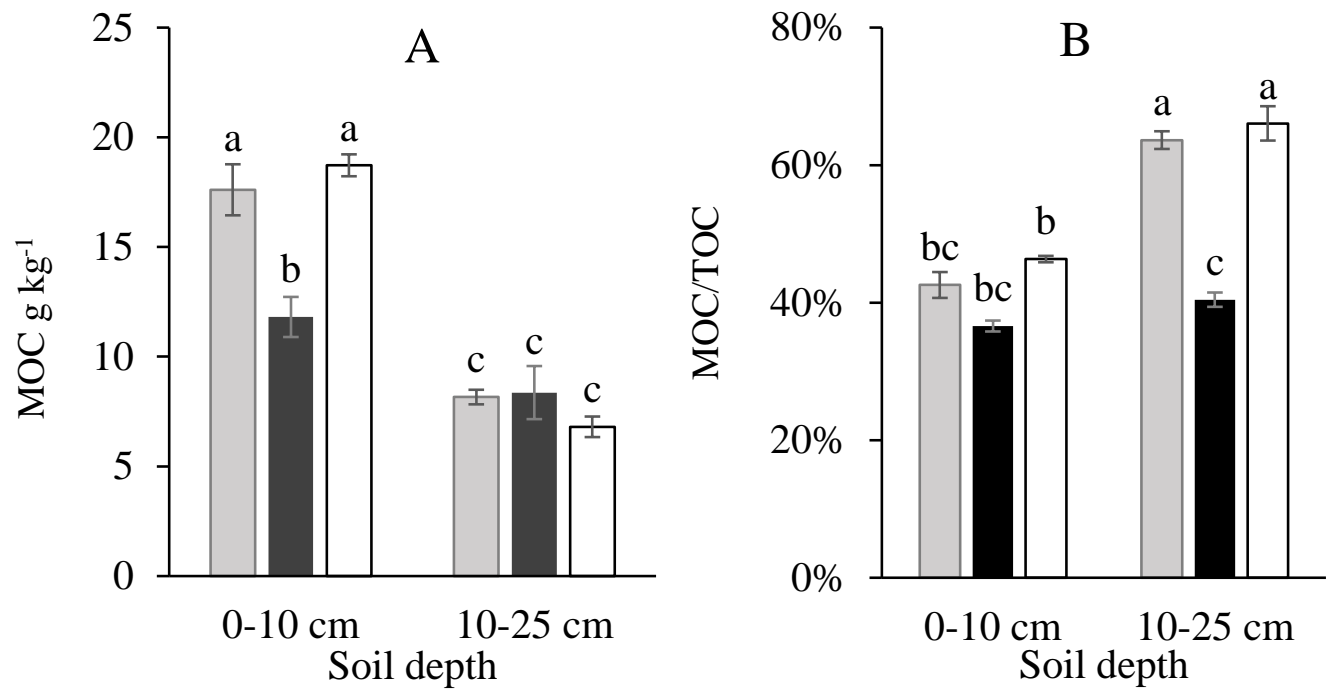

Figure 2. 4 Mineral associated organic carbon (MOC) (A) and MOC/TOC (total organic carbon) (B) at 0$10 \mathrm{~cm}$ and $10-25 \mathrm{~cm}$ depths under hardwood forest (HF, gray filled bar), cropland with manure (CM, black filled bar), and continuous pasture ( $\mathrm{CP}$, white filled bar) soils.

Different letters indicated significant differences at $p<0.05$. The error bar represented the standard deviation $(n=3)$. 
Chapter 3 Fe-bound Organic Carbon and Sorption of Aromatic Dissolved Organic Carbon in Surface Soil: Comparing a Forest, a Cropland, and a Pasture Soil in a Central Appalachian Region, West Virginia

\subsection{Abstract}

The essential roles of Fe oxides in stabilizing long-term soil organic carbon (SOC), especially aromatic dissolved organic carbon $\left(\mathrm{DOC}_{\mathrm{aro}}\right)$, are well-established in forest soils and sediments. We chose to focus on these processes in agricultural soils in which the input and translocation of native DOC to deeper soils are impacted by management practices. We quantified SOC, Fe oxide bound SOC (Fe-bound OC), and the $\mathrm{DOC}_{\text {aro }}$ sorption in a forest, a cropland, and a pasture soil at $0-10$ and $10-25 \mathrm{~cm}$. A significantly larger amounts of Fe oxides in the cropland soil was observed compared to the forest and pasture soils at both depths $(p<0.05)$. Land management practices and depth both significantly influenced proportion of the Fe-bound OC $(p<0.05)$. A larger maximum sorption of DOC in the cropland $\left(315.0 \mathrm{mg} \mathrm{kg}^{-1}\right)$ and pasture $\left(395.0 \mathrm{mg} \mathrm{kg}^{-1}\right)$ soils than the forest soil ( $96.6 \mathrm{mg} \mathrm{kg}^{-1}$ ) at 10-25 $\mathrm{cm}$ was found. DOC aro sorption decreased in the three soils at $0-10 \mathrm{~cm}$ (slope of -0.002 to $\left.-0.014 \mathrm{~L}^{2} \mathrm{mg}^{-2} \mathrm{~m}^{-1}\right)$ as well as the forest soil at $10-25 \mathrm{~cm}(-0.016$ $\left.\mathrm{L}^{2} \mathrm{mg}^{-2} \mathrm{~m}^{-1}\right)$ with increasing equilibrium DOC concentration. Conversely, the cropland and pasture soils at $10-25 \mathrm{~cm}$ increased $\left(0.012\right.$ to $\left.0.014 \mathrm{~L}^{2} \mathrm{mg}^{-2} \mathrm{~m}^{-1}\right)$. These results indicate that the forest, cropland, and pasture managed soils may have more complex sorption behaviors in stabilizing $\mathrm{DOC}_{\text {aro }}$ and non- $\mathrm{DOC}_{\text {aro }}$ than previously known.

Key words: Soil Organic Carbon · Agricultural soils · Fe oxides · Non-aromatic DOC · Sorption 


\subsection{Introduction}

Soil organic carbon (SOC) bridges biogeochemical C cycling among soil, aquatic, and atmospheric environments (Lehmann and Kleber, 2015). Without appropriate soil management, SOC is linked to current environmental issues, such as global warming and surface water brownification (Han et al., 2017; Kritzberg and Ekström, 2012). These issues are results of increased decomposition of SOC, which releases carbon dioxide to the atmosphere and also leads to the leaching of dissolved organic carbon (DOC) from soil to surface water (Han et al., 2017; Kritzberg and Ekström, 2012). In a changing climate, sequestering more SOC is a promising approach to mitigate these environmental issues (Schmidt et al., 2011).

Iron $(\mathrm{Fe})$ oxides are critical in regulating SOC dynamics and significantly impact SOC biogeochemical cycling due to their high surface areas, surficial hydroxyl groups (create exchangeable sites), and their abundance in many soils (particularly in redoximorphic features) (Chorover and Amistadi, 2001; Kleber et al., 2005; Riedel et al., 2013; Wagai and Mayer, 2007; Wagai et al., 2013). The SOC bound to Fe oxides (Fe-bound OC) is physically inaccessible to soil microorganisms, which inhibits the degradation and mineralization of SOC and thus has a long residence time (Kaiser and Guggenberger, 2000; Kalbitz et al., 2005). Therefore, Fe oxides have an important role in contributing to long-term SOC preservation in soils and sediments (Lalonde et al., 2012; Wagai and Mayer, 2007). About $19-45 \times 10^{15} \mathrm{~g}$ organic carbon (OC) in sediments and $266-809 \times 10^{15} \mathrm{~g}$ OC in forest soils are preserved by Fe oxides at the global scale (Lalonde et al., 2012; Zhao et al., 2016). However, the roles of Fe oxides in SOC stabilization in agricultural soils are not as well documented as in the forest soils and in sediment.

One dominant mechanism of stabilizing SOC is the sorption of DOC to soil mineral surfaces mediated by Fe oxides, which is supported by recent molecular level technologies (Coward et al., 
2018; Eusterhues et al., 2003; Kaiser and Guggenberger, 2000; Oren and Chefetz, 2012). SOC is a complex assemblage of various microbial-derived and plant-derived compounds, root exudates, and polyaromatic char with different reactivity caused by various functional groups (Lehmann and Kleber, 2015; Schmidt et al., 2011). This SOC chemical heterogeneity, which is due to various sources and alteration factors, brings more uncertainty and diversity to a full understanding of the mechanisms of SOC stabilization, especially in agricultural soils with varied management practices (Lützow et al., 2006; Martens et al., 2004; Tilman et al., 2002). It has been reported that grass and cropland have a higher potential to preserve OC compared to forest soil (Wiesmeier et al., 2014). Carbon stocks in agricultural soils contribute a significant amount of $\mathrm{C}$ to global C stock and play an important role in mitigating global warming (Leifeld et al., 2005).

Land management practices effect soil physical (e.g. soil aggregate stability), chemical (e.g. C and $\mathrm{N}$ mineralization, soil and water relationship), and biological properties and thus soil organic carbon dynamics in agriculture (García-Orenes et al., 2009; Houlbrooke et al., 2011; Islam and Weil, 2000; Singh et al., 1994; Wilson et al., 2008). Thus, management practices are commonly adapted as strategies to improve crop production and sequester more SOC (Gomiero et al., 2011; Martens et al., 2004; Schmidt et al., 2011). Manure application in croplands and continuous grazing in pastures is a common management practice in agricultural ecosystems, which increases the aromaticity of DOC in soil (Bhattacharyya et al., 2010; Briske et al., 2008; Gomiero et al., 2011; Gong et al., 2009; Greenwood and McKenzie, 2001; Kalbitz et al., 1999). Agricultural management practices also alter the concentrations of Fe oxides in soil solution, which, in turn, influences the preservation of DOC by Fe oxides (Huang et al., 2016a). Poorly crystalline iron oxides in agricultural soils increased significantly due to manure application (Huang et al., 2016b; 
Wen et al., 2019; Zhang et al., 2013). Since soil Fe occurs in various forms differing in reducibility, it is important to have a better understanding of Fe oxides with different reducibility in soil in stabilizing SOC, for example, exchangeable Fe and microbially reducible Fe (Lovley and Phillips, 1987; Van Bodegom et al., 2003). However, multiple forms of Fe oxides with different reducibility in stabilizing SOC is still understudied in agricultural soils.

Plant-derived aromatic and lignin-like high molecular weight compounds are preferentially retained by reactive amorphous Fe oxides by forming irreversible inner-sphere bonds, which resist DOC desorption and thus contribute to long-term SOC preservation (Coward et al., 2018; Kramer et al., 2012; Oren and Chefetz, 2012; Zimmerman et al., 2004). Long term agriculture inputs reshape the quantity and quality of SOC present in the soil including aromatic structures, structural complexity, and DOC molecular weight (Kalbitz et al., 1999; Takata et al., 2011; Wilson and Xenopoulos, 2009). This highly impacts the interactions between DOC and Fe oxides due to the changes in quantity and quality of DOC accessible to soil Fe minerals. Current studies mostly focus on Fe-bound OC in sediment, permafrost, and forest soils (Kramer et al., 2012; Mu et al., 2016; Wagai and Mayer, 2007; Zhao et al., 2016).

In the central Appalachian region, anthropogenic disturbances are increasing, which leads to a major issue of soil degradation and depletion of carbon stocks. In this region, the forest, pasture, and cropland soils account for 62,18 , and $8 \%$ of land use. Thus, assessing the soil quality and carbon sequestration is paramount to develop best management practices for restoration and sustainable agriculture. Most previous studies focus on SOC sequestration of severely disturbed soils (Chaudhuri et al., 2011; Chaudhuri et al., 2012) and dissolved organic C fluxes in peatland soils (Yavitt, 1994). However, there are few studies on the capacities of forest, cropland, and pasture soils for long-term SOC sequestration, especially by incorporating the role of Fe oxides. 
An improved understanding of Fe-bound OC and interactions between Fe oxides and DOC, especially aromatic DOC, is crucial for a better understanding of the mechanisms of long-term SOC sequestration in agricultural soils. Additionally, filling this research gap is essential for developing and evaluating the best management practices in terms of soil nutrient dynamics. It may provide useful information to accurately predict the global SOC changes in the warming environment.

Climate and soil properties are important factors influencing SOC dynamics (Gosling et al., 2013; Jobbágy and Jackson, 2000; Luo et al., 2017). Current studies have been done at the scale of larger watersheds (Duval et al., 2016; Kalambukattu et al., 2013; Luo et al., 2017; Nahrawi et al., 2012; Sainepo et al., 2018). However, these studies are potentially confounded by differences within watershed other than land management practices, for example, different parent materials, topography, and climate. To minimize the effects of parent materials, topography, and climate within a watershed on SOC dynamics, pseudo-replicated studies may be informative. Therefore, a single fine-scale watershed was chosen in our study, which was derived from the same source parent material and had similar climate conditions (Kellner et al., 2018). Specifically, a cropland, a pasture, and a forest soil within this small catchment were selected.

Sorption experiments in the majority of studies used DOC extracted from forest $\mathrm{O}$ horizon soils, which were different from the sorbent soils (Chevallier et al., 2010; Coward et al., 2018; Kramer et al., 2012; Wagai and Mayer, 2007; Wiseman and Püttmann, 2006). This prevents the interpretation of these studies for naturally occurring sorption processes; the DOC source to subsurface soils are from in-situ surface soils. Thus, we were interested in using the DOC extracted from the cropland, pasture, and forest managed topsoil to mimic the sorption processes as they occur in-situ. 
The objectives of this study were to (1) operationally quantify three forms of Fe oxides (the exchangeable, amorphous Fe, and crystallized Fe oxides), three forms of SOC (total SOC (TOC), Fe-bound $\mathrm{OC}$, and DOC released during amorphous Fe extraction), and $\mathrm{Fe}$ and TOC molar ratio (OC:Fe), and (2) quantify the sorption of DOC and changes in aromaticity of DOC after sorption using batch experiments from the pasture, cropland, and hardwood forest managed soils. We hypothesized that if cropland and pasture soils had higher potential to stabilize more organic carbon, then cropland and pasture soils would show higher amounts of Fe-bound OC, more adsorption of aromatic DOC, and larger adsorption capacity than the forest soil.

\subsection{Materials and Methods}

\subsubsection{Study site description}

This study was carried out at the West Virginia University's Animal Science Farm in Morgantown, West Virginia $\left(39^{\circ} 40^{\prime} \mathrm{N}, 79^{\circ} 56^{\prime} \mathrm{W}\right)$. The mean annual precipitation is $99.6 \mathrm{~cm}$. The mean annual temperature is $11.4^{\circ} \mathrm{C}$ (Wright, 1982). The elevation of the whole study area ranges from $287 \mathrm{~m}$ to $381 \mathrm{~m}$.

The three representative land management types were forest, pasture, and cropland. The forest was composed of mixed deciduous hardwood (HF) trees that were approximately 120 years old. The permanent pasture was continuously grazed (CG) with $0.5-0.75$ dry dairy cows and/or heifers per hectare for 20 years. The cropland was a continuous corn (Zea mays) field with manure application (CM) for at least 20 years. More descriptions about the management and botanical composition of each land type are illustrated in Chapter 2.2.1 and 2.2.2.

Through a combination of computer mapping and field surveys, four $10 \mathrm{~m} \times 10 \mathrm{~m}$ plots were selected within the forest, cropland, and pasture, which is illustrated in Figure. 2.1. The elevation of the four plots at forest field was from $303.5-338.7 \mathrm{~m}$. The slope was $25-35 \%$. The soil was 
mapped as Celleoka-Westmoreland silt loams (Fine-loamy, mixed, active, mesic Ultic Haplusdalfs) (Soil Survey Staff, 2017). The four plots from the pasture were located within delineations of the same soil map unit as the forest plots and had similar elevation (324.4 -341.8 m) and slope (25 - 35\%). The parent material was loamy residuum weathered from limestone, sandstone, and shale (Soil Survey Staff, 2017). In the cropland, the elevation of the four plots were from 289.0 - 292.4 m. The soil was mapped as Holly silt loam) (Fine-loamy, mixed, active, nonacid, mesic Typic Fluvaquents) and Lobdell silt loam (Fine-loamy, mixed, active, mesic Fluvaquentic Eutrudepts). These four plots were on the flood plain adjacent to the slope where the forest and pasture plots were located. The parent material was recent loamy alluvium derived from limestone, sandstone, and shale.

\subsubsection{Soil sampling}

Soil samples were collected in June 2018. Four 10 m x 10 m soil plots with silimilar microenvironmental conditions, like vegetation distribution, were randomly selected in the field for each land type. The forest plots had a very thin, minimally decomposed litter layer. When sampling, the litter layer was removed. The pasture plots excluded the supplemental feeding and watering post for the dry dairy cows and heifers and were at least $5 \mathrm{~m}$ away from the edge of the field. The cropland plots were at least $10 \mathrm{~m}$ away from the riparian grass buffer. Six soil sample cores at each plot were collected in an $\mathrm{S}$ pattern to a depth of $25 \mathrm{~cm}$ using a soil sampling probe with a $3 \mathrm{~cm}$ diameter. All soil cores were sectioned into two layers $(0-10 \mathrm{~cm}$ and $10-25 \mathrm{~cm})$. Pairs of cores from each plot were combined then composited across all four plots within a land type to form three pseudoreplications for both depth increments and all three land management types. The study and sampling site is presented in Fig. 2.1. 
For the adsorption experiment, three $0.5 \mathrm{~m} \times 0.5 \mathrm{~m}$ subplots were chosen from each plot and the soil of the top $5 \mathrm{~cm}$ from the three subplots was collected. The collected soil samples from three subplots of all four plots within each land type were composited to make one representative and homogeneous sample for each land type. Then, the collected soil samples were sieved to a 2$\mathrm{mm}$ seive and used to extract DOC as a DOC source of mimicing DOC percolating from surface to deeper mineral soils in the field condition. The study and sampling site is presented in Fig. 2.1.

\subsubsection{Soil physical and chemical analysis}

Each bulk sample was divided into two subsamples. One subsample was air dried at room temperature, ground, and sieved through a $2-\mathrm{mm}$ sieve for determination of soil $\mathrm{pH}, \mathrm{EC}$, and particle density. The description of these determinations is summarized in Chap 2.2.3. The physical and chemical properties were determined using the air-dried soil samples and are presented in Table 2.1. The other subsample was sieved through a $2-\mathrm{mm}$ sieve and stored at $4^{\circ} \mathrm{C}$ until analysis within three days.

The air-dried soil samples for determination of OC fraction were acidified with $1 \mathrm{M} \mathrm{HCl}$ with a 1:2 (m:V) solid:solution ratio to degas the inorganic $\mathrm{C}$ in soil and then dried at $70^{\circ} \mathrm{C}$ for 24 hours. TOC in the oven-dried soil samples was determined by dry combustion (Elementar Vario MAX Cube, Hanau, Germany). The Fe-bound OC was determined using citrate-bicarbonate-dithionite (CBD) method (Mu et al., 2016; Zhao et al., 2016). The reactive Fe concentrations in the filtrate after CBD extraction were determined using ICP-OES, which represented the crystalline Fe(III) oxides in soil (Van Bodegom et al., 2003). The OC:Fe was calculated using the Fe-bound OC and the reactive $\mathrm{Fe}$ concentration in the $\mathrm{CBD}$ extraction. Exchangeable $\mathrm{Fe}\left(\mathrm{Fe}_{\mathrm{ex}}\right)$ in fresh soil subsamples was determined to using $0.5 \mathrm{M} \mathrm{HCl}$ and the microbially reducible amorphous $\mathrm{Fe}$ $\left(\mathrm{Fe}_{\mathrm{amor}}\right)$ was calculated as the $\mathrm{Fe}$ extracted from fresh soil using $0.25 \mathrm{M}$ hydroxylamine 
hydrochloride and $0.25 \mathrm{M} \mathrm{HCl}$ minus the Fe extracted with $0.5 \mathrm{M} \mathrm{HCl}$ (Lovley and Phillips, 1987; Van Bodegom et al., 2003). Exchangeable Fe represented the directly exchangeable Fe portion forming soil adsorption complexes; Microbially reducible amorphous Fe represented the portion of amorphous Fe (III) oxyhydroxide which could be reduced (Van Bodegom et al., 2003). The released Fe was determined according to methods described by Lovley and Phillips (1987). The released DOC in the filtrate was determined using Shimadzu-TOC V (Tokyo, Japan) and, as a measure of aromaticity, the specific ultraviolet absorbance at $254 \mathrm{~nm}\left(\mathrm{SUVA}_{254}\right)$ of the released DOC was determined using method described by Weishaar et al. (2003).

\subsubsection{Adsorption experiments}

A DOC stock solution from each land type was obtained by percolating the composited soil samples with $12.5 \mathrm{mM} \mathrm{CaCl}_{2}$ solution using a $1: 1(\mathrm{~m}: \mathrm{V})$ fresh soil to solution ratio (Alva et al., 1991; Houba et al., 2000). The mixture was shaken at 200 cycles per minute for 6 days at room temperature. The percolates were centrifuged and filtered through $0.45-\mu \mathrm{m}$ filters. The filtrate was used as DOC stock solution and stored at $-20^{\circ} \mathrm{C}$ until used in adsorption experiments. The extracted DOC stock solution was 119,120 , and $150 \mathrm{mg} \mathrm{L}^{-1}$ for forest, cropland, and pasture soils. The stock solution was diluted to five DOC concentrations (forest and cropland: 12, 24, 48, 60, $72 \mathrm{mg} \mathrm{L}^{-1}$; pasture: $15,30,60,75$, and $90 \mathrm{mg} \mathrm{L}^{-1}$ ) using $12.5 \mathrm{mM} \mathrm{CaCl}_{2}$ solution, which was adjusted using the same ratio for each DOC concentration level of each soil. The $\mathrm{pH}$ and $\mathrm{EC}$ were adjusted to be about 7 using $1 \mathrm{M} \mathrm{HCl}$ and $1 \mathrm{M} \mathrm{NaOH}$ and $2.5 \mu \mathrm{Scm}^{-1}$ using $12.5 \mathrm{mM} \mathrm{CaCl}$ before starting the sorption experiment. The $\mathrm{pH}$ and $\mathrm{EC}$ of the initial DOC extract solution of each land type are summarized in Table 3.1.

For generating sorption adsorption data, $3.0 \mathrm{~g}$ of air dried soil was mixed with $30.0 \mathrm{ml}$ of one of the five DOC solutions in $50 \mathrm{ml}$ centrifuge tubes with two replications each. The control for 
each isotherm was done by using $12.5 \mathrm{mM} \mathrm{CaCl}_{2}$ with $0 \mathrm{mg} \mathrm{L}^{-1} \mathrm{DOC}$. The mixtures were shaken for $24 \mathrm{hr}$ at $30 \mathrm{rpm}$ on a rotary shaker. Then the mixtures were centrifuged for $30 \mathrm{~min}$ at 3000 $\operatorname{rpm}(1600 \mathrm{~g})$. The supernatant was filtered through $0.45-\mu \mathrm{m}$ filters. The filtrate was stored at $4^{\circ} \mathrm{C}$ and analyzed within two days. The $\mathrm{pH}, \mathrm{EC}, \mathrm{DOC}$ concentration, and SUVA 254 of DOC in the filtrate were determined after the sorption experiment as described above.

\subsubsection{Isotherms}

The modified Langmuir isotherm (Eq. 5), which added a desorption term b, in $\mathrm{mg} \mathrm{kg}^{-1}$, to correct for the desorption of native adsorbed solute on the soil surface, was used (Kothawala et al., 2008).

$\mathrm{ADS}=\frac{\mathrm{k} \times \mathrm{Q}_{\max } \times \mathrm{q}_{\mathrm{e}}}{1+\mathrm{k} \times \mathrm{q}_{\mathrm{e}}}-\mathrm{b}$

Where ADS is amount of adsorbed DOC in $\mathrm{mg} \mathrm{kg}^{-1}, \mathrm{k}$ is binding affinity in $\mathrm{L} \mathrm{mg}^{-1}, \mathrm{Q}_{\max }$ is the maximum sorption capacity in $\mathrm{mg} \mathrm{kg}^{-1}$, and $\mathrm{q}_{\mathrm{e}}$ is the equilibrium concentration in $\mathrm{mg} \mathrm{L}^{-1}$.

\subsubsection{Statistical analysis}

Repeated measure analysis of variance (rmANOVA) and Tukey adjustment were performed to test main effects of land management practice, depth, and their interaction on TOC, Fe-bound OC, reactive Fe, and OC:Fe molar ratio at $\alpha=0.05$ using SAS PROC MIXED procedure (Version 11. SAS Institute Inc., Cary, NC, USA). Across all three land management practices and two depths, a linear regression was conducted between released DOC and Fe during extracting exchangeable Fe and microbially reducible Fe, assuming independence. Similarly, a non-linear regression was performed between the $\mathrm{SUVA}_{254}$ of released DOC and released Fe. Correlations between TOC, $\mathrm{Fe}_{\mathrm{ex}}, \mathrm{Fe}_{\mathrm{amor}}$, reactive $\mathrm{Fe}$, Fe-bound $\mathrm{OC}$, and $\mathrm{OC}: \mathrm{Fe}$ molar ratio were determined using non-parametric Spearman's correlation using JMP 10.0 (SAS Institute Inc., Cary, NC, 
USA). The probability of false positives in multiple analyses of the non-parametric Spearman's correlation was adjusted using a Benjamini-Hochberg procedure with a false discovery rate of 0.25 (Benjamini and Hochberg, 1995). The isotherms were fit using a G-Newton iterative method with least square functions to estimate the fit using JMP (Kothawala et al., 2008). The performance of the fit was evaluated using the minimum root mean square error (RMSE) when estimating how well the model fit the data (Kothawala et al., 2008). The linear regression was performed between the changes in $\mathrm{SUVA}_{254}$ of the DOC solution and equilibrium DOC concentrations for the adsorption experiment.

\subsection{Results and Discussion}

\subsubsection{Effects of soil texture on TOC, Fe-bound OC in proportion, and reactive Fe}

Soil texture is an important factor influencing SOC dynamics. It has been reported that SOC is significantly linear correlated with the combined silt and clay content in soils with similar climate, vegetation, and topography at 0-1 m depth (Hassink, 1997; Zinn et al., 2005). Increasing clay content increases the stability and decreases the mineralization of sensitive SOC fractions, such as particulate SOC (Franzluebbers and Arshad, 1997). However, Hassink (1994) only observed this relationship in soil with a high water table (Hassink, 1994). This relationship was also shown to be different between the forest and cropland soils (Matus et al., 2007). Other studies reported weak or no relationship between SOC and soil texture (Franzluebbers et al., 1996; Hassink, 1994). Likewise, we didn't find significant relationships between the combined silt and clay content and TOC, reactive Fe, and OC-Fe in proportion in soil ( $p>0.05)$ (Table 3.4). This indicated soil texture didn't have significant influences on the TOC and Fe oxides in the soils with different land management practices in our study. 


\subsubsection{TOC and Fe-bound OC in forest, cropland, and pasture managed soils}

Significant influences of land management practices, depth, and the interaction between management and depth were observed on TOC and Fe-bound OC in proportion ( $\mathrm{p}<0.01)$ except for main effects of management practices on TOC $(p=0.07)$. No significant differences were observed among the forest, cropland, and pasture managed soils at 0-10 cm (Fig. 3.1A). The cropland managed soil at $10-25 \mathrm{~cm}$ had significantly higher TOC $\left(17.79 \mathrm{~g} \mathrm{~kg}^{-1}\right)$ compared to the forest soil $\left(12.13 \mathrm{~g} \mathrm{~kg}^{-1}\right)$ and pasture soil $\left(9.61 \mathrm{~g} \mathrm{~kg}^{-1}\right)$.

Significantly higher Fe-bound OC in proportion was found in the forest (32\%) and pasture (34\%) soils at 10-25 cm, which was similar to the Fe-bound OC range in forest soils reported by Zhao et al. (2016). However, compared to the forest and pasture soils at $10-25 \mathrm{~cm}$, significantly lower Fe-bound OC in forest (25\%) and pasture soils (26\%) at 0-10 $\mathrm{cm}$ and cropland soil at both 0-10 $\mathrm{cm} \mathrm{(23 \% )} \mathrm{and} \mathrm{10-25} \mathrm{cm}(22 \%)$ were observed (Fig. $3.1 \mathrm{~B})$, which had a similar range as marine sediment and permafrost ecosystem (approximate 20\%) (Lalonde et al., 2012; Mu et al., 2016). This indicated that the Fe oxides were more efficient in stabilizing SOC in the pasture and forest soil at 10-25 $\mathrm{cm}$ than the soils at $0-10 \mathrm{~cm}$, which could reveal different mechanisms of $\mathrm{Fe}$ oxides in stabilizing SOC between top and subsurface layer of forest and pasture managed soils (Guggenberger and Kaiser, 2003). Although manure application likely increased total SOC concentration in cropland soils, especially in the subsurface soil, there was no significant difference of Fe-bound OC in proportion between top and subsurface soils (Figure. 3.1B) (Tong et al., 2014). This indicated limited influence of manure application on increasing SOC bound with Fe oxides even though the high aromaticity of DOC was present (Table 3.1). Other mechanisms may contribute to the SOC increase in the cropland soil. Although these significant differences of Fe-bound OC in proportion were observed, only depth was a significant influence 
in terms of the amount of Fe-bound OC (Table 3.4). This indicated other non-Fe oxides associated SOC play an important role in stabilizing SOC and contributed to the observed differences in Febound OC in proportion in soils with three management practices.

\subsubsection{Reactive Fe and $O C$ : Fe molar ratio among three land use management practices}

Only land management practices had significant influence on reactive Fe concentration $(\mathrm{p}<$ 0.01). The reactive Fe significantly influenced the Fe-bound OC proportion in soil, which was indicated by a significant negative correlation $(\rho=-0.5, p=0.03$ ) (Table 3.2) (Fig. 3.2C). The three soils had a similar reactive Fe range compared to the forest soil reported by Zhao et al. (2016) (up to $19.3 \mathrm{~g} \mathrm{~kg}^{-1}$ ) and a lower range than that reported by Wagai et al. (2013) (up to 180

$\mathrm{g} \mathrm{kg}^{-1}$ ). The crop land soil had a significantly higher reactive Fe concentration at both $0-10 \mathrm{~cm}$ (23.86 $\left.\mathrm{g} \mathrm{kg}^{-1}\right)$ and $10-25 \mathrm{~cm}\left(23.72 \mathrm{~g} \mathrm{~kg}^{-1}\right)$ than forest and pasture soils at both layers (Fig. 3.1C). This may be due to long-term manure application, which can increase the concentration of poorly crystalized Fe oxides (Zhang et al., 2013). It also suggested that cropland soil had a high amount of reactive Fe that was not bound with OC (Fig. 3.1C; Table 3.4), which may result from disturbance due to tillage. The forest and pasture soils at both depth increments had similar reactive Fe concentrations ( $\mathrm{HF}_{0-10 \mathrm{~cm}}: 16.93 \mathrm{~g} \mathrm{~kg}^{-1} ; \mathrm{HF}_{10-25 \mathrm{~cm}}: 16.75 \mathrm{~g} \mathrm{~kg}^{-1} ; \mathrm{CG}_{0-10 \mathrm{~cm}}: 12.98 \mathrm{~g} \mathrm{~kg}^{-}$ 1; $\mathrm{CG}_{10-25 \mathrm{~cm}}: 14.71 \mathrm{~g} \mathrm{~kg}^{-1}$ ) (Fig. 3.1C).

Significant main effects of land management practices and depth, as well as the interaction between management and depth were observed on OC:Fe molar ratio $(\mathrm{p}<0.01)$. The OC:Fe molar ratio is an indictor used to assess the type of interactions between Fe oxides and OC (Wagai and Mayer, 2007). When the ratio is between 0 to 1 , the dominant sorption between Fe oxides and OC occurs (Wagai and Mayer, 2007). The dominant interaction is incorporation and/or chelation 
when the ratio is above 1 (Wagai and Mayer, 2007). It significantly influenced the concentrations of Fe oxides in soil which indicated by a significant negative correlation between reactive Fe and OC:Fe molar ratio $(\rho=-0.5, p=0.03$ ) (Table 3.2). The $0-10 \mathrm{~cm}$ samples from all three land management practices had an OC:Fe molar ratio larger than 1 (Fig. 3.1D), which indicated that incorporation and/or chelation interactions dominated. This was similar to Zhao et al. (2016), who reported that forest soils had a dominant incorporation between Fe oxides and OC in the top 20 $\mathrm{cm}$. However, all 10-25 $\mathrm{cm}$ samples from the three land management practices had dominant sorption interactions, which was indicated by a OC:Fe molar ratio close to 1 (Fig. 3.1D).

\subsubsection{Association between OC and amorphous and exchangeable Fe}

Amorphous Fe oxides are strongly associated with SOC (Kleber et al., 2005; Porras et al., 2017; Wiseman and Püttmann, 2006) and contribute to 64\% of SOC storage (Kramer et al., 2012). Chemical retention of aromatic DOC by amorphous Fe contributes to long-term SOC storage, especially for subsurface soil (Kramer et al., 2012). The microbial reducible amorphous Fe, the exchangeable Fe, the DOC concentration during extraction, and $\mathrm{SUVA}_{254}$ of released DOC were determined in our study. A significantly positive linear relationship was found between the released DOC and Fe concentration across all land management practices $\left(\mathrm{r}^{2}=0.54, p<0.01\right)$ (Fig. 3.2A). This is consistent with Kramer et al. (2012) which reported the released DOC during extraction was linearly related to the amount of short range ordered Fe minerals. The forest and pasture soils had the highest amounts of released DOC during microbially reducible amorphous Fe extraction (Fig. 3.2A). Although high aromatic DOC and amorphous Fe concentration were observed in cropland soil, lower amounts of released DOC were found in cropland soil (Fig. 3.2A). This indicated that Fe oxides were more efficient in stabilizing aromatic DOC in the forest and pasture soils than the cropland soil. The interactions of amorphous Fe and SOC may be altered 
by intensive disturbance or other non-sorptive mechanisms could be a reason for the low amounts of SOC associated with amorphous Fe oxides in cropland soil (Coward et al., 2017).

In our study, the aromaticity of released DOC had a significantly positive relationship with amorphous Fe concentration $\left(\mathrm{r}^{2}=0.89, p<0.001\right)$ (Fig. 3.2B). These results were consistent with Kramer et al. (2012). This indicated amorphous Fe had similar roles in preserving aromatic DOC across different land management practices. However, a higher aromaticity of released DOC stabilized by microbially-reducible amorphous $\mathrm{Fe}$ was found in pasture and cropland soils than forest soil only at $0-10 \mathrm{~cm}$ (Fig. 3.2B), which was consistent with higher $\mathrm{SUVA}_{254}$ of DOC in pasture and cropland soils than the forest soil (Table 3.1). These differences suggested interactions between aromatic DOC and amorphous Fe differed at different depths in these three soils.

\subsubsection{Sorption of DOC to three land use management practices soils}

The three land management practice soils had increasing DOC sorption with increasing equilibrium concentration and a higher amount of DOC sorption at 10-25 cm than 0-10 cm (Fig. 3.3 HF-a, CM-a, and CP-a). The desorption occurred at low equilibrium concentrations ( $<30 \mathrm{mg}$ $\mathrm{L}^{-1}$ ) of the cropland soil, pasture soil, and forest soil at $10-25 \mathrm{~cm}$, while sorption and stabilization of DOC from soil solution only occurred at higher soil DOC concentrations (Fig. 3.3 HF-a, CMa, and CP-a). The soil DOC is dynamically altered by a multitude of soil conditions, for example, the stabilization of DOC only occurs in conditions leading to high soil DOC production, like continuing flooding or wet-dry cycles (Chow et al., 2006). The forest soil at 0-10 cm had desorption of the studied equilibrium concentration range $\left(0-72 \mathrm{mg} \mathrm{L}^{-1}\right)$ at $0-10 \mathrm{~cm}$ (Fig. $3.3 \mathrm{HF}-$ a). This revealed that forest topsoil released DOC to solution, which could be leached and 
percolated to deep surface soil for sorption and stabilization (Fig. 3.3HF-a). Overall, agricultural soils had a higher maximum capacity to sorb and stabilize DOC than the forest soil (Table 3.5), which was consistent with higher SUVA $_{254}$ of agricultural soils than forest soil (Table 3.1) (Kaiser and Zech, 1999). It implied a higher potential to sequester additional SOC in the cropland and pasture soils than the forest soil (Wiesmeier et al., 2014). Additionally, cropland soil at $10-25 \mathrm{~cm}$ and pasture soils at $0-10 \mathrm{~cm}$ had greater binding affinity compared to forest soils at $0-10 \mathrm{~cm}$ (Table 3.5). The lowest binding affinity was observed in cropland soil at $0-10 \mathrm{~cm}$ (Table 3.5), which may be due to tillage disturbance. These differences could be also due to different soil minerology. For example, goethite was shown to preferentially retain aromatic OC while montmorillonite was shown to retain low molecular weight $\mathrm{OC}$ and no preference to aromatic OC (Chorover and Amistadi, 2001). However, future study is still needed to confirm this.

\subsubsection{Changes of aromaticity of DOC during sorption}

The changes of aromaticity of DOC in the solution were significantly related to the equilibrium DOC concentration (Fig. 3.3 HF-b, CM-b, and CP-b; Table 3.3). Kramer et al. (2012) reported a similar retention trend of aromatic DOC by short ranged Fe minerals across all soil types. However, Rumpel et al. (2015) found the main decomposed plant-derived OC (high aromaticity) in the topsoil layer and microbial-derived OC (low aromaticity) in the deep soil layer, which leads to different SOC stabilization processes. The evidence in our study that the observed different sorption trends at different land type soils at different depths may be due to different DOC sources (Rumpel et al., 2015).

We used $\triangle \mathrm{SUVA}_{254}$ to indicate the change of aromaticity of DOC during sorption processes. $\triangle \mathrm{SUVA}_{254}$ was calculated as $\mathrm{SUVA}_{254}$ of the DOC after 24 hours sorption minus the $\mathrm{SUVA}_{254}$ at 
the beginning of sorption experiment. A negative $\triangle \mathrm{SUVA}_{254}$ meant the $\mathrm{SUVA}_{254}$ of DOC in solution decreased after adsorption, which indicated the net loss of aromatic DOC in solution, while a positive $\triangle \mathrm{SUVA}_{254}$ meant the $\mathrm{SUVA}_{254}$ of DOC in solution increased after sorption, which indicated the net gain of aromatic DOC in solution. Agricultural soils at $0-10 \mathrm{~cm}$ had positive $\triangle \mathrm{SUVA}_{254}$ values and similar decreasing trends with increasing equilibrium concentrations, which indicated desorption processes of aromatic DOC from soil mineral surface (Fig. 3.3 CM-b and CP-b; Table 3.3). This is different from the majority of current studies that report preferential sorption of aromatic and phenolic moieties of DOC to soil or iron minerals (Coward et al., 2018; Kramer et al., 2012; Oren and Chefetz, 2012; Scott and Rothstein, 2014).

Coward et al. (2018) proposed a three-step sequential sorption processes of DOC (aromatic, lignin-like, and aliphatic compounds) on Fe oxyhydroxide within the first four hours of sorption. Surface exchange of DOC between mineral surface and solution still occurs beyond four hours, which may lead to mobilization of stabilized DOC (Oren and Chefetz, 2012; Sowers et al., 2019). The binding of aromatic and carboxyl moieties with soil minerals are typically irreversible by forming inner-sphere bonds, while outer-sphere bonding with carboxyl moieties are readily desorbed (Oren and Chefetz, 2012). Our study indicated more reversible bonding with nonaromatic DOC might be the mechanisms occurring in agricultural topsoil, like multiple exchange processes (Leinemann et al., 2018). Adhikari and Yang (2015) found that stabilized aliphatic acid by hematite was more resistant than aromatic carbon during reduction release. This reveals that stabilization of non-aromatic DOC, like carboxyl-rich DOC, and reduction release of aromatic OC may be important pathways of SOC stabilization and destabilization in topsoil (Coward et al., 2018; Kaiser and Guggenberger, 2000; Kalbitz and Kaiser, 2008; Sowers et al., 2019). 
The pasture and cropland soils at $10-25 \mathrm{~cm}$ had negative $\Delta \mathrm{SUVA}_{254}$ values. The increasing trends with increasing equilibrium DOC concentrations had similar increasing slopes, which indicated sorption of aromatic DOC decreased with increasing DOC concentration (Fig. 3.3 CMb; Fig. 3.3 CP-b; Table 3.3). This indicates more irreversible bonds with aromatic DOC were formed in agricultural soils at 10-25 cm, especially at lower equilibrium concentrations. Unlike cropland soils with an aromatic sorption of the studied DOC concentration range $\left(0-72 \mathrm{mg} \mathrm{L}^{-1}\right)$, the pasture soils reached a zero-net sorption of aromatic DOC. This may indicate that desorption processes of aromatic DOC occurs, which may reveal more complex processes between aromatic DOC and soil surfaces than reported interactions between Fe pure minerals and DOC (Coward et al., 2018; Sowers et al., 2019).

Unlike the sorption pattern of the cropland and pasture soils at both $0-10$ and $10-25 \mathrm{~cm}$, forest soils had decreasing trends of $\triangle \mathrm{SUVA}_{254}$ with increasing equilibrium DOC concentrations (Fig. 3.3 HF-b; Table 3.3). The 0-10 cm soil materials reached zero net sorption of aromatic DOC at high equilibrium DOC concentrations (Fig. $3.3 \mathrm{HF}-\mathrm{b}$ ). The $10-25 \mathrm{~cm}$ soils had net desorption of aromatic DOC at low equilibrium DOC concentration $\left(<35 \mathrm{mg} \mathrm{L}^{-1}\right)$ and sorption of aromatic DOC at high equilibrium DOC concentration (35 - $72 \mathrm{mg} \mathrm{L}^{-1}$ ) (Fig. $\left.3.3 \mathrm{HF}-\mathrm{b}\right)$. Confirmation of molecular level characteristics of sorbed or released DOC remains unclear, which are still in need for future research to uncover the reasons behind these trends in different land managed soils.

\subsubsection{Implications for land use and stabilization of DOC for long-term SOC accumulation}

Although most well documented studies had reported the role of amorphous Fe on aromatic DOC sorption and Fe oxides on SOC preservation in forest soils and marine sediments (Coward et al., 2017; Guggenberger and Kaiser, 2003; Kalbitz and Kaiser, 2008; Riedel et al., 2013; Wiesmeier et al., 2014; Zhao et al., 2016), we didn't find direct and aligned evidences of 
significant influence of reactive $\mathrm{Fe}$ and amorphous $\mathrm{Fe}$ in increasing aromatic sorption in 0-10 cm or 10-25 $\mathrm{cm}$ soils of forest, pasture, and cropland. The three land managed soils had different sorption trends of aromatic DOC between agricultural soils (pasture and cropland) and forest soils, as well as between agricultural soils from $0-10 \mathrm{~cm}$ and soils from 10-25 cm (Fig. $3.3 \mathrm{HF}-\mathrm{b}, \mathrm{CM}$ b, CP-b). The stabilization of aromatic DOC was only enhanced in agricultural soils at $10-25 \mathrm{~cm}$ with low DOC concentration and in forest soils with high DOC concentration (Fig. 3.3 HF-b, CM-b, CP-b). This indicated non-aromatic sorption might be a preference or desorption of aromatic OC from soil surfaces occurred in forest soil and agricultural soils at $0-10 \mathrm{~cm}$ at low soil DOC concentrations (Fig. 3). Thus, a uncertainty exists regarding interactions of soil Fe minerals and DOC or aromatic DOC in different land managed soils at different depths and multiple factors may regulate DOC and aromatic DOC sorption processes, such as DOC composition (Du et al., 2018), soil mineralogy (Han et al., 2016), soil mineral surface chemistry (Chorover and Amistadi, 2001), and structural features of soil aggregates (Chevallier et al., 2010). Future studies are still necessary to uncover the influencing factor behind these phenomena.

Land types and management practices highly influence the quantity and quality of soil $\mathrm{Fe}$ minerals and DOC and also the conditions of transferring and transformation processes (Anesio et al., 2005; Hobley et al., 2017; Kalbitz, 2001; Petrone et al., 2009; Wilson and Xenopoulos, 2009). This causes more uncertainty in understanding Fe oxides and DOC interactions in agricultural soils with different land management practices, and points to a need for future studies using a wide range of agricultural soils. This study revealed important contributions of nonaromatic sorption to soil mineral surfaces in agricultural topsoil. This indicated the limitation of current generalized understanding of highly selected sorption of aromatic DOC to Fe oxides, 
which is still weakly supported by our studies using DOC from in-situ soils and specifying the soils with different management practices at different depth.

Although Leinemann et al. (2018), Lützow et al. (2006), and Scott and Rothstein (2014) proposed models that showed stepwise processes or several sorption mechanisms simultaneously occurring during sorption, our study indicated more specific context studies in different land soils and field studies deserve more efforts and should be the subject of future study (Kaiser and Guggenberger, 2000; Leinemann et al., 2018; Lützow et al., 2006; Rumpel et al., 2015). Since cropland and pasture are two dominant land types in the world (Václavík et al., 2013), it is essential to incorporate more studies in terms of the mechanisms of Fe oxides in stabilizing SOC, especially for both non-aromatic and aromatic DOC, to provide theories for appropriate management practices in agriculture and robust global $\mathrm{C}$ cycling models for $\mathrm{C}$ dynamics prediction.

\subsection{Conclusions}

Our study confirmed the role of total Fe oxides and amorphous Fe in stabilization of SOC in both agricultural and forest soils. Our hypothesis was partially supported. We did find significantly different proportion of Fe-bound OC and reactive Fe concentration in the cropland, pasture, and forest managed soils. However, we didn't observe a significant correlation between TOC and reactive $\mathrm{Fe}$, or between $\mathrm{Fe}-$ bound $\mathrm{OC}$ and reactive Fe. Although the cropland soil at 010 and 10-25 cm had the highest amounts of Fe oxides, lower proportion of Fe-bound OC was observed in cropland soil at both depths than forest and pasture soils at 10-25 cm, which indicated a higher potential to stabilize SOC by Fe oxides in the cropland soil. Additionally, our sorption experiments supported our hypothesis because we observed higher sorption of DOC in the cropland and pasture soils than the forest soil. The sorption behaviors of aromatic DOC between 
the cropland and pasture soils were similar at both $0-10 \mathrm{~cm}$ and $10-25 \mathrm{~cm}$, which were different from that of the forest soil.

Unlike other studies, our study indicated the significant role of non-aromatic DOC in stabilizing DOC in the cropland and pasture soils at 0-10 cm. Additionally, this study indicated the native DOC concentrations significantly altered the sorption of aromatic and non-aromatic DOC. The changes in the quality and quantity of DOC may reshape SOC dynamics and thus is likely a factor for the observed differences of soil nutrient conditions in our soils (Table 2.1). The potential for these central Appalachian region soils to sequester carbon may be influenced by the quality and quantity of DOC. 
Table 3. 1 The properties of DOC stock solution, extracted from hardwood forest (HF), cropland with manure application $(\mathrm{CM})$, and continuous pasture $(\mathrm{CP})$ soils at $0-5 \mathrm{~cm}$ depth, used in sorption experiment

\begin{tabular}{lccc}
\hline & $\begin{array}{c}\text { Hardwood Forest } \\
(\mathrm{HF})\end{array}$ & Cropland (CM) & Pasture (CP) \\
\hline $\mathrm{pH}$ & 7.1 & 7.1 & 7.2 \\
$\mathrm{EC}\left(\mu \mathrm{s} \mathrm{cm}^{-1}\right)$ & 2.4 & 2.5 & 2.5 \\
$\mathrm{SUVA}_{254}\left(\mathrm{~L} \mathrm{~m}^{-1} \mathrm{mg}^{-1}\right)$ & 0.8 & 1.4 & 1.2 \\
\hline
\end{tabular}


Table 3. 2 Correlation matrix of Spearman correlation coefficients (r) of the investigated parameters

\begin{tabular}{lllllll}
\hline Parameters & TOC & $\mathrm{Fe}_{\mathrm{ex}}$ & $\mathrm{Fe}_{\text {amor }}$ & $\mathrm{OC}: \mathrm{Fe}$ & Reactive $\mathrm{Fe}$ & $\mathrm{Fe}-$ bound OC \\
\hline TOC & 1 & & & & & \\
$\mathrm{Fe}_{\mathrm{ex}}$ & $0.64^{*}$ & 1 & & & & \\
$\mathrm{Fe}_{\mathrm{amor}}$ & $0.63^{*}$ & $0.95^{*}$ & 1 & & & \\
$\mathrm{OC}: \mathrm{Fe}$ & $0.77^{*}$ & 0.42 & 0.39 & 1 & & \\
Reactive Fe & -0.04 & 0.30 & 0.33 & $-0.50 *$ & 1 & \\
Fe-bound OC & $-0.54^{*}$ & $-0.67^{*}$ & $-0.67^{*}$ & -0.02 & $-0.50^{*}$ & 1
\end{tabular}

TOC: Total organic carbon; $\mathrm{Fe}_{\mathrm{ex}}$ : Released $\mathrm{Fe}$ after $0.5 \mathrm{M} \mathrm{HCl}$ extraction; $\mathrm{Fe}_{\text {amor: Released } \mathrm{Fe}}$ after $0.25 \mathrm{M} \mathrm{HCl}$ and $0.25 \mathrm{M} \mathrm{NH} 2 \mathrm{OH} \cdot \mathrm{HCl}$ extraction; OC:Fe: Organic carbon over Fe molar ratio; $\mathrm{Fe}-$ bound OC: Organic carbon preserved by Fe; $*$ p $<0.01$. 
Table 3. 3 Linear regressions between $\triangle \mathrm{SUVA}_{254}$ of DOC solution and equilibrium DOC concentration for three land type soils at $0-10 \mathrm{~cm}$ and $10-25 \mathrm{~cm}$ depths.

\begin{tabular}{|c|c|c|c|c|}
\hline $\begin{array}{l}\text { Land } \\
\text { type }\end{array}$ & Depth & Equation & Adjusted $\mathrm{r}^{2}$ & $p$ \\
\hline \multirow{2}{*}{ Forest } & $0-10 \mathrm{~cm}$ & $\Delta \mathrm{SUVA}_{254}=-0.014 \mathrm{q}_{\mathrm{e}}+1.10$ & 0.93 & 0.005 \\
\hline & $10-25 \mathrm{~cm}$ & $\Delta \mathrm{SUVA}_{254}=-0.016 \mathrm{q}_{\mathrm{e}}+0.71$ & 0.86 & 0.014 \\
\hline \multirow{2}{*}{ Cropland } & $0-10 \mathrm{~cm}$ & $\Delta \mathrm{SUVA}_{254}=-0.002 \mathrm{q}_{\mathrm{e}}+0.18$ & 0.68 & 0.053 \\
\hline & $10-25 \mathrm{~cm}$ & $\Delta \mathrm{SUVA}_{254}=0.014 \mathrm{q}_{\mathrm{e}}-0.76$ & 0.78 & 0.031 \\
\hline \multirow{2}{*}{ Pasture } & $0-10 \mathrm{~cm}$ & $\Delta$ SUVA $_{254}=-0.006 \mathrm{q}_{\mathrm{e}}+0.61$ & 0.77 & 0.031 \\
\hline & $10-25 \mathrm{~cm}$ & $\Delta$ SUVA $_{254}=0.012 \mathrm{q}_{\mathrm{e}}-0.49$ & 0.89 & 0.01 \\
\hline
\end{tabular}

$\overline{\triangle S U V A}_{254}\left(\mathrm{~m}^{-1} \mathrm{~L} / \mathrm{mg}\right)$ : The specific ultraviolet absorbance at $254 \mathrm{~nm}$ of filtered DOC in solution at equilibrium minus that of DOC at original solutions; $\mathrm{q}_{\mathrm{e}}(\mathrm{mg} / \mathrm{L})$ : The equilibrium concentration of filtered DOC solution. 
Table 3. 4 Estimated linear regression using a standard square least approach between total organic carbon (TOC), Fe-bound OC, and reactive Fe and the combined silt and clay content in in hardwood forest (HF), cropland with manure application (CM), and continuous pasture $(\mathrm{CP})$ soils at $0-10 \mathrm{~cm}$ and $10-25 \mathrm{~cm}$ depth

\begin{tabular}{llll}
\hline $\begin{array}{l}\text { Investigator } \\
\text { factor }\end{array}$ & Model equation & $\mathrm{r}^{2}$ & $p$ \\
\hline TOC & TOC $=0.25$ (silt+clay) +0.15 & 0.31 & 0.25 \\
Fe-bound OC & Fe-bound OC = 0.57 (silt+clay) +0.71 & 0.09 & 0.56 \\
Reactive Fe & Reactive Fe $=0.44$ (silt+clay) +0.93 & 0.15 & 0.44 \\
\hline
\end{tabular}


Table 3. 5 Sorption characteristics of three land type soils at 0-10 $\mathrm{cm}$ and $10-25 \mathrm{~cm}$ depths.

\begin{tabular}{lcccccc}
\hline \multirow{2}{*}{ Parameters } & \multicolumn{2}{c}{ Forest } & \multicolumn{2}{c}{ Cropland } & \multicolumn{2}{c}{ Pasture } \\
& $0-10 \mathrm{~cm}$ & $10-25 \mathrm{~cm}$ & $0-10 \mathrm{~cm}$ & $10-25 \mathrm{~cm}$ & $0-10 \mathrm{~cm}$ & $10-25 \mathrm{~cm}$ \\
\hline $\mathrm{Q}_{\max }\left(\mathrm{mg} \mathrm{kg}^{-1}\right)$ & 518 & 1685 & 1159 & 3203 & 1631 & 2638 \\
$\mathrm{k}\left(\mathrm{L} \mathrm{mg}^{-1}\right)$ & 0.0029 & 0.0024 & 0.0018 & 0.0073 & 0.0039 & 0.0025 \\
$\mathrm{~b}\left(\mathrm{mg} \mathrm{kg}^{-1}\right)$ & 219 & 148 & 148 & 81 & 139 & 84 \\
RMSE & 3.6 & 8.2 & 7.8 & 3.2 & 5.6 & 7.3 \\
\hline
\end{tabular}

Modified Langmuir isotherm (Eq 5) was used to describe the DOC sorption. The maximum sorption capacity $\left(\mathrm{Q}_{\max }\right)$ and binding affinity (b) were obtained to compare the sorption characteristics of three land types. The crop land soil at $0-10 \mathrm{~cm}$ had the highest $\mathrm{Q}_{\max }(3203 \mathrm{mg}$ $\mathrm{kg}^{-1}$ ) while forest soil at $0-10 \mathrm{~cm}$ had the lowest $Q_{\max }\left(518 \mathrm{mg} \mathrm{kg}^{-1}\right)$. The forest and pasture soils showed larger $\mathrm{Q}_{\max }$ (forest: $1685 \mathrm{mg} \mathrm{kg}^{-1}$; pasture: $2638 \mathrm{mg} \mathrm{kg}^{-1}$ ) at $10-25 \mathrm{~cm}$ than the soils at 0$10 \mathrm{~cm}$ (forest: $518 \mathrm{mg} \mathrm{kg}^{-1}$; pasture: $1631 \mathrm{mg} \mathrm{kg}^{-1}$ ). The cropland had the opposite trend. The two highest sorption affinity, $\mathrm{k}$, was found in crop land soil at $10-25 \mathrm{~cm}\left(0.0073 \mathrm{mg} \mathrm{L}^{-1}\right)$ and grassland soil at $0-10 \mathrm{~cm}\left(0.0039 \mathrm{mg} \mathrm{L}^{-1}\right)$ while the lowest $\mathrm{k}$ was in cropland soil at $0-10 \mathrm{~cm}^{-0.0018 \mathrm{mg} \mathrm{L}^{-}}$ $\left.{ }^{1}\right)$. 

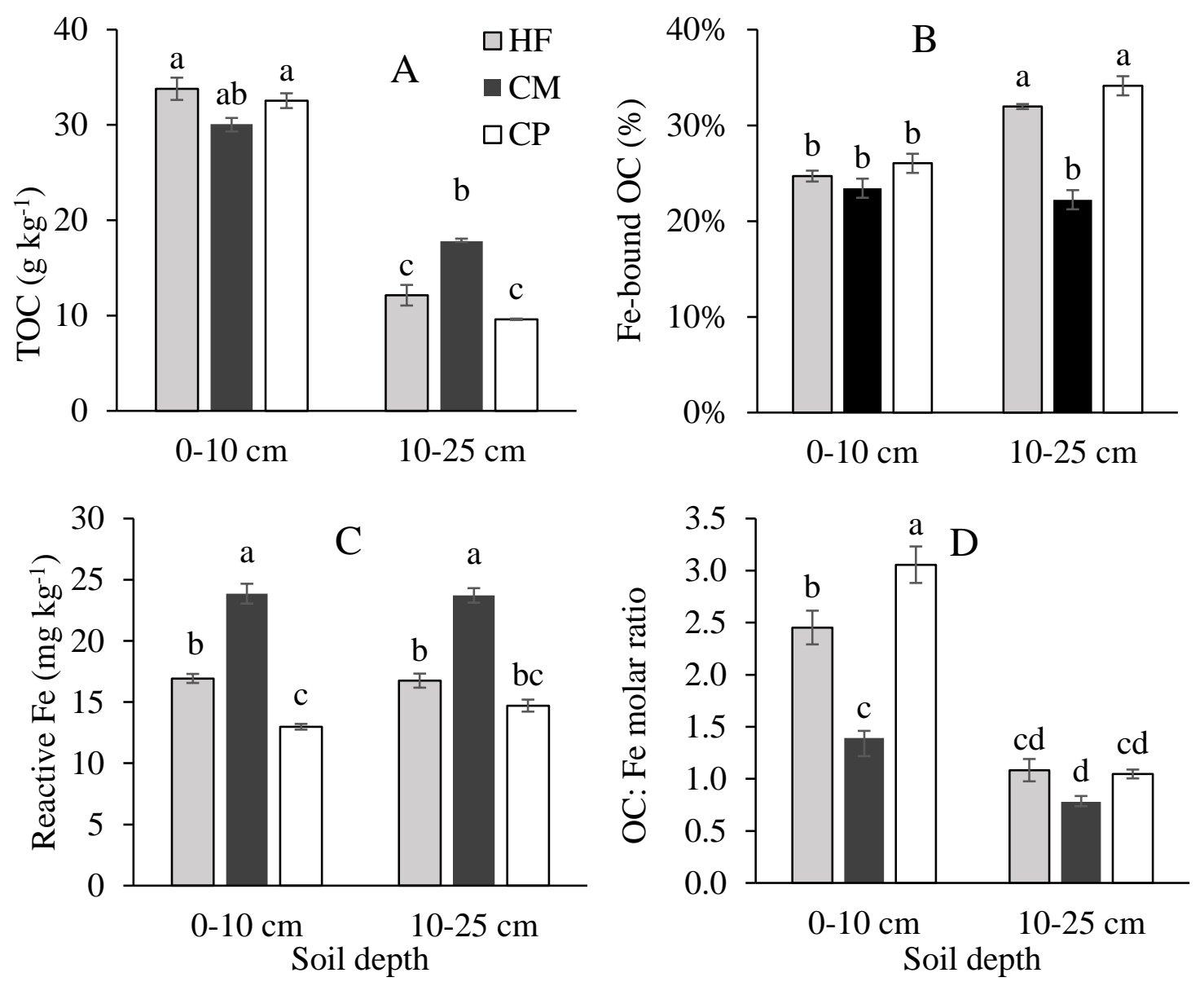

Figure 3. 1 Total organic carbon (TOC) (A), Fe-bound OC (B), reactive Fe (C), and organic carbon Fe molar ratio (D) in forest (HF), cropland (CM), and pasture (CP) soils at 0-10 cm and 10-25 cm depth.

Different lower-case letters indicated significant differences at $\alpha=0.05$. The error bar represented the standard deviation $(n=3)$. 

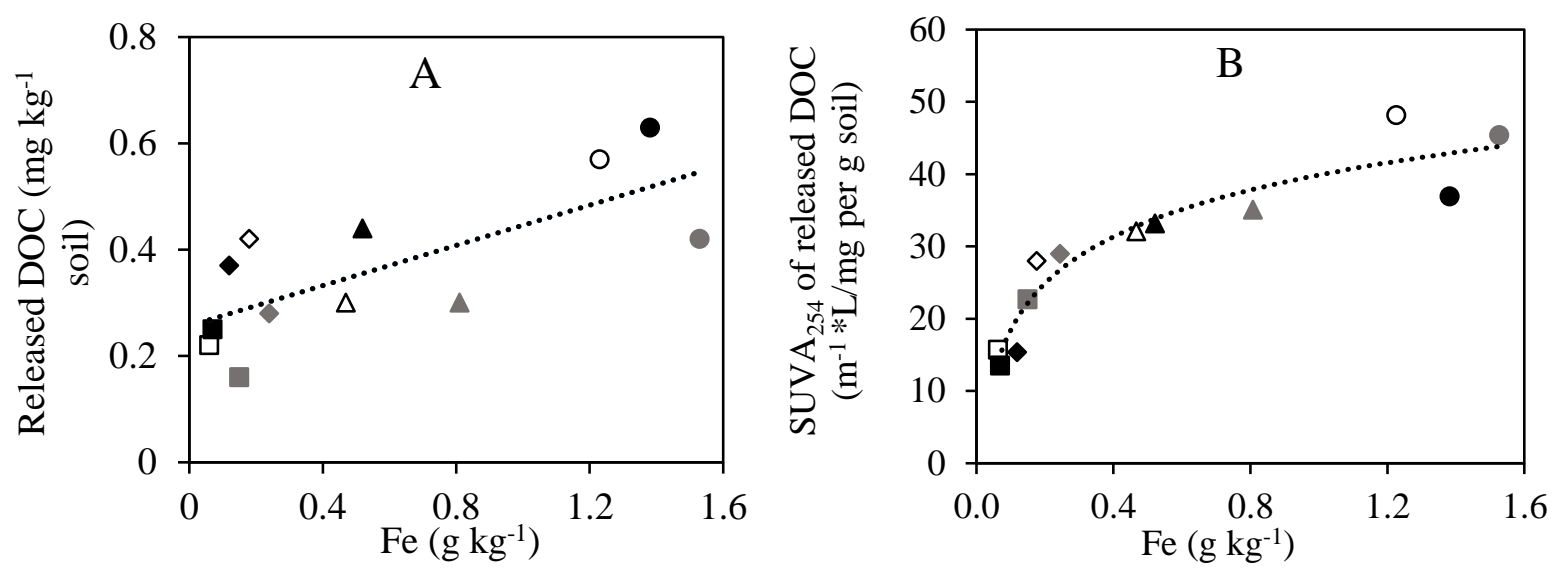

Figure 3. 2 Regression relationship between the amount of released DOC (A) and SUVA 254 of DOC released (B) from soils after $0.5 \mathrm{M} \mathrm{HCl}$ at $0-10 \mathrm{~cm}$ (diamonds) and $10-25 \mathrm{~cm}$ (squares), $0.25 \mathrm{M} \mathrm{HCl}$ and $0.25 \mathrm{M}$ $\mathrm{NH}_{2} \mathrm{OH} \cdot \mathrm{HCl}$ extraction at $0-10 \mathrm{~cm}$ (circles) and $10-25 \mathrm{~cm}$ (triangles) in forest (black fill), cropland (gray fill), and pasture (no fill).

Panel A: Released DOC $\left(\mathrm{mg} \mathrm{kg}^{-1}\right.$ soil $)=0.19 * \mathrm{Fe}\left(\mathrm{g} \mathrm{kg}^{-1}\right)+0.16, \mathrm{r}^{2}=0.54, p<0.01$; Panel B: SUVA $_{254}$ of released DOC $\left(\mathrm{m}^{-1} \mathrm{mg}^{-1} \mathrm{~L}\right.$ per g soil $)=9.27 * \ln (\mathrm{Fe})\left(\mathrm{g} \mathrm{kg}^{-1}\right)+39.84, \mathrm{r}^{2}=0.89, p<$ 0.0001 . 

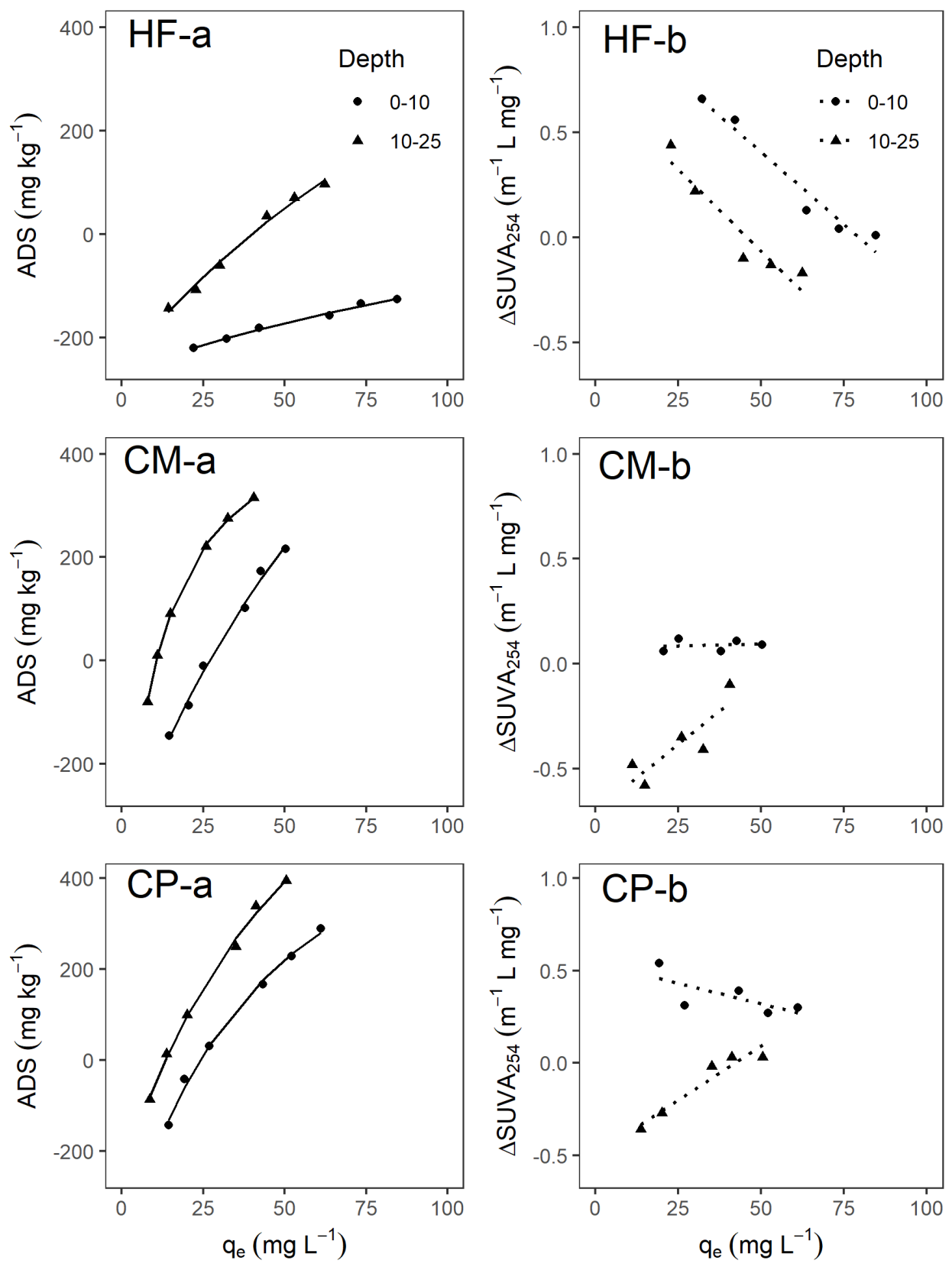

Figure 3. 3 Dissolved organic carbon (DOC) sorption to the forest (HF-a), cropland (CM-a), and pasture $(\mathrm{CP}-\mathrm{a})$ soils and the change of $\mathrm{SUVA}_{254}\left(\Delta \mathrm{SUVA}_{254}\right)$ of the DOC solution after sorption to the forest (HFb), cropland (CM-b), and pasture (CP-b) soils at 0-10 $\mathrm{cm}$ and $10-25 \mathrm{~cm}$ depth.

The solid lines were the fitted modified Langmuir isotherm. The dashed lines were the fitted linear regression. ADS: adsorbed DOC; $\triangle \mathrm{SUVA}_{254}$ : The specific ultraviolet absorbance at $254 \mathrm{~nm}$ of filtered DOC in solution at equilibrium minus that of DOC at original solutions; 


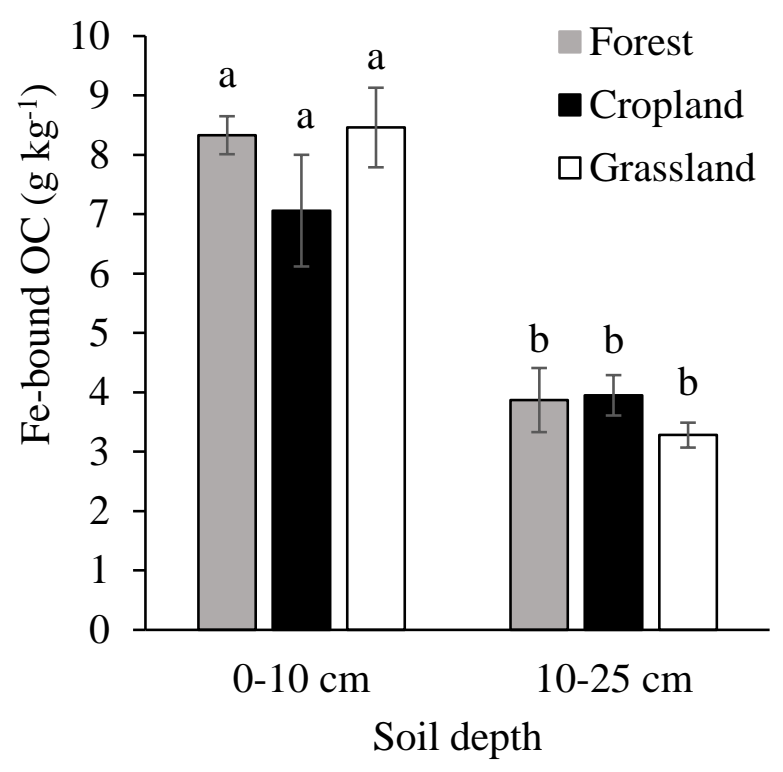

Figure 3. 4 Fe-bound OC in hardwood forest (HF), cropland with manure application (CM), and continuous pasture (CP) soils at $0-10 \mathrm{~cm}$ and $10-25 \mathrm{~cm}$ depth.

Different lower-case letters indicated significant differences at $\alpha=0.05$. The error bar represented the standard deviation $(n=3)$. 
Chapter 4 Assessment of Dissolved Organic Carbon and Iron Effects on Water Color Between a Forest and Pasture Dominated Fine-scale Catchment in a Central Appalachia Region, West Virginia $^{1}$

\subsection{Abstract}

Dissolved organic carbon (DOC) and iron (Fe) have been observed to be the important contributors to surface water brownification. Additionally, the DOC quality influences water color by forming Fe-DOC complexes that provide additive effects and is influenced by dominant land use type within watersheds. However, the influence of quantity and quality of DOC on $\mathrm{Fe}$ and water color is poorly understood in headwater streams. The aim of this study was to investigate the effects of DOC and Fe on water color in forest (FC) and pasture (GFC) fine-scale watersheds to remove the confounding effects of climate and soil parent material. Significant differences of DOC, Fe, and water absorbance at 420nm (a $\left.\mathrm{a}_{420}\right)$ between FC and GFC were found $(p<0.05)$. A dominant contribution to water color was from DOC $(95.5-63.7 \%)$ with a decreasing trend when Fe increased from 0.011 to $0.258 \mathrm{mg} \mathrm{L}^{-1}$. There were no significant interactions between FC and GFC and Fe on either a420/DOC $(p=0.06)$ or specific ultraviolet absorbance at $254 \mathrm{~nm}\left(\mathrm{SUVA}_{254}\right)$ $(p=0.30)$. Increasing a $420 / \mathrm{DOC}$ and $\mathrm{SUVA}_{254}$ were significantly associated with increasing $\mathrm{Fe}$ concentration $(p<0.01)$. Significant interactions were found between FC and GFC and Fe on spectral slope ratio (S ratio) $(p<0.01)$. The response rate of $\mathrm{S}$ ratio with increasing Fe per unit was 0.235 for GFC while it was -11.043 for FC. These differences indicate that land use may change the quality of DOC, influence Fe-DOC interactions, and thus affect water color. Linking the effects of soil Fe and DOC and headwater Fe and DOC may help identify optimal management practice to mitigate surface water brownification.

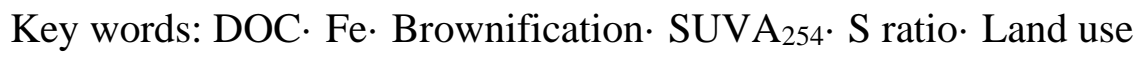

\footnotetext{
${ }^{1}$ This chapter has been published in the journal of Environmental Science and Pollution Research.
} 


\subsection{Introduction}

Increasing surface water brownification is frequently reported and is predicted to continuously increase in many large-scale watersheds of the northern hemisphere (Haaland et al., 2010; Weyhenmeyer et al., 2016). It is a current environmental concern with wide-reaching ecological and societal impact, e.g. on functions of aquatic ecosystems (Williamson et al., 2015) and potentially increasing pretreatment cost of drinking water due to the formation of toxic byproducts (Richardson et al., 2007).

It is known that dissolved organic carbon (DOC) contributes to water brownification due to the presence of colored DOC (Pace and Cole, 2002; Roulet and Moore, 2006). However, it is also found that an increase of water brownification is not sufficiently explained solely by increased DOC concentration (Erlandsson et al., 2008). Given the interaction of iron (Fe) with DOC, it has been reported that Fe can provide additive effects to water color by forming complexes with DOC (Maloney et al., 2005; Weyhenmeyer et al., 2014). The complexes between Fe and DOC can extend the residence time of both Fe and DOC in water (Maloney et al., 2005) and thus increase water brownification (Sarkkola et al., 2013). Specifically, Sarkkola et al. (2013) concluded that this phenomenon is attributed to increasing concentrations of both DOC and Fe.

Several studies have been done to quantify the relative contributions of DOC and Fe to water color. Although the dominant contribution is from DOC in most large-scale watersheds, carbon specific absorbance increases due to the presence of Fe (Weyhenmeyer et al., 2014). The contribution from Fe to water color increases with increasing Fe concentration. Xiao et al. (2015) reported that Fe dominated water color when Fe concentration reached $4.6 \mathrm{mg} \mathrm{L}^{-1}$. Apart from quantifying contribution to water color from the concentrations of DOC and Fe, the quality of DOC and interactions between DOC and Fe influence water color (Xiao et al., 2013). However, 
studies combining quality of DOC and thus interactions between DOC and Fe to explain surface water color are rare.

Stream DOC concentration is largely regulated by the quantity and quality of soil DOC since the catchment soil is the main source at both the regional and global scales in different ecosystems (Battin et al., 2008; Graeber et al., 2012; Tank et al., 2010). Stream water DOC concentration is strongly correlated with soil C pool (Aitkenhead et al., 1999). Three fundamental processes influencing DOC in surface water include soil DOC production, hydrologic transport of DOC from soil to stream, and modification of DOC during transport in soil and stream, which controls the transport of carbon from soil to stream (Brooks et al., 1999; Sanderman et al., 2009). Thus, land use/land cover is an important factor influencing the transport of DOC and Fe in soil to adjacent water bodies, especially in upstream waters (Dillon and Molot, 1997; McDowell, 1984). It is known that high molecular weight DOC preferentially forms Fe complexes (Ekström et al., 2011; Pennanen and Frisk, 1984). It has been shown that changes in land use lead to changes in the amount and composition of DOC in a stream (Graeber et al., 2012; Petrone et al., 2011; Wilson and Xenopoulos, 2009; Yang et al., 2012). The changes in the amount and composition of DOC may influence the presence of Fe, the complex of DOC and Fe, and thus water color.

Other biotic and abiotic factors govern the three processes, such as temperature, discharge, vegetation, hydrological factors, and soil minerals (Armstrong et al., 2012; Camino-Serrano et al., 2014; Erlandsson et al., 2008; Lambert et al., 2013; Maurice et al., 2002; Sanderman and Amundson, 2008) in addition to land cover. Most studies have quantified the contribution of DOC and Fe to water color according to concentration of DOC and Fe in large-scale watersheds based on dominant land cover of the catchments of sampling locations (Ekström et al., 2016; Köhler et al., 2013a; Kritzberg et al., 2014; Kutser et al., 2015; Sarkkola et al., 2013; Weyhenmeyer et al., 
2014; Williamson et al., 2015). However, multiple locations within a large-scale watershed bring more factors beyond land cover, especially for high order streams. This has been weakly addressed and is a limitation of these studies. Additionally, the quantity and quality of DOC and Fe change with passage through watersheds (Fellman et al., 2009; Neubauer et al., 2013). Thus, there is still uncertainty regarding the role of land cover on water color in these large-scale watershed studies; Pseudo-replicated fine-scale studies may help address that uncertainty (De Paula et al., 2016; Kellner et al., 2018).

Watersheds dominated by agricultural land management tend to have a significantly higher concentrations of $\mathrm{Fe}$ and $\mathrm{DOC}$ and thus darker water color compared to forest dominated watersheds (Temnerud et al., 2014). The DOC and Fe in fine-scale headwater watersheds with different land use has different influences on the presence of DOC and Fe in higher order streams. Thus, a better understanding of DOC and Fe on water color is necessary and essential in finescale forest and agricultural headwater streams for developing best management practices to mitigate surface water brownification. This is especially important in the watersheds in the central Appalachian region, which shows issues of surface water quality and deteriorated aquatic ecosystems (Bryce et al., 1999). However, little information is available in terms of combining both quality of DOC and quantity of DOC and Fe to explain water color in fine-scale agricultural and forestry headwater streams in this region.

Altogether, to address the limitations of current studies in large-scale watersheds and the issues of deteriorated surface water quality in the central Appalachian region, we chose two headwater catchments (dominated by a long-term pasture and hardwood deciduous forest) with similar soil types, size, discharge, climate, topography, and geological regimes (Fig 2.1) (Kellner et al., 2018). In addition, soil management practices in these two headwater streams have been maintained for 
more than 20-years, which makes their long-term effects on surface water chemistry significant. The aims were to (i) quantify and compare DOC and Fe concentrations and their relative contributions to water color between pasture and forest dominated headwater streams, and (ii) determine which the DOC fractions interacted with Fe indicating by DOC quality indexes and thus contributed to watercolor in these two headwater streams.

\subsection{Materials and Methods}

\subsubsection{Study area and sampling}

This study was carried out at West Virginia University's Animal Science Farm (39 $40^{\prime} \mathrm{N}$, $79^{\circ} 56^{\prime} \mathrm{W}$ ) in Morgantown, West Virginia. The elevation ranges from $287 \mathrm{~m}$ to $381 \mathrm{~m}$ above sea level. The mean annual temperature is $11.4^{\circ} \mathrm{C}$ and the mean annual precipitation is $99.5 \mathrm{~cm}$ (Wright, 1982).

Three representative land-use types were found in these two watersheds: forest, permanent pasture, and annual crop land. The forest was composed of mixed hardwood trees that are approximately 120 years old (Fithian, 1979). The dominant hardwood types included white oak (Quercus alba), northern red oak (Quercus rubra), yellow poplar (Liriodendron tulipifera), white ash (Fraxinus americana), and hickory (Carya tomentosa) (Fithian, 1979). The pasture was continuously grazed with 10-15 dry dairy cows and/or heifers and mowed once in October each year for 20 years. The vegetation present included grasses, legumes, and forbs. The dominant species were red clover (Trifolium pretense), white clover (Trifolium repens), ironweed (Vernonia baldwinii), smart weed (Polygonum pensylvanica), horsenettle (Solanum carolinense), kentucky bluegrass (Poa pratensis), and timothy (Phleum pretense). The crop land was a continuous corn (Zea mays) field with conventional tillage. Each year for at least 20 years composted dairy manure had been incorporated at a rate of 2,700 to 3,600 kilograms per hectare. Additional 100 kilograms 
urea per hectare was applied to corn at 0.2 - 0.5-meter growth stage. Winter wheat (Triticum aestivum) was planted as a cover crop after the corn was harvested.

Stream water samples were collected from two fine-scale headwater catchments $\left(1.308 \mathrm{~km}^{2}\right)$ (Fig. 4.1). The first headwater stream (FC) $\left(0.913 \mathrm{~km}^{2}\right)$ was predominately the forest land use $\left(0.774 \mathrm{~km}^{2}, 85.8 \%\right)$. The other three types included grassland $\left(0.097 \mathrm{~km}^{2}, 9.8 \%\right)$, crop land $(0.03$ $\left.\mathrm{km}^{2}, 3.3 \%\right)$, and developed area $\left(0.01 \mathrm{~km}^{2}, 1.1 \%\right)$. We collected one sample influenced by the forest land use (F) and the other influenced by the crop land use (C) (Fig. 4.1). The second headwater stream (GFC) $\left(0.405 \mathrm{~km}^{2}\right)$ was predominantly pasture $\left(0.201 \mathrm{~km}^{2}, 49.6 \%\right)$. The other three types along this stream included forest $\left(0.142 \mathrm{~km}^{2}, 35 \%\right)$, crop land $\left(0.039 \mathrm{~km}^{2}, 9.6 \%\right)$, and developed area $\left(0.023 \mathrm{~km}^{2}, 5.8 \%\right)$. All land cover delineations were determined using ArcGIS (Version 10.7.1) and National Land Cover Dataset from 2011.

We collected four samples potentially influenced by pasture (GH and GG), forest (GF), and crop land use (GC) (Fig. 1). Water samples were collected from the six sites on June 26, July 17, August 21, 2017, November 6, 2017, and January 10, 2018. All samples were collected using acid washed $1 \mathrm{~L}$ polyethylene bottles in triplicate and transported immediately to the laboratory. All water samples were filtered through Whatman $0.45-\mu \mathrm{m}$ filters and stored in a refrigerator under $4^{\circ} \mathrm{C}$ and analyzed within 3 days after collection. All laboratory analyses were performed in triplicate.

\subsubsection{Laboratory analysis}

The $\mathrm{pH}$ was determined using a Mettler Toledo SevenEasy $\mathrm{pH}$ meter (Columbus, OH, USA). Non-purgeable organic carbon (NPOC) was determined using a Shimadzu-TOC V (Tokyo, Japan) to represent DOC concentration (detection limit: $50 \mathrm{ug} \mathrm{L}^{-1}$ ). The quantity and quality of DOC in surface water are influenced by microbial activity, which is enhanced by nutrient enrichment, 
such as nitrate and phosphate (Gulis and Suberkropp, 2003). Microorganisms have an important role in changing the quantity and quality of DOC. So, nitrate and phosphate in the filtrate were determined colorimetrically by the difference between the absorbance of $220 \mathrm{~nm}$ and $275 \mathrm{~nm}$ (Armstrong, 1963), and at $880 \mathrm{~nm}$ (Murphy and Riley, 1962), respectively, using a Cary $50 \mathrm{UV}$ spectrophotometer (CA, USA). Total dissolved Fe was determined using inductively coupled plasma-optical emission spectroscopy (ICP-OES) (Optima DV2100, Perkin Elmer, Waltham, MA) (detection limit (12 ug L $\mathrm{L}^{-1}$ ) was determined using the standard curve).

Absorbance spectra from $230-600 \mathrm{~nm}$ at $1 \mathrm{~nm}$ intervals were obtained using a BIOTEK microplate reader (Epoch 2, Winooski, VT, USA) in a $1 \mathrm{~cm}$ cuvette. All spectra (a $\mathrm{a})$ were expressed as $\mathrm{m}^{-1}$ (Helms et al., 2008). Absorbance at $420 \mathrm{~nm}$ (a420) was used to assess stream water color (Köhler et al., 2013a). The absorbance spectral slope ratio (S ratio) was calculated as the ratio of the spectral slope at $350-400 \mathrm{~nm}$ and at $275-300 \mathrm{~nm}$ (Helms et al., 2008). The specific ultraviolet absorbance at $254 \mathrm{~nm}\left(\mathrm{SUVA}_{254}\right)$ was calculated as the ratio of absorbance at 254nm (a 254) and DOC concentration (Weishaar et al., 2003).

Excitation scans were performed to determine fluorescence indices (including $\beta / \alpha, \mathrm{HIX}$, and FI) using a Cary Eclipse spectrophotometer (Palo Alto, CA, USA) for all water samples. Raman scattering was removed by subtracting a deionized water blank. Inner filter effects were corrected for all samples (Ohno, 2002). The freshness index $(\beta / \alpha)$ was determined as the ratio between intensity at emission wavelength $\left(\lambda_{\mathrm{em}}\right) 380 \mathrm{~nm}$ over $\lambda_{\mathrm{em}}$ maximum between $420 \mathrm{~nm}$ and $435 \mathrm{~nm}$ at excitation wavelength $\left(\lambda_{\mathrm{ex}}\right) 310 \mathrm{~nm}$ (Huguet et al., 2009). The humification index (HIX) was determined by the ratio of the area of the peak at $\lambda_{\mathrm{em}} 435-480 \mathrm{~nm}$ and $\lambda_{\mathrm{em}} 300-345$ at $\lambda_{\mathrm{ex}} 254$ $\mathrm{nm}$ (Zsolnay et al., 1999). The fluorescence index (FI) was determined as the ratio between $\lambda_{\mathrm{em}}$ $470 \mathrm{~nm}$ and $\lambda_{\mathrm{em}} 520 \mathrm{~nm}$ at $\lambda_{\mathrm{ex}} 370 \mathrm{~nm}$ (Cory and McKnight, 2005; McKnight et al., 2001). 


\subsubsection{Data analysis}

A goodness-of-fit Shapiro-Wilk test was performed to assess the normality of distribution of all continuous variables. Differences in DOC, Fe, and $\mathrm{a}_{420}$ between FC and GFC were assessed using t-tests. Single and multiple linear regression models were developed to explain a 420 by $\mathrm{Fe}$ and DOC and their relative contributions to water color as described by Köhler et al. (2013a). The effects of stream type (FC and GFC: fixed effect), Fe (random effect) and their interaction on carbon specific absorbance (a420/DOC), S ratio, and SUVA 254 were determined using mixed models with location nested within stream types as a fixed effect using SAS PROC Mixed procedure (Version 11. SAS Institute Inc., Cary, NC, USA). Significant differences were declared at $p<0.05$. If a significant interaction between stream type and Fe in the mixed model was found, separate regression models were developed. Otherwise a combined regression line was used. Regression was performed regressing a420/DOC, S ratio, and $\mathrm{SUVA}_{254}$ on Fe for FC and GFC.

Principle component analysis (PCA) was performed to evaluate the variability of this system using $a_{420}, \mathrm{DOC}, \mathrm{Fe}, \mathrm{SUVA}_{254}, \mathrm{~S}$ ratio, HIX, $\beta / \alpha$, FI, nitrate, and phosphate. A non-parametric Spearman's correlation was performed to investigate the correlation of $\mathrm{a}_{420}$, DOC, Fe, SUVA 254 , $\mathrm{S}$ ratio, HIX, $\beta / \alpha, \mathrm{FI}$, nitrate, and phosphate with $\mathrm{a}_{420}$, DOC, and Fe at $\alpha=0.05$ using JMP (Version 10. SAS Institute Inc., Cary, NC, USA). A Benjamini-Hochberg procedure was used to control the false positives of multiple analyses of the non-parametric Spearman's correlation by using a false discovery rate of 0.25 (Benjamini and Hochberg, 1995).

\subsection{Results}

\subsubsection{DOC and Fe trends and their relative contribution to $a_{420}$}

All DOC, Fe, and $\mathrm{a}_{420}$ had significant differences between FC and GFC ( $\left.p<0.01\right)$. There were no significant differences among different sites within each headwater stream $(p>0.05)$. DOC, 
$\mathrm{Fe}$, and a420 were greater in all four sites (GH, GG, GF, and GC) at GFC compared to the two sites (F and C) at FC (Table 4.1). The average DOC, Fe, and a420 at GFC were 1.91, 2.79, and 4.34 times greater, respectively, compared to FC. The highest DOC $\left(8.16 \pm 0.028 \mathrm{mg} \mathrm{L}^{-1}\right), \mathrm{Fe}$ $\left(0.258 \pm 0.063 \mathrm{mg} \mathrm{L}^{-1}\right)$, and a420 $\left(4.33 \pm 0.016 \mathrm{~m}^{-1}\right)$ were at $\mathrm{GH}(\mathrm{GFC})$ in January 2018 (Table 4.1). The lowest DOC $\left(1.86 \pm 0.02 \mathrm{mg} \mathrm{L}^{-1}\right.$, July $)$ and a420 $\left(0.19 \pm 0.04 \mathrm{~m}^{-1}\right.$, June $)$ were at $\mathrm{F}$ while the lowest Fe $\left(0.011 \pm 0.001 \mathrm{mg} \mathrm{L}^{-1}\right.$, June) was at C (FC) (Table 4.1).

The variation of a420 explained by DOC and Fe was estimated using linear and multiple regression analysis for the whole dataset $(n=30)$. The variation in a 420 explained by DOC was $79.9 \%\left(\mathrm{M}_{\mathrm{DOC}}, p<0.0001\right)$ and by Fe was $59.9 \%\left(\mathrm{M}_{\mathrm{Fe}}, p<0.0001\right)$ (Table 4.2). An improved model for a420 explained $86.3 \%$ of the variation by both DOC and Fe $\left(\mathrm{M}_{\mathrm{DOC}+\mathrm{Fe}}, p<0.0001\right)$ (Table 4.2). The increase of a 420 with increasing Fe concentration per unit was much higher $\left(\mathrm{M}_{\mathrm{Fe}}: 10.286\right.$; $\left.\mathrm{M}_{\mathrm{DOC}+\mathrm{Fe}}: 4.471\right)$ than with increasing DOC concentration per unit $\left(\mathrm{M}_{\mathrm{DOC}}: 0.518 ; \mathrm{M}_{\mathrm{DOC}+\mathrm{Fe}}: 0.390\right)$ (Table 4.2).

The relative contribution of DOC and Fe to water color was estimated using $\mathrm{M}_{\mathrm{DOC}+\mathrm{Fe}}$ (Table 4.2). The relative contribution of DOC to a420 was dominant and followed a negative linear trend decreasing from $95.48 \%$ to $63.74 \%$ when Fe concentration increased from 0.011 to $0.258 \mathrm{mg} \mathrm{L}^{-1}$ (Fig. 4.2). The relative contribution of Fe had a positive increasing trend ranging from $4.52 \%$ to $26.26 \%$ (Fig. 4.2).

\subsubsection{Estimating variations of interaction between DOC and Fe}

There were main effects of stream type and Fe a420/DOC $(p<0.01)$ on a420/DOC while there were no significant interactions between Fe and types of streams on a420/DOC $(p=0.06)$ (Table 4.3). Overall, Fe had additive effects on a420/DOC, as indicated by a positive logarithmic relationship (Fig. 4.3) $\left(\mathrm{r}^{2}=0.55, p<0.0001\right)$. 
To evaluate how the quality of DOC influenced the interaction of DOC and Fe, we included an estimate of the relationship between $\mathrm{SUVA}_{254}, \mathrm{~S}$ ratio, and Fe. There were significant main effects of stream type and Fe on $\mathrm{SUVA}_{254}$ and $\mathrm{S}$ ratio $(p<0.01)$ (Table 4.3). There was no significant interaction between Fe and type of streams on $\operatorname{SUVA}_{254}(p=0.30)$ (Table 4.3). The concentration of $\mathrm{Fe}$ and the $\mathrm{SUVA}_{254}$ of DOC had a significant positive increasing relationship $\left(\mathrm{r}^{2}=0.73, p=1.97 \mathrm{E}-9\right)$ (Fig. 4.4). Significant interactions between Fe and type of streams on $\mathrm{S}$ ratio were found $(p<0.01$ ) (Table 4.3). When comparing S ratio and Fe between FC and GFC, a more rapidly decreasing trend of FC (slope: -11.04) was found in comparison to that of GFC (slope: 0.24) with increasing Fe (Fig. 4.5).

\subsubsection{Principle component analyses}

The PCA was carried out to determine the variability of the system at both FC and GFC as a function of a a420, DOC, Fe, S ratio, $\mathrm{SUVA}_{254}, \mathrm{HIX}, \beta / \alpha, \mathrm{FI}$, nitrate, and phosphate. It indicated that components 1 and 2 explained $73.2 \%$ of variance for FC and 66.5\% of variances for GFC (Fig 4.6). At FC, significant positive correlations were found between Fe and FI and a420 as well as nitrate and DOC (Fe-a $420: \rho=0.68, p=0.029$; FI-a $a_{420}: \rho=0.75, p=0.013$; nitrate-DOC: $\rho=0.68$, $p=0.029$ ) (Table 4.4). At GFC, both DOC and Fe had significant positive correlation to a420 (DOC-a 420: $\rho=0.62, p<0.01 ; \mathrm{Fe}-\mathrm{a}_{420}: \rho=0.66, p<0.01$ ). The SUVA 254 and $\beta / \alpha$ were positively correlated to Fe (SUVA $254-\mathrm{Fe}: \rho=0.61, p<0.01 ; \beta / \alpha-\mathrm{Fe}: \rho=0.69, p<0.01)$ while phosphate was negatively correlated to Fe (phosphate-Fe: $\rho=-0.69, p<0.01$ ) (Table 4.4).

\subsection{Discussion}

\subsubsection{DOC and Fe contributions to water color}

Our study showed a similar a 420 range in the two headwater streams compared to large-scale watersheds (Köhler et al., 2013a; Kritzberg and Ekström, 2012; Kutser et al., 2015; Temnerud et 
$a l ., 2014)$. DOC with Fe were found to be the main predictor to water color in these two headwater streams. A better model was obtained with DOC and Fe as predictors, which indicated by a higher $\mathrm{R}^{2}$ (0.86). This is consistent with trends of DOC and Fe to water color in large-scale watersheds (Köhler et al., 2013a; Kritzberg and Ekström, 2012; Weyhenmeyer et al., 2014). However, a higher variance (> 90\%) explained by DOC and Fe has been found in large-scale watersheds (Köhler et al., 2013a; Xiao et al., 2015). This might indicate a higher amount of uncolored DOC was present in this headwater watershed (Xiao et al., 2015).

The relative contribution of DOC was greater than $\mathrm{Fe}$ and dominated water color in these two headwater streams in this study. However, it depends on Fe concentration when determining the dominant contributors. Xiao et al. (2015) found Fe concentration is $4.6 \mathrm{mg} \mathrm{L}^{-1}$ at large-scale watersheds while our study observed a much lower Fe concentration $\left(0.341 \mathrm{mg} \mathrm{L}^{-1}\right.$ : extrapolated from fit equations in Fig. 4.2) for an equal contribution of DOC and Fe to water color. This variability might be due to completely different catchment properties and it has been shown that significantly larger trends of water brownification are expected at agricultural dominant catchments compared to forest dominant catchments (Temnerud et al., 2014). It has been reported that the saturation point of Fe contribution to adsorption is $1 \mathrm{mg} \mathrm{L}^{-1}$ (Maloney et al., 2005). Therefore, because the Fe breakeven point in these two headwater streams $\left(0.341 \mathrm{mg} \mathrm{L}^{-1}\right)$ was lower than $1 \mathrm{mg} \mathrm{L}^{-1}$ and also the reported $\mathrm{Fe}$ concentrations in large-scale watershed. We anticipated that it is easy to achieve the concentrations where the contribution of Fe has a dominant effect on water color in headwater stream. Therefore, more significant water brownification would be expected in these two headwater streams compared to higher order streams. 
Similar to large-scale watershed, iron provided additive effects on a420, which was indicated by the positive logarithmic increase of a420/DOC with increasing Fe concentration (Fig. 4.3) and model improvement with $\mathrm{DOC}$ and $\mathrm{Fe}$ as independent variables. Addition of $\mathrm{Fe}$ to humic lake water leads to higher absorbance because of the formation of Fe-DOC complexations (Maloney et al., 2005). Fe and DOC co-variation occur in our headwaters and similar results have been found in 11 small headwater streams in Swede (Weyhenmeyer et al., 2014). According to Maloney et al. (2005), these additive effects of Fe level off when Fe concentration increases up to $1 \mathrm{mg} \mathrm{L}^{-1}$ and DOC is saturated with Fe. In our study, the highest a420/DOC was 0.53 when $\mathrm{Fe}$ was $0.258 \pm 0.063 \mathrm{mg} \mathrm{L}^{-1}$ at GFC headwater streams. The Fe concentration was much lower than $1 \mathrm{mg} \mathrm{L}^{-1}$, which implies that water color is expected to continue to increase as Fe concentration increases in these two headwaters.

\subsubsection{DOC quality influence DOC-Fe interaction in water}

The change of DOC quality is a reason for the observed variation of carbon specific absorbance. DOC quality closely links to DOC and Fe cycling in an aqueous environments (Riedel et al., 2013). High molecular weight (MW) DOC is the preferential source forming DOC-Fe complexes (Pennanen and Frisk, 1984). Soil water treated with low acid deposition tends to have high MW and aromatic DOC, which results in high carbon specific absorbance (Ekström et al., 2011). This is consistent with our study. At a shallow oxic surface water, $\mathrm{Fe}$ is oxidized and preferentially bound with aromatic DOC (Riedel et al., 2012) and thus the retention of Fe increases.

In our study, we used $\mathrm{SUVA}_{254}$ to indicate the aromaticity of DOC because $\mathrm{SUVA}_{254}$ has been shown as a good proxy to estimate dissolved aromatic carbon (Weishaar et al., 2003). We found that $\mathrm{SUVA}_{254}$ and Fe were higher in GFC headwater than FC headwater (Fig 4.4), which might be due to high $\mathrm{SUVA}_{254}$ of DOC translocated from grassland soil compared to forest soil 
(McDowell, 1984; Sanderman and Amundson, 2008). This indicated that the increasing concentration of aromatic DOC was associated with increasing Fe concentration and thus increasing water color in agricultural headwaters. However, Riedel et al. (2012) found that upon adding Fe to a DOC solution, the DOC and Fe both decrease and DOC tend to be more aliphatic acids rich in carboxyl and less aromatic. This is likely due to the high Fe concentration used in this experiment, which is higher than in natural waters. It has been reported that Fe tends to coagulate with DOC and precipitate from the system when Fe concentration reaches $1 \mathrm{mg} \mathrm{L^{-1 }}$ (Maloney et al., 2005). We found a significant positive relationship between SUVA 254 and Fe, which is different from Riedel et al. (2012) due to low Fe concentrations that are far below saturated concentrations in these two shallow oxic headwaters streams.

Even though dominant land use could be a factor leading to the difference of SUVA 254 in headwater streams, in situ DOC and Fe transformation could also be factors, e.g. microbial degradation (Miller and Moran, 1997). These processes can lead to the change of spectrofluorometric properties of DOC. Freshness index $(\beta / \alpha)$ indicated the relative proportion of DOC that was produced recently by microbial degradation (Huguet et al., 2009). The average $\beta / \alpha$ ratio of GFC and FC headwater were $0.671 \pm 0.096$ and $0.529 \pm 0.162$, respectively. This might imply a higher microbial transformation of DOC and Fe in pasture dominant headwater.

Another clue for microbial degradation is that the $\mathrm{S}$ ratio of DOC in GFC headwater was smaller compared to DOC in FC headwater (Fig. 4.5). S ratio is used to estimate the average MW of DOC and a smaller S ratio indicates higher MW DOC (Helms et al., 2008). Thus, this implies that the MW of DOC in GFC headwater was higher than the MW of DOC in FC headwater. Higher visible absorbance was obtained for hydrophobic acids which were larger MW DOC compared to smaller MW hydrophilic acids at the same Fe concentration (Pullin et al., 2007). 
And higher MW DOC indicates higher bacterial growth rate and respiration rate (Amon and Benner, 1996). Carbohydrates derived from plants are the preferable substrate to degrade and the products released from degradation processes are difficult to be degraded again and have longer retention time (Kalbitz et al., 2003). However, S ratio was not sensitive enough to illustrate the interaction of Fe and DOC with different MW in these two headwater streams (Fig. 4.5). The higher $\beta / \alpha$ ratio and lower S ratio in GFC headwater indicated greater high MW DOC which might be produced from microbial degradation and became refractory. This fraction could be DOC source to form more Fe-DOC complexes, increase Fe retention in water and thus increase carbon absorbance for an extended time (Maloney et al., 2005).

The PCA revealed a high degree of variability explained by a420, DOC, Fe, $\mathrm{SUVA}_{254}, \mathrm{~S}$ ratio, HIX, $\beta / \alpha$, FI, nitrate, and phosphate at both FC (73.2\%) and GFC (66.5\%), which might indicate different processes in GFC and FC headwater catchments. Phosphate was negatively related to Fe in GFC headwater streams (phosphate-Fe: $\rho=-0.69, p<0.01$ ) (Table 4.4). This might be because phosphate tends to complex with oxidized Fe, precipitate, and thus remove oxidized Fe from solution (Voegelin et al., 2013). The FI index indicated precursors of DOC. When FI is larger than 1.8, the DOC precursor is more microbial (McKnight et al., 2001). In our study, the average FI at GFC was 2.27 while it was 1.56 at FC. The FI was significant positively correlated with $\mathrm{a}_{420}$ in FC stream water (FI-a $\left.\mathrm{a}_{420}: \rho=0.75, p=0.013\right)$, which indicated the water brownification is increased when more DOC was derived from microbial precursors. We found a lower HIX and higher S ratio at FC and higher HIX and a lower S ratio at GFC. Although there were no significant correlations of HIX and S ratio on a420, DOC and Fe, we found HIX and S ratio to be negatively correlated with a420, DOC and $\mathrm{Fe}$ at FC while HIX and S ratio were positively correlated with a420 and Fe and negatively correlated with DOC at GFC (Table 4.4). 
This indicated lower MW DOC at FC and higher MW DOC at GFC, which might explain the browner water color at GFC.

\subsubsection{Implication for land use management to mitigate water color increase}

Land use/land cover is an important factor influencing the transport of DOC and Fe in soil to adjacent water bodies, especially in headwater streams (Dillon and Molot, 1997; McDowell, 1984). Headwater streams account for $53 \%$ of the total stream miles in the continental U.S. (Nadeau and Rains, 2007), so it is very important to have a better understanding of $\mathrm{C}$ and $\mathrm{Fe}$ cycling in headwater streams that highly influence downstream water quality. Differences in land use lead to variations in input and composition of DOC into soil solution and further into water body (Kalbitz, 2001; Poeplau and Don, 2013; Takata et al., 2011; Twongyirwe et al., 2013). Stream water DOC concentration is strongly correlated with soil C pool (Aitkenhead et al., 1999). Molecular characteristics of dissolved organic matter differ due to land cover (McElmurry et al., 2013) and also the concentration of DOC differs even in adjacent catchments (Oni et al., 2014). In the U.S., the three dominant land use types are pasture (29\%), forest (28\%), and crop land (17\%) (Bigelow and Borchers, 2017). Because brownification of surface water is expected to continue due to future climate change (Weyhenmeyer et al., 2016), it is very important to get a better understanding of the DOC and Fe chemistry in headwater streams influenced by pasture, forest, and crop land.

We found that the GFC headwater stream had higher DOC, Fe, $\beta / \alpha$ ratio, FI, and lower S ratio. This indicated the presence of microbially-derived DOC in the headwater stream. In other studies it has been shown that microorganisms first decompose the non-chromophoric DOC and leave the chromophoric DOC, which turns water color to brown (He et al., 2018). The indexes from this study might indicate that pasture managed headwater streams had a higher amount microbial 
decomposed chromophoric DOC compared to forest headwater streams. This accumulated chromophoric DOC might explain the browner water color in the GFC headwater catchment. This is consistent with the findings of Riedel et al. (2012), which showed aromatic DOC is the preferential carbon species for Fe to form complexes. We found strong significant positive relationship between $\mathrm{SUVA}_{254}$ and Fe concentration (Fig. 4.5). Thus, we interpret that microbial processes might lead to the higher aromatic DOC at GFC headwater.

\subsection{Conclusion}

In conclusion, compared to large-scale watersheds, our studies observed a similar water color (a420) range with lower DOC and Fe concentration ranges in the two fine-scale streams. Likewise, the dominant contributor to water color was from DOC. However, a much lower Fe concentration is expected when Fe dominates water color in the two headwater streams. Additionally, our study found DOC with lower S ratio, microbially-derived and higher SUVA254 was present in the pasture headwater stream compared to the forest dominant headwater stream. The strong significant relationship between $\mathrm{SUVA}_{254}$ and Fe indicated water color was strongly influenced by interactions between Fe and aromatic DOC in both headwater streams. In the absence of chemical speciation of DOC and Fe, our evidence for the processes behind DOC and Fe interactions, and their influence on water color was indirect. In addition, due to the modification of DOC during transport in both soil and stream processes, this study can be improved by disentangling DOC sources from the soil and/or upstream. To get a better understanding of the DOC and Fe biogeochemical cycling and their effects on water color, future studies should integrate soil and soil water studies. 


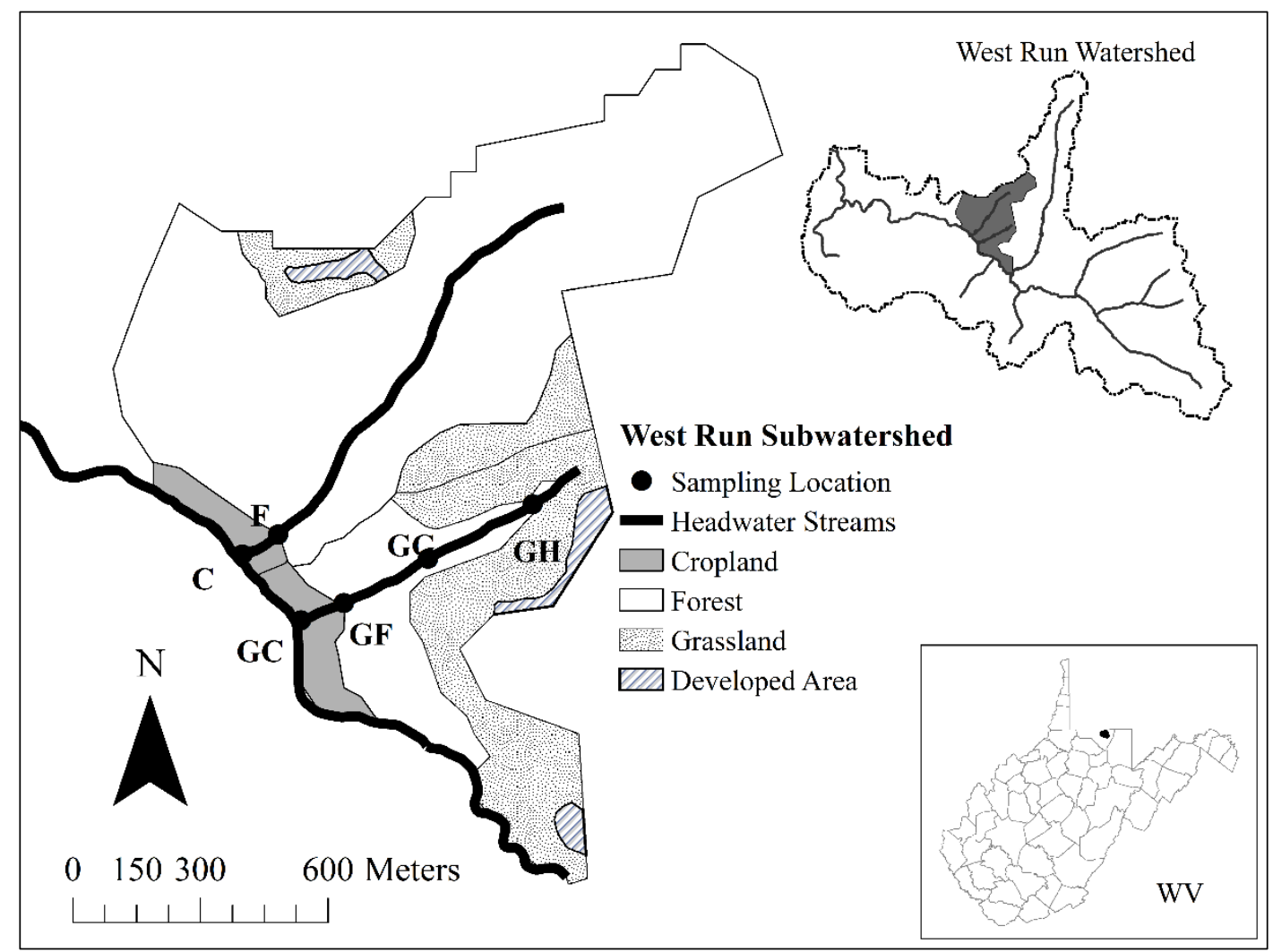

Figure 4. 1 Sampling sites and water sampling locations

( $\mathrm{C}$ and $\mathrm{F}$ at forest dominant headwater stream (FC); GH, GG, GF, and GC at pasture dominant headwater stream (GFC); The black dot in the West Virginia (WV) map at the bottom represented West Run watershed) 


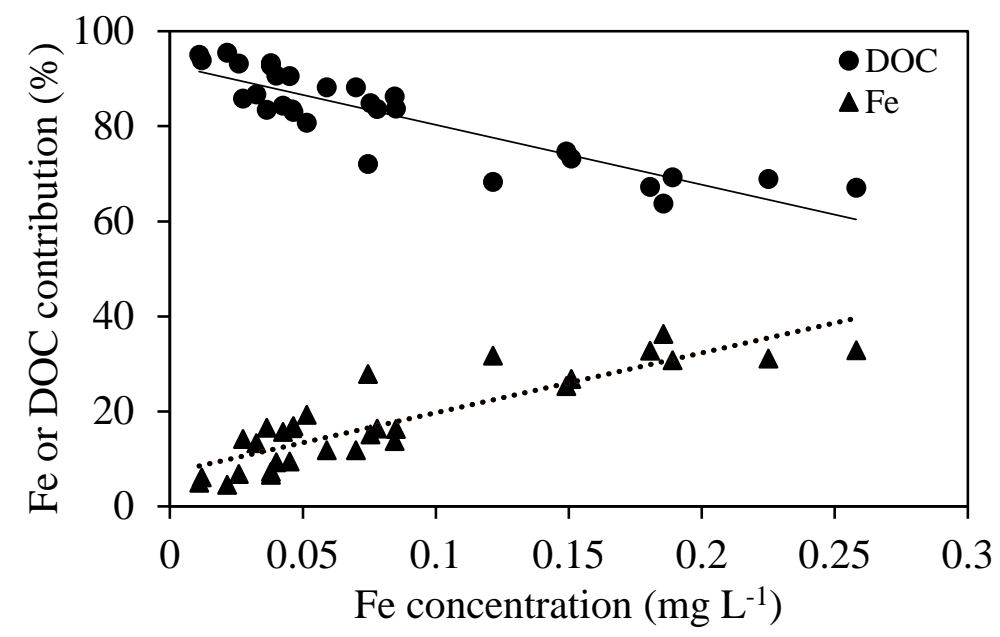

Figure 4. 2 The relative contributions of Fe and DOC to $\mathrm{a}_{420}$ at forest dominant and pasture dominant headwaters $(n=30)$.

The contributions were determined using model $\mathrm{M}_{\mathrm{DOC}+\mathrm{Fe}}$ in Table 2 according to methods described by Köhler et al. (2013b). The fit equations for Fe (dash line) is Fe\%=125.983 Fe + 7.107 $\left(\mathrm{r}^{2}=774, p=1.54 \mathrm{E}-\right.$ $10)$, for DOC (solid line) is DOC\% $=-125.983 \mathrm{Fe}+92.983\left(\mathrm{r}^{2}=774, p=1.54 \mathrm{E}-10\right)$ 


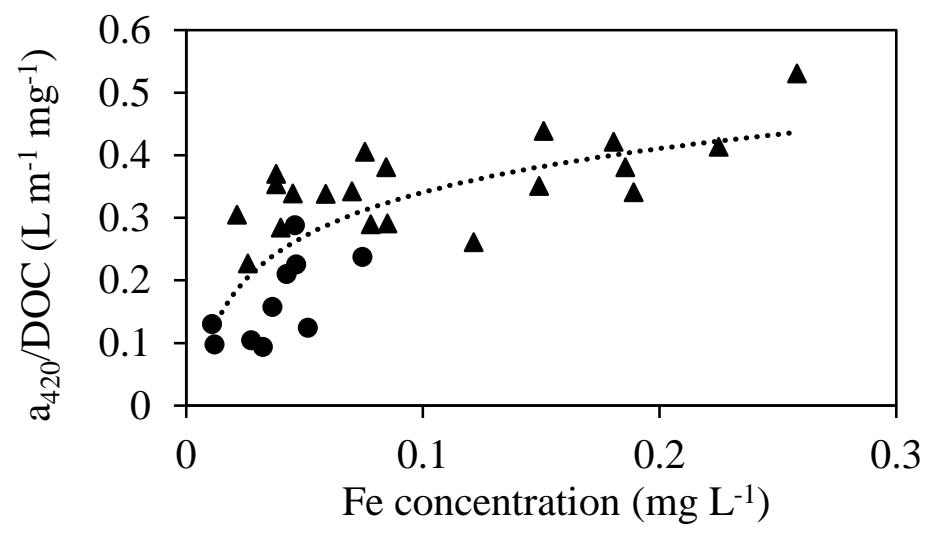

Figure 4. 3 Regression of $\mathrm{a}_{420} / \mathrm{DOC}$ on $\mathrm{Fe}(\mathrm{n}=30)$.

The triangles represented GFC data. The circles represented FC data. No significant interactions between Fe and types of streams on $\mathrm{a}_{420} / \mathrm{DOC}$ were observed $(p=0.06)$, so only one fitting line was developed. The fit equation was $\mathrm{a}_{420} / \mathrm{DOC}=0.101 \ln (\mathrm{Fe})+0.0573\left(\mathrm{r}^{2}=0.548, p=2.89 \mathrm{E}-06\right)$ 


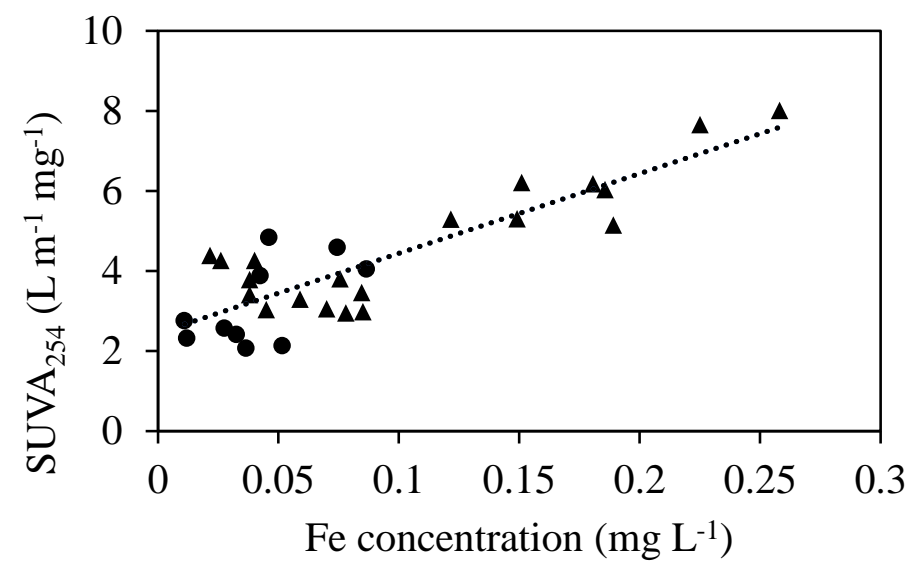

Figure 4. 4 Regression of specific ultra-violet absorption at $254 \mathrm{~nm}\left(\mathrm{SUVA}_{254}\right)$ on Fe at GFC and FC (n=30).

The triangles represented GFC data. The circles represented FC data. No significant interactions between Fe and types of streams on SUVA 254 were observed $(p=0.30)$, so only one fitting line was developed. The fit equation was $\mathrm{SUVA}_{254}=19.73 \mathrm{Fe}+2.49\left(\mathrm{r}^{2}=0.729, p=1.97 \mathrm{E}-9\right)$ 


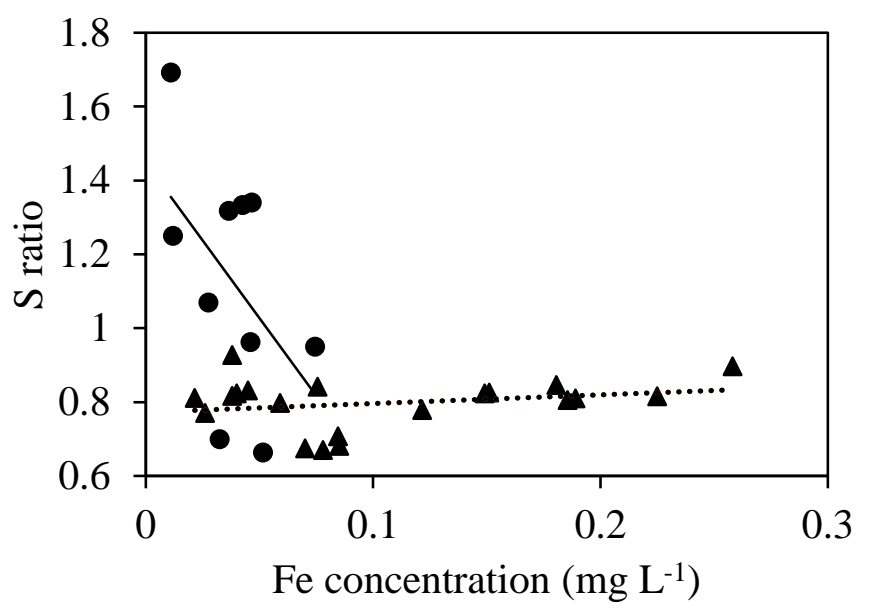

Figure 4. 5 Regression of spectral slope ratio (S ratio) on Fe at GFC and FC ( $n=30)$.

The triangles represented GFC data. The circles represented FC data. The fit equation for GFC (dash line) was $\mathrm{S}$ ratio $=0.2352 \mathrm{Fe}+0.77253\left(\mathrm{r}^{2}=0.0598, \mathrm{p}=0.298\right)$. The fit equation for $\mathrm{FC}$ (solid line) was $\mathrm{S}$ ratio $=-11.0432 \mathrm{Fe}+1.6278\left(\mathrm{r}^{2}=0.248, \mathrm{p}=0.1156\right)$ 

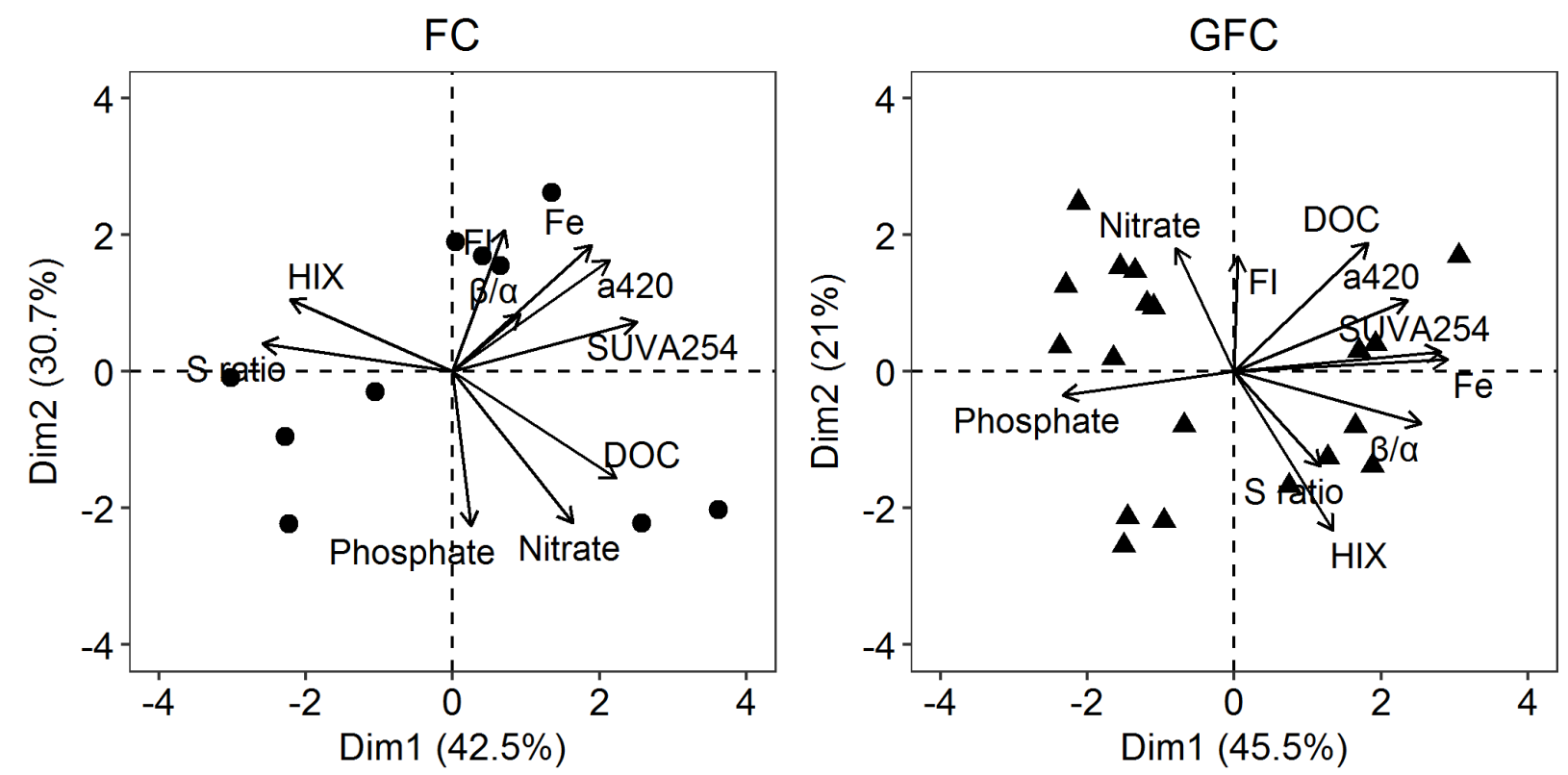

Figure 4. 6 Loading plots for component 1 and 2 at FC (left) and GFC (right) headwaters

a420: Adsorption at $420 \mathrm{~nm}$; DOC: Dissolved organic carbon; Fe: Iron; S ratio: Spectral slope ratio;

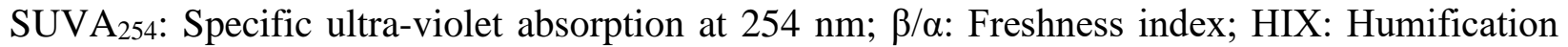
index; FI: Fluorescence index. 
Table 4. 1 Means of $\mathrm{a}_{420}$, dissolved organic carbon (DOC), and iron (Fe) at FC and GFC headwater streams $(n=3)$

(F and C from upstream to downstream at FC headwater stream; GH, GG, GF and GC from upstream to downstream at GFC headwater stream; June, July, August, and November at 2017; January from 2018)

\begin{tabular}{lllllll}
\hline & Location & June & July & August & November & January \\
\hline & C & $0.31 \pm 0.14$ & $0.31 \pm 0.11$ & $0.41 \pm 0.03$ & $0.52 \pm 0.08$ & $0.54 \pm 0.16$ \\
& F & $0.21 \pm 0.02$ & $0.19 \pm 0.04$ & $0.52 \pm 0.2$ & $0.58 \pm 0.16$ & $0.55 \pm 0.32$ \\
$\mathrm{a} 420^{-1} \mathrm{mg}^{-1}$ & GH & $1.66 \pm 0.30$ & $1.55 \pm 0.23$ & $1.45 \pm 0.41$ & $1.04 \pm 0.16$ & $4.33 \pm 0.16$ \\
& GG & $1.24 \pm 0.29$ & $1.55 \pm 0.23$ & $1.66 \pm 0.01$ & $1.61 \pm 0.32$ & $2.76 \pm 0.32$ \\
& GF & $1.04 \pm 0.03$ & $1.45 \pm 0.23$ & $1.97 \pm 0.40$ & $1.78 \pm 0.24$ & $2.07 \pm 0.08$ \\
& GC & $1.45 \pm 0.29$ & $1.47 \pm 0.21$ & $2.07 \pm 0.34$ & $1.84 \pm 0.08$ & $1.96 \pm 0.16$ \\
\hline & C & $2.42 \pm 0.10$ & $1.98 \pm 0.03$ & $4.44 \pm 0.08$ & $2.18 \pm 0.23$ & $2.55 \pm 0.03$ \\
& F & $2.13 \pm 0.01$ & $1.86 \pm 0.02$ & $4.17 \pm 0.70$ & $2.00 \pm 0.1$ & $2.45 \pm 0.29$ \\
$\mathrm{mOC}$ & GH & $4.69 \pm 0.03$ & $4.59 \pm 0.08$ & $5.02 \pm 0.03$ & $3.97 \pm 0.06$ & $8.16 \pm 0.28$ \\
& GG & $4.38 \pm 0.04$ & $3.83 \pm 0.18$ & $5.71 \pm 0.35$ & $4.24 \pm 0.04$ & $6.69 \pm 0.55$ \\
& GF & $4.56 \pm 0.33$ & $4.28 \pm 0.36$ & $5.76 \pm 1.21$ & $4.23 \pm 0.06$ & $6.08 \pm 0.13$ \\
& GC & $4.76 \pm 0.22$ & $3.96 \pm 0.32$ & $5.45 \pm 0.26$ & $4.20 \pm 0.12$ & $5.58 \pm 0.17$ \\
\hline & C & $0.011 \pm 0.001$ & $0.037 \pm 0.006$ & $0.033 \pm 0.003$ & $0.075 \pm 0.004$ & $0.043 \pm 0.014$ \\
& F & $0.012 \pm 0.001$ & $0.028 \pm 0.008$ & $0.052 \pm 0.002$ & $0.046 \pm 0.002$ & $0.047 \pm 0.004$ \\
$\mathrm{mg}$ & GH & $0.038 \pm 0.000$ & $0.059 \pm 0.006$ & $0.078 \pm 0.001$ & $0.122 \pm 0.017$ & $0.258 \pm 0.063$ \\
& GG & $0.040 \pm 0.001$ & $0.076 \pm 0.003$ & $0.085 \pm 0.021$ & $0.186 \pm 0.013$ & $0.225 \pm 0.014$ \\
& GF & $0.026 \pm 0.001$ & $0.045 \pm 0.016$ & $0.070 \pm 0.002$ & $0.181 \pm 0.032$ & $0.189 \pm 0.042$ \\
& GC & $0.022 \pm 0.001$ & $0.038 \pm 0.000$ & $0.085 \pm 0.022$ & $0.151 \pm 0.052$ & $0.149 \pm 0.011$ \\
\hline
\end{tabular}


Table 4. 2 The estimated single and multiple linear regression for $\mathrm{a}_{420}$ explained by dissolved organic carbon (DOC) and iron (Fe)

\begin{tabular}{llll}
\hline Model & Model equation & $\mathrm{R}^{2}$ & $p$ \\
\hline $\mathrm{M}_{\mathrm{DOC}}$ & $\mathrm{a} 420=0.518 \mathrm{DOC}-0.846$ & 0.799 & $1.73 \mathrm{E}-11^{*}$ \\
$\mathrm{M}_{\mathrm{Fe}}$ & $\mathrm{a}_{420}=10.287 \mathrm{Fe}+0.479$ & 0.599 & $3.2 \mathrm{E}-7^{*}$ \\
$\mathrm{M}_{\mathrm{DOC}+\mathrm{Fe}}$ & $\mathrm{a}_{420}=0.390 \mathrm{DOC}+4.471 \mathrm{Fe}-0.676$ & 0.863 & $8.6 \mathrm{E}-13^{*}$ \\
\hline
\end{tabular}

$*$ significant at $\alpha=0.0$; Each model was developed using data from five sampling time and all locations at both forest and pasture headwater streams. 
Table 4. 3 Mixed model analyses of variance of the effects of stream type (FC and GFC; fixed effects), Fe (random effects) and interaction between Fe and stream type on carbon specific absorbance ( $\left.\mathrm{a}_{420} / \mathrm{DOC}\right)$, spectral slope ratio (S ratio), and specific ultra-violet absorption at $254 \mathrm{~nm}\left(\mathrm{SUVA}_{254}\right)$ with location nested within stream types as fixed effect

\begin{tabular}{lllll}
\hline Response & $\mathrm{Fe}$ & Type $(\mathrm{T})$ & $\mathrm{Fe} * \mathrm{~T}$ & Location $(\mathrm{T})$ \\
\hline $\mathrm{A}_{420} / \mathrm{DOC}$ & $* *$ & $* *$ & 0.06 & 0.66 \\
SUVA $_{254}$ & $* *$ & 0.27 & 0.3 & 0.9 \\
S ratio & $* *$ & $* *$ & 0.0025 & 0.99 \\
\hline
\end{tabular}

** $p<0.01$ at $\alpha=0.05$; Type: forest headwater stream (FC) and pasture headwater stream (GFC); Location represented all two locations ( $\mathrm{F}$ and $\mathrm{C}$ ) at forest headwater stream (FC) and all four locations (GH, GG, GF, and GC) at pasture headwater stream (GFC); Location (T) indicated location nested within stream types as a fixed effect. 
Table 4. 4 Pearson's correlation coefficients among DOC quantity and quality, Fe and a420 parameters at FC and GFC headwaters

\begin{tabular}{|c|c|c|c|c|c|c|c|c|c|}
\hline Type & & $\mathrm{a}_{420}$ & DOC & $\mathrm{Fe}$ & Type & & $a_{420}$ & DOC & $\mathrm{Fe}$ \\
\hline \multirow{10}{*}{$\mathrm{FC}$} & $a_{420}$ & 1 & & & \multirow{10}{*}{ GFC } & $\mathrm{a}_{420}$ & 1 & & \\
\hline & DOC & 0.44 & 1 & & & DOC & $0.66^{*}$ & 1 & \\
\hline & $\mathrm{Fe}$ & $0.68 *$ & 0.25 & 1 & & $\mathrm{Fe}$ & $0.62 *$ & 0.33 & 1 \\
\hline & $S$ ratio & -0.31 & -0.47 & -0.53 & & $S$ ratio & 0.1 & -0.37 & 0.09 \\
\hline & SUVA $_{254}$ & 0.62 & -0.03 & 0.35 & & SUVA $_{254}$ & 0.37 & 0.04 & $0.61^{*}$ \\
\hline & $\beta / \alpha$ & -0.1 & -0.16 & 0.25 & & $\beta / \alpha$ & 0.13 & -0.16 & $0.69 *$ \\
\hline & Nitrate & -0.05 & $0.68 *$ & -0.3 & & Nitrate & 0.2 & 0.59 & -0.12 \\
\hline & Phosphate & -0.41 & 0.13 & -0.31 & & Phosphate & -0.28 & -0.22 & $-0.69 *$ \\
\hline & HIX & -0.24 & -0.65 & -0.13 & & HIX & 0.17 & -0.34 & 0.39 \\
\hline & FI & $0.75^{*}$ & 0.27 & 0.48 & & FI & 0.16 & 0.37 & $<0.01$ \\
\hline
\end{tabular}

* means a significant correlation after Benjamini-Hochberg adjustment with a false discovery rate of 0.25. a420: adsorption at $420 \mathrm{~nm}$; DOC: dissolved organic carbon; Fe: iron; S ratio: spectral slope ratio; SUVA254: specific ultra-violet absorption at $254 \mathrm{~nm} ; \beta / \alpha$ : freshness index; HIX: humification index; FI: fluorescence index.

* For forest headwater stream (FC), The analysis was conducted using data from five sampling times and two locations ( $\mathrm{F}$ and $\mathrm{C}$ ) while the analysis was performed using data from five sampling time and four locations (GH, GG, GF, and GC) for pasture headwater stream (GFC). 


\section{Chapter 5 Comparing Dissolved Organic Carbon and Fe in the Soil and Headwater Streams in a Forest and a Pasture Catchment in a Central Appalachian Region, West Virginia}

\subsection{Abstract}

Dissolved organic carbon (DOC) and Fe concentrations cause surface water brownification. Land-use effects on the quantity and quality of DOC are well-established in large-scale watersheds. However, there is more to understand about how soil Fe oxides are involved in DOC and Fe processes in soil and streams, especially in fine-scale catchments. We investigated DOC, the specific ultraviolet absorbance at $254 \mathrm{~nm}\left(\mathrm{SUVA}_{254}\right)$, exchangeable $\mathrm{Fe}\left(\mathrm{Fe}_{\mathrm{ex}}\right)$, and amorphous $\mathrm{Fe}$ concentrations ( $\mathrm{Fe}_{\mathrm{amor}}$ ) in soils as well as DOC, $\mathrm{SUVA}_{254}$, and dissolved $\mathrm{Fe}$ in stream water within a fine-scale forest and pasture catchment. Forest soil had a significantly larger average DOC concentration $\left(71.7 \pm 33.8 \mathrm{mg} \mathrm{kg}^{-1}\right)$ and lower average SUVA $254\left(2.8 \pm 1.0 \mathrm{~L} \mathrm{~m}^{-1} \mathrm{mg}^{-1}\right)$ than the pasture soil at 0-10 cm (DOC: $71.7 \pm 33.8 \mathrm{mg} \mathrm{kg}^{-1}$; SUVA $254: 4.2 \pm 1.4 \mathrm{~L} \mathrm{~m}^{-1} \mathrm{mg}^{-1}$ ). The pasture soil at $0-10 \mathrm{~cm}$ had significantly larger average $\mathrm{Fe}_{\mathrm{ex}}\left(132.8 \pm 57.6 \mathrm{mg} \mathrm{kg}^{-1}\right)$ and $\mathrm{Fe}_{\text {amor }}(813.9 \pm$ $\left.461.2 \mathrm{mg} \mathrm{kg}^{-1}\right)$ concentrations than the forest soil $\left(\mathrm{Fe}_{\mathrm{ex}}: 120.3 \pm 55.4 \mathrm{mg} \mathrm{kg}^{-1} ; \mathrm{Fe}_{\text {amor: }}: 303.2 \pm 213.5\right.$ $\left.\mathrm{mg} \mathrm{kg}{ }^{-1}\right)$. Negative correlations between $\mathrm{Fe}_{\mathrm{ex}}$ and $\mathrm{DOC}$ in the forest soil and positive correlations between $\mathrm{Fe}_{\mathrm{ex}}, \mathrm{Fe}_{\text {amor }}$ and $\mathrm{SUVA}_{254}$ in both forest and pasture soils were found $(\mathrm{p}<0.05)$. The pasture headwater stream had significantly larger DOC, SUVA 254 , and Fe than the forest headwater stream $(\mathrm{p}<0.05)$. Our study indicated Fe oxides may have different interactions with DOC, which leads to differences in the quantity and quality of DOC and dissolved Fe in watersheds of differing scale.

Key words: Surface Water Brownification · Catchments · Forest Pasture · SUVA 2544 


\subsection{Introduction}

Dissolved organic carbon (DOC) is a major component of the global C cycle (Cole et al., 2007; Jardine et al., 2006). It is highly mobile and reactive (Neff and Asner, 2001), which affects the biogeochemical $\mathrm{C}$ processes occurring in soil, aquatic environment, and atmosphere (Kalbitz et al., 2000; Lehmann and Kleber, 2015; Thomas, 1997). Many large-scale watersheds in the northern hemisphere have been shown increased DOC concentration, which leads to increased surface water brownification (Evans et al., 2005; Haaland et al., 2010; Weyhenmeyer et al., 2016). Brownification deteriorates the ecological and societal functions of surface water and thus is a current environmental concern (Williamson et al., 2015). Additionally, it leads to the increasing pretreatment cost of drinking water (Richardson et al., 2007).

The quantity and quality of stream DOC concentration are largely regulated by the quantity and quality of soil DOC at both the regional and global scales (Battin et al., 2008; Graeber et al., 2012; Tank et al., 2010). Soil DOC production, hydrologic transport from soil to stream, and modification during transport in soil and stream, are three fundamental processes controlling the quantity and quality of DOC in stream water (Brooks et al., 1999; Sanderman et al., 2009). Various biotic and abiotic factors govern DOC transport processes, such as climatic conditions, discharge, and soil minerals (Armstrong et al., 2012; Camino-Serrano et al., 2014; Lambert et al., 2013; Maurice et al., 2002; Sanderman et al., 2008). Studies have been conducted on the effects of land-use on DOC and dissolved Fe concentrations in large-scale watersheds (Ekström et al., 2016; Köhler et al., 2013a; Kritzberg et al., 2014; Kutser et al., 2015; Sarkkola et al., 2013; Weyhenmeyer et al., 2014; Williamson et al., 2015). However, large-scale watershed studies bring effects other than land use within a watershed, for example, different parent materials, topography, and climate, that confound interpretations. Thus, these studies potentially bring 
uncertainty to the current understanding of DOC and Fe dynamics in the surface water. Pseudoreplicated studies may be helpful to address this uncertainty by minimizing influences derived from confounding effects.

The interactions between soil Fe oxides and DOC in soil play an important role in influencing the availability and mobility of DOC (Chorover and Amistadi, 2001; Coward et al., 2017; Du et al., 2018). For example, forming Fe-DOC complexes through sorption to preserve DOC (Anesio et al., 2005; Lovley et al., 1998; Singh et al., 2016). The reductive dissolution of amorphous Fe facilitates the export of soil DOC to stream in headwater catchments, especially during long periods of water logging (Grybos et al., 2009; Lambert et al., 2013). Lambert et al. (2013) observed large amounts of released DOC and increased dissolved Fe(II) concentration due to the reduction of amorphous Fe during high flow periods. Therefore, Fe oxides may influence the amount and composition of DOC exported from soil to stream, which influences dissolved Fe concentration in headwater stream and thus surface water brownification (Kritzberg et al., 2014; Kritzberg and Ekström, 2012; Neal et al., 2008; Pullin et al., 2007; Sarkkola et al., 2013).

Fe-oxides regulate not only DOC sorption contributing to soil organic carbon stabilization, but also the release of DOC leading to increasing $\mathrm{CO}_{2}$ efflux and thus OC loss (Coward et al., 2018; Creed et al., 2013; Grybos et al., 2009; Porras et al., 2017). Soil Fe occurs in various forms differing in reducibility which may play different roles in regulating DOC production and export processes. For example, exchangeable Fe representing the exchangeable Fe portion forming soil sorption complexes; amorphous Fe representing the portion of amorphous Fe (III) oxyhydroxide which could be reduced by microorganisms (Lovley and Phillips, 1987; Van Bodegom et al., 2003). The reduction of Fe-oxyhydroxides leading to the release of DOC has been reported in wetland soils (Hagedorn et al., 2000), in organo-mineral soils (Lambert et al., 2013), and forest 
soils (Creed et al., 2013). Thus, it is important to have a better understanding of Fe oxides with different reducibility in controlling DOC availability and mobility. However, there is more to understand about the role of soil Fe minerals in soil DOC modification and export to stream.

Various management practices have been applied to improve crop yield and soil productivity in agriculture. These practices alter the quantity and quality of soil DOC, which also alters Fe minerals in soil (Chantigny, 2003; Huang et al., 2016a; Huang et al., 2015; Kalbitz, 2001; Takata et al., 2011; Wilson and Xenopoulos, 2009; Zhang et al., 2013). Agricultural management practices also lead to the loss of soil organic carbon as DOC and alteration of hydrologic pathways (Autio et al., 2016; Graeber et al., 2012; Ogle et al., 2005). These influence the export of DOC from soils to streams (Lambert et al., 2013; Spencer et al., 2008; Van Gaelen et al., 2014). In addition, Agricultural management practices alter the concentrations of Fe oxides in soil, which influences the mobility of DOC (Huang et al., 2016a). Poorly crystalline iron oxides in agricultural soils are significantly increased by manure application (Huang et al., 2016b; Wen et al., 2019; Zhang et al., 2013). Plant-derived aromatic compounds are preferentially retained by poorly crystalline amorphous Fe oxides (Coward et al., 2018; Kramer et al., 2012; Oren and Chefetz, 2012; Zimmerman et al., 2004). The stabilized DOC by Fe oxides can be mobilized and released into soil solution through Fe reduction and dissolution in reducing microsites (Creed et al., 2013). This evidence leads to more uncertainty of our understanding of DOC inputs and outputs in catchments (Chantigny, 2003; Graeber et al., 2012; Sanderman and Amundson, 2008; Tank et al., 2010; Temnerud et al., 2014). Additionally, linking DOC in the soil to DOC quantity and quality in headwater streams provides important information for developing best management practices in agriculture to promote soil productivity and surface water quality. However, few 
studies have used Fe oxides differing in reducibility to link DOC and Fe in soil and headwater streams in either agricultural or forest catchments.

In the central Appalachian region, major issues of soil degradation, depletion of SOC stocks, and deterioration of aquatic ecosystems are increasing due to increasing anthropogenic disturbances (Bryce et al., 1999; Chaudhuri et al., 2012; Lei et al., 2020). To better understand Fe effects on DOC and Fe trends in the stream and the deteriorated surface water quality in the central Appalachian region, a single fine-scale catchment was chosen in our study which had been maintained in this state for more than 20 -years. In addition, this catchment was derived from the same source parent material and had similar climate conditions (Kellner et al., 2018).

The aims of our study were to 1) compare the temporal variations in DOC amount and composition in both soil and stream waters, and 2) examine the temporal variations of exchangeable $\mathrm{Fe}$ and amorphous Fe minerals in the soil as well as the temporal and spatial variations in dissolved Fe concentration in an agricultural pasture catchment and forest catchment in West Virginia.

\subsection{Materials and Methods}

\subsubsection{Study area and sampling}

This study was carried out at West Virginia University’s Animal Science Farm $\left(39^{\circ} 40^{\prime} \mathrm{N}\right.$, $79^{\circ} 56^{\prime} \mathrm{W}$ ) in Morgantown, West Virginia. The elevation ranged from $287 \mathrm{~m}$ to $381 \mathrm{~m}$ above sea level. The mean annual temperature was $11.4^{\circ} \mathrm{C}$ and the mean annual precipitation was $99.5 \mathrm{~cm}$ (Wright 1982). The average precipitation of the sampling period was $0.12 \mathrm{~cm}$ and the daily precipitation is presented in Fig. 5.2. 
Two headwater catchments $\left(1.308 \mathrm{~km}^{2}\right)$ were chosen (Fig. 5.1). The three representative land use types were forest, cropland, and pasture. The forest headwater stream $\left(0.913 \mathrm{~km}^{2}\right)$ was predominately the forest land use $\left(0.774 \mathrm{~km}^{2}, 85.8 \%\right)$. The other three types included pasture $\left(0.097 \mathrm{~km}^{2}, 9.8 \%\right)$, cropland $\left(0.03 \mathrm{~km}^{2}, 3.3 \%\right)$, and developed area $\left(0.01 \mathrm{~km}^{2}, 1.1 \%\right)$. The pasture headwater stream $\left(0.405 \mathrm{~km}^{2}\right)$ was predominantly pasture $\left(0.201 \mathrm{~km}^{2}, 49.6 \%\right)$. The other three types along this stream included forest $\left(0.142 \mathrm{~km}^{2}, 35 \%\right)$, cropland $\left(0.039 \mathrm{~km}^{2}, 9.6 \%\right)$, and developed area $\left(0.023 \mathrm{~km}^{2}, 5.8 \%\right)$. All land cover delineations were determined using ArcGIS (Version 10.7.1) and National Land Cover Dataset from 2011. In our study, we focused on the forest and pasture, which were two dominant land types. The forest was composed of mixed deciduous hardwood trees which were approximately 120 years old. The permanent grassland was continuously grazed with $0.5-0.75$ dry dairy cows or/and heifers per hectare for 20 years. The pasture was mowed once in October every year. More descriptions about the management and vegetation of each land type are illustrated in Chap 2.2.21.

We collected one sample potentially influenced by the forest land use (F) and the other influenced by the cropland use (C) (Fig. 5.1). Four samples potentially influenced by pasture (GH and GG), forest (GF), and cropland use (GC) were collected (Fig. 5.1). Water samples were collected from the six sites on October $1^{\text {st }}$, November $6^{\text {th }}, 2017$, January $10^{\text {th }}$, February $28^{\text {th }}$, June $16^{\text {th }}$, July $14^{\text {th }}, 2018$ (Fig. 1). All samples were collected using acid washed $1 \mathrm{~L}$ polyethylene bottles and transported immediately to the laboratory. All water samples were filtered through Whatman $0.45-\mu \mathrm{m}$ filters and stored in a refrigerator under $4^{\circ} \mathrm{C}$ and analyzed within 3 days after collection. All analyses were performed in triplicate.

Soil sampling was conducted at the same time when the stream water samples were collected. Four $10 \times 10 \mathrm{~m}$ plots with similar micro-environmental conditions like vegetation distribution, 
were randomly selected in the field for each land type. The forest plots had a very thin, minimally decomposed litter layer $(<1 \mathrm{~cm})$. When sampling, the litter layer was removed. The pasture plots that were not disturbed by feeding and watering dry dairy cows and heifers and at least 5 meters away from the edge of the field. One plot was on the shoulder slope. Two plots were on the backslope. The other one was on the foot slope. Six soil sample cores were collected from each plot in an $\mathrm{S}$ pattern to a depth of $25 \mathrm{~cm}$ using a soil sampling probe $(3 \mathrm{~cm}$ in diameter). The six soil cores from each plot were divided into two layers $(0-10 \mathrm{~cm}$ and $10-25 \mathrm{~cm})$ and composited in pairs to provide three replications at each depth at each plot. Four replications from four plots were composited so that there were three replications at each depth for each land management practice. The study and sampling site are presented in Fig. 5.1. More details of the four plots at each filed were summarized in Chap 2.2.2.

Each bulk sample was divided into two subsamples. One subsample was air-dried at room temperature, ground, and sieved through a 2-mm sieve for determination of soil $\mathrm{pH}$, EC, and particle density. The description of these determinations is summarized in Table 2.1. The physical and chemical properties were determined using the air-dried soil samples and are presented in Table S2-2. The other subsample was sieved through a 2-mm sieve and stored at $4^{\circ} \mathrm{C}$ until analysis within three days.

\subsubsection{Laboratory analysis}

For stream water samples, the $\mathrm{pH}$ was determined using a Mettler Toledo SevenEasy $\mathrm{pH}$ meter (Columbus, OH, USA). Non-purgeable organic carbon (NPOC) was determined using a Shimadzu-TOC V (Tokyo, Japan) to represent DOC concentration. Total dissolved Fe was determined using inductively coupled plasma-optical emission spectroscopy (ICP-OES) (Optima DV2100, Perkin Elmer, Waltham, MA). Absorbance spectra from 230-600 nm at $1 \mathrm{~nm}$ intervals 
were obtained using a BIOTEK microplate reader (Epoch 2, Winooski, VT, USA) in a $1 \mathrm{~cm}$ cuvette. All spectra $\left(\mathrm{a}_{\lambda}\right)$ were expressed as $\mathrm{m}^{-1}$ (Helms et al. 2008). The specific ultraviolet absorbance at $254 \mathrm{~nm}\left(\mathrm{SUVA}_{254}\right)$, as a measure of aromaticity, was calculated as the ratio of absorbance at $254 \mathrm{~nm}\left(\mathrm{a}_{254}\right)$ and DOC concentration (Weishaar et al., 2003). Exchangeable Fe $\left(\mathrm{Fe}_{\mathrm{ex}}\right)$ and microbially reducible amorphous $\mathrm{Fe}\left(\mathrm{Fe}_{\mathrm{amor}}\right)$ were determined in fresh soil subsamples. $\mathrm{Fe}_{\mathrm{ex}}$ in fresh soil subsamples was extracted using $0.5 \mathrm{M} \mathrm{HCl}$ and $\mathrm{Fe}_{\text {amor }}$ was calculated as the $\mathrm{Fe}$ extracted from fresh soil using $0.25 \mathrm{M}$ hydroxylamine hydrochloride and $0.25 \mathrm{M} \mathrm{HCl}$ minus the Fe extracted with 0.5 M HCl (Lovley and Phillips, 1987; Van Bodegom et al., 2003). The released Fe was determined according to methods described by Lovley and Phillips (1987). For DOC determination in fresh soil subsamples, $5 \mathrm{~g}$ fresh soil was extracted with $50 \mathrm{ml} 12.5 \mathrm{mM} \mathrm{CaCl}_{2}$ solution. The mixture was shaken for about 2 hours at 200 cycles per minute and then centrifuged at $3000 \mathrm{rpm}(1600 \mathrm{~g})$ for 10 minutes. The supernatant was filtered through 0.45 -um sterile nitrile membrane filter and stored at $4^{\circ} \mathrm{C}$ until further analysis. The DOC concentration and SUVA254 of DOC in the supernatant were determined as described above. The air-dried soil subsamples for the determination of total organic carbon (TOC) and the proportion of Fe-bound OC were acidified with $1 \mathrm{M} \mathrm{HCl}$ with a 1:2 (m: V) solid: solution ratio to degas the inorganic $\mathrm{C}$ in soil and then dried at $70^{\circ} \mathrm{C}$ for 24 hours. TOC in the oven-dried soil samples was determined by dry combustion (Elementar Vario MAX Cube, Hanau, Germany). The proportion of Fe-bound OC was determined using citrate-bicarbonate-dithionite (CBD) method (Mu et al., 2016; Zhao et al., 2016).

\subsubsection{Statistical analysis}

The two-way repeated measure analysis of variance (rmANOVA) (repeated depth and month) and Tukey adjustment were performed to test the main effects of the land-use management 
practice, depth, month, two-way interactions, and three-way interactions on TOC, DOC in soil, SUVA $_{254}$ of soil DOC, $\mathrm{Fe}_{\mathrm{ex}}$, and $\mathrm{Fe}_{\mathrm{amor}}$ at $\alpha=0.05$ using SAS PROC MIXED procedure (Version 9.4. SAS Institute Inc., Cary, NC, USA). The one-way repeated measure analysis of variance (rmANOVA) (repeated depth) and Tukey adjustment were performed to compare the average of TOC, soil DOC, SUVA 254 of soil DOC, $\mathrm{Fe}_{\mathrm{ex}}, \mathrm{Fe}_{\mathrm{amor}}$, and the proportion of $\mathrm{Fe}$-bound OC of six months. Correlations between TOC, soil DOC, $\mathrm{SUVA}_{254}, \mathrm{Fe}_{\mathrm{ex}}$, and $\mathrm{Fe}_{\text {amor }}$ were determined using non-parametric Spearman's correlation using JMP 12.0 (SAS Institute Inc., Cary, NC, USA). The probability of false positives in multiple analyses of the non-parametric Spearman's correlation was adjusted using a Benjamini-Hochberg procedure with a false discovery rate of 0.25 (Benjamini and Hochberg, 1995).

Since the DOC, Fe, and SUVA 254 at the two locations in forest headwater stream and the four locations at pasture headwater stream were not independent, a non-parametric Wilcoxon signedrank test was used to compare the significance of DOC, Fe, and SUVA 254 among the six locations. If a p-value less than 0.05 was found, a non-parametric comparison using Wilcoxon methods was conducted to compare the significant differences for each pair.

\subsection{Results}

5.4.1 Average and seasonal changes of DOC, SUVA 254 and Fe concentrations in the soils at the forest and pasture catchments

Land-use management practice, depth, month, two-way interactions, and three-way interactions all had significant influences on TOC, DOC, and SUVA $254(\mathrm{p}<0.01)$ (Table S1-1). The forest and pasture soil at $0-10 \mathrm{~cm}$ (forest: $33.7 \pm 4.3 \mathrm{~g} \mathrm{~kg}^{-1}$; pasture: $31.7 \pm 3.0 \mathrm{~g} \mathrm{~kg}^{-1}$ ) had a significantly larger average TOC than forest and pasture soils (forest: $10.6 \pm 1.4 \mathrm{~g} \mathrm{~kg}^{-1}$; pasture: $9.3 \pm 1.6 \mathrm{~g} \mathrm{~kg}^{-1}$ ) at 10-25 $\mathrm{cm}$ (Table S1-2 and Fig S1-1). 
Forest soil had significantly larger average DOC concentration at $0-10 \mathrm{~cm}\left(71.7 \pm 33.8 \mathrm{mg} \mathrm{kg}^{-}\right.$ ${ }^{1}$ ) than $10-25 \mathrm{~cm}\left(53.1 \pm 30.2 \mathrm{~m} \mathrm{~kg}^{-1}\right)$, which all significantly larger than the pasture soil at both depths (Table S1-2 and Fig. 5.3a). However, a significantly larger average SUVA $_{254}$ was observed in the pasture soil $\left(4.2 \pm 1.4 \mathrm{~L} \mathrm{~m}^{-1} \mathrm{mg}^{-1}\right)$ than the forest soil at $0-10 \mathrm{~cm}\left(2.8 \pm 1.0 \mathrm{~L} \mathrm{~m}^{-1} \mathrm{mg}^{-1}\right)$ (Table S1-2 and Fig. 5.3b). A significantly larger average SUVA ${ }_{254}$ were found in the pasture soil $\left(2.2 \pm 1.3 \mathrm{~L} \mathrm{~m}^{-1} \mathrm{mg}^{-1}\right)$ compared to the forest $\left(1.6 \pm 0.7 \mathrm{~L} \mathrm{~m}^{-1} \mathrm{mg}^{-1}\right)$ at $10-25 \mathrm{~cm}$ (Table $\mathrm{S} 1-2$ and Fig. 5.3b). All the forest and pasture soils had larger DOC concentrations in October, November, and January than the average except for the pasture soil at $10-25 \mathrm{~cm}$ (Fig. 5.3a). The two soils at both depths in February, June, and July all showed lower DOC concentration than the average of the six months (Fig. 5.3a). Contrary to the DOC trends, the two soils at both depths showed larger $\mathrm{SUVA}_{254}$ than the average in June and July while lower $\mathrm{SUVA}_{254}$ in October, November, and January (Fig. 5.3b).

Land-use management practice, depth, month, two-way interactions, and three-way interactions all had significant influences on $\mathrm{Fe}_{\mathrm{ex}}$, and $\mathrm{Fe}_{\text {amor }}(\mathrm{p}<0.05)$ (Table S1-1). The pasture soil at $0-10 \mathrm{~cm}$ had significantly larger average exchangeable Fe concentration (pasture: $132.8 \pm$ $\left.57.6 \mathrm{mg} \mathrm{kg}^{-1}\right)$ than forest soils $\left(120.3 \pm 55.4 \mathrm{mg} \mathrm{kg}^{-1}\right)$ while there was no significant difference between forest and pasture soils at 10-25 $\mathrm{cm}$ (Forest: $71.8 \pm 47.0 \mathrm{mg} \mathrm{kg}^{-1}$; pasture: $60.6 \pm 17.7$ $\mathrm{mg} \mathrm{kg}^{-1}$ ) (Table S1-2 and Fig. 5.4a). For the average microbially reducible Fe, the highest content was found in pasture soil at $0-10 \mathrm{~cm}\left(813.9 \pm 461.2 \mathrm{mg} \mathrm{kg}^{-1}\right)$ (Table S1-2 and Fig. 5.4b). Exchangeable $\mathrm{Fe}$ in pasture soil $\mathrm{Fe}$ had larger content in February, June and lower contents in October, November, January, and July while forest soil showed highest exchangeable concentration in July compared to the average (Fig. 5.4a). All two soils at two depths showed 
larger microbially reducible Fe concentrations in February and June and lower at October, November, January and July except the pasture soil at 0-10 cm (Fig. 5.4b).

5.4.2 Seasonal changes of DOC and Fe concentrations in the forest and pasture headwater streams

The DOC, SUVA254, and Fe concentrations showed significant differences between the pasture headwater and the forest headwater stream (Fig. 5.5 and 5.6; Table 5.2 and 5.3) $(\mathrm{p}<0.05)$. It showed significantly greater DOC and Fe concentrations at GH, GG, GF, and GC than the F and C (Fig. 5.5; Table 5.2). However, only significantly larger $\mathrm{SUVA}_{254}$ were observed at GH, GG, GF, and GC than the C (Fig. 5.6; Table 5.3).

Additionally, the DOC, $\mathrm{SUVA}_{254}$, and Fe concentrations had a wider seasonal change at the four locations in the pasture headwater stream than the two locations at the forest headwater stream, which was shown by the observed larger standard deviation (Fig. 5.5 and 5.6; Table 5.2). Compared to the upstream locations at each stream, the seasonal changes in DOC, SUVA 254 , and Fe concentrations become smaller than at downstream locations, which was shown by the smaller standard deviations (Table 5.2).

The seasonal trends of both DOC and Fe were different among locations (Fig. 5.5). For example, GH was different from GG, GF, and GC (Fig. 5.5). The DOC concentration at GH in the pasture headwater stream was greater in January, February and lower in October, November, June, and July compared to the average DOC (Fig. 5.5). The DOC concentrations at GG, GF, and GC were all larger in October, January, and July and lower in November, February, and June (Fig. 5.5). The Fe concentration at GH was larger in January, and July and lower in October, November, February, and June than the average Fe while the Fe concentrations at GG, GF, and GC were larger in November, January, and June and lower in October, February, and July (Fig. 5.5). DOC 
concentration was highest at both $\mathrm{F}$ and $\mathrm{C}$ locations in October (Fig. 5.5). Except for October, the seasonal DOC and Fe concentrations were close to the average DOC and Fe concentrations at F and $\mathrm{C}$ locations.

Unlike the seasonal trends of DOC and Fe concentrations at the four locations (GH, GG, GF, and GC) in the pasture headwater stream, $\mathrm{SUVA}_{254}$ showed similar changes all four locations except for January and February (Fig. 5.6). Compared to the average of $\mathrm{SUVA}_{254}$ at each location, GH and GG showed larger SUVA 254 while GF and GC showed lower SUVA254 in January (Fig. 5.6). At February, GH showed larger SUVA 254 while GG, GF, and GC showed lower $\mathrm{SUVA}_{254}$ (Fig. 5.6).

\subsection{Discussion}

\subsubsection{Effects of land-use management practices on the average DOC and SUVA 254 in the soil}

Our study showed that land-use management practices, depth, and two-way interactions all significantly influenced DOC concentration and $\mathrm{SUVA}_{254}$ in the soil (Table S1-1). The forest soils had significantly larger average DOC concentration than the pasture soil at both $0-10 \mathrm{~cm}$ and 10-25 cm (Fig. 5.3a). This is similar to other reported studies (Chantigny, 2003; Jiao et al., 2009; Khomutova et al., 2000). Armstrong et al. (2012) suggested that vegetation regulated DOC concentration in the pore water by affecting the quality and quantity of the litter with different vegetation types. In our study, the larger average DOC concentration in the forest soils may be due to the thin litter layer in this hardwood forest, which contributed to DOC in the mineral layer from the release of organic molecules during the litter decomposition (Borken et al., 2011; Janeau et al., 2014; Qi et al., 2012; Strobel et al., 2001). Contrary to the DOC trends, the pasture soil at 0-10 $\mathrm{cm}$ had larger annual average $\mathrm{SUVA}_{254}$ than that of soils at $10-25 \mathrm{~cm}$ and also forest soils at 
both depths (Fig. 5.3b). This may be due to the presence of a larger proportion of humic-like compounds in agricultural soils compared to forest soils (Gui et al., 2016; Shang et al., 2018).

\subsubsection{Seasonal changes of DOC and SUVA 254 in the forest and pasture soils}

Soils from the two land-use managements showed consistent seasonal changes of DOC and SUVA $_{254}$ between 0-10 $\mathrm{cm}$ and $10-25 \mathrm{~cm}$ (Fig. 5.3). Compared to the average DOC concentration of six months, both soils had larger DOC concentration in the fall and earlier winter (October, November, and January) and lower DOC concentrations in winter and early summer (February, June, and July) (Fig. 5.3a; Table S1-2). In contrast, the SUVA 254 of DOC was lower in October, November, January, and February while it was larger in June and July compared to average $\mathrm{SUVA}_{254}$ (Fig. 5.3b; Table S1-2). After the long drying period without precipitation in September (Fig. 5.2), all soils showed the highest DOC concentration and lowest SUVA 254 in October or November and then decreased during the rewetting period. This is consistent with De Troyer et al. (2014) who reported increased DOC and decreased SUVA 254 of DOC after soil drying and rewetting processes. Soil drying and rewetting cycles may be a significant factor in our study, which largely affected DOC concentration and composition due to the alternation of biological processes (De Troyer et al., 2014; Merckx et al., 2001). This indicated a major role of microbes in regulating DOC dynamics in the season involving in drying and rewetting cycles. The SUVA 254 trends in the forest and pasture soils of our study indicated a similar shift of DOC sources from relatively fresh or microbial-derived DOC after the long dry season to more altered and highly decomposed sources during the rewetting and wetting season as water moves through soils (Sanderman et al., 2008).

Different DOC sources were an important factor leading to the differences in the quantity and quality of DOC as well as the seasonal trend (Sanderman et al., 2008). A wider range of the DOC 
concentrations in the forest soil than the pasture soil was observed in our study (Fig. 5.3a; Table S1-2). Root exudates throughout the growing season are the majority of fresh $\mathrm{C}$ input in the grassland soil while litter fall is dominated the SOC input and distributed through the year in the forest soil (Sanderman et al., 2008; Yano et al., 2000). This indicated that the seasonal dynamics of DOC in the forest soils are processes highly dependent on climatic factors. For example, soil moisture and temperature, are important factors involved in DOC production and decomposition through microbial biological activity in the forest soil (Camino-Serrano et al., 2014; Kaiser et al., 2001). Similar results were also reported by Dawson et al. (2008) who confirmed the main role of biological activity instead of discharge in influencing the seasonal change of DOC. Additionally, the soil samples from forest and pasture were collected from different positions at the hillslope. Hillslope is a factor influencing water flow pathways, which depend on season (Curmi et al., 1998; Sanderman et al., 2009). This suggests that different water flow pathways may occur in the pasture and forest soils. The flow paths depend on the seasonal water table fluctuations and thus influenced the concentration and composition of DOC seasonal changes in soil and stream (Janeau et al., 2014). Toosi et al. (2014) also found flow paths had significant differences of DOC in forest soil while the DOC concentration and properties in agricultural soil didn't show clear differences. This is consistent with our study which showed a wider seasonal variation of DOC in forest compared to the pasture soil.

\subsubsection{Comparison of average of DOC and SUVA 254 between two catchments}

Different flow pathways and DOC in-soil and/or in-stream processes within a catchment alter the amounts and sources of DOC exported to the stream water (Hood et al., 2006; Van Gaelen et al., 2014). Although the DOC concentration in the pasture soil was significantly lower compared to the forest soil at both depths (Fig. 5.3; Table S1-2), a significantly larger DOC concentration 
was observed in the pasture headwater stream at the four locations compared to the forest headwater stream at the two locations (Fig. 5.5a; Fig. 5.6; Table S1-2 and 5.4). This may indicate different flow pathways and DOC in-soil and in-stream processes occurring in the forest and pasture catchments, which influenced the amounts and sources of DOC exported to the stream water. Van Gaelen et al. (2014) reported seepage as an important pathway in grassland with shallow water tables while riparian and throughfall contribute to the rising of DOC concentration in the forest headwater stream. Additionally, the contribution of groundwater differs in soils during base flow in altering the DOC seasonal trends (Hur et al., 2014; Van Gaelen et al., 2014). Our results indicated the flow paths through groundwater may be different between the two catchments, which highly altered the interactions of DOC with subsurface soil. However, the significantly larger $\mathrm{SUVA}_{254}$ in the pasture soil at $0-10 \mathrm{~cm}$ and the overall high DOC concentration in the pasture headwater was likely due to a larger proportion of flow path through DOC-rich topsoil through all seasons (Hood et al., 2006). Additionally, we found the forest headwater stream and pasture headwater stream showed varied DOC changes while SUVA 254 showed consistent seasonal changes (Fig. 5.5 and 5.6). Van Gaelen et al. (2014) reported similar SUVA $_{254}$ trends during base flow for both the forest and pasture catchments and showed larger SUVA $_{254}$ during summer, which is consistent with our study. Similarly, we didn't find significant SUVA $_{254}$ differences between F, GH, GG, GF, and GC locations (Fig. 5.6; Table 5.3).

Since clay and silt in soil have high sorption capacities, they are an important factor in affecting DOC concentration and composition in soil solution and also the exporting soil DOC to rivers (Kalbitz et al., 2005; Nelson et al., 1992). Thus, the significantly lower DOC concentration in the forest catchment may be explained by the larger clay and silt content in the forest soil (Table 2.1), so this may lead to larger selective sorption of DOC to soil minerals and lower DOC export to 
headwater stream in the forest soil than the pasture soil (Sanderman et al., 2008). Aromatic DOC is preferred to absorb by mineral soils (Maurice et al., 2002), so the DOM exported from clay soils is less aromatic than that from organic soils (Autio et al., 2016). A significantly lower retention time of DOC was observed in prairie mineral soils compared to forest mineral soils (Sanderman and Amundson, 2008). These may explain why the DOC concentration and SUVA 254 of DOC in forest headwater stream were significantly lower than the pasture headwater stream. The surface runoff is likely another reason for the larger DOC concentration in the pasture catchment since steep slope significantly positive related to DOC export (Janeau et al., 2014)

\subsubsection{Linking DOC and Fe between soil and stream}

In-stream and in-soil processes are both important factors influencing the transport of DOC from soil to stream spatially and temporally in headwater catchments (Dawson et al., 2001; Sawicka et al., 2016; Vidon et al., 2014), which may lead to DOC spatial and chemical variances within a headwater stream at different locations. Although a lowest $\mathrm{SUVA}_{254}$ at all locations in both forest and pasture catchments was observed at October, we found the DOC concentration and $\mathrm{SUVA}_{254}$ had different seasonal trends between the upstream location and the downstream locations at each catchment (Fig 5.3; Fig. 5.5a; Fig. 5.6). For example, in July, the DOC concentrations at GG, GF, and GC locations were larger while it was much lower at GH location compared to the annual DOC concentration at each location (Fig. 5.5a). This may indicate more DOC input sources downstream during July. Additionally, larger SUVA 254 was observed at GH location while GG, GF, and GC locations showed lower SUVA $_{254}$ in February compared to average $\mathrm{SUVA}_{254}$ (Fig. 5.6). This suggested that in-stream and in-soil processes in our study were important factors altering the DOC and $\mathrm{SUVA}_{254}$ seasonal trends, especially at the pasture catchments with mixed land-use types. 
Fellman et al. (2009) reported quality of DOC became more similar after passing through the watershed. Consistently, we found a larger seasonal variation of $\mathrm{SUVA}_{254}$ at the upstream location compared to the downstream location (Table S1-2). The seasonal SUVA 254 trends were highly similar at the downstream locations of the whole sampling period (GF and GC) (Fig. 5.6). However, different $\mathrm{SUVA}_{254}$ trends were observed during the winter season at the upstream location, such as January and February (Fig. 5.6). Larger SUVA 254 was also observed at GH at January and February and at GG at January compared to the annual DOC concentration of each location (Fig. 5.6). This indicated more aromatic DOC sources or processes increasing aromatic DOC in-stream during winter only occurred at the upstream locations. Or there were processes that decreased the aromatic DOC at the downstream locations in the pasture catchment.

Drying and rewetting processes influence the quantity and quality of DOC transported from soil to headwater streams (De Troyer et al., 2014). We found lower aromatic SUVA 254 during the rewetting period in October, November, and January while larger SUVA 254 during spring flush and early summer in June, and July in three soils and the two headwater streams (Fig. 5.3 and 5.6). This indicated the DOC was recently leached from microbial fractions during the rewetting period and aromatic fractions during spring flush, which were similar trends observed in other upland streams (Fellman et al., 2009; Striegl et al., 2005). However, DOC residence time may change this trend due to the microbial influence. For example, Striegl et al. (2005) found a low $\mathrm{SUVA}_{254}$ in summer due to longer DOC residence time and increased microbial consumption. In addition, vegetation root and fungi associated with vegetation exudes organic acids, which can mobilize stabilized aromatic DOC and thus increasing the aromaticity of DOC, for example, oxalic acid (Keiluweit et al., 2015; Strobel, 2001). This may be a factor leading to the high $\mathrm{SUVA}_{254}$ at pasture soils and then the pasture headwater stream (e.g. June and July in our study 
at the growing stage). Unfortunately, we don't have data to evaluate the influence of low molecule weight organic acids on mobilizing stabilized aromatic DOC.

\subsubsection{Iron role in regulating the quantity and quality of DOC in soils}

By only considering the land use and seasonal effects, studies of effects of land-use management practices and the season on the concentration and composition of DOC at watershed of various scales reported conflicting results (Autio et al., 2016; Graeber et al., 2012; Hur et al., 2014; Wilson and Xenopoulos, 2008). For example, Graeber et al. (2012) showed land use had a strong seasonally independent influence on the export of DOC from soil to stream. In contrast, Wilson and Xenopoulos (2008) didn't observe significant differences between forest and agricultural catchments.

Fe-oxyhydroxides regulates not only DOC sorption contributing to soil organic carbon stabilization, but also the release of DOC leading to increasing $\mathrm{CO}_{2}$ efflux and thus OC loss (Coward et al., 2018; Creed et al., 2013; Grybos et al., 2009; Porras et al., 2017). The reduction of Fe-oxyhydroxides leading to the release of DOC has been reported in the wetland soils (Hagedorn et al., 2000), in the organo-mineral, and albic soil horizons (Lambert et al., 2013). Similarly, we found significant negative correlations between $\mathrm{Fe}_{\mathrm{ex}}$ and DOC in the forest soil (Table 5.1). However, no significant correlation between these two Fe fractions and DOC was observed in the pasture soil (Table 5.1). Creed et al. (2013) found topographic features (e.g. slope) along the hillslopes regulated the mobile DOC. More specifically, toeslope and footslope features are transiently saturated zones leading to spatially and temporally reducing conditions (Creed et al., 2013). This may explain the reason for no significant correlation between Fe fractions and DOC since the soil sampling from pasture soils were from the shoulder, backslope, and toeslope 
along the hillslope. This indicates the reduction of Fe-oxyhydroxides may play an important role in regulating the DOC quantity in the forest soil and the export of Fe to headwater stream.

Grybos et al. (2009) found aromatic organic molecules was the most reactive DOC pool contributing reduction of Fe-oxyhydroxides. The reduction of Fe-oxyhydroxides is accompanied by the release of DOC and the increase of SUVA 254 of the released DOC (Grybos et al., 2009). Consistently, we observed significant positive correlations between $\mathrm{Fe}_{\mathrm{ex}}, \mathrm{Fe}_{\text {amor }}$ and $\mathrm{SUVA}_{254}$ in both forest and pasture soils (Table 5.1). This suggests that aromatic DOC was one of the most important source pools that may involve in the reduction of Fe-oxyhydroxides in the forest and pasture soils. We found $\mathrm{SUVA}_{254}$ of DOC in forest and pasture soils were significant predictors to DOC variation in F location in the forest headwater stream and GH location at the pasture headwater stream (Table S2-1). This may influence Fe concentration in headwater streams due to the interaction between Fe and aromatic DOC. For example, Lei et al. (2020) found a significant positive regression between aromatic DOC and dissolved Fe concentration in headwater streams. Therefore, our study indicated that Fe-oxyhydroxides reducing processes may be more important in influencing the aromatic DOC proportion instead of the whole DOC pool.

We found microbially reducible $\mathrm{Fe}$ concentration in forest soils at $0-10 \mathrm{~cm}$ significantly negative explained Fe variation at the F location (Table S2-1). However, the amorphous Fe and exchangeable Fe were not significant predictors of Fe concentrations in the pasture catchment (Table S2-1). This indicated that the Fe-reducing processes may directly influence $\mathrm{Fe}$ concentrations in the forest headwater stream. Conversely, Fe-reducing processes may indirectly influence Fe concentration by influencing aromatic DOC in the pasture headwater stream (Table 5.1). Since reducing microsites are spatially and temporally dynamic (Creed et al., 2013), our 
study also indicated different reducing microsites may occur between these two catchments, which lead to different Fe and DOC in-soil and in-stream interactions.

The dissolved Fe influenced the quantity and quality of DOC in water, especially aromatic DOC (Kutser et al., 2015; Pullin et al., 2007; Xiao et al., 2016). Thus it impacts surface water brownification since dissolved $\mathrm{Fe}$ is a significant contributor to water brownification (Ekström et al., 2016; Kritzberg and Ekström, 2012; Neal et al., 2008). Except for DOC sources, Fe-reducing processes are influenced by both the seasonal hydrology and soil properties since both specific hydroclimatic conditions and pedologic characteristics influence the occurrence of Fe-reducing conditions (Lambert et al., 2013). However, how Fe-reducing processes influence the quantity and quality of DOC and also the dissolved Fe concentration in headwater catchments still need to incorporate intense seasonal and spatial soil data for a better understanding. Additionally, since our soil sampling only represented part of DOC sources to the headwater stream, our study could be improved by soil sampling from all representing DOC sources which contribute to the DOC quantity and quality in the headwater water stream.

\subsection{Conclusions}

Altogether, our study indicated that both land-use management practices and the season played important roles in regulating the concentration and composition of DOC and Fe in both forest and pasture catchments. We found a larger average DOC and a wider seasonal change in the forest soil than the pasture soil. Conversely, an average larger $\mathrm{SUVA}_{254}$ and a wider seasonal change in pasture soil compared to the forest soil. In addition, the pasture soil at $0-10 \mathrm{~cm}$ had significantly larger average $\mathrm{Fe}_{\mathrm{ex}}$ and $\mathrm{Fe}_{\mathrm{amor}}$ concentrations than the forest soil. The pasture headwater stream had significantly larger DOC, $\mathrm{SUVA}_{254}$, and Fe $(\mathrm{p}<0.05)$ and a wider seasonal change than the forest headwater stream. This may indicate different flow pathways and DOC in-soil and in- 
stream processes occurring in the forest and pasture catchments, which influenced the quantity and quality of DOC exported to the stream water. Moreover, negative correlations between $\mathrm{Fe}_{\mathrm{ex}}$ and DOC in the forest soil and positive correlations between $\mathrm{Fe}_{\mathrm{ex}}, \mathrm{Fe}_{\mathrm{amor}}$ and $\mathrm{SUVA}_{254}$ in both forest and pasture soils were found. Our study indicated that Fe-oxyhydroxides reducing processes may be more important in interacting with aromatic DOC proportion instead of the whole DOC pool.

There are inherent difficulties in using stream DOC from regional and global to infer stream DOC in local scale watersheds. Our study indicated the significant roles of Fe oxides in regulating the quantity and quality of DOC in both surface soils and headwater streams, which was different in forest and pasture catchments. To better understand Fe-oxyhydroxides and DOC interactive processes at fine-scale local environments, the next step should be to establish the effects of hydrologic processes and DOC sources. This may help explain DOC stabilization and destabilization as well as surface water brownification. 


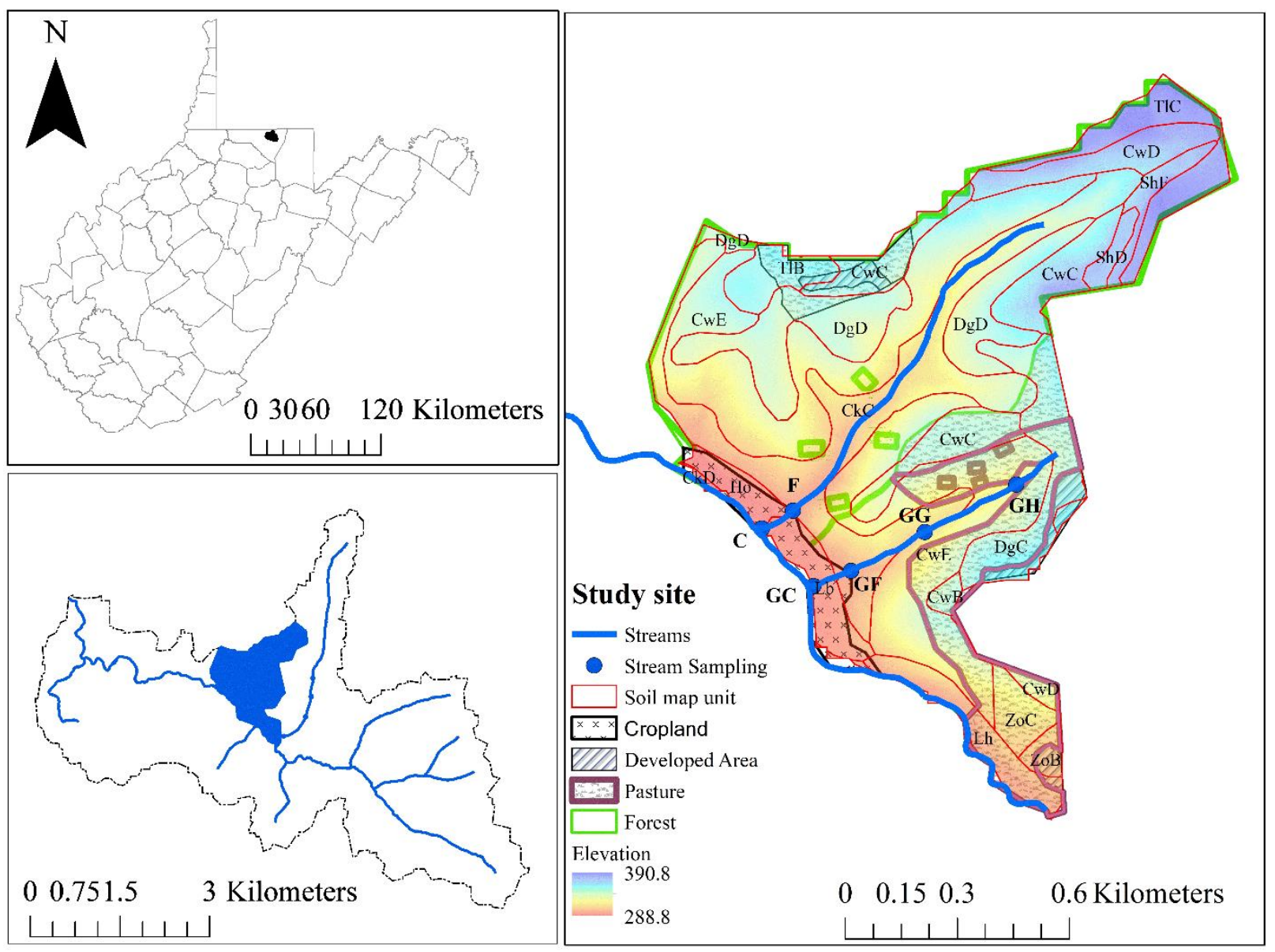

Figure 5. 1. The location of study site. The rectangles represented $10 \mathrm{~m} \times 10 \mathrm{~m}$ soil sampling plots (not to scale) while the black filled circles represented stream water sampling locations. 


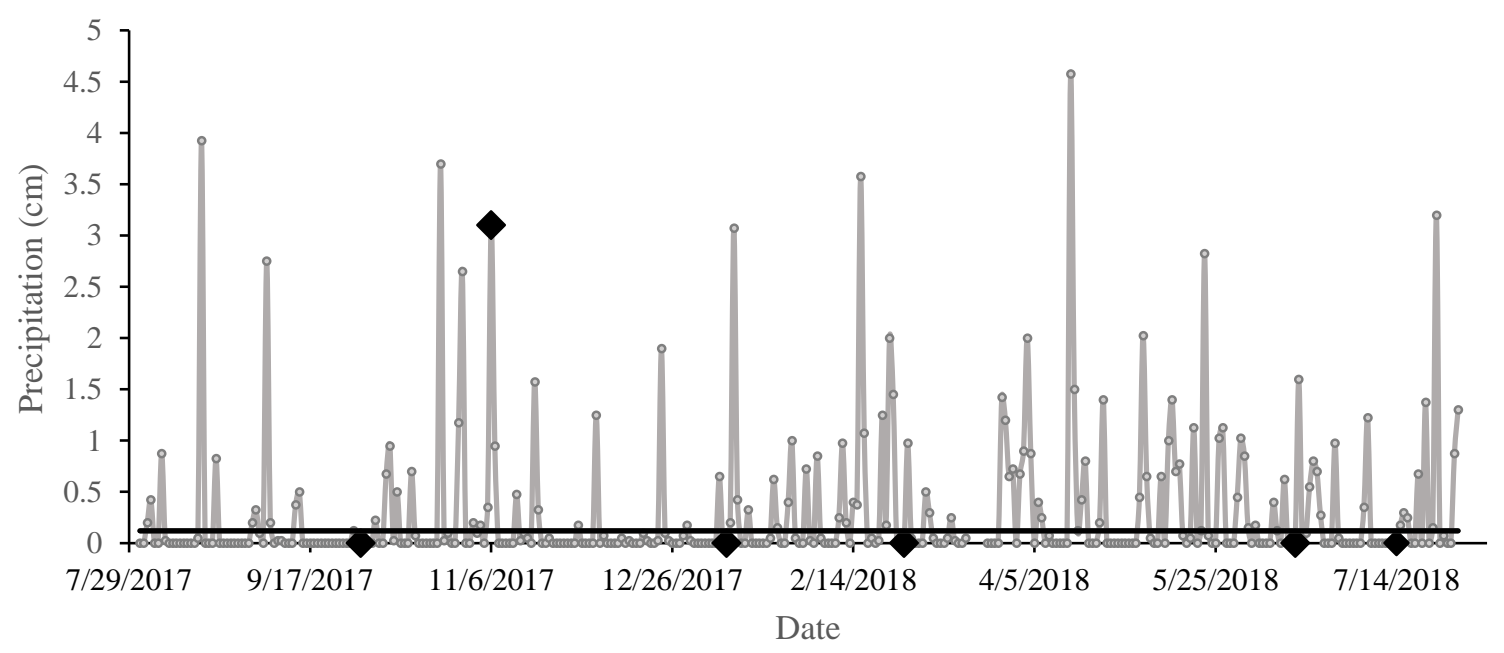

Figure 5. 2 Precipitation during the sampling period

(data extracted from: http://api.wunderground.com/history/ airport/KMGW/2017/8/1/DailyHistory.html). The diamonds indicated the six sampling dates. The black straight line indicated the average precipitation of the whole sampling period. 
(a)

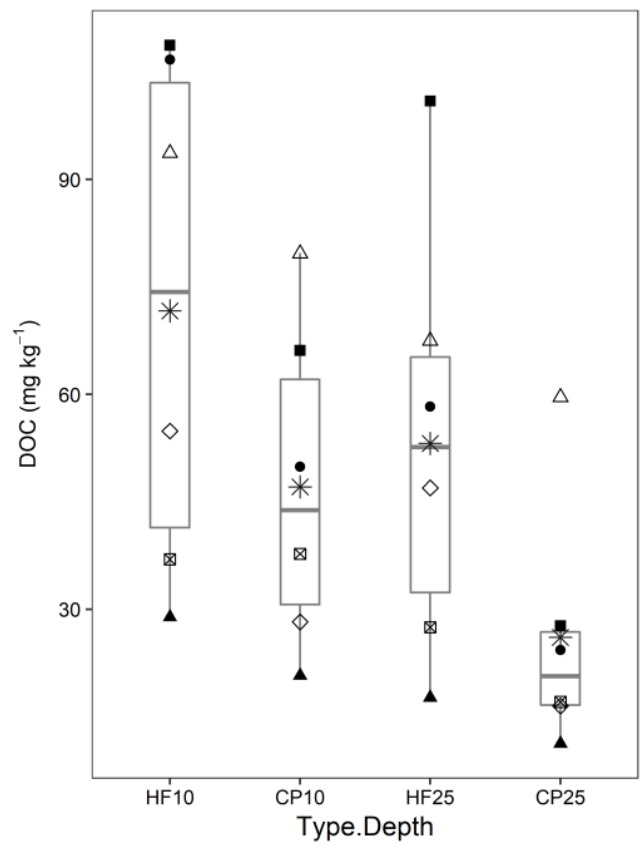

(b)

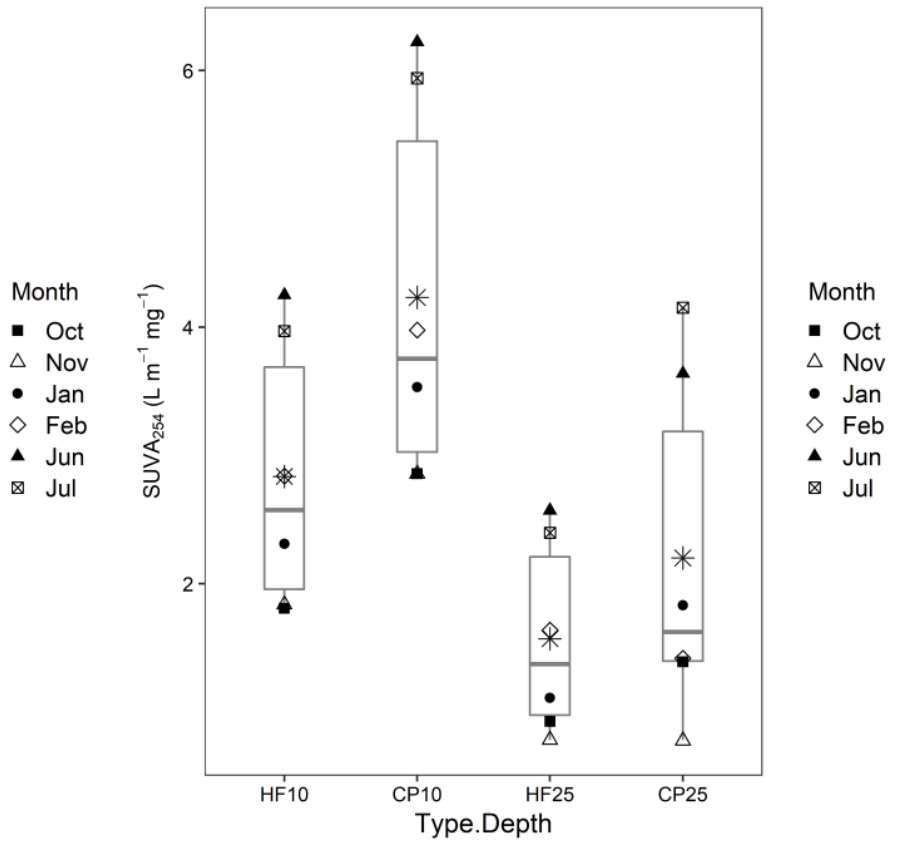

Figure 5. 3 Dissolved organic carbon (DOC) (a) concentration and the specific ultraviolet absorbance at $254 \mathrm{~nm}$ of DOC (SUVA 254 ) (b) of six months (October, November, January, February, June, and July) in hardwood forest (HF) and continuous pasture (CP) soils at 0-10 and 10-25 depths. The asterisk represented the average of the six months. 
(a)

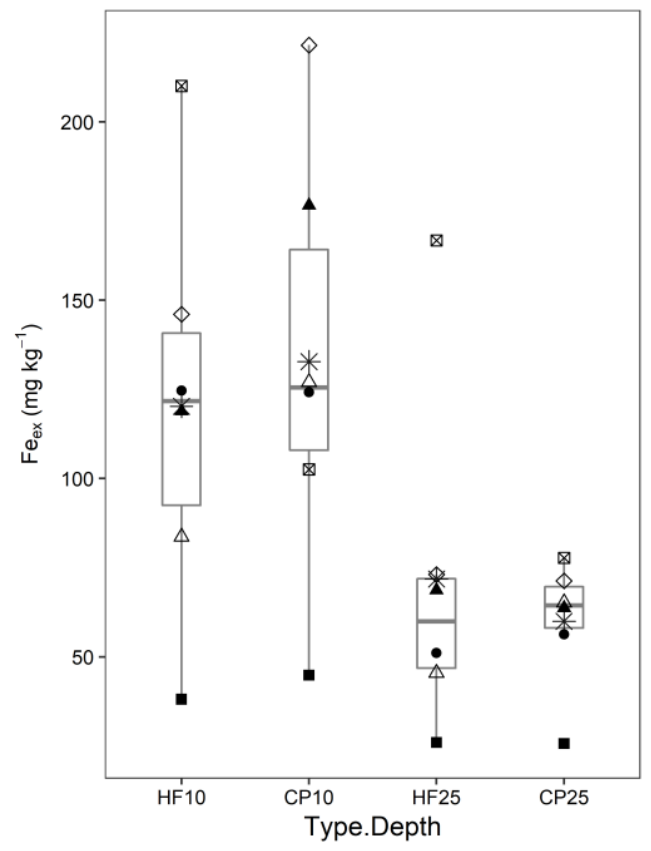

(b)

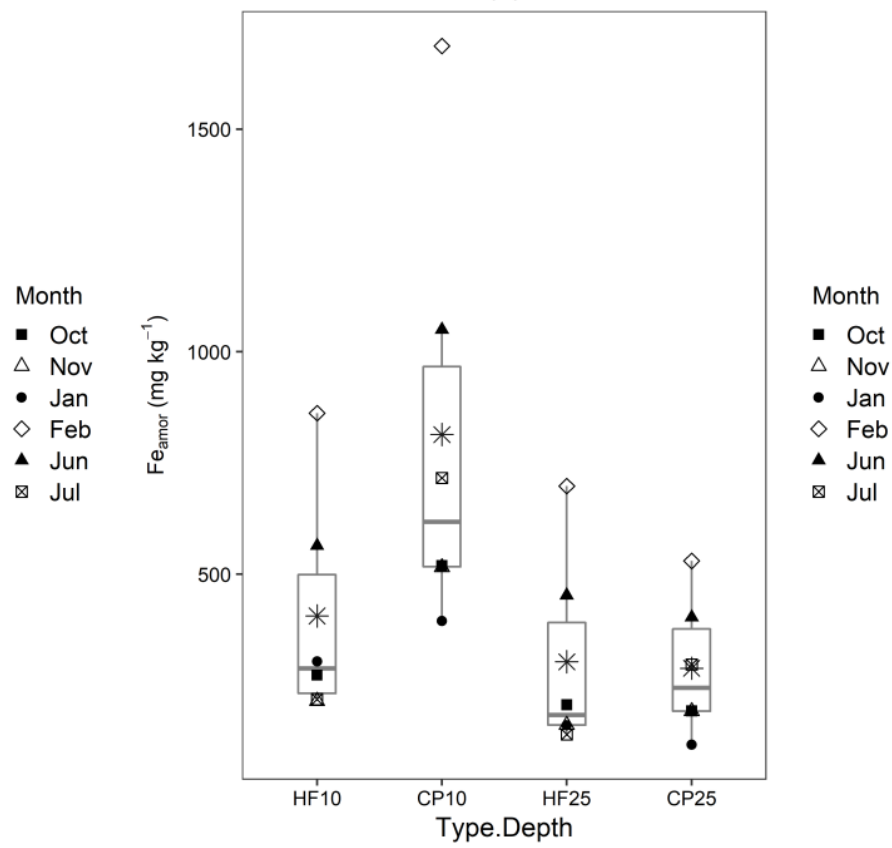

Figure 5. 4 Exchangeable $\mathrm{Fe}$ extracting using $0.5 \mathrm{M} \mathrm{HCl}$ extraction $\left(\mathrm{Fe}_{\mathrm{ex}}\right)$ and microbially reducible $\mathrm{Fe}$ extracting using $0.25 \mathrm{M} \mathrm{HCl}$ and $0.25 \mathrm{M} \mathrm{NH}_{2} \mathrm{OH} \cdot \mathrm{HCl}\left(\mathrm{Fe}_{\text {amor }}\right.$ ) of six months (October, November, January, February, June, and July) in hardwood forest (HF) and continuous pasture (CP) soils at 0-10 and 10-25 depths. The asterisk represented the average of the six months. 
(a)

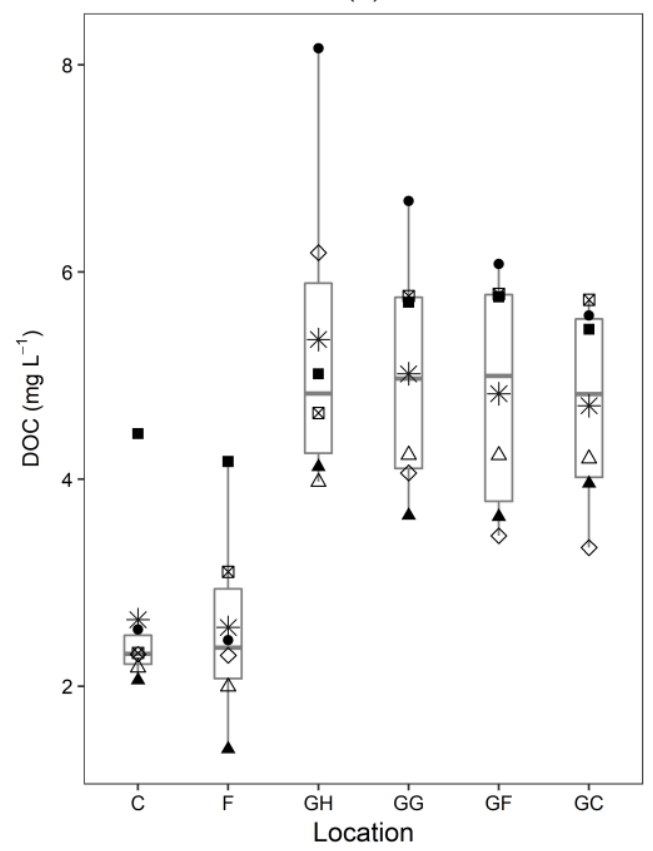

(b)

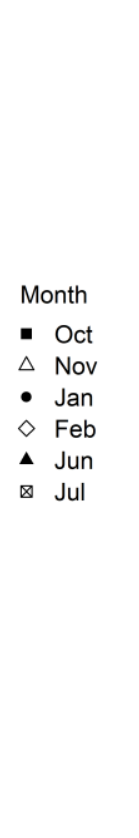

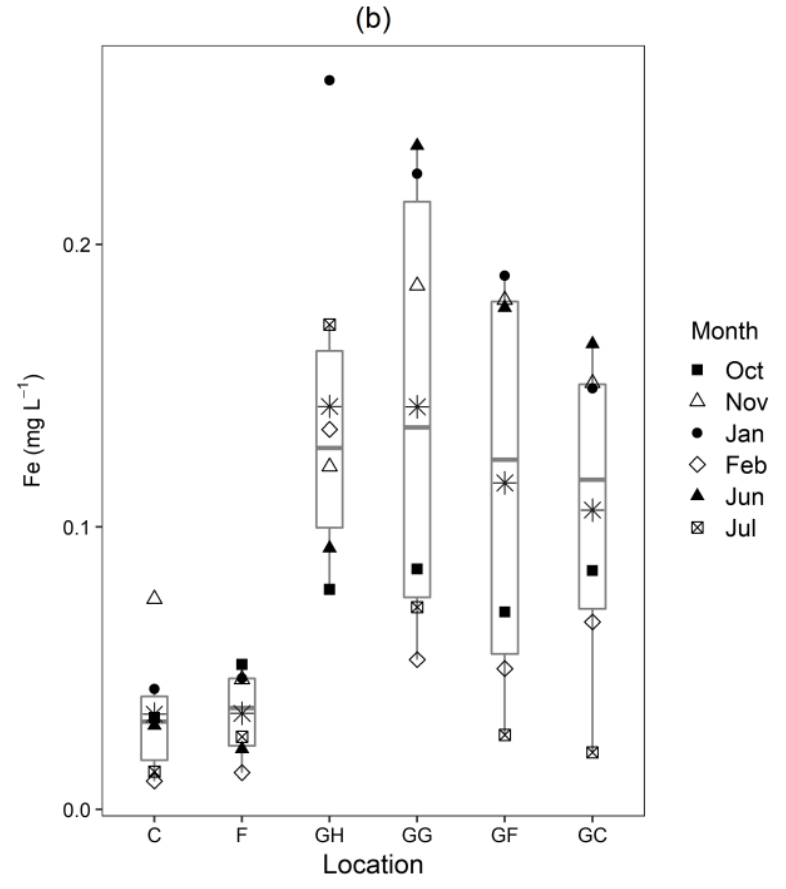

Figure 5. 5 Dissolved organic carbon (DOC) (a) and dissolved iron (Fe) (b) in the forest headwater stream at $\mathrm{F}$ and $\mathrm{C}$ location and in the pasture headwater stream at $\mathrm{GH}, \mathrm{GG}, \mathrm{GF}$, and GC location in October, November, January, February, June, and July.

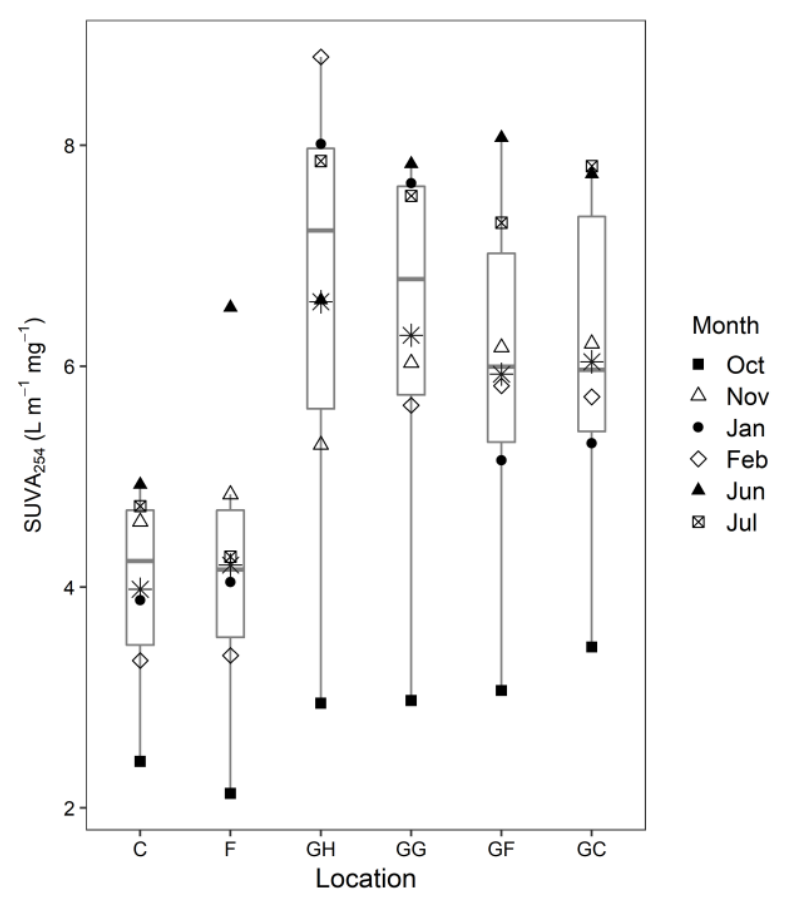

Figure 5. 6 Specific ultraviolet absorbance at $254 \mathrm{~nm}$ of DOC $\left(\mathrm{SUVA}_{254}\right)$ in the forest headwater stream at $\mathrm{F}$ and $\mathrm{C}$ location and in the pasture headwater stream at GH, GG, GF, and GC location in October, November, January, February, June, and July. 
Table 5. 1 Correlation matrix of Spearman correlation coefficients ( $r$ ) of the investigated parameters in hardwood forest (HF) and continuous pasture (CP) soils

\begin{tabular}{|c|c|c|c|c|c|c|}
\hline Type & Parameters & TOC & DOC & SUVA $_{254}$ & $\mathrm{Fe}_{\mathrm{ex}}$ & $\mathrm{Fe}_{\text {amor }}$ \\
\hline \multirow{5}{*}{$\mathrm{HF}$} & TOC & 1 & & & & \\
\hline & DOC & & 1 & & & \\
\hline & SUVA $_{254}$ & $\underline{0.65 *}$ & $-0.56^{*}$ & 1 & & \\
\hline & $\mathrm{Fe}_{\mathrm{ex}}$ & $\underline{0.53 *}$ & $-0.43 *$ & $0.73 *$ & 1 & \\
\hline & $\mathrm{Fe}_{\text {amor }}$ & $\underline{0.50 *}$ & & $\underline{0.41 *}$ & & 1 \\
\hline \multirow{5}{*}{$\mathrm{CP}$} & TOC & 1 & & & & \\
\hline & DOC & $0.49^{*}$ & 1 & & & \\
\hline & SUVA $_{254}$ & $\underline{0.71 *}$ & & 1 & & \\
\hline & $\mathrm{Fe}_{\mathrm{ex}}$ & $\underline{0.62 *}$ & & $0.64 *$ & 1 & \\
\hline & $\mathrm{Fe}_{\mathrm{amor}}$ & $\underline{0.64 *}$ & & $\underline{0.63 *}$ & $0.74 *$ & 1 \\
\hline
\end{tabular}

TOC: Total organic carbon; DOC: dissolved organic carbon; SUVA 254: the specific ultraviolet absorbance at $254 \mathrm{~nm}$ of DOC; Fe : Released Fe after $0.5 \mathrm{M} \mathrm{HCl}$ extraction; Feamor: Released Fe after $0.25 \mathrm{M} \mathrm{HCl}$ and $0.25 \mathrm{M} \mathrm{NH} 2 \mathrm{OH} \cdot \mathrm{HCl}$ extraction. * represented $\mathrm{p}<0.05$; Blank cells: no significant correlation. 
Table 5. 2 The average and standard deviation of DOC, Fe, and SUVA 254 of six months (October, November, January, February, June, and July) in the two locations (C and F) at the forest headwater stream and four locations (GH, GG, GF, and GC) at the pasture headwater stream.

\begin{tabular}{lllllll}
\hline Parameters & F & C & GH & GG & GF & GC \\
\hline DOC & $2.56 \pm 0.96$ & $2.64 \pm 0.89$ & $5.35 \pm 1.59$ & $5.02 \pm 1.2$ & $4.82 \pm 1.18$ & $4.7 \pm 1.00$ \\
Fe & $0.034 \pm 0.015$ & $0.033 \pm 0.023$ & $0.14 \pm 0.07$ & $0.14 \pm 0.08$ & $0.12 \pm 0.07$ & $0.11 \pm 0.06$ \\
SUVA $_{254}$ & $4.19 \pm 1.47$ & $3.98 \pm 0.96$ & $6.58 \pm 2.16$ & $6.28 \pm 1.86$ & $5.93 \pm 1.76$ & $6.04 \pm 1.63$ \\
\hline
\end{tabular}

DOC: dissolved organic carbon in $\mathrm{mg} \mathrm{L}^{-1}$; $\mathrm{SUVA}_{254}$ : the specific ultraviolet absorbance at $254 \mathrm{~nm}$ of DOC in $\mathrm{m}^{-1} \mathrm{~L} \mathrm{mg}^{-1}$; Fe: dissolved Fe in $\mathrm{mg} \mathrm{L}^{-1}$. 
Table 5. 3 Non-parametric Wilcoxon signed-rank test of DOC, Fe, and SUVA 254 among the six locations ( $\mathrm{F}$ and $\mathrm{C}$ at the forest headwater stream; GH, GG, GF, and GC at the pasture headwater stream (first column) and non-parametric comparisons for each pair using Wilcoxon methods (fourth to ninth columns)

\begin{tabular}{|c|c|c|c|c|c|c|c|c|}
\hline Parameters & Type & Location & $\mathrm{F}$ & $\mathrm{C}$ & $\mathrm{GH}$ & GG & GF & $\mathrm{GC}$ \\
\hline \multirow{6}{*}{ DOC* } & \multirow{2}{*}{ Forest } & $\mathrm{F}$ & & & & & & \\
\hline & & $\mathrm{C}$ & & & & & & \\
\hline & \multirow{4}{*}{ Pasture } & $\mathrm{GH}$ & & $*$ & & & & \\
\hline & & GG & $*$ & $*$ & & & & \\
\hline & & GF & $*$ & $*$ & & & & \\
\hline & & GC & $*$ & $*$ & & & & \\
\hline \multirow{6}{*}{$\mathrm{Fe}^{*}$} & \multirow{2}{*}{ Forest } & $\mathrm{F}$ & & & & & & \\
\hline & & $\mathrm{C}$ & & & & & & \\
\hline & \multirow{4}{*}{ Pasture } & $\mathrm{GH}$ & $*$ & $*$ & & & & \\
\hline & & GG & $*$ & $*$ & & & & \\
\hline & & GF & $*$ & & & & & \\
\hline & & GC & $*$ & $*$ & & & & \\
\hline \multirow{6}{*}{$\mathrm{SUVA}_{254}{ }^{*}$} & \multirow{2}{*}{ Forest } & $\mathrm{F}$ & & & & & & \\
\hline & & $\mathrm{C}$ & & & & & & \\
\hline & \multirow{4}{*}{ Pasture } & $\mathrm{GH}$ & & $*$ & & & & \\
\hline & & GG & & $*$ & & & & \\
\hline & & GF & & $*$ & & & & \\
\hline & & $\mathrm{GC}$ & & $*$ & & & & \\
\hline
\end{tabular}

* indicated significant differences at $\alpha=0.05$ level. DOC: dissolved organic carbon in $\mathrm{mg} \mathrm{L}^{-1}$; $\mathrm{SUVA}_{254}$ : the specific ultraviolet absorbance at $254 \mathrm{~nm}$ of DOC in $\mathrm{m}^{-1} \mathrm{~L} \mathrm{mg}^{-1}$; Fe: dissolved Fe in $\mathrm{mg} \mathrm{L}^{-1}$. 


\section{Chapter 6 Summary and Conclusions}

In this study, I was interested in differences in SOC and Fe oxide fractions in a hardwood, cropland, and pasture soils at 0-10 and $10-25 \mathrm{~cm}$ in a fine-scale catchment with similar climate and geography, especially the capacity of these soils to sorb aromatic dissolved organic carbon (Chapter 2, 3, and 4). Additionally, I elucidated how the temporal pattern of soil dissolved organic carbon and reducible Fe oxides influenced the temporal and spatial pattern of dissolved organic carbon and dissolved Fe in surface headwater streams (Chapter 5). The major findings of this project were:

1. Soil organic carbon fractions differed in stabilization mechanisms and thus, by extension, turnover times. Multiple indicators including TOC, POC, MOC, and CMI were used to compare cropland with manure application (CM) and continuous pasture (CP) effects to a hardwood forest (HF) at soil depths of 0-10 $\mathrm{cm}$ and $10-25 \mathrm{~cm}$ were used (Chapter 2). The cropland soil at 10-25 $\mathrm{cm}$ under manure application and tillage had a larger POC content compared to the pasture and forest soil while no differences in MOC content were observed. According to CMI, improved SOC lability only occurred in cropland soil while decreased SOC lability were observed in pasture soils at both $0-10$ and $10-25 \mathrm{~cm}$. However, the dominant contribution to SOC was from POC at cropland and pasture which implied potential rapid SOC loss under disturbance due to a fast turnover time of POC, especially the topsoil. This study indicates that management practices increasing SOC input and driving the translocation of labile SOC to subsurface soil may be helpful to increase SOC stabilization in these agricultural soils. 
2. SOC, Fe-bound OC, and the aromatic DOC sorption behaviors of cropland, pasture, and forest soil at $0-10 \mathrm{~cm}$ and $10-25 \mathrm{~cm}$ were investigated (Chapter 3 ). The role of total Fe oxides and amorphous Fe in stabilization of SOC in both agricultural and forest soils was confirmed. A significantly different proportion of Fe-bound OC and reactive $\mathrm{Fe}$ content was found in the cropland, pasture, and forest managed soils. Although the cropland soil at $0-10$ and $10-25 \mathrm{~cm}$ had the highest amounts of $\mathrm{Fe}$ oxides, lower proportion of Fe-bound $\mathrm{OC}$ was observed in cropland soil at both depths than forest and pasture soils at $10-25 \mathrm{~cm}$, which indicated a higher potential to stabilize SOC by Fe oxides in the cropland soil. Additionally, the sorption experiments had higher sorption of DOC in the cropland and pasture soils than the forest soil. The sorption behaviors of aromatic DOC between the cropland and pasture soils were similar at both 0-10 cm and 10-25 cm, which were different form that of the forest soil. Unlike other studies, this study indicated the significant role of non-aromatic DOC in stabilizing DOC in the cropland and pasture soils at $0-10 \mathrm{~cm}$. Additionally, this study indicated the native DOC concentrations significantly altered the sorption of aromatic and nonaromatic DOC. The potential for these central Appalachian region soils to sequester carbon may be influenced by the quality and quantity of DOC.

3. The spatial trends of DOC and Fe in forest (FC) and pasture (GFC) dominant headwater watersheds and their effects on water color were studied (Chapter 4). Compared to large-scale watersheds, this study observed a similar water color (a420) range with lower DOC and Fe concentration ranges in the two fine-scale streams. Likewise, the dominant contributor to water color was from DOC. However, a much lower Fe concentration is expected when Fe dominates water color in the two headwater streams. 
Additionally, this study found DOC with lower S ratio, microbially-derived and higher $\mathrm{SUVA}_{254}$ was present in the pasture headwater stream compared to the forest dominant headwater stream. The strong significant relationship between SUVA $_{254}$ and $\mathrm{Fe}$ indicated water color was strongly influenced by interactions between $\mathrm{Fe}$ and aromatic DOC in both headwater streams. In the absence of chemical speciation of DOC and Fe, this evidence for the processes behind DOC and Fe interactions, and their influence on water color was indirect. In addition, due to the modification of DOC during transport in both soil and stream processes, this study can be improved by disentangling DOC sources from the soil and/or upstream. To get a better understanding of the DOC and Fe biogeochemical cycling and their effects on water color, future studies should integrate soil and soil water studies.

4. Dissolved organic carbon (DOC) and Fe concentration in surface water, which is regulated by soil DOC sources and the transport processes from the soil to stream, are two main contributors to surface water brownification (Chapter 5). The seasonal DOC, the specific ultraviolet absorbance at $254 \mathrm{~nm}\left(\mathrm{SUVA}_{254}\right)$, exchangeable $\mathrm{Fe}\left(\mathrm{Fe}_{\mathrm{ex}}\right)$, and microbially reducible amorphous $\mathrm{Fe}$ content $\left(\mathrm{Fe}_{\text {amor }}\right)$ were investigated in the forest, cropland, and pasture soils at $0-10 \mathrm{~cm}$ and $10-25 \mathrm{~cm}$. A larger average DOC and a wider seasonal change was found in the forest soil than the pasture soils. Conversely, an average larger $\mathrm{SUVA}_{254}$ and a wider seasonal change in pasture soils compared to the forest soil. In addition, the pasture soil at $0-10 \mathrm{~cm}$ had significantly larger average $\mathrm{Fe}_{\mathrm{ex}}$ and $\mathrm{Fe}_{\text {amor }}$ concentrations than the forest soil. However, the pasture headwater stream had significantly larger DOC, $\mathrm{SUVA}_{254}$, and $\mathrm{Fe}(\mathrm{p}<0.05)$ and a wider seasonal change than the forest headwater stream. This may indicate different flow pathways 
and DOC in-soil and in-stream processes occurring in the forest and pasture catchments, which influenced the quantity and quality of DOC exported to the stream water. Moreover, negative correlations between $\mathrm{Fe}_{\mathrm{ex}}$ and $\mathrm{DOC}$ in the forest soil and positive correlations between $\mathrm{Fe}_{\mathrm{ex}}, \mathrm{Fe}_{\text {amor }}$ and $\mathrm{SUVA}_{254}$ in both forest and pasture soils were found. This study indicated that Fe-oxyhydroxides reducing processes may be more important in interacting with aromatic DOC proportion instead of the whole DOC pool.

Altogether, this study indicated that both land-use management practices and the season played important roles in regulating the concentration and composition of SOC and Fe factions and their interactions in both fine-scale forest and pasture catchments. There are inherent difficulties in using stream DOC from regional and global to infer stream DOC in local scale watersheds. Our study indicated the significant roles of Fe oxides in regulating the quantity and quality of DOC in both surface soils and headwater streams, which was different in forest and pasture catchments. To better understand Fe-oxyhydroxides and DOC interactive processes at fine-scale local environments, the next step should be to establish the effects of hydrologic processes and DOC sources. This may help explain DOC stabilization and destabilization as well as surface water brownification. 


\section{Appendix S1}

Table S1- 1 The two-ways repeated measures of variance analysis (repeated depth and month)

\begin{tabular}{llllllll}
\hline Effect & Type & Depth & Type*Depth & Month & Type*Month & Depth*Month & Type*Depth*Month \\
\hline df & 1 & 1 & 1 & 5 & 5 & 5 & 5 \\
TOC & 0.0148 & $<.0001$ & 0.369 & 0.0035 & 0.0138 & 0.0080 & 0.0345 \\
DOC & $<.0001$ & $<.0001$ & 0.0667 & $<.0001$ & $<.0001$ & $<.0001$ & 0.0003 \\
SUVA $_{254}$ & $<.0001$ & $<.0001$ & $<0.0001$ & $<.0001$ & $<.0001$ & 0.0006 & 0.0557 \\
$\mathrm{Fe}_{\text {ex }}$ & 0.8596 & $<.0001$ & $<.0001$ & $<.0001$ & $<.0001$ & $<.0001$ & $<.0001$ \\
$\mathrm{Fe}_{\text {amor }}$ & $<.0001$ & $<.0001$ & $<.0001$ & $<.0001$ & $<.0001$ & $<.0001$ & $<.0001$ \\
\hline
\end{tabular}

TOC: Total organic carbon; DOC: dissolved organic carbon; SUVA254: the specific ultraviolet absorbance at $254 \mathrm{~nm}$ of DOC; $\mathrm{Fe}_{\mathrm{ex}}$ Released Fe after $0.5 \mathrm{M} \mathrm{HCl}$ extraction; Feamor: Released Fe after $0.25 \mathrm{M} \mathrm{HCl}$ and $0.25 \mathrm{M} \mathrm{NH}_{2} \mathrm{OH} \cdot \mathrm{HCl}$ extraction; Fe-bound $\mathrm{OC}$ : proportion of organic carbon preserved by Fe oxides. 
Table S1- 2 The average and standard deviation of TOC, DOC, SUVA $254, \mathrm{Fe}_{\mathrm{ex}}$, and $\mathrm{Fe}_{\text {amor }}$ of six months (October, November, January, February, June, and July) in hardwood forest (HF) and continuous pasture (CP) soils at 0-10 and 10-25 depths.

\begin{tabular}{lcccccc}
\hline \multirow{2}{*}{ Type } & \multirow{2}{*}{ Depth } & TOC & DOC & SUVA $_{254}$ & $\mathrm{Fe}_{\text {ex }}$ & $\mathrm{Fe}_{\text {amor }}$ \\
\cline { 2 - 7 } & & $\mathrm{g} \mathrm{kg}^{-1}$ & $\mathrm{mg} \mathrm{kg}^{-1}$ & $\mathrm{~m}^{-1} \mathrm{~L} \mathrm{mg}^{-1}$ & $\mathrm{mg} \mathrm{kg}^{-1}$ & $\mathrm{mg} \mathrm{kg}^{-1}$ \\
\hline $\mathrm{F}$ & $1-10$ & $33.7 \pm 4.3 \mathrm{a}$ & $71.7 \pm 33.8 \mathrm{a}$ & $2.8 \pm 1.0 \mathrm{~b}$ & $120.3 \pm 55.4 \mathrm{~b}$ & $406.7 \pm 244.0 \mathrm{~b}$ \\
$\mathrm{~F}$ & $10-25$ & $10.6 \pm 1.4 \mathrm{~b}$ & $53.1 \pm 30.2 \mathrm{~b}$ & $1.6 \pm 0.7 \mathrm{~d}$ & $71.8 \pm 47.0 \mathrm{c}$ & $303.2 \pm 213.5 \mathrm{c}$ \\
$\mathrm{P}$ & $1-10$ & $31.7 \pm 3.0 \mathrm{a}$ & $47.1 \pm 21.5 \mathrm{c}$ & $4.2 \pm 1.4 \mathrm{a}$ & $132.8 \pm 57.6 \mathrm{a}$ & $813.9 \pm 461.2 \mathrm{a}$ \\
$\mathrm{P}$ & $10-25$ & $9.3 \pm 1.6 \mathrm{c}$ & $26.1 \pm 16.6 \mathrm{~d}$ & $2.2 \pm 1.3 \mathrm{c}$ & $60.6 \pm 17.7 \mathrm{c}$ & $288.7 \pm 152.5 \mathrm{c}$
\end{tabular}

TOC: Total organic carbon; DOC: dissolved organic carbon; SUVA 254 : the specific ultraviolet absorbance at $254 \mathrm{~nm}$ of DOC; Fe : Released Fe after $0.5 \mathrm{M} \mathrm{HCl}$ extraction; Feamor: Released Fe after $0.25 \mathrm{M} \mathrm{HCl}$ and $0.25 \mathrm{M} \mathrm{NH} 2 \mathrm{OH} \cdot \mathrm{HCl}$ extraction; Fe-bound OC-CPs: proportion of organic carbon preserved by Fe oxides. 


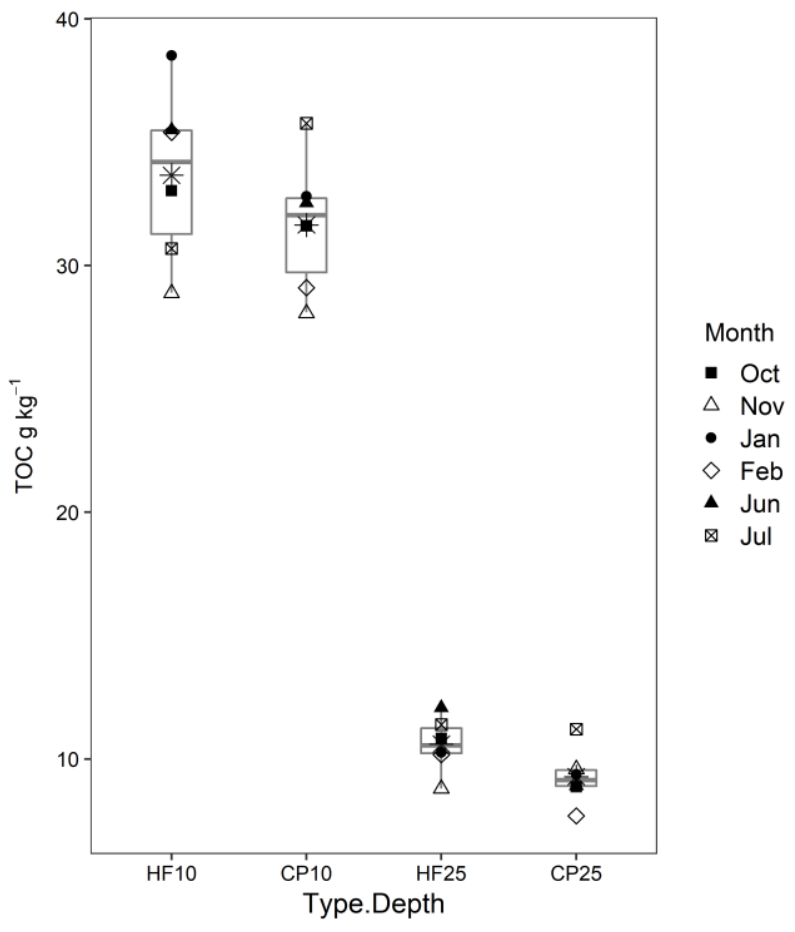

Figure S1- 1 Total organic carbon of six months (October, November, January, February, June, and July) in hardwood forest (HF) and continuous pasture (CP) soils at 0-10 and 10-25 depths. 


\section{Appendix S2 Predictors for variations of DOC and Fe concentrations in forest and pasture headwater streams}

\section{S2.1 Statistical analysis}

The data collected in Chapter 5 were used to develop statistical models to predict the significant factors explaining the variations of DOC and Fe concentrations in forest and pasture headwater streams.

To pre-screen the most significant predictors from the soil and stream water parameters to explain stream water DOC and dissolved Fe, the stepwise linear regression analysis was conducted including soil data at both depths and stream water data at each location. The variation inflation factor was used to exclude predictor variables with collinearity. Models with the highest explained variance $\left(\mathrm{R}^{2}\right)$ were selected (Table S2-2). Variables were also checked for normality of distribution using the Shapiro-Wilk W test. A transformation was applied when applicable. After the significant predictors for DOC or Fe at each location were selected from pre-screening, PROC MIXED models were conducted at both $0-10 \mathrm{~cm}$ and $10-25 \mathrm{~cm}$ separately when soil parameters were selected in the models (Version 9.4; SAS Institute Inc., Cary, NC, USA). The month was treated as a repeated effect using autoregressive or compound symmetry covariance structure when developing PROC MIXED models. The models with the smallest Adjusted Akaike Information Criterion (AAIC) were selected and reported.

\section{S2.2 Results}

For DOC concentration at $\mathrm{F}$ location, only Fe concentration of stream water at $\mathrm{F}$ location was the significant predictor $(\rho$ Fe-Fw $=-0.75)$ (Fig S2-1; Table S2-1 and 2). Additionally, SUVA254 of DOC in forest soil ( $\rho$ sUVA254-Fs $=0.74)$ and SUVA $_{254}$ of DOC of stream water at F location $(\rho$ SUVA254-Fw $=39.9$ ) had a tendency to be significant predictors (Fig S2-1; Table S2-1). DOC 
concentration at $\mathrm{F}$ location positively correlated with DOC concentration at $\mathrm{C}$ location ( $\rho$ DoC-Fw $=0.84)($ Fig S2-1; Table S2-1). For Fe concentration at F location, DOC concentration ( $\rho$ Doc-Fs $=-0.02)$ and microbially reducible $\mathrm{Fe}$ concentrations in the forest soil at $0-10 \mathrm{~cm}$ were significant predictors while they showed a tendency to be significant predictors at 10-25 cm (Fig S2-1; Table S2-1). DOC concentration in cropland soil at both $0-10 \mathrm{~cm}$ and $10-25 \mathrm{~cm}$ significantly predicted the Fe concentration at C location (Fig S2-1; Table S2-1).

For DOC concentrations at GH, GG, GF, and GC locations, the pre-selected predictors using stepwise regression didn't show significant effects at GG and GF locations when considering repeated month effects (Table S2-1). The DOC concentration at the GH location significantly explained by both soil parameters at both depths and stream parameters (Fe-GHw, DOC-Gs, SUVA254-Gs, C-Fe-Gs) (Fig S2-1; Table S2-1). However, only the proportion in Fe-bound OC at 0-10 cm C-Fe-Gs significantly predicted DOC concentration at the GH location. Conversely, the DOC concentration at the GC locations only influenced by stream parameters (DOC-GFw, SUVA254-GFw, FeGHw) (Fig S2-1; Table S2-1).

The pre-selected predictors didn't show significant effects on Fe concentration at upstream GH and GG locations when considering repeated month effects in the developed models (Table S2-1). However, the Fe concentrations at downstream GF and GC location were significantly influenced by the Fe concentrations of the upstream locations (Fig S2-1; Table S2-1). For example, Fe concentration at GG significantly influenced the Fe concentration at GF location which significantly influenced the concentration at GC location (Fig S2-1; Table S2-1). 


\section{S2.3 Discussion}

\section{S2.3.1 Significant explaining factors of DOC variation in headwater stream}

Different in-soil and in-stream processes may occur, which leads to different trends of the quantity and quality of DOC between upstream and downstream locations in the forest and pasture headwater streams (Fig S2-1; Table S2-1). Both parameters associated with the quantity and quality of DOC in soil and stream significantly explained the DOC variance at upstream locations at both the forest and pasture catchments ( $\mathrm{F}$ at forest catchment; $\mathrm{GH}$ and $\mathrm{GG}$ at pasture catchment) (Fig S2-1; Table S2-1). However, only parameters associated with the quantity and quality of DOC in the upstream location significantly explained the variance of DOC concentration at the downstream location (Fig S2-1; Table S2-1). Thus, the quantity and quality of DOC at upstream location highly influenced quantity and quality of DOC at downstream location. This indicated that both in-soil and in-stream processes co-influence the dynamics of DOC at upstream locations while dominant in-stream processes influences involved in the DOC transport and transformation at downstream locations, which is supported by Fellman et al. (2009) study.

DOC concentration in pasture soils was a significant negative predictor of DOC concentrations at GH location (Table S2-1). This is similar to Huang et al. (2013) study who found a negative relationship between headwater stream DOC and riparian DOC at mountain area with a significant altitude gradient. SUVA 254 of DOC in the forest soils was a significantly positive predictor in forest headwater stream while SUVA 254 of DOC in the pasture soil was a significant negative predictor of explaining the DOC concentration in pasture headwater stream (Fig S2-1; Table S2-1). This indicated different sources, transformation, and transport processes altering the quality of DOC in the soil to stream water occurred between the forest and pasture catchments. Different hydrological regimes may be occurred due to the variation of precipitation along the 
season (Fig 5.2) and thus various seasonal trends of DOC concentration and SUVA 254 of DOC in the stream (Hood et al., 2006; Lambert et al., 2013; Maurice et al., 2002). For example, the rewetting period is on the rising limb of hydrograph and the DOC sources are dominantly from riparian areas (Hood et al., 2006; McGlynn and McDonnell, 2003). However, due to the lack of hydrological data and limited soil sampling from both hillslope and riparian areas restricted direct evidence and conclusions in terms of the DOC sources and transport processes.

\section{S2.3.2 Iron role in regulating the quantity and quality of DOC in soils}

The SUVA 254 of DOC in forest and pasture soils were significant predictors to DOC variation at F and GH locations (Fig S2-1; Table S2-1), which was consistent with Grybos et al. (2009) who found aromatic organic molecules was the most reactive DOC pool contributing reduction of Fe-oxyhydroxides. The reduction of Fe-oxyhydroxides is accompanied by the release of DOC and the increase of SUVA 254 of the released DOC (Grybos et al., 2009). Fe-bound OC in the pasture soil at 0-10 cm significantly explained the variation of DOC at GH location (Table S2-1). In addition, microbially reducible Fe in forest soils at 0-10 cm negatively significantly explained Fe variation at the F location (Table S2-2). These evidence indicated that the reduction of Feoxyhydroxides may be more reactive only in $0-10 \mathrm{~cm}$ compared to $10-25 \mathrm{~cm}$. Along with the significantly high $\mathrm{SUVA}_{254}$ of DOC in both the pasture soil and the headwater stream, our results indicated the reduction of Fe-oxyhydroxides may also play an important role in regulating the mobility of aromatic DOC from soil to headwater stream at upstream locations in both forest and pasture catchments. Our study also indicated that Fe-oxyhydroxides reducing processes may be more important in influencing the aromatic DOC proportion instead of the whole DOC pool. Since the soil sampling only represented part of DOC sources to the headwater stream, this study 
could be improved by soil sampling from all representing DOC sources which contribute to the DOC quantity and quality in the headwater water stream. 

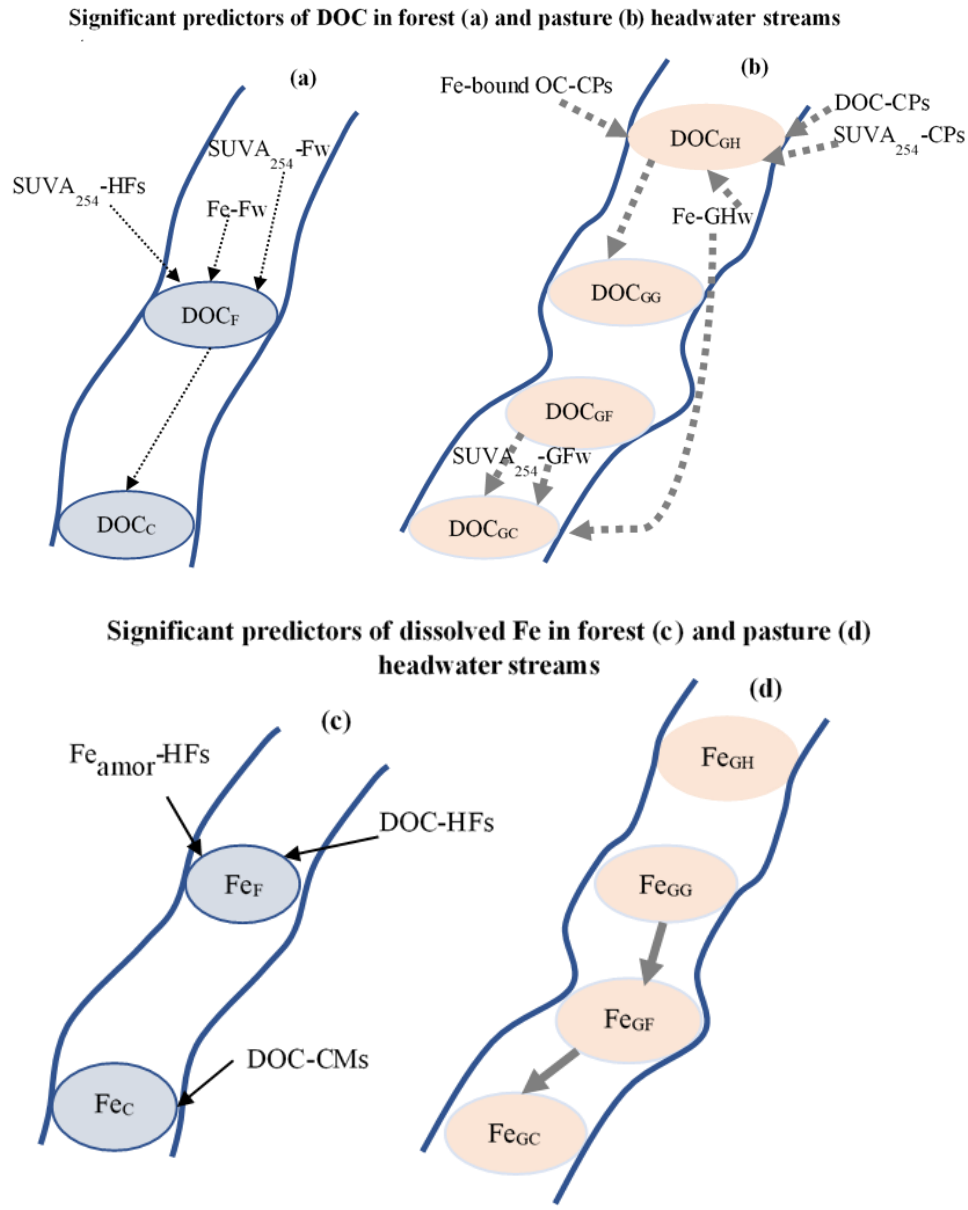

Figure S2- 1 The significant explanatory variables selected using stepwise regression models for dissolved organic carbon (DOC) (dashed lines) and dissolved iron (solid lines) in forest (non-bold lines) and pasture (bold lines) headwater streams.

The parameters with arrows inside the stream represented influences of stream parameters while the parameters with arrows outside the stream represented influences of soil parameters. The little w with instream parameters represented stream water parameters while little s outside stream with capital HF, CM, and $\mathrm{CP}$ represented soil parameters of forest, cropland, and pasture. $\mathrm{C}$ and $\mathrm{F}$ inside the forest stream were sampling location at forest headwater stream while GH, GG, GF, and GC inside the pasture stream were sampling location at pasture headwater stream. DOC: dissolved organic matter in soil solution or in stream water; SUVA 254 : The specific ultraviolet absorbance at $254 \mathrm{~nm}$ of DOC in soil solution or stream water. $\mathrm{Fe}_{\text {amor: }}$ : Released $\mathrm{Fe}$ after $0.25 \mathrm{M} \mathrm{HCl}$ and $0.25 \mathrm{M} \mathrm{NH}_{2} \mathrm{OH} \cdot \mathrm{HCl}$ extraction; Fe-bound OC: proportion of organic carbon preserved by Fe oxides. 
Table S2- 1 Significant final predictor variables for dissolved organic carbon (DOC) and dissolved iron (Fe) in both forest and pasture headwater streams at different locations (F, C, GH, GG, GF, and GC) which represented different influences from different land management practices.

\begin{tabular}{|c|c|c|c|c|c|c|c|}
\hline \multirow{2}{*}{$\begin{array}{l}\text { Stream } \\
\text { Type }\end{array}$} & \multirow{2}{*}{ Location } & \multirow{2}{*}{$\begin{array}{l}\text { Investigated } \\
\text { Parameters }\end{array}$} & \multirow{2}{*}{ Explaining Term } & \multicolumn{2}{|l|}{ Estimate } & \multicolumn{2}{|l|}{ AAIC } \\
\hline & & & & $0-10 \mathrm{~cm}$ & $10-25 \mathrm{~cm}$ & $0-10 \mathrm{~cm}$ & $10-25 \mathrm{~cm}$ \\
\hline \multirow{11}{*}{ Forest } & \multirow{7}{*}{$\mathrm{F}$} & \multirow{4}{*}{ DOC } & Intercept & 2.23 & 2.50 & \multirow{4}{*}{2.6} & \multirow{4}{*}{1.4} \\
\hline & & & $\mathrm{SUVA}_{254}-\mathrm{FW}$ & $39.9^{\#}$ & $41.88^{\#}$ & & \\
\hline & & & $\mathrm{Fe}-\mathrm{Fw}$ & $-0.75^{*}$ & $-0.7^{*}$ & & \\
\hline & & & SUVA $_{254}-\mathrm{HFs}$ & $0.74^{\#}$ & $1.01^{\#}$ & & \\
\hline & & \multirow{3}{*}{$\mathrm{Fe}$} & Intercept & 0.1 & 0.09 & \multirow{3}{*}{-9.4} & \multirow{3}{*}{-6.2} \\
\hline & & & DOC-HFs & $0.0002 *$ & $0.0003^{\#}$ & & \\
\hline & & & $\mathrm{Fe}_{\text {amor}}-\mathrm{HFs}$ & $-0.014 *$ & $-0.014^{\#}$ & & \\
\hline & \multirow{4}{*}{$\mathrm{C}$} & \multirow{2}{*}{ DOC } & Intercept & $-0.62 *$ & & \multirow{2}{*}{-7.1} & \\
\hline & & & DOC-Fw & $0.84 *$ & & & \\
\hline & & \multirow{2}{*}{$\mathrm{Fe}$} & Intercept & -0.016 & 0.0011 & \multirow{2}{*}{-11.4} & \multirow{2}{*}{-10.9} \\
\hline & & & DOC-CMs & $0.0012 *$ & $0.001 *$ & & \\
\hline \multirow{24}{*}{ Pasture } & \multirow{6}{*}{$\mathrm{GH}$} & \multirow{5}{*}{ DOC } & Intercept & $2.71 *$ & $9.6^{*}$ & \multirow{5}{*}{-4.1} & \multirow{5}{*}{1.4} \\
\hline & & & $\mathrm{Fe}-\mathrm{GHw}$ & $25.1 *$ & $22.29 *$ & & \\
\hline & & & $\mathrm{SUVA}_{254}-\mathrm{CPs}$ & $-0.76^{*}$ & $-0.94 *$ & & \\
\hline & & & Ln DOC-CPs & $-2.7^{*}$ & $-2.19^{*}$ & & \\
\hline & & & Fe-bound OC-CPs & $0.66^{*}$ & 1.08 & & \\
\hline & & $\mathrm{Fe}$ & SUVA $_{254}-\mathrm{GHw}$ & NS & & & \\
\hline & \multirow{7}{*}{ GG } & \multirow{5}{*}{ DOC } & Intercept & $4.3^{\#}$ & 1.91 & & \\
\hline & & & $\mathrm{Fe}_{\mathrm{ex}}-\mathrm{CPs}$ & -0.014 & 0.65 & & \\
\hline & & & DOC-GHw & $0.52^{\#}$ & -0.006 & 28.2 & 24.9 \\
\hline & & & SUVA $_{254}-\mathrm{GGw}$ & NS & & & \\
\hline & & & DOC-CPs & NS & & & \\
\hline & & & DOC-CPs & NS & & & \\
\hline & & $\mathrm{Fe}$ & SUVA $_{254}-\mathrm{GG}_{\mathrm{w}}$ & NS & & & \\
\hline & & & Intercept & NS & & & \\
\hline & & $\mathrm{DOC}$ & DOC-GGw & NS & & 8.3 & \\
\hline & GF & & Intercept & 0.12 & & & \\
\hline & & $\mathrm{Fe}$ & $\mathrm{Fe}-\mathrm{GGw}$ & $0.85^{*}$ & & -8.3 & \\
\hline & & & SUVA $_{254-G H w}$ & -0.0021 & & & \\
\hline & & & Intercept & $-0.4^{\#}$ & & & \\
\hline & & & DOC-GFw & $0.99 *$ & & & \\
\hline & & DOC & $\mathrm{SUVA}_{254}-\mathrm{GFW}$ & $0.12 *$ & & -3.3 & \\
\hline & GC & & $\mathrm{Fe}-\mathrm{GHw}$ & $-2.50 *$ & & & \\
\hline & & & Intercept & 0.017 & & & \\
\hline & & $\mathrm{Fe}$ & $\mathrm{Fe}-\mathrm{GFw}$ & $0.78^{*}$ & & -21.3 & \\
\hline
\end{tabular}

SUVA $_{254}-\mathrm{HFs}$ (CMs, CPs, Fw, GHw, GGw, and GFw) represented the specific ultraviolet absorbance at $254 \mathrm{~nm}$ of DOC in forest soil solution (cropland soil solution, pasture soil solution, stream water at GH location, stream water at GG location, and stream water at GF location); DOC- HFs (CMs and CPs) represented the concentration of dissolved organic carbon in forest soil (cropland soil and pasture soil); $\mathrm{Fe}-\mathrm{Fw}(\mathrm{GHw})$ represented dissolved iron concentration in stream water at $\mathrm{F}$ and $\mathrm{GH}$ location; $\mathrm{Fe}_{\mathrm{ex}}$-CPs: Released $\mathrm{Fe}$ after $0.5 \mathrm{M} \mathrm{HCl}$ extraction in pasture soil; $\mathrm{Fe}_{\text {amor }}$-HFs: Released $\mathrm{Fe}$ after $0.25 \mathrm{M} \mathrm{HCl}$ and $0.25 \mathrm{M} \mathrm{NH}_{2} \mathrm{OH} \cdot \mathrm{HCl}$ extraction in forest soil; Fe-bound OC-CPs: proportion of organic carbon preserved by Fe oxides in pasture soil; AAIC: Adjusted alkaike information criterion; NS: non-significant; $*$ represented $\mathrm{p}<0.05 ; \#$ represented $0.05<\mathrm{p}<0.1$. 
Table S2- 2 Significant final predictor variables for dissolved organic carbon (DOC) and dissolved iron (Fe) in both forest and pasture headwater streams at different locations (F, C, GH, GG, GF, and GC) using forward stepwise regression analysis

\begin{tabular}{|c|c|c|c|c|c|}
\hline $\begin{array}{l}\text { Stream } \\
\text { Type }\end{array}$ & Location & $\begin{array}{l}\text { Investigated } \\
\text { Parameters }\end{array}$ & Explaining Term & $p$ & Adjusted $\mathrm{R}^{2}$ \\
\hline \multirow{14}{*}{ Forest } & \multirow[t]{5}{*}{$\mathrm{F}$} & \multirow[t]{5}{*}{ DOC } & Intercept & \multirow{5}{*}{0.0001} & \multirow{5}{*}{0.86} \\
\hline & & & SUVA $_{254}-\mathrm{FW}$ & & \\
\hline & & & $\mathrm{Fe}-\mathrm{FW}$ & & \\
\hline & & & SUVA $_{254-H F s}$ & & \\
\hline & & & DOC-HFs & & \\
\hline & \multirow[t]{3}{*}{$\mathrm{F}$} & \multirow[t]{3}{*}{$\mathrm{Fe}$} & Intercept & \multirow{3}{*}{0.0002} & \multirow{3}{*}{0.75} \\
\hline & & & DOC-HFs & & \\
\hline & & & $\mathrm{Fe}_{\text {amor-HFs }}$ & & \\
\hline & \multirow[t]{2}{*}{$\mathrm{C}$} & \multirow[t]{2}{*}{ DOC } & Intercept & \multirow{2}{*}{$<0.0001$} & \multirow{2}{*}{0.76} \\
\hline & & & DOC-Fw & & \\
\hline & \multirow[t]{4}{*}{$\mathrm{C}$} & \multirow[t]{4}{*}{$\mathrm{Fe}$} & Intercept & \multirow{4}{*}{$<0.0001$} & \multirow{4}{*}{0.88} \\
\hline & & & $\mathrm{SUVA}_{254}-\mathrm{FW}$ & & \\
\hline & & & DOC-CMs & & \\
\hline & & & SUVA $_{254}-\mathrm{CMs}$ & & \\
\hline \multirow{20}{*}{ Pasture } & \multirow[t]{5}{*}{$\mathrm{GH}$} & \multirow[t]{5}{*}{ DOC } & Intercept & \multirow{5}{*}{$<0.0001$} & \multirow{5}{*}{0.98} \\
\hline & & & $\mathrm{Fe}-\mathrm{GHw}$ & & \\
\hline & & & $\mathrm{SUVA}_{254}-\mathrm{CPs}$ & & \\
\hline & & & DOC-CPs & & \\
\hline & & & Fe-bound OC-CPs & & \\
\hline & GH & $\mathrm{Fe}$ & Intercept & \multirow[t]{2}{*}{$<0.0001$} & 0.97 \\
\hline & \multirow{3}{*}{ GG } & \multirow{3}{*}{ DOC } & $\begin{array}{l}\text { SUVA } 254-G H W \\
\text { Intercept }\end{array}$ & & \\
\hline & & & $\mathrm{Fe}_{\mathrm{ex}}-\mathrm{CPs}$ & \multirow[t]{2}{*}{0.004} & 0.57 \\
\hline & & & DOC-GHw & & \\
\hline & GG & $\mathrm{Fe}$ & Intercept & & \\
\hline & & & $\mathrm{SUVA}_{254}-\mathrm{GGw}$ & 0.03 & 0.38 \\
\hline & & & DOC-CPs & & \\
\hline & GF & DOC & $\begin{array}{l}\text { Intercept } \\
\text { DOC-GGw }\end{array}$ & $<0.0001$ & 0.92 \\
\hline & GF & $\mathrm{Fe}$ & Intercept & & \\
\hline & & & $\mathrm{Fe}-\mathrm{GGw}$ & $<0.0001$ & 0.97 \\
\hline & & & SUVA $_{254}-\mathrm{GHw}$ & & \\
\hline & GC & DOC & Intercept & & \\
\hline & & & DOC-GFw & $<0.0001$ & 0.99 \\
\hline & & & $\begin{array}{l}\text { SUVA } 254-G F w \\
\text { Fe-GHw }\end{array}$ & .0 .0001 & (0.J) \\
\hline & GC & $\mathrm{Fe}$ & $\begin{array}{l}\text { Intercept } \\
\text { Fe-GFw }\end{array}$ & $<0.0001$ & 0.97 \\
\hline
\end{tabular}

SUVA $_{254}$ HFs (CMs, CPs, Fw, GHw, GGw, and GFw) represented the specific ultraviolet absorbance at $254 \mathrm{~nm}$ of DOC in forest soil solution (cropland soil solution, pasture soil solution, stream water at GH location, stream water at GG location, and stream water at GF location); DOC- HFs (CMs and CPs) represented the concentration of dissolved organic carbon in forest soil (cropland soil and pasture soil); Fe-Fw (GHw) represented dissolved iron concentration in stream water at $\mathrm{F}$ and $\mathrm{GH}$ location; $\mathrm{Fe}_{\mathrm{ex}}-\mathrm{CPs}$ : Released $\mathrm{Fe}$ after $0.5 \mathrm{M} \mathrm{HCl}$ extraction in pasture soil; $\mathrm{Fe}_{\text {amor-HFs: }}$ Released $\mathrm{Fe}$ after $0.25 \mathrm{M} \mathrm{HCl}$ and $0.25 \mathrm{M} \mathrm{NH}_{2} \mathrm{OH} \cdot \mathrm{HCl}$ extraction in forest soil; Fe-bound OC-CPs: proportion of organic carbon preserved by Fe oxides in pasture soil; 


\section{References}

Abramoff, R., Xu, X., Hartman, M., O’Brien, S., Feng, W., Davidson, E., Finzi, A., Moorhead, D., Schimel, J., Torn, M., 2018. The Millennial model: In search of measurable pools and transformations for modeling soil carbon in the new century. Biogeochemistry 137(1-2), 5171.

Adhikari, D., Yang, Y., 2015. Selective stabilization of aliphatic organic carbon by iron oxide. Scientific Reports 5, 11214.

Aitkenhead, J.A., Hope, D., Billett, M.F., 1999. The realtionship between dissolved organic carbon in stream water and soil organic carbon pools at different spatial scales. Hydrological Processes 13(8), 1289-1302.

Aller, R., Blair, N., Xia, Q., Rude, P., 1996. Remineralization rates, recycling, and storage of carbon in Amazon shelf sediments. Continental Shelf Research 16(5-6), 753-786.

Alva, A., Sumner, M., Miller, W., 1991. Relationship between ionic strength and electrical conductivity for soil solutions. Soil Science 152(4), 239-242.

Amon, R.M., Benner, R., 1996. Bacterial utilization of different size classes of dissolved organic matter. Limnology and Oceanography 41(1), 41-51.

Anesio, A.M., Granéli, W., Aiken, G.R., Kieber, D.J., Mopper, K., 2005. Effect of humic substance photodegradation on bacterial growth and respiration in lake water. Applied and Environmental Microbiology 71(10), 6267-6275.

Aoyama, M., Angers, D., N'dayegamiye, A., Bissonnette, N., 1999. Protected organic matter in water-stable aggregates as affected by mineral fertilizer and manure applications. Canadian Journal of Soil Science 79(3), 419-425. 
Arai, H., Tokuchi, N., 2010. Soil organic carbon accumulation following afforestation in a Japanese coniferous plantation based on particle-size fractionation and stable isotope analysis. Geoderma 159(3-4), 425-430.

Armstrong, A., Holden, J., Luxton, K., Quinton, J., 2012. Multi-scale relationship between peatland vegetation type and dissolved organic carbon concentration. Ecological Engineering 47, 182-188.

Armstrong, F., 1963. Determination of nitrates in water by ultraviolet spectrophotometry. Analytical Chemistry 35, 1292.

Autio, I., Soinne, H., Helin, J., Asmala, E., Hoikkala, L., 2016. Effect of catchment land use and soil type on the concentration, quality, and bacterial degradation of riverine dissolved organic matter. Ambio 45(3), 331-349.

Baldock, J., Oades, J., Waters, A., Peng, X., Vassallo, A., Wilson, M., 1992. Aspects of the chemical structure of soil organic materials as revealed by solid-state $13 \mathrm{C}$ NMR spectroscopy. Biogeochemistry 16(1), 1-42.

Baldock, J.A., 2007. Composition and cycling of organic carbon in soil, In Nutrient cycling in terrestrial ecosystems (pp. 1-35). Springer, Berlin, Heidelberg.

Battin, T.J., Kaplan, L.A., Findlay, S., Hopkinson, C.S., Marti, E., Packman, A.I., Newbold, J.D., Sabater, F., 2008. Biophysical controls on organic carbon fluxes in fluvial networks. Nature Geoscience 1(2), 95.

Benjamini, Y., Hochberg, Y., 1995. Controlling the false discovery rate: A practical and powerful approach to multiple testing. Journal of the Royal Statistical Society. Series B (Methodological), 289-300. 
Berhongaray, G., Alvarez, R., De Paepe, J., Caride, C., Cantet, R., 2013. Land use effects on soil carbon in the Argentine Pampas. Geoderma 192, 97-110.

Bhattacharyya, R., Prakash, V., Kundu, S., Srivastva, A., Gupta, H., Mitra, S., 2010. Long term effects of fertilization on carbon and nitrogen sequestration and aggregate associated carbon and nitrogen in the Indian sub-Himalayas. Nutrient Cycling in Agroecosystems 86(1), 1-16.

Bigelow, D.P., Borchers, A., 2017. Major Uses of Land in the United States, 2012 EIB-178. U.S. Department of Agriculture, Economic Research Service.

Bird, M., Santrùcková, H., Lloyd, J., Veenendaal, E., 2001. Global soil organic carbon pool, Global biogeochemical cycles in the climate system. Elsevier, pp. 185-199.

Blair, G.J., Lefroy, R.D., Lisle, L., 1995. Soil carbon fractions based on their degree of oxidation, and the development of a carbon management index for agricultural systems. Australian Journal of Agricultural Research 46(7), 1459-1466.

Borken, W., Ahrens, B., Schulz, C., Zimmermann, L., 2011. Site-to-site variability and temporal trends of DOC concentrations and fluxes in temperate forest soils. Global Change Biology 17(7), 2428-2443.

Boyer, J., Groffman, P., 1996. Bioavailability of water extractable organic carbon fractions in forest and agricultural soil profiles. Soil Biology and Biochemistry 28(6), 783-790.

Briske, D.D., Derner, J., Brown, J., Fuhlendorf, S.D., Teague, W., Havstad, K., Gillen, R.L., Ash, A.J., Willms, W., 2008. Rotational grazing on rangelands: Reconciliation of perception and experimental evidence. Rangeland Ecology \& Management 61(1), 3-17.

Brooks, P., McKnight, D.M., Bencala, K.E., 1999. The relationship between soil heterotrophic activity, soil dissolved organic carbon (DOC) leachate, and catchment-scale DOC export in headwater catchments. Water Resources Research 35(6), 1895-1902. 
Bryce, S.A., Larsen, D.P., Hughes, R.M., Kaufmann, P.R., 1999. Assessing Relative Risks To Aquatic Ecosystems: A Mid-Applachian Case Study. Journal of the American Water Resources Association 35(1), 23-36.

Budge, K., Leifeld, J., Hiltbrunner, E., Fuhrer, J., 2011. Alpine grassland soils contain large proportion of labile carbon but indicate long turnover times. Biogeosciences 8(7), 1911-1923.

Burdige, Lerman, 2006. Geochemistry of marine sediments. Princeton University Press, Princeton, New Jersy.

Burdige, D.J., 1993. The biogeochemistry of manganese and iron reduction in marine sediments. Earth-Science Reviews 35(3), 249-284.

Butman, D.E., Wilson, H.F., Barnes, R.T., Xenopoulos, M.A., Raymond, P.A., 2015. Increased mobilization of aged carbon to rivers by human disturbance. Nature Geoscience 8(2), 112-116.

Buyanovsky, G., Aslam, M., Wagner, G., 1994. Carbon turnover in soil physical fractions. Soil Science Society of America Journal 58(4), 1167-1173.

Cambardella, C., Elliott, E., 1992. Particulate soil organic-matter changes across a grassland cultivation sequence. Soil Science Society of America Journal 56(3), 777-783.

Camino-Serrano, M., Gielen, B., Luyssaert, S., Ciais, P., Vicca, S., Guenet, B., Vos, B.D., Cools, N., Ahrens, B., Altaf Arain, M., 2014. Linking variability in soil solution dissolved organic carbon to climate, soil type, and vegetation type. Global Biogeochemical Cycles 28(5), 497509.

Chabbi, A., Kögel-Knabner, I., Rumpel, C., 2009. Stabilised carbon in subsoil horizons is located in spatially distinct parts of the soil profile. Soil Biology and Biochemistry 41(2), 256-261.

Chantigny, M.H., 2003. Dissolved and water-extractable organic matter in soils: A review on the influence of land use and management practices. Geoderma 113(3), 357-380. 
Chaudhuri, S., Pena-Yewtukhiw, E.M., McDonald, L.M., Skousen, J., Sperow, M., 2011. Land use effects on sample size requirements for soil organic carbon stock estimations. Soil Science 176(2), 110-114.

Chaudhuri, S., Pena-Yewtukhiw, E.M., McDonald, L.M., Skousen, J., Sperow, M., 2012. Early C sequestration rate changes for reclaimed minesoils. Soil Science 177(7), 443-450.

Chevallier, T., Woignier, T., Toucet, J., Blanchart, E., 2010. Organic carbon stabilization in the fractal pore structure of Andosols. Geoderma 159(1-2), 182-188.

Chorover, J., Amistadi, M.K., 2001. Reaction of forest floor organic matter at goethite, birnessite and smectite surfaces. Geochimica et Cosmochimica Acta 65(1), 95-109.

Chow, A.T., Tanji, K.K., Gao, S., Dahlgren, R.A., 2006. Temperature, water content and wet-dry cycle effects on DOC production and carbon mineralization in agricultural peat soils. Soil Biology and Biochemistry 38(3), 477-488.

Coble, P.G., Lead, J., Baker, A., Reynolds, D.M., Spencer, R.G.M., 2014. Aquatic organic matter fluorescence. Cambridge University Press, New York.

Cole, J.J., Prairie, Y.T., Caraco, N.F., McDowell, W.H., Tranvik, L.J., Striegl, R.G., Duarte, C.M., Kortelainen, P., Downing, J.A., Middelburg, J.J., 2007. Plumbing the global carbon cycle: Integrating inland waters into the terrestrial carbon budget. Ecosystems 10(1), 172-185.

Cory, R.M., McKnight, D.M., 2005. Fluorescence spectroscopy reveals ubiquitous presence of oxidized and reduced quinones in dissolved organic matter. Environmental Science \& Technology 39(21), 8142-8149.

Cotrufo, M.F., Ranalli, M.G., Haddix, M.L., Six, J., Lugato, E., 2019. Soil carbon storage informed by particulate and mineral-associated organic matter. Nature Geoscience 12(12), 989-994. 
Coward, E., Ohno, T., Sparks, D.L., 2018. Direct evidence for temporal molecular fractionation of dissolved organic matter at the iron oxyhydroxide interface. Environmental Science \& Technology 53(2), 642-650.

Coward, E.K., Thompson, A.T., Plante, A.F., 2017. Iron-mediated mineralogical control of organic matter accumulation in tropical soils. Geoderma 306, 206-216.

Creed, I., Webster, K., Braun, G., Bourbonniere, R., Beall, F., 2013. Topographically regulated traps of dissolved organic carbon create hotspots of soil carbon dioxide efflux in forests. Biogeochemistry 112, 149-164.

Curmi, P., Durand, P., Gascuel-Odoux, C., Mérot, P., Walter, C., Taha, A., 1998. Hydromorphic soils, hydrology and water quality: Spatial distribution and functional modelling at different scales, Soil and Water Quality at Different Scales. Springer, pp. 127-142.

Dawson, J., Soulsby, C., Tetzlaff, D., Hrachowitz, M., Dunn, S., Malcolm, I., 2008. Influence of hydrology and seasonality on DOC exports from three contrasting upland catchments. Biogeochemistry 90(1), 93-113.

Dawson, J.J.C., Bakewell, C., Billett, M., 2001. Is in-stream processing an important control on spatial changes in carbon fluxes in headwater catchments? Science of the Total Environment 265(1-3), 153-167.

De Paula, J.D.A., Luizão, F.J., Piedade, M.T.F., 2016. The size distribution of organic carbon in headwater streams in the Amazon basin. Environmental Science and Pollution Research 23(12), 11461-11470.

De Troyer, I., Merckx, R., Amery, F., Smolders, E., 2014. Factors controlling the dissolved organic matter concentration in pore waters of agricultural soils. Vadose Zone Journal 13(7). 
Delprat, L., Chassin, P., Lineres, M., Jambert, C., 1997. Characterization of dissolved organic carbon in cleared forest soils converted to maize cultivation. Developments in Crop Science $25,257-266$.

Diekow, J., Mielniczuk, J., Knicker, H., Bayer, C., Dick, D.P., Kögel-Knabner, I., 2005. Soil C and $\mathrm{N}$ stocks as affected by cropping systems and nitrogen fertilisation in a southern Brazil Acrisol managed under no-tillage for 17 years. Soil and Tillage Research 81(1), 87-95.

Dillon, P.J., Molot, L.A., 1997. Effect of landscape form on export of dissolved organic carbon, iron, and phosphorus from forested stream catchments. Water Resources Research 33(11), 2591-2600.

Du, Y., Ramirez, C.E., Jaffé, R., 2018. Fractionation of dissolved organic matter by coprecipitation with iron: Effects of composition. Environmental Processes 5(1), 5-21.

Du, Z., Ren, T., Hu, C., Zhang, Q., 2015. Transition from intensive tillage to no-till enhances carbon sequestration in microaggregates of surface soil in the North China Plain. Soil and Tillage Research 146, 26-31.

Duval, M.E., Galantini, J.A., Iglesias, J.O., Canelo, S., Martinez, J.M., Wall, L., 2013. Analysis of organic fractions as indicators of soil quality under natural and cultivated systems. Soil and Tillage Research 131, 11-19.

Duval, M.E., Galantini, J.A., Martínez, J.M., López, F.M., Wall, L.G., 2016. Sensitivity of different soil quality indicators to assess sustainable land management: Influence of site features and seasonality. Soil and Tillage Research 159, 9-22.

Ekström, S.M., Kritzberg, E.S., Kleja, D.B., Larsson, N., Nilsson, P.A., Graneli, W., Bergkvist, B., 2011. Effect of acid deposition on quantity and quality of dissolved organic matter in soilwater. Environmental Science \& Technology 45(11), 4733-4739. 
Ekström, S.M., Regnell, O., Reader, H.E., Nilsson, P.A., Löfgren, S., Kritzberg, E.S., 2016. Increasing concentrations of iron in surface waters as a consequence of reducing conditions in the catchment area. Journal of Geophysical Research: Biogeosciences 121(2), 479-493.

Erlandsson, M., Buffam, I., Fölster, J., Laudon, H., Temnerud, J., Weyhenmeyer, G.A., Bishop, K., 2008. Thirty-five years of synchrony in the organic matter concentrations of Swedish rivers explained by variation in flow and sulphate. Global Change Biology 14(5), 1191-1198.

Eusterhues, K., Rumpel, C., Kleber, M., Kögel-Knabner, I., 2003. Stabilisation of soil organic matter by interactions with minerals as revealed by mineral dissolution and oxidative degradation. Organic Geochemistry 34(12), 1591-1600.

Evans, C., Monteith, D., Cooper, D., 2005. Long-term increases in surface water dissolved organic carbon: observations, possible causes and environmental impacts. Environmental pollution 137(1), 55-71.

Fellman, J., Hood, E., D’Amore, D.V., Boone, R., 2008. Fluorescence characteristics and biodegradability of DOM in forest and wetland soils from coastal temperate watersheds in southeast Alaska. Biogeochemistry 88(2), 169-184.

Fellman, J.B., Hood, E., D'amore, D.V., Edwards, R.T., White, D., 2009. Seasonal changes in the chemical quality and biodegradability of dissolved organic matter exported from soils to streams in coastal temperate rainforest watersheds. Biogeochemistry 95(2-3), 277-293.

Fithian, R.W., 1979. A history and evaluation of the plantations at the West Virginia University farm woods [dissertation], Morgantown: West Virginia University. Accessed from: ProQuest Dissertations \& Theses Global.

Fontaine, S., Barot, S., Barre, P., Bdioui, N., Mary, B., Rumpel, C., 2007. Stability of organic carbon in deep soil layers controlled by fresh carbon supply. Nature 450(7167), 277-280. 
Franzluebbers, A., Arshad, M., 1997. Particulate organic carbon content and potential mineralization as affected by tillage and texture. Soil Science Society of America Journal 61(5), $1382-1386$.

Franzluebbers, A., Haney, R., Hons, F., Zuberer, D., 1996. Active fractions of organic matter in soils with different texture. Soil Biology and Biochemistry 28(10-11), 1367-1372.

García-Orenes, F., Cerdà, A., Mataix-Solera, J., Guerrero, C., Bodí, M., Arcenegui, V., Zornoza, R., Sempere, J., 2009. Effects of agricultural management on surface soil properties and soilwater losses in eastern Spain. Soil and Tillage Research 106(1), 117-123.

Ghosh, B., Meena, V., Alam, N., Dogra, P., Bhattacharyya, R., Sharma, N., Mishra, P., 2016. Impact of conservation practices on soil aggregation and the carbon management index after seven years of maize-wheat cropping system in the Indian Himalayas. Agriculture, Ecosystems \& Environment 216, 247-257.

Glendell, M., Brazier, R., 2014. Accelerated export of sediment and carbon from a landscape under intensive agriculture. Science of the Total Environment 476, 643-656.

Gomiero, T., Pimentel, D., Paoletti, M.G., 2011. Environmental impact of different agricultural management practices: Conventional vs. organic agriculture. Critical Reviews in Plant Sciences 30(1-2), 95-124.

Gong, W., Yan, X., Wang, J., Hu, T., Gong, Y., 2009. Long-term manuring and fertilization effects on soil organic carbon pools under a wheat-maize cropping system in North China Plain. Plant and Soil 314(1-2), 67-76.

Gosling, P., Parsons, N., Bending, G.D., 2013. What are the primary factors controlling the light fraction and particulate soil organic matter content of agricultural soils? Biology and fertility of soils 49(8), 1001-1014. 
Graeber, D., Boëchat, I.G., Encina-Montoya, F., Esse, C., Gelbrecht, J., Goyenola, G., Gücker, B., Heinz, M., Kronvang, B., Meerhoff, M., 2015. Global effects of agriculture on fluvial dissolved organic matter. Scientific Reports 5, 16328.

Graeber, D., Gelbrecht, J., Pusch, M.T., Anlanger, C., von Schiller, D., 2012. Agriculture has changed the amount and composition of dissolved organic matter in Central European headwater streams. Science of the Total Environment 438, 435-446.

Greenwood, K., McKenzie, B., 2001. Grazing effects on soil physical properties and the consequences for pastures: A review. Australian Journal of Experimental Agriculture 41(8), $1231-1250$.

Grosse, G., Harden, J., Turetsky, M., McGuire, A.D., Camill, P., Tarnocai, C., Frolking, S., Schuur, E.A., Jorgenson, T., Marchenko, S., 2011. Vulnerability of high-latitude soil organic carbon in North America to disturbance. Journal of Geophysical Research: Biogeosciences 116(G4).

Grybos, M., Davranche, M., Gruau, G., Petitjean, P., Pédrot, M., 2009. Increasing pH drives organic matter solubilization from wetland soils under reducing conditions. Geoderma 154(12), 13-19.

Guggenberger, G., Kaiser, K., 2003. Dissolved organic matter in soil: Challenging the paradigm of sorptive preservation. Geoderma 113(3-4), 293-310.

Gui, H., Li, F., Wei, Y., Yamada, T., Desmiarti, R., 2016. Characteristics of NOM Released to Water from Different Forest and Agricultural Soils. Journal of Engineering and Technological Sciences 48(5), 631-644.

Gulis, V., Suberkropp, K., 2003. Leaf litter decomposition and microbial activity in nutrientenriched and unaltered reaches of a headwater stream. Freshwater biology 48(1), 123-134. 
Haaland, S., Hongve, D., Laudon, H., Riise, G., Vogt, R., 2010. Quantifying the drivers of the increasing colored organic matter in boreal surface waters. Environmental science \& technology 44(8), 2975-2980.

Hagedorn, F., Kaiser, K., Feyen, H., Schleppi, P., 2000. Effects of redox conditions and flow processes on the mobility of dissolved organic carbon and nitrogen in a forest soil. Journal of Environmental Quality 29(1), 288-297.

Hamer, U., Marschner, B., 2005. Priming effects in soils after combined and repeated substrate additions. Geoderma 128(1-2), 38-51.

Han, L., Sun, K., Jin, J., Xing, B., 2016. Some concepts of soil organic carbon characteristics and mineral interaction from a review of literature. Soil Biology and Biochemistry 94, 107-121.

Han, X., Zhao, F., Tong, X., Deng, J., Yang, G., Chen, L., Kang, D., 2017. Understanding soil carbon sequestration following the afforestation of former arable land by physical fractionation. Catena 150, 317-327.

Hassink, J., 1994. Effects of soil texture and grassland management on soil organic C and $\mathrm{N}$ and rates of $\mathrm{C}$ and $\mathrm{N}$ mineralization. Soil Biology and Biochemistry 26(9), 1221-1231.

Hassink, J., 1997. The capacity of soils to preserve organic C and $\mathrm{N}$ by their association with clay and silt particles. Plant and Soil 191(1), 77-87.

He, Y., Song, N., Jiang, H.-L., 2018. Effects of dissolved organic matter leaching from macrophyte litter on black water events in shallow lakes. Environmental Science and Pollution Research 25(10), 9928-9939.

Helms, J.R., Stubbins, A., Ritchie, J.D., Minor, E.C., Kieber, D.J., Mopper, K., 2008. Absorption spectral slopes and slope ratios as indicators of molecular weight, source, and photobleaching of chromophoric dissolved organic matter. Limnology and Oceanography 53(3), 955-969. 
Hobley, E., Baldock, J., Hua, Q., Wilson, B., 2017. Land-use contrasts reveal instability of subsoil organic carbon. Global Change Biology 23(2), 955-965.

Hood, E., Gooseff, M.N., Johnson, S.L., 2006. Changes in the character of stream water dissolved organic carbon during flushing in three small watersheds, Oregon. Journal of Geophysical Research 111(G01007).

Houba, V., Temminghoff, E., Gaikhorst, G., Van Vark, W., 2000. Soil analysis procedures using $0.01 \mathrm{M}$ calcium chloride as extraction reagent. Communications in Soil Science and Plant Analysis 31(9-10), 1299-1396.

Houlbrooke, D., Paton, R., Littlejohn, R., Morton, J., 2011. Land-use intensification in New Zealand: effects on soil properties and pasture production. The Journal of Agricultural Science 149(3), 337-349.

Howarth, R.W., Fruci, J.R., Sherman, D., 1991. Inputs of sediment and carbon to an estuarine ecosystem: Influence of land use. Ecological Applications 1(1), 27-39.

Huang, C., Liu, S., Li, R., Sun, F., Zhou, Y., Yu, G., 2016a. Spectroscopic evidence of the improvement of reactive iron mineral content in red soil by long-term application of swine manure. PloS one 11(1).

Huang, W., McDowell, W.H., Zou, X., Ruan, H., Wang, J., Li, L., 2013. Dissolved organic carbon in headwater streams and riparian soil organic carbon along an altitudinal gradient in the Wuyi Mountains, China. PloS One 8(11), e78973.

Huang, W., McDowell, W.H., Zou, X., Ruan, H., Wang, J., Ma, Z., 2015. Qualitative differences in headwater stream dissolved organic matter and riparian water-extractable soil organic matter under four different vegetation types along an altitudinal gradient in the Wuyi Mountains of China. Applied Geochemistry 52, 67-75. 
Huang, X., Jiang, H., Li, Y., Ma, Y., Tang, H., Ran, W., Shen, Q., 2016b. The role of poorly crystalline iron oxides in the stability of soil aggregate-associated organic carbon in a ricewheat cropping system. Geoderma 279, 1-10.

Huguet, A., Vacher, L., Relexans, S., Saubusse, S., Froidefond, J.-M., Parlanti, E., 2009. Properties of fluorescent dissolved organic matter in the Gironde Estuary. Organic Geochemistry 40(6), 706-719.

Hur, J., Nguyen, H.V., Lee, B., 2014. Influence of upstream land use on dissolved organic matter and trihalomethane formation potential in watersheds for two different seasons. Environmental Science and Pollution Research 21(12), 7489-7500.

Islam, K., Weil, R.R., 2000. Land use effects on soil quality in a tropical forest ecosystem of Bangladesh. Agriculture, Ecosystems \& Environment 79(1), 9-16.

Jamala, Y., 2013. Soil organic carbon fractions as affected by land use in the Sourthern Guinea Savanna ecosystem of Adamawa State, Nigeria. Journal of Soil Science and Environmental Management 4(6), 116-122.

Janeau, J., Gillard, L., Grellier, S., Jouquet, P., Le, T.P.Q., Luu, T.N.M., Ngo, Q.A., Orange, D., Pham, D.R., Tran, D.T., 2014. Soil erosion, dissolved organic carbon and nutrient losses under different land use systems in a small catchment in northern Vietnam. Agricultural Water Management 146, 314-323.

Jardine, P.M., Mayes, M., Mulholland, P.J., Hanson, P.J., Tarver, J., Luxmoore, R.J., McCarthy, J.F., Wilson, G., 2006. Vadose zone flow and transport of dissolved organic carbon at multiple scales in humid regimes. Vadose Zone Journal 5(1), 140-152. 
Jiao, Y., Xu, Z., Zhao, J., 2009. Effects of grassland conversion to cropland and forest on soil organic carbon and dissolved organic carbon in the farming-pastoral ecotone of Inner Mongolia. Acta Ecologica Sinica 29(3), 150-154.

Jobbágy, E.G., Jackson, R.B., 2000. The vertical distribution of soil organic carbon and its relation to climate and vegetation. Ecological Applications 10(2), 423-436.

Jones, C., Falloon, P., 2009. Sources of uncertainty in global modelling of future soil organic carbon storage, Uncertainties in Environmental Modelling and Consequences for Policy Making. Springer, pp. 283-315.

Kaiser, K., Guggenberger, G., 2000. The role of DOM sorption to mineral surfaces in the preservation of organic matter in soils. Organic Geochemistry 31(7-8), 711-725.

Kaiser, K., Guggenberger, G., 2007. Sorptive stabilization of organic matter by microporous goethite: Sorption into small pores vs. surface complexation. European Journal of Soil Science 58(1), 45-59.

Kaiser, K., Guggenberger, G., Haumaier, L., Zech, W., 2001. Seasonal variations in the chemical composition of dissolved organic matter in organic forest floor layer leachates of old-growth Scots pine (Pinus sylvestris L.) and European beech (Fagus sylvatica L.) stands in northeastern Bavaria, Germany. Biogeochemistry 55(2), 103-143.

Kaiser, K., Guggenberger, G., Haumaier, L., Zech, W., 2002. The composition of dissolved organic matter in forest soil solutions: Changes induced by seasons and passage through the mineral soil. Organic Geochemistry 33(3), 307-318.

Kaiser, K., Guggenberger, G., Zech, W., 1996. Sorption of DOM and DOM fractions to forest soils. Geoderma 74(3-4), 281-303. 
Kaiser, K., Zech, W., 1999. Release of natural organic matter sorbed to oxides and a subsoil. Soil Science Society of America Journal 63(5), 1157-1166.

Kalambukattu, J.G., Singh, R., Patra, A.K., Arunkumar, K., 2013. Soil carbon pools and carbon management index under different land use systems in the Central Himalayan region. Acta Agriculturae Scandinavica, Section B-Soil \& Plant Science 63(3), 200-205.

Kalbitz, K., 2001. Properties of organic matter in soil solution in a German fen area as dependent on land use and depth. Geoderma 104(3), 203-214.

Kalbitz, K., Geyer, W., Geyer, S., 1999. Spectroscopic properties of dissolved humic substancesa reflection of land use history in a fen area. Biogeochemistry 47(2), 219-238.

Kalbitz, K., Kaiser, K., 2008. Contribution of dissolved organic matter to carbon storage in forest mineral soils. Journal of Plant Nutrition and Soil Science 171(1), 52-60.

Kalbitz, K., Schwesig, D., Rethemeyer, J., Matzner, E., 2005. Stabilization of dissolved organic matter by sorption to the mineral soil. Soil Biology and Biochemistry 37(7), 1319-1331.

Kalbitz, K., Schwesig, D., Schmerwitz, J., Kaiser, K., Haumaier, L., Glaser, B., Ellerbrock, R., Leinweber, P., 2003. Changes in properties of soil-derived dissolved organic matter induced by biodegradation. Soil Biology and Biochemistry 35(8), 1129-1142.

Kalbitz, K., Solinger, S., Park, J.H., Michalzik, B., Matzner, E., 2000. Controls on the dynamics of dissolved organic matter in soil: A review. Soil Science 165(4), 277-304.

Kallenbach, C.M., Frey, S.D., Grandy, A.S., 2016. Direct evidence for microbial-derived soil organic matter formation and its ecophysiological controls. Nature communications 7, 13630.

Keiluweit, M., Bougoure, J.J., Nico, P.S., Pett-Ridge, J., Weber, P.K., Kleber, M., 2015. Mineral protection of soil carbon counteracted by root exudates. Nature Climate Change 5(6), 588. 
Kellner, E., Hubbart, J., Stephan, K., Morrissey, E., Freedman, Z., Kutta, E., Kelly, C., 2018. Characterization of sub-watershed-scale stream chemistry regimes in an Appalachian mixedland-use watershed. Environmental Monitoring and Assessment 190(10), 586.

Kettler, T., Doran, J.W., Gilbert, T., 2001. Simplified method for soil particle-size determination to accompany soil-quality analyses. Soil Science Society of America Journal 65(3), 849-852.

Khomutova, T., Shirshova, L., Tinz, S., Rolland, W., Richter, J., 2000. Mobilization of DOC from sandy loamy soils under different land use (Lower Saxony, Germany). Plant and Soil 219(12), 13-19.

Kleber, M., Mikutta, R., Torn, M., Jahn, R., 2005. Poorly crystalline mineral phases protect organic matter in acid subsoil horizons. European Journal of Soil Science 56(6), 717-725.

Koehler, A.K., Murphy, K., Kiely, G., Sottocornola, M., 2009. Seasonal variation of DOC concentration and annual loss of DOC from an Atlantic blanket bog in South Western Ireland. Biogeochemistry 95(2-3), 231-242.

Köhler, S.J., Kothawala, D., Futter, M.N., Liungman, O., Tranvik, L., 2013a. In-lake processes offset increased terrestrial inputs of dissolved organic carbon and color to lakes. PloS One 8(8), e70598. doi: 70510.71371/journal.pone.0070598.

Köhler, S.J., Kothawala, D., Futter, M.N., Liungman, O., Tranvik, L., 2013b. In-lake processes offset increased terrestrial inputs of dissolved organic carbon and color to lakes. PloS one 8(8), e70598.

Kothawala, D., Moore, T., Hendershot, W., 2008. Adsorption of dissolved organic carbon to mineral soils: A comparison of four isotherm approaches. Geoderma 148(1), 43-50. 
Kramer, C., Gleixner, G., 2008. Soil organic matter in soil depth profiles: distinct carbon preferences of microbial groups during carbon transformation. Soil Biology and Biochemistry 40(2), 425-433.

Kramer, M.G., Sanderman, J., Chadwick, O.A., Chorover, J., Vitousek, P.M., 2012. Long-term carbon storage through retention of dissolved aromatic acids by reactive particles in soil. Global Change Biology 18(8), 2594-2605.

Kritzberg, E.S., Bedmar Villanueva, A., Jung, M., Reader, H.E., 2014. Importance of boreal rivers in providing iron to marine waters. PloS One 9(9), e107500. doi.org/107510.101371/journal.pone.0107500.

Kritzberg, E.S., Ekström, S.M., 2012. Increasing iron concentrations in surface waters - a factor behind brownification? Biogeosciences 9(4), 1465-1478.

Kritzberg, E.S., Hasselquist, E.M., Škerlep, M., Löfgren, S., Olsson, O., Stadmark, J., Valinia, S., Hansson, L.-A., Laudon, H., 2019. Browning of freshwaters: Consequences to ecosystem services, underlying drivers, and potential mitigation measures. Ambio 49, 375-390.

Kutser, T., Alikas, K., Kothawala, D.N., Köhler, S.J., 2015. Impact of iron associated to organic matter on remote sensing estimates of lake carbon content. Remote Sensing of Environment $156,109-116$.

Lalonde, K., 2014. Intertwining the elemental cycles of iron and carbon: Iron's influence on the fate and dynamics of organic carbon in the environment [dissertation], Concordia University, Quebec, Canada.

Lalonde, K., Mucci, A., Ouellet, A., Gelinas, Y., 2012. Preservation of organic matter in sediments promoted by iron. Nature 483(7388), 198-200. 
Lambert, T., Pierson-Wickmann, A., Gruau, G., Jaffrezic, A., Petitjean, P., Thibault, J., Jeanneau, L., 2013. Hydrologically driven seasonal changes in the sources and production mechanisms of dissolved organic carbon in a small lowland catchment. Water Resources Research 49(9), $5792-5803$.

Lee, B.S., Lajtha, K., Jones, J.A., White, A.E., 2018. Fluorescent DOC characteristics are related to streamflow and pasture cover in streams of a mixed landscape. Biogeochemistry 140(3), 317-340.

Lehmann, J., Kleber, M., 2015. The contentious nature of soil organic matter. Nature 528(7580), 60-68.

Lei, L., Thompson, J.A., McDonald, L.M., 2020. Assessment of dissolved organic carbon and iron effects on water color between a forest and pasture-dominated fine-scale catchment in a Central Appalachian region, West Virginia. Environmental Science and Pollution Research, https://doi.org/10.1007/s11356-11020-09251-11359.

Leifeld, J., Bassin, S., Fuhrer, J., 2005. Carbon stocks in Swiss agricultural soils predicted by landuse, soil characteristics, and altitude. Agriculture, Ecosystems \& Environment 105(1-2), 255266.

Leifeld, J., Zimmermann, M., Fuhrer, J., Conen, F., 2009. Storage and turnover of carbon in grassland soils along an elevation gradient in the Swiss Alps. Global Change Biology 15(3), 668-679.

Leinemann, T., Preusser, S., Mikutta, R., Kalbitz, K., Cerli, C., Höschen, C., Mueller, C., Kandeler, E., Guggenberger, G., 2018. Multiple exchange processes on mineral surfaces control the transport of dissolved organic matter through soil profiles. Soil Biology and Biochemistry 118, 79-90. 
Li, W., Zheng, Z., Li, T., Zhang, X., Wang, Y., Yu, H., He, S., Liu, T., 2015. Effect of tea plantation age on the distribution of soil organic carbon fractions within water-stable aggregates in the hilly region of Western Sichuan, China. Catena 133, 198-205.

Lopez-Bellido, R.J., Muñoz-Romero, V., Fuentes-Guerra, R., Fernandez-Garcia, P., LopezBellido, L., 2017. No-till: A key tool for sequestering $\mathrm{C}$ and $\mathrm{N}$ in microaggregates on a Mediterranean Vertisol. Soil and Tillage Research 166, 131-137.

Lorenz, K., Lal, R., Preston, C.M., Nierop, K.G., 2007. Strengthening the soil organic carbon pool by increasing contributions from recalcitrant aliphatic bio (macro) molecules. Geoderma 142(1-2), 1-10.

Lou, Y., Xu, M., Wang, W., Sun, X., Liang, C., 2011. Soil organic carbon fractions and management index after $20 \mathrm{yr}$ of manure and fertilizer application for greenhouse vegetables. Soil Use and Management 27(2), 163-169.

Lovley, Fraga, J.L., Blunt-Harris, E.L., Hayes, L., Phillips, E., Coates, J.D., 1998. Humic substances as a mediator for microbially catalyzed metal reduction. Acta Hydrochimica et Hydrobiologica 26(3), 152-157.

Lovley, D., Phillips, E., 1987. Rapid assay for microbially reducible ferric iron in aquatic sediments. Applied and Environmental Microbiology 53(7), 1536-1540.

Luo, Z., Feng, W., Luo, Y., Baldock, J., Wang, E., 2017. Soil organic carbon dynamics jointly controlled by climate, carbon inputs, soil properties and soil carbon fractions. Global Change Biology 23(10), 4430-4439.

Lützow, M.v., Kögel-Knabner, I., Ekschmitt, K., Matzner, E., Guggenberger, G., Marschner, B., Flessa, H., 2006. Stabilization of organic matter in temperate soils: Mechanisms and their 
relevance under different soil conditions-a review. European Journal of Soil Science 57(4), 426-445.

Maloney, K.O., Morris, D.P., Moses, C.O., Osburn, C.L., 2005. The role of iron and dissolved organic carbon in the absorption of ultraviolet radiation in humic lake water. Biogeochemistry 75(3), 393-407.

Martens, D.A., Reedy, T.E., Lewis, D.T., 2004. Soil organic carbon content and composition of 130-year crop, pasture and forest land-use managements. Global Change Biology 10(1), 6578.

Matus, F.J., Lusk, C.H., Maire, C.R., 2007. Effects of soil texture, carbon input rates, and litter quality on free organic matter and nitrogen mineralization in Chilean rain forest and agricultural soils. Communications in Soil Science and Plant Analysis 39(1-2), 187-201.

Maurice, P.A., Cabaniss, S.E., Drummond, J., Ito, E., 2002. Hydrogeochemical controls on the variations in chemical characteristics of natural organic matter at a small freshwater wetland. Chemical Geology 187(1-2), 59-77.

McDowell, W.H., 1984. Podzolization: Soil processes control dissolved organic carbon concentration in stream water. Soil Science 137(1), 23-32.

McElmurry, S.P., Long, D.T., Voice, T.C., 2013. Stormwater dissolved organic matter: influence of land cover and environmental factors. Environmental Science \& Technology 48(1), 45-53.

McGlynn, B.L., McDonnell, J.J., 2003. Role of discrete landscape units in controlling catchment dissolved organic carbon dynamics. Water Resources Research 39(4).

McKnight, D.M., Boyer, E.W., Westerhoff, P.K., Doran, P.T., Kulbe, T., Andersen, D.T., 2001. Spectrofluorometric characterization of dissolved organic matter for indication of precursor organic material and aromaticity. Limnology and Oceanography 46(1), 38-48. 
Merckx, R., Brans, K., Smolders, E., 2001. Decomposition of dissolved organic carbon after soil drying and rewetting as an indicator of metal toxicity in soils. Soil Biology and Biochemistry 33(2), 235-240.

Miller, W.L., Moran, M.A., 1997. Interaction of photochemical and microbial processes in the degradation of refractory dissolved organic matter from a coastal marine environment. Limnology and Oceanography 42(6), 1317-1324.

Mu, C., Zhang, T., Zhao, Q., Guo, H., Zhong, W., Su, H., Wu, Q., 2016. Soil organic carbon stabilization by iron in permafrost regions of the Qinghai-Tibet Plateau. Geophysical Research Letters 43(19), 10286-10294.

Murphy, J., Riley, J., 1962. A modified single solution method for the determination of phosphate in natural waters. Analytica Chimica Acta 27, 31-36.

Nadeau, T.L., Rains, M.C., 2007. Hydrological connectivity between headwater streams and downstream waters: how science can inform policy 1. Journal of the American Water Resources Association 43(1), 118-133.

Nahrawi, H., Husni, M., Radziah, O., 2012. Labile carbon and carbon management index in peat planted with various crops. Communications in Soil Science and Plant Analysis 43(12), 16471657.

Neal, C., Lofts, S., Evans, C., Reynolds, B., Tipping, E., Neal, M., 2008. Increasing iron concentrations in UK upland waters. Aquatic Geochemistry 14(3), 263-288.

Neff, J.C., Asner, G.P., 2001. Dissolved organic carbon in terrestrial ecosystems: Synthesis and a model. Ecosystems 4(1), 29-48. 
Neff, J.C., Finlay, J.C., Zimov, S.A., Davydov, S.P., Carrasco, J.J., Schuur, E.A.G., Davydova, A.I., 2006. Seasonal changes in the age and structure of dissolved organic carbon in Siberian rivers and streams. Geophysical Research Letters 33(L23401).

Nelson, P., Baldock, J., Oades, J., 1992. Concentration and composition of dissolved organic carbon in streams in relation to catchment soil properties. Biogeochemistry 19(1), 27-50.

Neubauer, E., Kohler, S.J., von der Kammer, F., Laudon, H., Hofmann, T., 2013. Effect of pH and stream order on iron and arsenic speciation in boreal catchments. Environmental Science \& Technology 47(13), 7120-7128.

Ogle, S.M., Breidt, F.J., Paustian, K., 2005. Agricultural management impacts on soil organic carbon storage under moist and dry climatic conditions of temperate and tropical regions. Biogeochemistry 72(1), 87-121.

Ohno, T., 2002. Fluorescence inner-filtering correction for determining the humification index of dissolved organic matter. Environmental Science \& Technology 36(4), 742-746.

Oni, S.K., Futter, M.N., Molot, L.A., Dillon, P.J., 2014. Adjacent catchments with similar patterns of land use and climate have markedly different dissolved organic carbon concentration and runoff dynamics. Hydrological Processes 28(3), 1436-1449.

Oren, A., Chefetz, B., 2012. Sorptive and desorptive fractionation of dissolved organic matter by mineral soil matrices. Journal of Environmental Quality 41(2), 526-533.

Ouellet, A., Lalonde, K., Plouhinec, J.B., Soumis, N., Lucotte, M., Gélinas, Y., 2012. Assessing carbon dynamics in natural and perturbed boreal aquatic systems. Journal of Geophysical Research: Biogeosciences 117(G3), G03024.

Pace, M.L., Cole, J.J., 2002. Synchronous variation of dissolved organic carbon and color in lakes. Limnology and Oceanography 47(2), 333-342. 
Pennanen, V., Frisk, T., 1984. Statistical model for conversion of absorbance measurements with significant iron interference into organic carbon in a polyhumic lake. Aqua Fennica (Finland) $14,171-178$.

Petrone, K.C., Fellman, J.B., Hood, E., Donn, M.J., Grierson, P.F., 2011. The origin and function of dissolved organic matter in agro-urban coastal streams. Journal of Geophysical Research: Biogeosciences 116, G01028. doi.org/01010.01029/02010JG001537

Petrone, K.C., Richards, J.S., Grierson, P.F., 2009. Bioavailability and composition of dissolved organic carbon and nitrogen in a near coastal catchment of south-western Australia. Biogeochemistry 92(1-2), 27-40.

Poeplau, Don, A., Vesterdal, L., Leifeld, J., Van Wesemael, B.A.S., Schumacher, J., Gensior, A., 2011. Temporal dynamics of soil organic carbon after land-use change in the temperate zone - carbon response functions as a model approach. Global Change Biology 17(7), 2415-2427.

Poeplau, C., Don, A., 2013. Sensitivity of soil organic carbon stocks and fractions to different land-use changes across Europe. Geoderma 192, 189-201.

Pongratz, J., Reick, C., Raddatz, T., Claussen, M., 2009. Effects of anthropogenic land cover change on the carbon cycle of the last millennium. Global Biogeochemical Cycles 23(4).

Porras, R.C., Pries, C.E.H., McFarlane, K.J., Hanson, P.J., Torn, M.S., 2017. Association with pedogenic iron and aluminum: Effects on soil organic carbon storage and stability in four temperate forest soils. Biogeochemistry 133(3), 333-345.

Pullin, M.J., Anthony, C., Maurice, P.A., 2007. Effects of iron on the molecular weight distribution, light absorption, and fluorescence properties of natural organic matter. Environmental Engineering Science 24(8), 987-997. 
Purakayastha, T., Rudrappa, L., Singh, D., Swarup, A., Bhadraray, S., 2008. Long-term impact of fertilizers on soil organic carbon pools and sequestration rates in maize-wheat-cowpea cropping system. Geoderma 144(1-2), 370-378.

Qi, Y., Dong, Y., Peng, Q., Xiao, S., He, Y., Liu, X., Sun, L., Jia, J., Yang, Z., 2012. Effects of a conversion from grassland to cropland on the different soil organic carbon fractions in Inner Mongolia, China. Journal of Geographical Sciences 22(2), 315-328.

Raiswell, R., Canfield, D.E., 2012. The iron biogeochemical cycle past and present. Geochemical Perspectives 1(1), 1-2.

Reicosky, D.C., Dugas, W.A., Torbert, H.A., 1997. Tillage-induced soil carbon dioxide loss from different cropping systems. Soil and Tillage Research 41(1), 105-118.

Richardson, S.D., Plewa, M.J., Wagner, E.D., Schoeny, R., DeMarini, D.M., 2007. Occurrence, genotoxicity, and carcinogenicity of regulated and emerging disinfection by-products in drinking water: A review and roadmap for research. Mutation Research 636(1), 178-242.

Riedel, T., Biester, H., Dittmar, T., 2012. Molecular fractionation of dissolved organic matter with metal salts. Environmental Science \& Technology 46(8), 4419-4426.

Riedel, T., Zak, D., Biester, H., Dittmar, T., 2013. Iron traps terrestrially derived dissolved organic matter at redox interfaces. Proceedings of the National Academy of Sciences 110(25), 1010110105.

Roulet, N., Moore, T.R., 2006. Environmental chemistry: browning the waters. Nature 444(7117), 283-284.

Rumpel, C., Baumann, K., Remusat, L., Dignac, M.-F., Barré, P., Deldicque, D., Glasser, G., Lieberwirth, I., Chabbi, A., 2015. Nanoscale evidence of contrasted processes for root-derived 
organic matter stabilization by mineral interactions depending on soil depth. Soil Biology and Biochemistry 85, 82-88.

Rumpel, C., Kögel-Knabner, I., 2011. Deep soil organic matter-a key but poorly understood component of terrestrial C cycle. Plant and Soil 338(1-2), 143-158.

Sainepo, B.M., Gachene, C.K., Karuma, A., 2018. Assessment of soil organic carbon fractions and carbon management index under different land use types in Olesharo Catchment, Narok County, Kenya. Carbon Balance and Management 13(1), 4.

Sanderman, J., Amundson, R., 2008. A comparative study of dissolved organic carbon transport and stabilization in California forest and grassland soils. Biogeochemistry 89(3), 309-327.

Sanderman, J., Baldock, J.A., Amundson, R., 2008. Dissolved organic carbon chemistry and dynamics in contrasting forest and grassland soils. Biogeochemistry 89(2), 181-198.

Sanderman, J., Lohse, K.A., Baldock, J.A., Amundson, R., 2009. Linking soils and streams: Sources and chemistry of dissolved organic matter in a small coastal watershed. Water Resources Research 45(3).

Sarkkola, S., Nieminen, M., Koivusalo, H., Lauren, A., Kortelainen, P., Mattsson, T., Palviainen, M., Piirainen, S., Starr, M., Finer, L., 2013. Iron concentrations are increasing in surface waters from forested headwater catchments in eastern Finland. Science of Total Environment 463, 683-689.

Sawicka, K., Monteith, D., Vanguelova, E., Wade, A.J., Clark, J.M., 2016. Fine-scale temporal characterization of trends in soil water dissolved organic carbon and potential drivers. Ecological Indicators 68, 36-51.

Schlesinger, W.H., 1986. Changes in soil carbon storage and associated properties with disturbance and recovery, The changing carbon cycle. Springer, pp. 194-220. 
Schmidt, M.W., Torn, M.S., Abiven, S., Dittmar, T., Guggenberger, G., Janssens, I.A., Kleber, M., Kögel-Knabner, I., Lehmann, J., Manning, D.A., 2011. Persistence of soil organic matter as an ecosystem property. Nature 478(7367), 49-56.

Scott, E.E., Rothstein, D.E., 2014. The dynamic exchange of dissolved organic matter percolating through six diverse soils. Soil Biology and Biochemistry 69, 83-92.

Shang, P., Lu, Y., Du, Y., Jaffé, R., Findlay, R.H., Wynn, A., 2018. Climatic and watershed controls of dissolved organic matter variation in streams across a gradient of agricultural land use. Science of the Total Environment 612, 1442-1453.

Sheng, H., Zhou, P., Zhang, Y., Kuzyakov, Y., Zhou, Q., Ge, T., Wang, C., 2015. Loss of labile organic carbon from subsoil due to land-use changes in subtropical China. Soil Biology and Biochemistry 88, 148-157.

Sherrod, L., Peterson, G., Westfall, D., Ahuja, L., 2002. Particulate soil organic matter carbon in surface soils after 12 years in no-till dryland cropping systems, Proceedings of the Great Plains Soil Fertility Conference. Lincoln, Nebraska: U.S. Department of Agriculture: Agricultural Research Service, Denver, Colorado.

Shields, M.R., Bianchi, T.S., Gélinas, Y., Allison, M.A., Twilley, R.R., 2016. Enhanced terrestrial carbon preservation promoted by reactive iron in deltaic sediments. Geophysical Research Letters 43(3), 1149-1157.

Singh, B., Chanasyk, D., McGill, W., Nyborg, M., 1994. Residue and tillage management effects of soil properties of a typic cryoboroll under continuous barley. Soil and Tillage Research $32(2-3), 117-133$. 
Singh, M., Sarkar, B., Biswas, B., Churchman, J., Bolan, N.S., 2016. Adsorption-desorption behavior of dissolved organic carbon by soil clay fractions of varying mineralogy. Geoderma $280,47-56$.

Singh, P., Heikkinen, J., Ketoja, E., Nuutinen, V., Palojarvi, A., Sheehy, J., Esala, M., Mitra, S., Alakukku, L., Regina, K., 2015. Tillage and crop residue management methods had minor effects on the stock and stabilization of topsoil carbon in a 30-year field experiment. Science of the Total Environment 518-519, 337-344.

Six, J., Elliott, E., Paustian, K., 2000. Soil macroaggregate turnover and microaggregate formation: A mechanism for $\mathrm{C}$ sequestration under no-tillage agriculture. Soil Biology and Biochemistry 32(14), 2099-2103.

Smith, P., 2004. Carbon sequestration in croplands: the potential in Europe and the global context. European Journal of Agronomy 20(3), 229-236.

Smith, P., 2008. Land use change and soil organic carbon dynamics. Nutrient Cycling in Agroecosystems 81(2), 169-178.

Soil Survey Staff, N.R.C.S., 2017. United States Department of Agriculture. Web Soil Survey, Available online at the following link:

https://websoilsurvey.sc.egov.usda.gov/App/HomePage.htm Accessed [12/2017].

Somasundaram, J., Reeves, S., Wang, W., Heenan, M., Dalal, R., 2017. Impact of 47 years of no tillage and stubble retention on soil aggregation and carbon distribution in a Vertisol. Land Degradation \& Development 28(5), 1589-1602.

Sowers, T.D., Holden, K.L., Coward, E.K., Sparks, D.L., 2019. Dissolved organic matter sorption and molecular fractionation by naturally-occurring bacteriogenic iron (oxyhydr) oxides. Environmental Science \& Technology 53(8), 4295-4304. 
Sparks, D.L., 2003. Environmental soil chemistry. Academic Press, Book Marketing Department, San Diego, Califonia.

Spencer, R.G.M., Aiken, G.R., Wickland, K.P., Striegl, R.G., Hernes, P.J., 2008. Seasonal and spatial variability in dissolved organic matter quantity and composition from the Yukon River basin, Alaska. Global Biogeochemical Cycles 22(4), GB4002.

Striegl, R.G., Aiken, G.R., Dornblaser, M.M., Raymond, P.A., Wickland, K.P., 2005. A decrease in discharge-normalized DOC export by the Yukon River during summer through autumn. Geophysical Research Letters 32(21).

Strobel, B.W., 2001. Influence of vegetation on low-molecular-weight carboxylic acids in soil solution—a review. Geoderma 99(3-4), 169-198.

Strobel, B.W., Hansen, H., Borggaard, O.K., Andersen, M.K., Raulund-Rasmussen, K., 2001. Composition and reactivity of DOC in forest floor soil solutions in relation to tree species and soil type. Biogeochemistry 56(1), 1-26.

Sui, Y., Jiao, X., Chen, W., Liu, X., Zhang, X., Ding, G., 2013. Labile organic matter content and distribution as affected by six-year soil amendments to eroded Chinese mollisols. Chinese Geographical Science 23(6), 692-699.

Takata, Y., Tani, M., Kato, T., Koike, M., 2011. Effects of land use and long-term organic matter application on low-molecular-weight organic acids in an Andisol. Journal of Soil Science and Environmental Management 2(10), 292-298.

Tank, J.L., Rosi-Marshall, E.J., Griffiths, N.A., Entrekin, S.A., Stephen, M.L., 2010. A review of allochthonous organic matter dynamics and metabolism in streams. Journal of the North American Benthological Society 29(1), 118-146. 
Temnerud, J., Hytteborn, J.K., Futter, M.N., Köhler, S.J., 2014. Evaluating common drivers for color, iron and organic carbon in Swedish watercourses. Ambio 43(1), 30-44.

Thomas, J., 1997. The role of dissolved organic matter, particularly free amino acids and humic substances, in freshwater ecosystems. Freshwater Biology 38(1), 1-36.

Tilman, D., Cassman, K.G., Matson, P.A., Naylor, R., Polasky, S., 2002. Agricultural sustainability and intensive production practices. Nature 418(6898), 671.

Tong, X., Xu, M., Wang, X., Bhattacharyya, R., Zhang, W., Cong, R., 2014. Long-term fertilization effects on organic carbon fractions in a red soil of China. Catena 113, 251-259.

Toosi, E.R., Schmidt, J.P., Castellano, M.J., 2014. Land use and hydrologic flowpaths interact to affect dissolved organic matter and nitrate dynamics. Biogeochemistry 120(1-3), 89-104.

Twongyirwe, R., Sheil, D., Majaliwa, J.G.M., Ebanyat, P., Tenywa, M.M., van Heist, M., Kumar, L., 2013. Variability of Soil Organic Carbon stocks under different land uses: A study in an afro-montane landscape in southwestern Uganda. Geoderma 193-194, 282-289.

Václavík, T., Lautenbach, S., Kuemmerle, T., Seppelt, R., 2013. Mapping global land system archetypes. Global Environmental Change 23(6), 1637-1647.

Van Bodegom, P.M., Van Reeven, J., Van Der Gon, H.A.D., 2003. Prediction of reducible soil iron content from iron extraction data. Biogeochemistry 64(2), 231-245.

Van Gaelen, N., Verheyen, D., Ronchi, B., Struyf, E., Govers, G., Vanderborght, J., Diels, J., 2014. Identifying the Transport Pathways of Dissolved Organic Carbon in Contrasting Catchments. Vadose Zone Journal 13(7), 0. https://doi.org/10.2136/vzj2013.11.0199

Van Miegroet, H., Olsson, M., 2011. Ecosystem disturbance and soil organic carbon-A review. Soil Carbon in Sensitive European Ecosystems, 85-117. 
Vidon, P., Carleton, W., Mitchell, M., 2014. Spatial and temporal variability in stream dissolved organic carbon quantity and quality in an Adirondack forested catchment. Applied geochemistry $46,10-18$.

Vieira, F., Bayer, C., Zanatta, J., Dieckow, J., Mielniczuk, J., He, Z., 2007. Carbon management index based on physical fractionation of soil organic matter in an Acrisol under long-term notill cropping systems. Soil and Tillage Research 96(1-2), 195-204.

Voegelin, A., Senn, A.-C., Kaegi, R., Hug, S.J., Mangold, S., 2013. Dynamic Fe-precipitate formation induced by Fe (II) oxidation in aerated phosphate-containing water. Geochimica et Cosmochimica Acta 117, 216-231.

Wagai, R., Mayer, L.M., 2007. Sorptive stabilization of organic matter in soils by hydrous iron oxides. Geochimica et Cosmochimica Acta 71(1), 25-35.

Wagai, R., Mayer, L.M., Kitayama, K., Shirato, Y., 2013. Association of organic matter with iron and aluminum across a range of soils determined via selective dissolution techniques coupled with dissolved nitrogen analysis. Biogeochemistry 112(1-3), 95-109.

Wang, G., A, Y., Xu, Z., Zhang, S., 2014. The influence of land use patterns on water quality at multiple spatial scales in a river system. Hydrological Processes 28(20), 5259-5272.

Wang, Z., Govers, G., Steegen, A., Clymans, W., Van den Putte, A., Langhans, C., Merckx, R., Van Oost, K., 2010. Catchment-scale carbon redistribution and delivery by water erosion in an intensively cultivated area. Geomorphology 124(1-2), 65-74.

Weishaar, J.L., Aiken, G.R., Bergamaschi, B.A., Fram, M.S., Fujii, R., Mopper, K., 2003. Evaluation of specific ultraviolet absorbance as an indicator of the chemical composition and reactivity of dissolved organic carbon. Environmental Science \& Technology 37(20), 47024708. 
Wen, Y., Liu, W., Deng, W., He, X., Yu, G., 2019. Impact of agricultural fertilization practices on organo-mineral associations in four long-term field experiments: Implications for soil C sequestration. Science of the Total Environment 651, 591-600.

Weyhenmeyer, Müller, R., Norman, M., Tranvik, L., 2016. Sensitivity of freshwaters to browning in response to future climate change. Climatic Change 134(1-2), 225-239.

Weyhenmeyer, Prairie, Y.T., Tranvik, L.J., 2014. Browning of boreal freshwaters coupled to carbon-iron interactions along the aquatic continuum. PloS One 9(2), e88104.

Wiesmeier, M., Hübner, R., Spörlein, P., Geuß, U., Hangen, E., Reischl, A., Schilling, B., Lützow, M., Kögel-Knabner, I., 2014. Carbon sequestration potential of soils in southeast Germany derived from stable soil organic carbon saturation. Global Change Biology 20(2), 653-665.

Williams, M., Hopkinson, C., Rastetter, E., Vallino, J., Claessens, L., 2005. Relationships of land use and stream solute concentrations in the Ipswich River Basin, Northeastern Massachusetts. Water, Air, and Soil Pollution 161(1-4), 55-74.

Williamson, C.E., Overholt, E.P., Pilla, R.M., Leach, T.H., Brentrup, J.A., Knoll, L.B., Mette, E.M., Moeller, R.E., 2015. Ecological consequences of long-term browning in lakes. Scientific Reports 5, 18666.

Wilson, B.R., Growns, I., Lemon, J., 2008. Land-use effects on soil properties on the north-western slopes of New South Wales: Implications for soil condition assessment. Soil Research 46(4), 359-367.

Wilson, H.F., Xenopoulos, M.A., 2008. Ecosystem and seasonal control of stream dissolved organic carbon along a gradient of land use. Ecosystems 11(4), 555-568.

Wilson, H.F., Xenopoulos, M.A., 2009. Effects of agricultural land use on the composition of fluvial dissolved organic matter. Nature Geoscience 2(1), 37-41. 
Wiseman, C., Püttmann, W., 2006. Interactions between mineral phases in the preservation of soil organic matter. Geoderma 134(1-2), 109-118.

Wolf, A., Beegle, D., 2011. Recommended soil tests for macro and micronutrients. Recommended Soil Testing Procedures for the Northeastern United States, 39-48.

Wolz, K.J., Lovell, S.T., Branham, B.E., Eddy, W.C., Keeley, K., Revord, R.S., Wander, M.M., Yang, W.H., DeLucia, E.H., 2018. Frontiers in alley cropping: Transformative solutions for temperate agriculture. Global change biology 24(3), 883-894.

Worrall, F., Harriman, R., Evans, C.D., Watts, C.D., Adamson, J., Neal, C., Tipping, E., Burt, T., Grieve, I., Monteith, D., 2004. Trends in dissolved organic carbon in UK rivers and lakes. Biogeochemistry 70(3), 369-402.

Wright, E.L., 1982. Soil Survey of Marion and Monongalia Counties, West Virginia.

Wu, F.C., Kothawala, D.N., Evans, R.D., Dillon, P.J., Cai, Y.R., 2007. Relationships between DOC concentration, molecular size and fluorescence properties of DOM in a stream. Applied Geochemistry 22(8), 1659-1667.

Xiao, Y., Hoikkala, L., Kasurinen, V., Tiirola, M., Kortelainen, P., Vähätalo, A.V., 2016. The effect of iron on the biodegradation of natural dissolved organic matter. Journal of Geophysical Research: Biogeosciences 121(10), 2544-2561.

Xiao, Y., SaraAho, T., Hartikainen, H., Vähätalo, A.V., 2013. Contribution of ferric iron to light absorption by chromophoric dissolved organic matter. Limnology and Oceanography 58(2), 653-662.

Xiao, Y.H., Raike, A., Hartikainen, H., Vahatalo, A.V., 2015. Iron as a source of color in river waters. Science of Total Environment 536, 914-923. 
Xu, M., Yu, R., Sun, X., Liu, H., Wang, B., Li, J., 2006. Effects of long-term fertilization on labile organic matter and carbon management index (CMI) of the typical soils of China (In chinese). Plant Nutrition and Fertilizer Science 12(4), 459-465.

Yang, L., Hong, H., Guo, W., Huang, J., Li, Q., Yu, X., 2012. Effects of changing land use on dissolved organic matter in a subtropical river watershed, southeast China. Regional Environmental Change 12(1), 145-151.

Yano, Y., McDowell, W.H., Aber, J., 2000. Biodegradable dissolved organic carbon in forest soil solution and effects of chronic nitrogen deposition. Soil Biology and Biochemistry 32(11-12), $1743-1751$.

Yavitt, J., 1994. Carbon dynamics in Appalachian peatlands of west Virginia and western Maryland. Water, Air, and Soil Pollution 77(3-4), 271-290.

Zhang, J., Zhang, L., Wang, P., Huang, Q., Yu, G., Li, D., Shen, Q., Ran, W., 2013. The role of non-crystalline $\mathrm{Fe}$ in the increase of SOC after long-term organic manure application to the red soil of s outhern $\mathrm{C}$ hina. European journal of soil science 64(6), 797-804.

Zhang, M., He, Z., Zhao, A., Zhang, H., Endale, D.M., Schomberg, H.H., 2011. Water-extractable soil organic carbon and nitrogen affected by tillage and manure application. Soil Science 176(6), 307-312.

Zhao, Q., Poulson, S.R., Obrist, D., Sumaila, S., Dynes, J.J., McBeth, J.M., Yang, Y., 2016. Ironbound organic carbon in forest soils: Quantification and characterization. Biogeosciences 13(16), 4777-4788.

Zimmerman, A.R., Chorover, J., Goyne, K.W., Brantley, S.L., 2004. Protection of mesoporeadsorbed organic matter from enzymatic degradation. Environmental Science \& Technology $38(17), 4542-4548$. 
Zinn, Y.L., Lal, R., Resck, D.V., 2005. Texture and organic carbon relations described by a profile pedotransfer function for Brazilian Cerrado soils. Geoderma 127(1-2), 168-173.

Zsolnay, A., Baigar, E., Jimenez, M., Steinweg, B., Saccomandi, F., 1999. Differentiating with fluorescence spectroscopy the sources of dissolved organic matter in soils subjected to drying. Chemosphere 38(1), 45-50. 